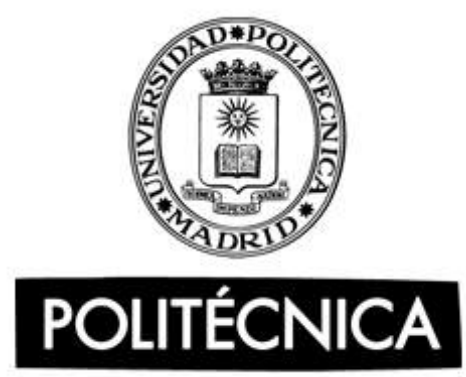

Escuela Técnica Superior de Ingenieros en Topografía, Geodesia y Cartografía Universidad Politécnica de Madrid

\title{
Desarrollo integrado de técnicas de análisis de imágenes y datos LiDAR para la actualización de bases de datos de ocupación del suelo
}

\author{
Tesis Doctoral \\ José Luis Gil Yepes \\ Ingeniero en Geodesia y Cartografía
}

Directores de Tesis:

Dr. Luis Ángel Ruiz Fernández - Doctor Ingeniero Agrónomo $\mathrm{y}$

Dr. Jorge Abel Recio Recio - Doctor en Geodesia, Cartografía y SIG 

Caminante, son tus huellas el camino y nada más; Caminante, no hay camino, se hace camino al andar. Al andar se hace el camino, y al volver la vista atrás se ve la senda que nunca se ha de volver a pisar.

Caminante no hay camino sino estelas en la mar. (Antonio Machado)

A mis padres.

A mi hermano.

A ti. 



\section{Agradecimientos}

Tras años de trabajo, esto parece que por fin se acaba, y no lo podría haber hecho sin el apoyo y ayuda de todos vosotros.

En primer lugar, quisiera agradecer profundamente a mis directores Luis Ángel y Jorge: por su atención, paciencia y disponibilidad durante estos años, por darme la oportunidad de comenzar mi carrera investigadora y de trabajar con ellos en el grupo de investigación. Muchísimas gracias.

A mi tutor de la Universidad Politécnica de Madrid Antonio, que pese a la distancia a la que me encuentro, ha hecho posible que esta tesis pueda presentarse.

A las instituciones públicas como el Instituto Geográfico Nacional, Ministerio de Industria, Turismo y Comercio, Generalitat Valenciana, Universidad Politécnica de Valencia, Instituto Murciano de Investigación y Desarrollo Agrario y Alimentario, por su apoyo material y económico que, a través de contratos, convenios y proyectos, han hecho posible la investigación y el desarrollo de esta tesis.

A mis profesores, a mis compañeros, a mis amigos. Todos ellos del Grupo de Investigación de Cartografía GeoAmbiental y Teledetección de la Universidad Politécnica de Valencia, que me han soportado durante los años que he trabajado allí (y todavía lo hacen). A Josep, Jesús, Maru y Javier. Quisiera destacar la ayuda de Ángel, que parte de esta tesis no habría sido posible sin él. Alfonso, no me he olvidado de ti. Gracias por apoyarme durante todos estos años, desde el proyecto de la técnica hasta hoy. Con un inmenso cariño, a toda la gente que ha pasado por el seminario durante estos años (Sergio, Rocio, Marieta, Jorge, Natasha, Dimo, Dimitris) y a las nuevas glorias que ahora están allí (Elenita, Marta, Carlos, Pablo). A Gerson, que era el único que hablaba en el seminario cuando yo llegué. Y como no, y de manera muy especial, quiero darles las gracias a Txomin y a Jaime, con los que he compartido buenos tiempos, tiempos difíciles, 
risas, discusiones, bromas, tensiones... Pero al fin y al cabo buenos compañeros, y sobre todo, amigos ("estupendo!").

A todo el grupo "Ola $k$ ase!", jsois muchísimos! Pero me voy a permitir mencionar a los cuatro fantásticos que hemos peleado desde la técnica, y que seguimos peleando aunque sea por separado: Sonia, Alex y Fran.

To my friends in Norway, Norwegian and not Norwegian.

Gracias tío Pepe, por los viajes en la máquina del AVE.

A mi familia, que nunca ha dejado de confiar en mí para acabar esta tesis: mis padres y Alberto.

Y en especial, a ti. A mí me ha costado, pero tú lo has sufrido. Gracias por estar a mi lado y animarme. Gracias Elena, "t'estime, t'estimo, t'estim". 


\section{Resumen}

Las áreas agrícolas y urbanas son entornos de gran importancia sujetos a cambios debido a la actividad humana, por lo que estas regiones constituyen zonas muy dinámicas, siendo la causa principal de cambios en las coberturas y usos del suelo en el territorio. A lo largo de las últimas décadas se han puesto en funcionamiento diferentes programas de observación del territorio con el fin de proveer datos para la detección de cambios y la generación de bases de datos a diferentes niveles (locales, nacionales e internacionales) que contengan información sobre usos y coberturas del suelo de manera fiable y actualizada. Los procesos de actualización de estas bases de datos y de detección de cambios se realizan con un alto grado de intervención humana, ya que están basados principalmente en revisiones de campo y técnicas de fotointerpretación de imágenes aéreas y satelitales, o en su comparación con otras imágenes o bases de datos, siendo estas técnicas lentas, caras y en la mayoría de los casos subjetivas. Mediante el procesado digital de imágenes puede procesarse un mayor número de datos y reducir las tareas manuales en este tipo de metodologías. En esta línea de trabajo es donde se enmarca esta tesis, que pretende contribuir a la automatización de la obtención de información relativa a los usos y coberturas del suelo mediante el análisis de datos proporcionados por los sistemas de observación del territorio, así como a la detección de cambios para la actualización de bases de datos cartográficas existentes.

El objetivo de esta tesis es desarrollar una metodología integrada de procesado digital de imágenes de alta resolución y datos LiDAR, basada en la extracción de características cuantitativas a nivel de objetos y subobjetos para la asignación de un tipo de uso o cobertura del suelo a cada objeto, orientada a la detección de cambios y a la actualización de bases de datos de ocupación del suelo. Los datos empleados son imágenes aéreas y de satélite de alta resolución de fechas diferentes, así como datos LiDAR y la cartografía catastral base en formato vectorial.

Para abordar el problema de la actualización de bases de datos se han empleado técnicas de detección de cambios mediante clasificación directa orientada a objetos. En primer lugar, la cartografía aporta los límites espaciales que delimitan los objetos de 
estudio, que en este caso se corresponden con las parcelas catastrales. En segundo lugar, se extraen las características descriptivas de las parcelas combinando información de las dos fechas de estudio. Posteriormente se realizan estudios de selección de características con el propósito de reducir el número de variables empleadas además de ver cuáles de ellas proporcionan mayor información sobre los cambios estudiados. Esta información es introducida en el algoritmo clasificador para la asignación de una de las clases de cambio o no cambio, relacionadas con los usos del suelo de las parcelas en las dos fechas estudiadas.

La descripción cuantitativa de cada objeto se hace por medio de un conjunto de características diseñadas específicamente para la descripción de parcelas. Se han extraído y estudiado diferentes tipos de características en función a la información que proporcionan: características espectrales, de textura, de forma, características tridimensionales, características derivadas de funciones geoestadísticas y características de fragmentación. El desarrollo y aplicación de estas características, en especial el carácter temporal que se les otorga mediante la combinación de información de dos fechas, es el núcleo central de esta tesis.

Los diferentes conjuntos de características propuestos en esta tesis: tridimensionales, derivadas de funciones geoestadísticas y características de fragmentación, han sido evaluados mediante ensayos de detección de cambios en cuanto a su utilización y rendimiento en diferentes estratos paisajísticos, como descriptores de diferentes propiedades que definen los cambios entre usos y coberturas del suelo de las parcelas. Por ejemplo, se ha comprobado que las características tridimensionales, extraídas de modelos de diferencias de las alturas de superficie normalizados obtenidos de los datos LiDAR, mejoran los resultados de clasificación de clases de cambio relacionadas con edificios en entornos urbanos y reducen la confusión entre clases que presentan gran variabilidad espectral en estos entornos. Así mismo, las características derivadas de funciones geoestadísticas sintetizan información temporal con respecto a la estructura interna de la parcela, por lo que son buenos indicadores de cambio en parcelas en las que se han producido arranques de cultivos arbóreos o en las que se han cultivado nuevas plantaciones. Además, presentan una gran complementariedad con las características espectrales, combinando la información sobre la estructura interna de la parcela con la respuesta espectral de las coberturas en las parcelas Por último, las características de fragmentación permiten describir los diferentes tipos de coberturas presentes en el interior de las parcelas.

Se han empleado dos métodos de detección de cambios: el método post-clasificación y el método de clasificación directa, siendo este segundo el más extendido entre los ensayos realizados. Estos métodos de detección de cambios permiten comparar información de 
fechas diferentes mediante la clasificación de imágenes. En el caso de la clasificación directa, admite la integración de información de dos fechas diferentes en una única clasificación. El algoritmo clasificador empleado es el algoritmo de árboles de decisión J48 (Witten et al., 2011), generando las reglas de clasificación a partir de un conjunto de parcelas de estudio empleadas como parcelas de aprendizaje.

La evaluación de los ensayos de detección de cambios de cada conjunto de características se ha realizado sobre un conjunto de parcelas de evaluación mediante matrices de confusión, tanto de clasificación como de detección de cambios, en las que se calculan las fiabilidades globales, de productor y de usuario, y los porcentajes de coincidencias, cambios, falsos positivos, falsos negativos, de calidad y de detección.

En un último ensayo se emplea un conjunto de características final derivado de los diversos ensayos realizados a lo largo de la tesis. En este ensayo se utilizan características seleccionadas en los ensayos anteriores, así como el uso previo de las parcelas, contenido en la base de datos a actualizar, como una característica adicional, como si de un caso real de actualización de bases de datos se tratase. Se han obtenido valores de fiabilidad global de la clasificación y de la detección de cambios entorno al $94 \%$ y al $95 \%$ respectivamente. En todos los casos estudiados, la introducción en los métodos de detección de cambios de los conjuntos de características propuestos reduce significativamente el trabajo manual realizado por operadores en forma de combinación de información temporal, procesado de datos y tareas de revisión por fotointerpretación. 



\section{Abstract}

Agricultural and urban environments are highly subject to changes as a result of human activity. These activities cause the environments to turn into dynamic areas in constant change within short time periods. Thus, human activity is becoming the main reason for changes in land use and land cover on the Earth's surface. During the last decades, several Earth monitoring systems have been developed with the objective of providing data for change detection. This includes land use/land cover (LU/LC) databases at different levels (regional, national and international), containing reliable and updated land use and land cover information. Methods employed for change detection and database update require a high level of human involvement since they are based on aerial and satellite image photointerpretation or visual comparison. These activities are slow, expensive and subjective methodologies. This thesis is framed in this line of work and the scope of work is to contribute to methods for efficiently obtaining information relative to land use and land cover through the analysis of data provided by Earth monitoring systems. Focus is therefore on automation of change detection techniques and the update of existing databases.

The main objective of this thesis is to develop an integrated methodology for high resolution image and LiDAR data processing. This methodology aims to extract quantitative features from these data for LU/LC change detection and database update purposes using object and sub-object based approaches. Data used are high resolution remote sensed images, LiDAR data and cadastral cartography in vector format from different epochs.

Object based classification change detection techniques have been used to address the database update procedures. Firstly, vector cartography has been used to define object boundaries, which match with the cadastral parcels. Secondly, descriptive features are extracted from parcels combining the information from the two study dates. Then, feature selection studies are performed. The purpose of the feature selection studies is to reduce the number of features and to pick those which contain the largest amount of change information. This information is introduced into the classifier algorithm for the 
classification of "change" and "no change" study classes related to the LU/LC of the parcels in the two study dates.

Quantitative object description is made using a set of features specially designed for the parcel description. Different feature types have been extracted and studied according to the type of information provided by these features: spectral features, texture, shape, three-dimensional features, features derived from geostatistical functions, and fragmentation features or landscape metrics. The development and usage of these features and specially, the temporal nature given to them by combining information of two dates, is the main core of this thesis.

The different sets of three-dimensional features, features derived from geostatistical functions and fragmentation features, have been evaluated through several change detection tests. The usage and performance of these features have been studied over different scenarios as LU/LC change descriptors. For example, it has been verified that threedimensional features, extracted from the differences of the normalized surface models obtained from LiDAR data, improve classification results of buildings in urban environments. At the same time, they reduce the confusion between classes having great spectral variability in these environments. The features derived from geostatistical functions summarize temporal information with regard to the internal parcel structure. These features are good change indicators in parcels where tree crops have been removed or new tree crops have been planted. In addition, they complement the spectral features, since they can combine information about the internal structure with the spectral reflectance of the parcels. The fragmentation features allow describing the land covers existing within the parcels. Two change detection methods have been employed in this study: the post-classification method and the direct classification method, being the latter the most used in the tests. These change detection methods allow to compare information from two different epochs using image classification procedures. In the case of the direct classification method, it also enables the integration of information of different dates in a single classification procedure. The classifier algorithm used is J48 (Witten et al., 2011), which generates classification rules based on a training sample set of study parcels.

Evaluation of the change detection for each feature set is performed over an evaluation parcel set. Confusion matrices are obtained in the classification and change detection procedures. Global, user's and producer's accuracies are calculated from the confusion matrix of the classification. Percentages of changes, coincidences, false positives, false negatives, and quality and detection percentages are calculated from the change detection confusion matrix.

As final test, a change detection study is performed using the features derived from 
the previous tests. Here, it is also included the parcel's previous LU/LC class, as in a database update case. The final features and the previous LU/LC class are included in the classifier algorithm. Global accuracies, obtained in the classification and in the change detection procedures, are $94 \%$ and $95 \%$ respectively. In all the cases studied in this thesis, the use of the different feature sets in the change detection procedures allow decreasing the amount of work performed by an operator. In this sense, the study methods allow time savings (in comparison with conventional methods) when processing multi-temporal data. In addition, these methods diminish the errors in the change detection methodologies, reducing considerably the photointerpretation revision tasks. 



\section{Índice general}

Índice general $\quad x v$

Índice de figuras $\quad$ XXI

Índice de tablas $\quad$ xxIx

1. Introducción y estado del arte 1

1.1. Introducción . . . . . . . . . . . . . . . . . . . . . . . . 1

1.2. Estado del arte . . . . . . . . . . . . . . . . . . . . . 3

1.2.1. Actualización de bases de datos de usos del suelo . . . . . . . . . 3

1.2.2. Evolución de las técnicas de detección de cambios . . . . . . . . . 9

1.2.2.1. Técnicas de detección de cambios basadas en objetos . . 10

1.2.3. Extracción de información/atributos a nivel de objeto . . . . . . . 15

1.2.3.1. Información tridimensional derivada de datos LiDAR . . 16

1.2.3.2. Información derivada de imágenes . . . . . . . . . . 18

1.2.3.3. Información derivada de imágenes y de datos LiDAR . . 23

1.2.4. Discusión de antecedentes . . . . . . . . . . . . . . . 26

2. Objetivos y estructura de la tesis $\quad 29$

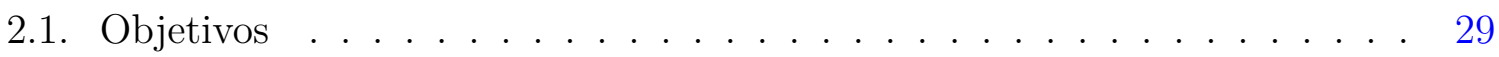

2.2. Estructura de la tesis . . . . . . . . . . . . . . . . 30

3. Zonas de estudio y datos empleados 33

3.1. Zonas de estudio . . . . . . . . . . . . . . . . . . . . . . 33

3.2. Datos . . . . . . . . . . . . . . . . . . . . 35

3.3. Pre-procesado de los datos . . . . . . . . . . . . . . . . . . . . . . . . . . 38

3.3.1. Procesado de los datos LiDAR para la generación de los modelos digitales del terreno . . . . . . . . . . . . . . . . . . 38 
4. Metodología $\quad 41$

4.1. Conceptos teóricos . . . . . . . . . . . . . . . . . . . . . . . 42

4.1.1. Métodos de detección de cambios y clasificadores . . . . . . . . . 42

4.1.1.1. Métodos de detección de cambios . . . . . . . . . . 42

4.1.1.1.1. Diferencias simples . . . . . . . . . . . 42

4.1.1.1.2. Método de post-clasificación . . . . . . . . . 43

4.1.1.1.3. Método de clasificación directa . . . . . . . . 44

4.1.1.2. Algoritmos clasificadores . . . . . . . . . . . . . 45

4.1.1.2.1. Clasificación ISODATA . . . . . . . . . 46

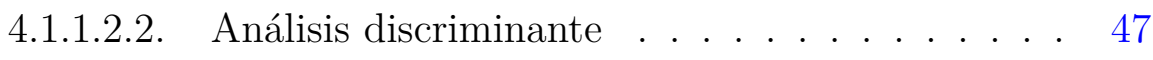

4.1.1.2.3. Árboles de decisión . . . . . . . . . . . . . . 47

4.1.2. Extracción de características a nivel de objeto . . . . . . . . . . 48

4.1.2.1. Extracción de características espectrales, de forma y de textura ....................... 48

4.1.2.2. Extracción de características derivadas de datos LiDAR 56

4.1.2.3. Extracción de características derivadas de funciones geoestadísticas . . . . . . . . . . . . . . 57

4.1.2.3.1. Funciones de semivariograma cruzado y codispersión ................. 6 61

4.1.2.3.2. Características bitemporales derivadas del semivariograma cruzado . . . . . . . . . . . . 62

4.1.2.3.3. Características bitemporales derivadas de la codispersión ............... . . 63

4.1.2.4. Extracción de características de fragmentación . . . . . . 64

4.1.2.4.1. Indicadores de área y perímetro . . . . . . . . 67

4.1.2.4.2. Indicadores de forma . . . . . . . . . . . . 68

4.1.2.4.3. Indicadores de contraste . . . . . . . . . . . . 69

4.1.2.4.4. Indicadores de agregación . . . . . . . . . . . . . 71

4.1.2.4.5. Índices de diversidad . . . . . . . . . . . . . 73

4.1.3. Métodos de evaluación de las clasificaciones y detección de cambios 76

4.1.3.1. Evaluación de clasificaciones a nivel de píxel . . . . . . 76

4.1.3.2. Evaluación de clasificaciones a nivel de objeto . . . . . . 76

4.1.3.3. Evaluación de la detección de cambios . . . . . . . . 77

4.1.3.4. Evaluación de parámetros de poda mediante curvas ROC 78

4.2. Descripción de los ensayos realizados . . . . . . . . . . . . . . 79 
4.2.1. Clases de usos de suelo y clases de cambio empleadas en los métodos de clasificación y detección de cambios . . . . . . . . . . . 79

4.2.1.1. Descripción de las clases de usos del suelo y las clases de cambio para la zona de Valencia . . . . . . . . . . . . . 79

4.2.1.2. Descripción de las clases de usos del suelo y las clases de cambio para la zona de Murcia . . . . . . . . . . . 84

4.2.2. Ensayo I. Análisis y estudios de clasificación empleando las características extraídas de datos LiDAR . . . . . . . . . . . . . 86

4.2.2.1. Ensayo I.A. Efecto de las características tridimensionales en métodos de detección de cambios orientados a objetos basados en post-clasificación de imágenes . . . . . . . . . 88

4.2.2.2. Ensayo I.B. Clasificación directa orientada a objetos empleando características tridimensionales con significado temporal .................. 90

4.2.3. Ensayo II. Estudio de detección de cambios empleando nuevas características bitemporales derivadas de funciones geoestadísticas 90

4.2.3.1. Análisis de las funciones geoestadísticas y selección de variables de diferencias de NDVI, semivariograma cruzado y codispersión . . . . . . . . . . . . . . . . . . 93

4.2.3.2. Ensayo II.A. Clasificación directa orientada a objetos empleando las nuevas características geoestadísticas bitemporales . . . . . . . . . . . . . . . .

4.2.3.3. Ensayo II.B. Comparación de detección de cambios mediante diferencias entre variables espectrales y geoestadísticas . . . . . . . . . . . . . . 96

4.2.4. Ensayo III. Análisis de características de fragmentación . . . . . . 96

4.2.4.1. Estudio de características de fragmentación sobre parcelas sintéticas . . . . . . . . . . . . . 98

4.2.4.2. Parcelas sintéticas vs. parcelas reales . . . . . . . . . . . 100

4.2.4.2.1. Parcelas de uso agrícola . . . . . . . . . . . . 100

4.2.4.2.2. Parcelas edificadas . . . . . . . . . . . . 101

4.2.4.3. Generación de mapas de coberturas para la extracción de características de fragmentación . . . . . . . . . . . 102

4.2.4.3.1. Generación de las máscaras binarias y mapas de coberturas básicas . . . . . . . . . . . . 102 
4.2.4.3.2. Clasificación no supervisada y asignación de coberturas . . . . . . . . . . . 105

4.2.4.3.3. Clasificación de zonas de sombras . . . . . . . . 107

4.2.4.3.4. Filtrado del mapa de coberturas . . . . . . . . . 107

4.2.4.3.5. Evaluación de los mapas de coberturas . . . . . 109

4.2.4.4. Estudios de detección de cambios mediante clasificación directa empleando características de fragmentación . . . 109

4.2.5. Ensayo IV. Análisis de características temporales para la detección de cambios . . . . . . . . . . . . . . . . . . . . 110

\section{Resultados}

5.1. Resultados del ensayo I. Análisis y estudios de clasificación de las características extraídas de datos LiDAR . . . . . . . . . . . . . . 114

5.1.1. Resultados del ensayo I.A. Efecto de las características tridimensionales en métodos de detección de cambios orientados a objetos basados en post-clasificación de imágenes . . . . . . . . . . 115

5.1.2. Resultados Ensayo I.B. Clasificación directa orientada a objetos empleando características tridimensionales con significado temporal119

5.2. Resultados del ensayo II. Estudio de detección de cambios empleando nuevas características bitemporales derivadas de funciones geoestadísticas 122

5.2.1. Resultados del análisis del comportamiento de las funciones geoestadísticas a nivel de objeto para la detección de cambios . . . . 123

5.2.2. Resultados de selección de variables de diferencias de NDVI, semivariograma cruzado y codispersión . . . . . . . . . . . . . 125

5.2.2.1. Resultados de la selección de variables del semivariograma cruzado . . . . . . . . . . . . . . 126

5.2.2.2. Resultados de la selección de variables de codispersión . 129

5.2.2.3. Resultados de clasificación de grupos de características por árboles de decisión .......... 132

5.2.2.4. Ajuste de los parámetros de poda de los árboles de decisión 134

5.2.3. Resultados del ensayo II.A. Clasificación directa orientada a objetos y resultados de detección de cambios empleando las nuevas características geoestadísticas bitemporales . . . . . . . . . 136

5.2.4. Resultados del ensayo II.B. Comparación de detección de cambios mediante diferencias entre variables espectrales y geoestadísticas . 138

5.3. Resultados del ensayo III. Análisis de características de fragmentación . . 140 
5.3.1. Resultados del estudio de características de fragmentación sobre parcelas sintéticas . . . . . . . . . . . . . . . . . . . . . . 141

5.3.1.1. Indicadores de área y perímetro . . . . . . . . . . . . . . 141

5.3.1.2. Indicadores de forma . . . . . . . . . . . . . . . . . . 144

5.3.1.3. Indicadores de contraste . . . . . . . . . . . . . . . 148

5.3.1.4. Indicadores de agregación . . . . . . . . . . . . . 150

5.3.1.5. Indicadores de diversidad . . . . . . . . . . . . . . 153

5.3.1.6. Resumen de indicadores seleccionados . . . . . . . . . 156

5.3.2. Resultados de la generación de los mapas de coberturas para la extracción de características de fragmentación . . . . . . . . . . 157

5.3.3. Resultados de detección de cambios mediante clasificación directa empleando características de fragmentación . . . . . . . . . . . . . 163

5.4. Resultados del ensayo IV. Análisis de características temporales para la detección de cambios . . . . . . . . . . . . . . . . . . . . 168

5.5. Discusión de resultados . . . . . . . . . . . . . . . . . . . . . 174

6. Conclusiones y líneas futuras de investigación 181

6.1. Conclusiones . . . . . . . . . . . . . . . . . . . 181

6.2. Líneas futuras de investigación . . . . . . . . . . . . . . . . . 185

$\begin{array}{lr}\text { Bibliografía } & 189\end{array}$

A. Publicaciones relacionadas con esta tesis 213

B. Listado de acrónimos 



\section{Índice de figuras}

3.1. Localización de las zonas de estudio. . . . . . . . . . . . . . . . . 34

3.2. Detalles de las zonas de estudio en falso color infrarrojo. . . . . . . . . . 34

3.3. Detalle de datos de la zona de Valencia. (a) imagen QuickBird 2004, (b) imagen PNOA 2008, (c) parcelario urbano y rústico y (d) modelo digital de superficies. . . . . . . . . . . . . . . . . 37

3.4. Detalle de datos de la zona de Murcia: (a) imagen PNOA 2007, (b) imagen PNOA 2009 y $($ c) parcelario rústico. . . . . . . . . . . . . . . . 37

3.5. Modelos digitales obtenidos a partir de datos LiDAR. . . . . . . . . . . 39

4.1. Flujo de trabajo del método de post-clasificación para la detección de cambios. . . . . . . . . . . . . . . . . . . . . 43

4.2. Flujo de trabajo del método de clasificación directa para la detección de cambios mediante combinación de imágenes. . . . . . . . . . . . . . . . . 44

4.3. Flujo de trabajo del método de clasificación directa para la detección de cambios mediante extracción de características de estudio por separado. .

4.4. Detalles de los modelos digitales de superficie normalizados de 2003, 2009 y diferencias entre modelos. . . . . . . . . . . . . . . 57

4.5. Parcelas con diferentes usos del suelo y sus respectivos semivariogramas experimentales superpuestos. En el eje de abscisas se encuentra la distancia entre píxeles o lag, y los valores de semivarianza en el eje de ordenadas. Parcelas de (a) cítricos, (b) terreno arable, (c) algarrobos y (d) bosque (Ruiz et al., 2011). . . . . . . . . . . . . . . . . . . . . . 59

4.6. Clasificación de características siguiendo el criterio de escala. . . . . . . 65

4.7. Clases de usos de suelo existentes en la zona de Valencia. (Detalles sobre imágenes PNOA 2008 - composición falso color infrarrojo). . . . . . . . . 


\section{Índice de figuras}

4.8. Ejemplos de parcelas con clases de cambio: cultivo 1 (CC1) con suelo arable en 2004 (a), y suelo cultivado en 2008 (b); cultivo 2 (CC2) con suelo cultivado en 2004 (c), y suelo arable en 2008 (d); arranques (ARR) con árboles en 2004 (e), y suelo arable en 2008 (f); nuevas plantaciones (NPL) con suelo arable en 2004 (g), y árboles en 2008 (h); nuevos edificios (NED) con suelo yermo en 2004 (i), y edificio urbano en 2008 (j); demoliciones (DEM) con edificio industrial en 2004 (k), y suelo yermo en 2008 (l). . .

4.9. Diagrama de cambios entre usos del suelo existentes en la zona de estudio de Valencia. . . . . . . . . . . . . . . . . . . . . . . . .

4.10. Ejemplos de parcelas con clase de: no cambio (NOC) con uso de suelo de árboles en 2007 (a); y en 2009 (b); arranques (ARR) con uso de suelo de árboles en 2007 (c); y suelo arable en 2009 (d); nuevas plantaciones (NPL) con uso de suelo arable en 2007 (e); y uso de suelo árboles en 2009

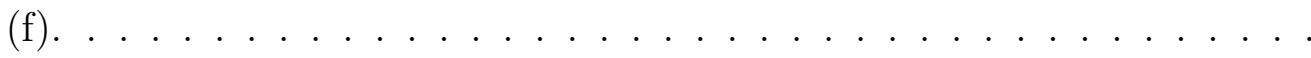

4.11. Esquema general del Ensayo I-A de detección de cambios con características espectrales, de textura, forma y tridimensionales. . . . . . . . . . .

4.12. Esquema general del Ensayo I-B de detección de cambios con características espectrales, de textura, forma y tridimensionales. . . . . . . . . . .

4.13. Desfase temporal entre toma de datos LiDAR e imágenes espectrales

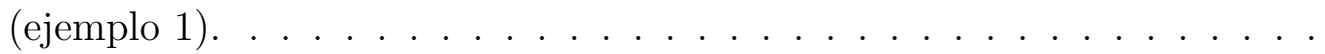

4.14. Desfase temporal entre toma de datos LiDAR e imágenes espectrales

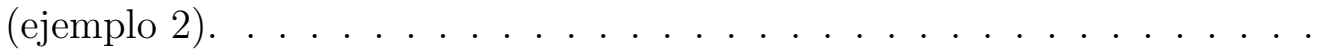

4.15. Esquema general del Ensayo II de detección de cambios con características derivadas del semivariograma cruzado y codispersión, en donde R 2007 es la banda del rojo de la imagen PNOA de 2007, R 2009 es la banda del rojo de la imagen del PNOA de 2009, CO son las características extraídas de la codispersión y CS son las características extraídas del semivariograma cruzado. . . . . . . . . . . . . . . . . .

4.16. Esquema general del Ensayo III de detección de cambios con características de fragmentación. . . . . . . . . . . . . . . . . . . . . 98

4.17. Grupo A de parcelas sintéticas. . . . . . . . . . . . . . . . . . . . . . 99

4.18. Grupo B de parcelas sintéticas. . . . . . . . . . . . . . . . 100

4.19. Detalle de la generación de los mapas de coberturas básicas empleando información espectral de intensidades y de NDVI e información de alturas del MDSn. . . . . . . . . . . . . . . . . . . . . . . . . . . . 104 
4.20. Detalles de los mapas de coberturas básicas generados para las dos épocas de estudio.

4.21. Detalles del mapa de clasificación no supervisada por el método ISODATA de la imagen QuickBird de 2004. . . . . . . . . . . . . . . . . . . 106

4.22. Detalle de la generación de los mapas de coberturas mediante la clasificación no supervisada y las máscaras binarias. . . . . . . . . . . . . . . . . 106

4.23. Detalle de mapa de coberturas de 2004 antes y después de la eliminación de sombras. . . . . . . . . . . . . . . . . . . . . 107

4.24. Ejemplo de mapa de coberturas de imagen QuickBird con filtrado morfológico de apertura y cierre con ventana de $5 x 5$ píxeles. . . . . . . . . . . 108

5.1. Esquema del Ensayo I. . . . . . . . . . . . . . . . . . . . . . . . 114

5.2. Matrices de confusión de clasificaciones mediante árboles de decisión de la imagen QuickBird de 2004 empleando y sin emplear características tridimensionales derivadas de datos LiDAR y gráficas comparativas de fiabilidades de productor y usuario. . . . . . . . . . . . . . . . 116

5.3. Matrices de confusión de clasificaciones mediante árboles de decisión de la imagen PNOA de 2008 empleando y sin emplear características tridimensionales derivadas de datos LiDAR y gráficas comparativas de fiabilidades de productor y usuario.

5.4. Fiabilidades globales de las clasificaciones de 2004 y 2008 empleando y sin emplear características tridimensionales. . . . . . . . . . . . . . . . 117

5.5. Matrices de confusión de la detección de cambios por el método de postclasificación empleando y sin emplear características tridimensionales derivadas de datos LiDAR y gráficas comparativas de fiabilidades de productor y usuario (siendo NOC la clase de no cambio, CC1 la clase de terreno arable a terreno cultivado, CC2 la clase de terreno cultivado a terreno arable, ARR arranques, NPL nuevas plantaciones, NED nuevos edificios y DEM demoliciones). . . . . . . . . . . . . . . . . . 118

5.6. Matrices de confusión de detección de cambios por el método de postclasificación empleando y no empleando características tridimensionales derivadas de datos LiDAR y gráfica de fiabilidades globales de las detecciones de cambio empleando características tridimensionales (relleno sólido) y sin emplear características tridimensionales (relleno tramado). . 119 


\section{Índice de figuras}

5.7. Matrices de confusión de clasificaciones directas empleando y sin emplear características tridimensionales derivadas de datos LiDAR y gráficas comparativas de fiabilidades de productor y usuario (siendo NOC la clase de no cambio, CC1 la clase de terreno arable a terreno cultivado, CC2 la clase de terreno cultivado a terreno arable, ARR arranques, NPL nuevas plantaciones, NED nuevos edificios y DEM demoliciones). . . . . . . . . . 120

5.8. Matrices de confusión de detección de cambios por clasificación directa empleando y no empleando características tridimensionales derivadas de datos LiDAR y gráfica de fiabilidades globales de las detecciones de cambio empleando características tridimensionales (relleno sólido) y sin emplear características tridimensionales (relleno tramado). . . . . . . . . 121

5.9. Esquema del Ensayo II. . . . . . . . . . . . . . . . . . . . . . . . 122

5.10. Semivariogramas, semivariograma cruzado y codispersión de las parcelas de ejemplo de la Figura 4.10. . . . . . . . . . . . . . . . . . . . . . . . . 124

5.11. Matriz de valores de correlación entre variables espectrales, codispersión y semivariograma cruzado. Los valores de mayor magnitud con colores más oscuros (azul oscuro y rojo oscuro) representan una mayor correlación.126

5.12. Fiabilidad global y fiabilidades predichas por clases de las variables del semivariograma cruzado empleando análisis discriminante paso a paso (siendo NOC la clase de no cambio, ARR arranques y NPL nuevas plantaciones). Características añadidas en orden de izquierda a derecha. . . . 127

5.13. Fiabilidad global y fiabilidades predichas por clases de las variables del semivariograma cruzado y características espectrales empleando análisis discriminante paso a paso (siendo NOC la clase de no cambio, ARR arranques y NPL nuevas plantaciones). Características añadidas en orden de izquierda a derecha. . . . . . . . . . . . . . . . . . . . . . . . . . . . 128

5.14. Análisis de componentes principales (ACP) de características espectrales y semivariograma cruzado. . . . . . . . . . . . . . . . . . . . . . 129

5.15. Fiabilidad global y fiabilidades predichas por clases de las variables de la codispersión empleando análisis discriminante paso a paso (siendo NOC la clase de no cambio, ARR arranques y NPL nuevas plantaciones). Características añadidas en orden de izquierda a derecha. . . . . . . . . . . 130 
5.16. Fiabilidad global y fiabilidades predichas por clases de las variables de la codispersión y características espectrales empleando análisis discriminante paso a paso (siendo NOC la clase de no cambio, ARR arranques y NPL nuevas plantaciones). Características añadidas en orden de izquierda a derecha. . . . . . . . . . . . . . . . . . . . . . . 131

5.17. Análisis de componentes principales (ACP) de características espectrales y semivariograma cruzado. . . . . . . . . . . . . . . . . . 132

5.18. Fiabilidades globales de la clasificación mediante árboles de decisión empleando diferentes combinaciones de grupos de características. . . . . . . 134

5.19. Fiabilidades globales de la clasificación mediante árboles de decisión empleando diferentes combinaciones de características seleccionadas. . . . . 134

5.20. Valores de área ROC en función de los parámetros de poda de los árboles de decisión para las diferentes fiabilidades (global y por clase). . . . . . 135

5.21. Resultados de clasificación directa mediante árboles de decisión empleando las características de NDVI (2 características), codispersión (CO_MEAN) y semivariograma cruzado (CS_MFM), y gráfica de fiabilidades de productor y usuario siendo NOC la clase de no cambio, ARR arranques y NPL nuevas plantaciones. . . . . . . . . . . . . . . . . . . 136

5.22. Resultados de detección de cambios empleando las características NDVI (2 características), codispersión (CO_MEAN) y semivariograma cruzado (CS_MFM) . . . . . . . . . . . . . . . 137

5.23. Resultados de clasificación directa mediante árboles de decisión empleando diferencias de características espectrales (35 características) y de semivariograma (14 características) y gráfica de fiabilidades de productor y usuario siendo NOC la clase de no cambio, ARR arranques y NPL nuevas plantaciones. . . . . . . . . . . . . . . . . 139

5.24. Resultados de detección de cambios empleando diferencias de características espectrales (35 características) y de semivariograma (14 características).139

5.25. Esquema del Ensayo III. . . . . . . . . . . . . . . . . . . . . . . . . . . . 140

5.26. Porcentaje de área de cobertura (PLAND) de parcelas sintéticas del grupo A. . . . . . . . . . . . . . . . . . . . 141

5.27. Índice de mayor objeto (LPI) de parcelas sintéticas del grupo A. . . . . . 142

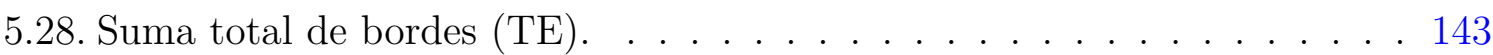

5.29. Suma total de bordes (TE) y densidad de bordes (ED) para las clases árboles y edificios. . . . . . . . . . . . . . . . . . . . . . 143 


\section{Índice de figuras}

5.30. Indicadores AREA MN y SD de la cobertura árboles de parcelas del grupo A.

5.31. Indicadores AREA MN y SD de la cobertura edificios de parcelas del grupo B. . . . . . . . . . . . . . . . . . . . . 144

5.32. Indicador de densidad de árboles DA para las parcelas del Grupo A. . . . 144

5.33. Indicadores SHAPE MN y SD de cobertura árboles y edificios de las parcelas del grupo A. . . . . . . . . . . . . . . . . . . . . . . 145

5.34. Indicadores PARA MN y SD para las parcelas de los grupos A y B. . . . 146

5.35. Parcelas edificios de formas simples. . . . . . . . . . . . . . . . 146

5.36. Valores PARA de edificios con formas simples. . . . . . . . . . . . . . . 146

5.37. Valores PAFRAC para la clase de árboles. . . . . . . . . . . . . . . . . 147

5.38. Indicadores FRAC para las clases de árboles y edificios. . . . . . . . . . . 147

5.39. Indicadores CIRCLE para las clases de árboles y edificios. . . . . . . . . . 148

5.40. Valores CONTIG para la clase árboles del grupo de parcelas A. . . . . . 148

5.41. Valores ECON MN y SD grupo de parcelas A. . . . . . . . . . . . . . 149

5.42. Valores CWED. . . . . . . . . . . . . . . . . . . . 150

5.43. Valores TECI. . . . . . . . . . . . . . . . . . . . . . . . 150

5.44. Valores de agregación CONTAG. . . . . . . . . . . . . . . 150

5.45. Valores de agregación AI. . . . . . . . . . . . . . . . . . . 151

5.46. Valores de agregación MESH. . . . . . . . . . . . . . . . . . . . . . 151

5.47. Valores de agregación SPLIT. . . . . . . . . . . . . . . . . . . 152

5.48. Valores de agregación ENN para las clases de árboles y edificios. . . . . . 152

5.49. Valores de agregación PD de cobertura de árboles. . . . . . . . . . . . . 153

5.50. Valores de diversidad SHDI y SIDI. . . . . . . . . . . . . . . . 153

5.51. Valores de diversidad SHEI y SIEI. . . . . . . . . . . . . . . . . . 153

5.52. Valores de diversidad PRD. . . . . . . . . . . . . . . . . . . 154

5.53. Valores de diversidad PR. . . . . . . . . . . . . . . . . . . . . . 154

5.54. Valores de diversidad DRA. . . . . . . . . . . . . . . . . 154

5.55. Valores de diversidad IFFR. . . . . . . . . . . . . . . . 154

5.56. Valores de diversidad IFFA. . . . . . . . . . . . . . . 155

5.57. Valores de diversidad DD. . . . . . . . . . . . . . . . . . . 155

5.58. Asignación de coberturas a la imagen QuickBird clasificada de 2004, en las que los ejes de abscisas contienen las clases numéricas resultantes de la clasificación no supervisada. . . . . . . . . . . . . . . . . . . 158

5.59. Asignación coberturas a la imagen PNOA clasificada de 2008. . . . . . . 159

5.60. Detalles de los mapas finales de coberturas. . . . . . . . . . . . . . . . 162 
5.61. Fiabilidades de análisis discriminante paso a paso de características de fragmentación.

5.62. Matriz de valores de correlación entre variables de fragmentación. Los valores de mayor magnitud con colores más oscuros (azul oscuro y rojo oscuro) representan una mayor correlación. . . . . . . . . . . . . . . . . 164

5.63. Matriz de valores de correlación entre variables de fragmentación seleccionadas en el análisis discriminante. Los valores de mayor magnitud con colores más oscuros (azul oscuro y rojo oscuro) representan una mayor correlación.

5.64. Fiabilidad global por clasificación directa de diferentes agrupaciones de características de fragmentación. . . . . . . . . . . . . . . . 166

5.65. Fiabilidades de las clases de estudio mediante clasificación directa por árboles de decisión con características de fragmentación. . . . . . . . . . 166

5.66. Fiabilidades de detección de cambios de características de fragmentación. 167

5.67. Esquema del Ensayo IV. . . . . . . . . . . . . . . . . . . . . . . . . . 168

5.68. Matrices de confusión de clasificación directa de los grupos de características del Ensayo IV. . . . . . . . . . . . . . . . . . . . . . . . . . . . 169

5.69. Fiabilidades de productor de clases de estudio por grupos de características. Grupo A: espectrales, textura y forma; Grupo B: Grupo A + tridimensionales; Grupo C: Grupo B + codispersión y semivariograma cruzado; Grupo D: Grupo C + fragmentación; Grupo E: grupo D + clase 2004 .

5.70. Fiabilidades de usuario de clases de estudio por grupos de características. Grupo A: espectrales, textura y forma; Grupo B: Grupo A + tridimensionales; Grupo C: Grupo B + codispersión y semivariograma cruzado; Grupo D: Grupo C + fragmentación; Grupo E: grupo D + clase 2004. . . 170

5.71. Matrices de confusión de los resultados de detección de cambios de los grupos de características del Ensayo IV.

5.72. Fiabilidad global de clasificación y detección de cambios por grupos de características. Grupo A: espectrales, textura y forma; Grupo B: Grupo A + tridimensionales; Grupo C: Grupo B + codispersión y semivariograma cruzado; Grupo D: Grupo C + fragmentación; Grupo E: grupo D + clase 2004 . 


\section{Índice de figuras}

5.73. Resultados de los errores en la detección de cambios. Grupo A: espectrales, textura y forma; Grupo B: Grupo A + tridimensionales; Grupo C: Grupo B + codispersión y semivariograma cruzado; Grupo D: Grupo C + fragmentación; Grupo E: grupo D + clase 2004. . . . . . . . . . . . . 173

5.74. Resultados de calidad de detección con porcentajes de calidad y detección por grupos de características. Grupo A: espectrales, textura y forma; Grupo B: Grupo A + tridimensionales; Grupo C: Grupo B + codispersión y semivariograma cruzado; Grupo D: Grupo C + fragmentación; Grupo

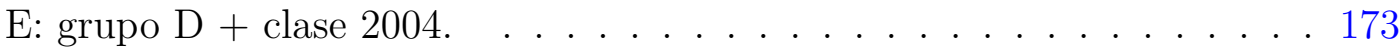




\section{Índice de tablas}

1.1. Ejemplos de bases de datos de ocupación del suelo. . . . . . . . . . . 5

1.2. Tipos de características extraídos por objeto en función de los datos empleados. . . . . . . . . . . . . . . . . 16

3.1. Resumen de datos empleados para el estudio. . . . . . . . . . . . . 36

4.1. Lista de características espectrales, forma y textura extraídas a nivel de parcela. Nota: las características espectrales se extraen para todas las bandas espectrales que componen la imagen además del NDVI. . . . . . . 55

4.2. Lista de características extraídas del semivariograma (Balaguer et al., 2010). 60

4.3. Características extraídas del semivariograma cruzado siendo: $h_{\max 1}$ el lag donde se localiza el primer máximo relativo del semivariograma cruzado, $h_{\min 1}$ donde se localiza el primer mínimo relativo, y $\gamma_{j k}\left(h_{i}\right)$ el valor del semivariograma cruzado en el $\operatorname{lag} h_{i} \ldots \ldots \ldots$. . . . . . . . . 63

4.4. Características extraídas de la codispersión siendo: $n$ el número de lags de estudio, $\nu_{j k}\left(h_{i}\right)$ el valor de la codispersión en el lag $h_{i}, h_{\max 1}$ el lag donde se localiza el primer máximo relativo de la función de codispersión, y $h_{\min 1}$ donde se localizad el primer mínimo relativo. . . . . . . . . . . 64

4.5. Características de fragmentación. . . . . . . . . . . . 66

4.6. Matriz de confusión de detección de cambios. . . . . . . . . . . . . . 77

4.7. Número de parcelas de cada clase de usos de suelo en 2004 y 2008 . . . . 83

4.8. Número de parcelas de cada clase de cambio. . . . . . . . . . . . . . . 83

4.9. Número de parcelas correspondientes a cada clase de estudio. . . . . . . . 84

4.10. Descripción de los ensayos realizados utilizando características tridimensionales. . . . . . . . . . . . . . . . . 86

4.11. Características generales de los ensayos realizados utilizando características de codispersión, semivariograma cruzado y semivariograma. . . . . . 93 
4.12. Combinación y número de características empleadas en clasificaciones directas mediante árboles de decisión. . . . . . . . . . . . . . . . . . . 95

4.13. Características generales del ensayo realizado utilizando características de fragmentación. . . . . . . . . . . . . . . . . 97

4.14. Grupos de características generados. . . . . . . . . . . . . . . . 110

4.15. Características generales del ensayo realizado empleando el conjunto total de características. . . . . . . . . . . . . . . . . . . . 111

5.1. Tabla de indicadores de fragmentación seleccionados, siendo para los indicadores de coberturas las coberturas de (A) árboles, (V) vegetación, (E) edificios y (Todas) todas las clases de estudio. . . . . . . . . . . . . . . 156

5.2. Matriz de confusión de asignación de coberturas imagen QuickBird 2004. 160

5.3. Matriz de confusión de asignación de coberturas imagen PNOA 2008. . . 160

5.4. Matriz de confusión de asignación de coberturas a las zonas de sombras imagen QuickBird 2004. . . . . . . . . . . . . . . . . . . . 161

5.5. Matriz de confusión de asignación de coberturas a las zonas de sombras imagen PNOA 2008. . . . . . . . . . . . . . . . . . . . 161

5.6. Grupos de características de fragmentación empleados en las clasificaciones. 167

5.7. Grupos de los conjuntos de características empleados en el ensayo IV. . . 168 


\section{Capítulo 1}

\section{Introducción y estado del arte}

\subsection{Introducción}

Desde los inicios de la humanidad, la cartografía -en forma de mapas- ha sido una de las formas más antiguas de comunicación. El significado de los mapas, y más todavía en el pasado, deriva del hecho de que la gente los realizaba para contar a otra gente sobre los lugares en los que había estado o hechos que había experimentado. Esto implica que a lo largo de la historia, los mapas han sido algo más que el resultado de un conjunto de procesos técnicos o artesanos para su producción y mucho más que una imagen estática de su contenido en el tiempo.

Cualquier apreciación de la importancia histórica de los mapas depende de la clara concepción de su naturaleza, de los factores que han dado forma a su producción y transmisión, y su rol dentro de las diferentes sociedades. En este sentido, es de suponer que los mapas constituyen un lenguaje gráfico especializado, un instrumento de comunicación que ha influenciado las características del comportamiento y de la vida social de la humanidad. La cartografía, ha servido como banco de memoria para datos espaciales y como nemotécnica en sociedades en las que la producción cartográfica era limitada (Harley, 1987).

Del mismo modo que el lenguaje, la cartografía ha ido evolucionando a medida que ha evolucionado el hombre y la tecnología, ya sea en su forma de adquisición de datos, con nuevos inventos como la brújula, el cuadrante, el teodolito, etc.; o en su forma de producción, desde la pintura mural, o papiro y pluma, hasta la invención de la imprenta y serigrafía, hasta el día de hoy.

Actualmente y más que nunca existen nuevos dispositivos que nos permiten gestionar 
grandes cantidades de información, adquirir un mayor volumen de datos con diferentes equipos (satélites, aviones, drones, teléfonos móviles), procesarlos y elaborar mapas y datos cartográficos en formato digital.

Durante los últimos años, tanto la industria como la administración han prestado especial interés a la gestión de bases de datos cartográficas, debido a la necesidad constante de almacenar información cartográfica con diferentes propósitos, incluyendo el desarrollo físico y económico, gestión del territorio o gestión de fondos públicos. La principal fuente de información de estas bases de datos cartográficas son imágenes por satélite, imágenes aéreas y más recientemente imágenes captadas por drones o vehículos aéreos no tripulados (VANT). Además de la información espectral de la superficie terrestre proporcionada por estos dispositivos, hay otro tipo de sensores capaces de proporcionar datos de altura, como los sensores LiDAR (Light Detection and Ranging) o escáneres láser, o los sensores RADAR (Radio Detecting and Ranging), que proveen información sobre la rugosidad de la superficie. El volumen de estos datos resulta extremadamente elevado, al igual que los requerimientos de su procesado, previo a su introducción en la base de datos para ponerlos a disposición del usuario.

Entre los diferentes tipos de bases de datos cartográficas, se encuentran las bases de datos de tipologías de usos del suelo. En la actualidad existen diversos programas autonómicos, nacionales y europeos para la creación de cartografía base de usos del suelo, algunos de ellos coordinados entre sí. La actualización de este tipo de bases de datos resulta necesaria debido a que los cambios en los usos del suelo afectan a la estructura y funciones de los ecosistemas, repercutiendo en diversos factores naturales como el clima, la vegetación y la biodiversidad (Broadbent et al., 2012; Collier et al., 2013; Wan et al., 2015). Además, la identificación de cambios para la actualización periódica y precisa de los datos cartográficos resulta de gran interés para un mejor entendimiento de las relaciones e interacciones entre las personas y los fenómenos naturales (Berberoglu y Akin, 2009).

Entre los paisajes más dinámicos bajo la influencia de las actividades humanas, se encuentran las zonas agrícolas y urbanas, sujetas a continuos cambios tanto en su estructura como en su vegetación (Lambin et al., 1999). Debido a la propia naturaleza de estas zonas, las bases de datos que contienen la información cartográfica referida a los usos del suelo quedan desactualizadas con rapidez. El conocimiento detallado de estas áreas se considera de vital importancia debido a su influencia en actividades económicas como el empleo, financiación gubernamental, estructuras de irrigación, producción de alimentos y otras actividades relacionadas con la planificación y gestión, como son el análisis 
de riesgos medioambientales y paisajísticos, el estudio de tendencias demográficas o la gestión de residuos, entre otros.

Debido a la extensión de las áreas urbanas y agrícolas y de la adquisición masiva de datos, los métodos automáticos para la detección de cambios y actualización de las bases de datos de ocupación del suelo son indispensables para una continua monitorización de las áreas de interés. En este sentido, la interpretación de datos adquiridos por sensores remotos, ya sea a bordo de satélites o aerotransportados, es imprescindible para el estudio de zonas extensas.

La diversidad de sensores ópticos en cuanto a su resolución espacial y espectral, la frecuencia de adquisición de datos y el incremento de posibilidades para la adquisición de imágenes, hacen que la teledetección sea el elemento clave para la detección y medición de cambios para la actualización de las bases de datos (Mialhe et al., 2015).

En esta tesis se desarrolla una metodología de procesado digital de imágenes y datos LiDAR basada en la extracción de características descriptivas a nivel de objeto y subobjeto que permite, mediante técnicas de clasificación, la detección de cambios para la actualización de bases de datos de ocupación del suelo. Los objetos en este estudio se obtienen a partir de los límites cartográficos de parcelas catastrales. Los conjuntos de características descriptivas propuestas se estudian y validan sobre diferentes estratos paisajísticos como regiones urbanas y zonas agrícolas empleando datos espectrales y tridimensionales de dos fechas diferentes.

\subsection{Estado del arte}

\subsubsection{Actualización de bases de datos de usos del suelo}

Existe un gran número de bases de datos cartográficas que almacenan información del territorio con distintos propósitos, diferentes tipos de datos y diferentes enfoques. Según su objetivo final, se pueden distinguir bases de datos catastrales, agrícolas, forestales, urbanas, etc.

En la actualidad, hay diversos programas de observación de la Tierra, como por ejemplo el programa europeo Copernicus Land Monitoring Services o el Plan Nacional de Observación de la Tierra en España (PNOT), entre otros, que hacen accesible distintos tipos de información y datos actualizados y fiables de varios sensores, que sirven de apoyo a diferentes bases de datos de ocupación del suelo a varios niveles o escalas. 
Las bases de datos de ocupación del suelo contienen información relativa a las características de la superficie terrestre desde dos puntos de vista diferentes: coberturas y usos del suelo. Las coberturas de suelo categorizan la superficie terrestre en función de su aspecto morfológico o material físico, como por ejemplo vegetación, superficie urbana o arbolado forestal. El uso del suelo hace referencia a la dimensión funcional o dedicación socioeconómica derivada de la actividad humana en un territorio, como por ejemplo uso agrícola, industrial o comercial, recreativo, etc. (Valcárcel Sanz y Castaño Fernández, 2012)

Algunos ejemplos de estas bases de datos de ocupación del suelo son (Tabla 1.1): el MODIS Land Cover, como parte del Global Land Cover Facility (GLCF) (Lindsay et al., 1999), el GLCMNO (Tateishi et al., 2011), el Global Land Cover SHARE (GLCSHARE) (Latham et al., 2014), el Geo-Wiki (See et al., 2015) y el Climate change inititiave land cover (CCI-LC) (ESA, 2014) a nivel global; el North American Land Cover Monitoring System (NALCMS) (Latifovic et al., 2012) a nivel continental para América del Norte, MERIS South America (MERISAM2009) (Gascon et al., 2012) y el Seguimiento y Estudio de los Recursos Naturales (SERENA) (Blanco et al., 2013) en América del Sur, AFRICOVER (Di Georgio y Jansen, 1996) en África, el Corine Land Cover (EEA, 1985) y el Atlas Urbano (CE, 2011), que son las componentes Pan-Europea y local de Copernicus; a nivel nacional, el National Land Cover Database (NLCD) en Estados Unidos (Jin et al., 2013), el LC map of Canada (LCC85-05) en Canadá (Latifovic y Pouliot, 2005), el Dynamic Land Cover Dataset 2002-2014 (Lymburner et al., 2013) en Australia, el National LC database of China (NLUD-C) (Hu et al., 2014) en China, o el Sistema de ocupación del suelo en España (SIOSE) (IGN, 2015) integrado en el PNOT.

La mayoría de procedimientos propuestos hasta la fecha para la actualización y delimitación de clases y coberturas de estas bases de datos están basados en metodologías tradicionales de fotointerpretación de imágenes por satélite asistida por ordenador, en las que las clasificaciones de imagen se emplean como información auxiliar en el proceso fotointerpretativo. 
1.2 Estado del arte

\begin{tabular}{|c|c|c|c|c|}
\hline Nivel & Nombre & Zona de uso & Entidad & Referencia \\
\hline \multirow{5}{*}{ Global } & MODIS Land Cover & Global & $\begin{array}{c}\text { NASA - Administración } \\
\text { Nacional de la Aeronáutica } \\
\text { y del Espacio }\end{array}$ & (Lindsay et al., 1999) \\
\hline & GLCMNO & & $\begin{array}{l}\text { ISCGM - International } \\
\text { Steering Committee for } \\
\text { Global Mapping }\end{array}$ & (Tateishi et al., 2011) \\
\hline & Global Land Cover SHARE (GLC-SHARE) & & $\begin{array}{c}\text { FAO - Organización de las } \\
\text { Naciones Unidas para la } \\
\text { Alimentación y la } \\
\text { Agricultura }\end{array}$ & (Latham et al., 2014) \\
\hline & Geo-Wiki & & GeoWiki & (See et al., 2015) \\
\hline & Climate change inititiave land cover (CCI-LC) & & $\begin{array}{c}\text { ESA - Agencia espacial } \\
\text { Europea }\end{array}$ & $(\mathrm{ESA}, 2014)$ \\
\hline \multirow{6}{*}{ Continental } & North American Land Cover Monitoring System (NALCMS) & América del norte & $\begin{array}{c}\text { USGS - Servicio Geológico } \\
\text { de los Estados Unidos }\end{array}$ & (Latifovic et al., 2012) \\
\hline & MERIS South America (MERISAM2009) & América del sur & $\begin{array}{l}\text { JRC - Centro Común de } \\
\text { Investigación }\end{array}$ & (Gascon et al., 2012) \\
\hline & Seguimiento y Estudio de los Recursos Naturales (SERENA) & América del sur & $\begin{array}{c}\text { Red LaTIF - Red } \\
\text { Latinoamericana de } \\
\text { Teledetección en Incendios } \\
\text { Forestales }\end{array}$ & (Blanco et al., 2013) \\
\hline & AFRICOVER & África & $\begin{array}{c}\text { FAO - Organización de las } \\
\text { Naciones Unidas para la } \\
\text { Alimentación y la } \\
\text { Agricultura }\end{array}$ & $\begin{array}{c}\text { (Di Georgio y Jansen, } \\
\text { 1996) }\end{array}$ \\
\hline & Corine Land Cover & Europa & $\begin{array}{l}\text { AEMA (EEA) - Agencia } \\
\text { Europea de Medio } \\
\text { Ambiente }\end{array}$ & $(E E A, 1985)$ \\
\hline & Atlas Urbano & Europa & $\begin{array}{l}\text { AEMA (EEA) - Agencia } \\
\text { Europea de Medio } \\
\text { Ambiente }\end{array}$ & $(\mathrm{CE}, 2011)$ \\
\hline \multirow{5}{*}{ Nacional } & National Land Cover Database (NLCD) & EEUU & $\begin{array}{c}\text { MLRC - Multi-Resolution } \\
\text { Land Characteristics } \\
\text { Consortium }\end{array}$ & (Jin et al., 2013) \\
\hline & LC map of Canada (LCC85-05) & Canadá & $\begin{array}{l}\text { NRCan - Natural } \\
\text { Resources Canada }\end{array}$ & (Latifovic y Pouliot, 2005) \\
\hline & Dynamic Land Cover Dataset 2002-2014 & Australia & GA - Geoscience Australia & (Lymburner et al., 2013) \\
\hline & National LC database of China (NLUD-C) & China & $\begin{array}{l}\text { CAS - Chinese Academy of } \\
\text { Sciences }\end{array}$ & (Hu et al., 2014) \\
\hline & Sistema de ocupación del suelo en España (SIOSE) & España & $\begin{array}{c}\text { IGN - Instituto Geográfico } \\
\text { Nacional }\end{array}$ & $(\mathrm{IGN}, 2015)$ \\
\hline
\end{tabular}

Tabla 1.1: Ejemplos de bases de datos de ocupación del suelo.

El referente europeo de bases de datos de ocupación del suelo durante las últimas décadas es la base de datos Corine Land Cover (CLC), en cuyas especificaciones quedan descritas las diferentes coberturas y usos del suelo para una escala de 1:100.000. Esta base de datos es una herramienta básica y fundamental para el análisis e inventariado de cambios en el territorio europeo, además de ser una herramienta de monitorización a largo plazo. CLC es la primera base de datos de coberturas y usos del suelo a nivel europeo y está generada a partir de fotointerpretación de imágenes por satélite para los años 1990, 2000, 2006 y 2012, generando los mapas de coberturas del suelo CLC1990, CLC2000, CLC2006 y CLC2012 respectivamente. El último producto (CLC 2012) fue publicado por la Agencia Europea de Medio Ambiente (AEMA) en el año 2015, siendo el retraso en su publicación el principal problema de este tipo de bases de datos (Inglada et al., 2017).

Para la actualización de los mapas de coberturas CLC es necesaria la generación de los mapas de cambios entre la fecha previa y la nueva fecha de actualización, como por 
ejemplo, es necesario el mapa de cambios entre 1990 y 2000 (CLC-Cambios 1990-2000) empleado para la generación del CLC2000. Estos mapas de cambios han sido obtenidos entre 1999 y 2000 (CLC-Cambios 1990-2000), 2000 y 2006 (CLC-Cambios 2000-2006) y entre 2006 y 2012 (CLC-Cambios 2006-2012). En Büttner y Kosztra (2014) se describe el proceso de actualización para la CLC2006, la cual resulta de la integración de CLC2000 con CLC-Cambios 2000-2006.

En Feranec et al. (2000) se describen las características básicas de la metodología para la generación de la base de datos CLC1990 además de la evaluación de los resultados de la detección de cambios en la República Checa, Hungría, Rumanía y Eslovaquia en el periodo de 1970 a 1990. Parte de una base de datos vectorial de los 90 generada a partir de interpretación visual de Landsat TM y posterior vectorización. Las imágenes de Landsat TM y Landsat MSS se preparan para la generación de las coberturas de los años 70 (CLC70), y se segmentan de acuerdo a la base vectorial CLC90. Se identifican las clases de CLC70 de manera visual reinterpretando los segmentos de la base CLC90, y se genera un mosaico de los segmentos individuales de la base de datos CLC70 de acuerdo a la integridad lógica y física de las nuevas clases. Finalmente se superpone la CLC70 generada con la CLC90 para la generación del CLC70-90 de cambios.

En Feranec et al. (2007) se describe un método para la actualización de la base de datos CLC aplicado en los Países Bajos y Eslovaquia, en la que se emplea el CLC1990 como plantilla base para la CLC2000. Todas las modificaciones necesarias para la actualización se realizan sobre la nueva plantilla CLC2000 comparando esta con imágenes Landsat de 2000 mediante métodos de visualización e interpretación por computador, por lo que solo son modificadas aquellas zonas que han cambiado. La detección final de cambios (CLC-Cambio 1990-2000) se realiza solapando las CLC de 1990 y 2000.

En Castaño et al. (2005) se describe la metodología empleada para la actualización del CLC únicamente para la Comunidad Autónoma de Castilla-La Mancha, en la cual se emplea una actualización mediante interpretación visual. En este proceso se compararan las imágenes de dos fechas de estudio y se delinean mediante fotointerpretación aquellas zonas cuya apariencia se ha modificado, siempre que la zona tenga un tamaño mínimo de 5 ha. Estas modificaciones se realizan sobre la capa vectorial base.

Una fuente más reciente de datos de ocupación del suelo de Europa (tanto de cobertura como de usos) es la encuesta de la Unión Europea sobre usos del suelo (LUCAS), basada en datos de campo y fotografía aérea, con el propósito de una recolección de datos integrada y posterior cálculo de los cambios cada 3 años empezando desde 2006. La última versión de LUCAS contiene datos de 2015 (EUROSTAT, 2015). La genera- 
ción de LUCAS se realiza solapando una malla ficticia, que sirve como base, sobre el territorio europeo. Los nodos de dicha malla se solapan a su vez con imágenes aéreas y de satélite y se preclasifican mediante fotointerpretación. Con el fin de evitar errores de fotointerpretación, se realizan muestreos de datos de campo sobre algunos de los nodos. Los resultados de campo se combinan con los resultados de la preclasificación para el cálculo del área de clases de coberturas y usos del suelo en toda Europa (Martino y Fritz, 2008).

Pocos proyectos han sido publicados con respecto a la actualización de la base de datos LUCAS, pero la información contenida en ella ha sido empleada para la validación de coberturas combinada con información de Corine en zonas de costa (Gallego y Bamps, 2008), generación y validación de cartografía y de nuevas bases de datos relacionadas con mapas de suelos (Ballabio et al., 2016) o estimación y validación de mapas de contenido de carbono en suelos orgánicos (De Brogniez et al., 2014; Panagos et al., 2013).

A nivel nacional, en España existen diferentes bases de datos de ocupación del suelo, como la Cartografía de la Dirección General del Catastro, el Sistema de Información Geográfica de Identificación de Parcelas Agrícolas (SIGPAC) o el Sistema de Información sobre Ocupación del Suelo de España (SIOSE), cuyo objetivo es integrar la información entre las bases de datos de coberturas y usos del suelo de las Comunidades Autónomas y de la Administración General del Estado. En las especificaciones del SIOSE se mencionan los métodos que se emplean para su actualización, siendo este método muy similar al del Corine Land Cover mediante procesos de fotointerpretación (IGN, 2015).

En Romero et al. (2010) se describen los procedimientos de actualización del SIOSE para la región de Andalucía, en la que la actualización se realiza por fotointerpretación asistida por ordenador con el apoyo de técnicas de clasificación con imágenes SPOT5 de 2005 y 2009 y PNOA 2010. A partir de una clasificación empleando las diferencias entre índices de NDVI y diferencias entre las imágenes pancromáticas, se genera una imagen que se utiliza como máscara de cambios para la fotointerpretación. El mismo procedimiento es empleado en Carpintero et al. (2010), con la diferencia de que se emplea una clasificación no supervisada para clasificar los tipos de cambios de la zona para ayudar al fotointérprete en la asignación de clases final.

En Vila-García et al. (2015) se emplea una técnica similar a la de Romero et al. (2010) y Carpintero et al. (2010) para actualizar el SIOSE en la región de Galicia. En el estudio se emplean imágenes SPOT5 de 2009 y 2011 e imágenes del PNOA 2009 y 2011. Tras la corrección de la imagen SPOT de 2011, ajustada radiométricamente mediante una transformación lineal de su radiometría tomando como referencia la imagen SPOT de 
2009, se genera una imagen de diferencias para la detección de cambios. Se obtienen las diferencias entre NDVI, las diferencias entre las bandas del rojo, las bandas del infrarrojo medio y las bandas del infrarrojo cercano de toda la imagen. Posteriormente se genera una capa de cambios mediante una clasificación no supervisada. Los cambios se definen mediante fotointerpretación con el apoyo de diferentes combinaciones entre bandas de las imágenes SPOT. Esta banda de cambios, junto con el SIOSE de 2009, se emplea como base para definir los límites y geometría de los cambios ocurridos. La asignación de la nueva cobertura sobre la nueva base de datos se realiza mediante fotointerpretación de las imágenes PNOA.

En Gamanya et al. (2009) se emplean métodos de post-clasificación orientada a objetos para la detección de cambios en la ciudad de Harare en Zimbabue entre 1989 y 2002. A pesar del proceso de detección de cambios automático, la actualización se basa en procedimientos manuales llevados a cabo por operarios para la detección de inconsistencias espaciales.

En general, todas las bases de datos mencionadas y trabajos comparten las siguientes características en cuanto a su generación y/o actualización:

- La unidad mínima de información es un polígono.

- La delimitación de dicho polígono se realiza de forma manual por un operador.

- Ninguna de los métodos anteriores asigna directamente una clase de cobertura o de uso del suelo a los polígonos de estudio.

- La metodología básica empleada es la fotointerpretación.

- Esta fotointerpretación es complementada con trabajos de campo.

- Es necesaria información adicional (como productos derivados de clasificaciones) que complemente a los métodos de fotointerpretación.

A pesar de ser esta la práctica más extendida, existen trabajos en los que se han probado métodos de actualización que no requieren de fotointerpretación.

En Fuller et al. (1994) se generó el Mapa de Usos del Suelo de Gran Bretaña (LCMGB - Land Cover Map of Great Britain) de 1990 empleando imágenes del satélite Landsat 5 TM mediante una clasificación supervisada a nivel de píxel. El mismo mapa de coberturas fue actualizado en su versión para el año 2000 (LCM200) en la que se emplearon métodos de clasificación por segmentos para su actualización y fue evaluado con datos de campo Fuller et al. (2005). 
En Hazeu et al. (2011) se describe la base de datos de usos del suelo de los Países Bajos (LGN) y las diferentes versiones y actualizaciones realizadas y proponen una nueva metodología para la actualización y generación de la última versión de la base de datos LGN6 (2007-2008), empleando métodos de segmentación y clasificación a nivel de mallas regulares que actúan como objetos.

Inglada et al. (2017) describen una metodología automática para la producción de mapas de coberturas de suelo a partir de imágenes de alta resolución, empleando métodos de clasificación supervisados combinados con la información previa de bases de datos como datos de entrenamiento y validación. En su estudio, aplica esta metodología para la actualización CLC para toda Francia, empleando como base la CLC de 2012.

En términos generales se ha observado que las metodologías actuales de detección de cambios empleadas para la actualización de bases de datos combinan diferentes técnicas de fotointerpretación, clasificación de imágenes y el uso de información auxiliar.

\subsubsection{Evolución de las técnicas de detección de cambios}

La detección de cambios se describe como el proceso por el cual se identifican diferencias en el estado de un objeto o fenómeno que ha sido observado en dos fechas diferentes (Singh, 1989). La premisa básica de la detección de cambios empleando datos obtenidos por métodos de teledetección es la detección de variaciones en los valores de reflectancia debidos a los cambios producidos en los usos del suelo y no a variaciones de reflectancia causados por otros factores como son el contenido de humedad en el suelo, condiciones atmosféricas o diferencias en el ángulo de inclinación del Sol en el momento de la toma (Jenson, 1983; Singh, 1989). El objetivo de la detección de cambios en teledetección es detectar un cambio en el objeto que está siendo estudiado con respecto a su respuesta espectral en el tiempo.

Durante los últimos años, las técnicas de teledetección han sido ampliamente empleadas para la detección de cambios de usos del suelo en áreas agrícolas y urbanas (Berberoglu y Akin, 2009; Feranec et al., 2007; Galletti y Myint, 2014; Kibret et al., 2016; Löw et al., 2013; Wan et al., 2015; Xian y Homer, 2010). En función de las necesidades y requisitos en los estudios de cambios, se pueden emplear diferentes metodologías de detección. Estos métodos se pueden agrupar según el tipo de cambio estudiado, zonas de estudio, el dominio o aplicación, e incluso los tipos de sensores e imágenes utilizados.

Según Hussain et al. (2013), el proceso de detección de cambios se puede dividir en varias fases: (i) pre-procesado; (ii) selección y aplicación del método de detección de 
cambios; y (iii) evaluación de los resultados. Además, hace hincapié en la importancia de seleccionar un método de detección adecuado en función del objetivo de estudio. Existen diferentes métodos de detección de cambios que únicamente indican si ha habido cambio o no (métodos binarios) (Lu et al., 2004), como es el método de diferencias simples, y métodos que indican el tipo de cambio (métodos direccionales), como pueden ser los métodos de detección de cambios mediante clasificaciones (Lunetta y Elvidge, 1999).

Entre los métodos de detección de cambios de tipo binario se encuentran los métodos de comparación directa entre imágenes, como es el método de diferencias simples o ratios entre imágenes, o aquellos en los que se realiza una modificación o transformación de las imágenes, como las diferencias entre índices de vegetación, transformación Tasseled cap o el análisis de cambios mediante componentes principales. El principal problema de estos métodos tradicionales es la definición del umbral para diferenciar entre lo que ha cambiado y lo que no, pudiendo cometer errores tanto por exceso como por defecto si los umbrales no están bien definidos (Lu et al., 2004; Xian et al., 2009). Como métodos direccionales se encuentran el vector de cambios o los basados en clasificación, tanto supervisados como no supervisados. En los no supervisados, a pesar de que no requieren un conocimiento previo del área de estudio, es necesario identificar a posteriori las direcciones de las clases de los cambios detectados y no cambios. En los métodos de clasificación supervisados es necesario conocer e identificar las diferentes clases de cambio y no cambio a estudiar además de seleccionar un conjunto previo de muestras de entrenamiento para realizar la clasificación. Entre los métodos de clasificación supervisados se encuentran los métodos de post-clasificación y clasificación directa, siendo estos dos los más extendidos para la detección de cambios.

Tewkesbury et al. (2015) incluyen un grado más en el proceso de detección de Hussain et al. (2013) añadiendo como una fase más de la detección de cambios la selección de la unidad de análisis. La unidad de análisis es uno de los criterios más extendidos de agrupar los métodos de detección de cambios, dividiéndolos en dos grandes grupos: a nivel de píxel y orientados a objeto (Gamanya et al., 2009; Huang et al., 2010; Hussain et al., 2013). Ambos enfoques han sido empleados para la detección de cambios de usos de suelo en diferentes estudios en los que se han comparado sus ventajas y desventajas (Gamanya et al., 2009; Moeller y Blaschke, 2005).

\subsubsection{Técnicas de detección de cambios basadas en objetos}

Los métodos de detección de cambios a nivel de píxel han sido y siguen siendo un tema de gran interés en teledetección (Chen et al., 2012; Inglada et al., 2017; Xian y Homer, 
2010). Hasta hace apenas unos años, las clasificaciones de usos del suelo se realizaban empleando análisis a nivel de píxel sobre imágenes de satélite, utilizando tanto métodos supervisados como no supervisados para la clasificación. Los métodos orientados a píxel analizan las propiedades espectrales de cada uno de los píxeles contenidos en el área de estudio, sin considerar la información espacial o contextual sobre el píxel estudiado (Weih y Riggan, 2008). Otro de los principales problemas del uso del píxel como unidad básica es la dificultad de definir una resolución espacial o escala para la identificación precisa de cambios de todos los tipos de objetos geográficos (Marceau et al., 1994).

El análisis de imágenes basado en objetos u OBIA (Object Based Image Analysis) no considera el píxel como unidad básica de estudio, sino la agrupación de píxeles u objeto (Berberoglu y Curran, 2004; Blaschke y Strobl, 2001; Ming et al., 2015). Los sistemas de información geográfica o SIG abrieron nuevos horizontes y posibilidades que permitieron abordar el análisis de imágenes desde un punto de vista diferente. La combinación de información de sensores remotos con técnicas SIG y bases de datos geoespaciales, ha permitido incrementar la fiabilidad de la detección de cambios, al mismo tiempo que se reduce el tiempo de procesado, en técnicas de clasificación y de detección de cambios (Berberoglu y Akin, 2009; Berberoglu et al., 2000; Garcia-Pedrero et al., 2015; Rozenstein y Karnieli, 2011).

En OBIA, los píxeles de las imágenes no son clasificados individualmente sino que se combinan en grupos homogéneos (objetos) y se clasifican en conjunto (Mui et al., 2015; Walter, 2004). Los objetos se definen como agrupaciones de píxeles contiguos que pueden contener niveles digitales similares, o bien comparten características de tamaño, forma y/o relación geométrica con aquellos elementos definidos en el mundo real (Hay y Castilla, 2006). El objeto se vuelve la unidad básica de análisis y se puede caracterizar por un elevado número de variables descriptivas derivadas de la imagen, de su forma, de la información contenida en la base de datos a actualizar, etc. El análisis de imágenes orientado a objeto ha demostrado tener un tremendo potencial para mejorar la generación de mapas y clasificación de usos del suelo, aunque todavía sus ventajas solo han sido analizadas y probadas en estudios de investigación (Platt y Rapoza, 2008).

Las fases del análisis de imágenes OBIA en estudios de generación y clasificación de mapas de coberturas son las siguientes (Inglada et al., 2015):

- Creación de los objetos mediante segmentación de imagen o definición de los mismos a partir de una capa vectorial

- Descripción y caracterización de los objetos mediante la extracción de caracterís- 


\section{Introducción y estado del arte}

ticas

- Clasificación de los objetos

En muchos casos, mediante procesos de análisis de imágenes, se pueden generar objetos segmentando la imagen en áreas espectralmente homogéneas (Blaschke y Strobl, 2001). La segmentación de imágenes es la forma más extendida para la extracción o delimitación de objetos dentro de la imagen. Uno de los problemas que presenta la segmentación es que puede afectar a la extracción de información sobre los objetos, ya que la forma y propiedades del objeto segmentado difieren dependiendo del algoritmo y los parámetros empleados (Hay y Castilla, 2006). Por otro lado, las bases de datos pueden proporcionar los límites para la generación de los objetos de estudio reduciendo los errores que se producen al generar los límites con algoritmos de segmentación. Este enfoque es un caso específico del análisis OBIA, que emplea los límites de los polígonos derivados de las bases de datos cartográficas de usos del suelo y es conocido, en ocasiones, como análisis de imágenes a nivel de parcela. Este método se considera apropiado para el análisis de paisajes en entornos urbanos, suburbanos y áreas periféricas, en donde los límites entre elementos están bien definidos (Hermosilla et al., 2012). Esto también sucede en entornos agrícolas, en los que los límites de las parcelas son relativamente estables mientras que su contenido varía con frecuencia, lo que facilita su clasificación (Blaschke y Strobl, 2001; Recio, 2009). El uso de parcelas como unidad de análisis también se ha empleado en otros trabajos de detección de cambios en zonas forestales (Hall y Hay, 2003) además de estudios agrícolas y urbanos (Gamanya et al., 2007; Hermosilla et al., 2012; Raza y Kainz, 2002; Walter, 2004) ya que permiten la integración de los cambios detectados de las parcelas con las bases de datos cartográficas. El principal inconveniente de tratar a la parcela como unidad básica de estudio es que no se consideran los cambios que puedan ocurrir en una parte de la parcela. Esta metodología requiere de una cartografía actualizada en cuanto a los límites de las parcelas de estudio, así como una correcta georreferenciación entre la cartografía base, la cual define los objetos, y las imágenes de estudio.

En comparación con los métodos orientados a píxel, la información espacial y contextual puede ser obtenida adicionalmente de los objetos en OBIA (Blaschke, 2010; Hussain et al., 2013; Ruiz et al., 2011; Wu et al., 2015), y puede ser fácilmente almacenada en una base de datos como atributos, variables o características descriptivas. Estas características son las que permiten caracterizar con gran detalle los objetos de estudio al extraer y combinar diferentes tipos de datos e información, lo que mejora la clasificación de los objetos y, por lo tanto, incrementan los resultados de detección de cambios. Es en esta 
dirección en la que se sitúa esta tesis tratando de mejorar la descripción de los objetos contenidos en la base de datos desde diferentes puntos de vista y empleando fuentes de datos variados.

En comparación con los métodos tradicionales de detección de cambios a nivel de píxel, la detección de cambios orientada a objetos mejora la identificación de los cambios sobre los diferentes elementos geográficos que se encuentran en el paisaje. Además, permite un enfoque y una metodología para el análisis y aprovechamiento de la información contenida en imágenes de alta resolución, captando la información más relevante y detallada para la identificación los cambios de forma sistemática y reproducible (Chen et al., 2012).

El éxito de los métodos de detección de cambios depende de diversos factores entre los que se encuentran, la escala espacial y temporal, la geometría de la toma de datos, el registro entre imágenes y las correcciones radiométricas o normalización entre imágenes. Además de estos factores a tener en cuenta, a día de hoy no existe ningún algoritmo en concreto designado como el mejor método de cambios aplicable para cualquier tipo de estudio.

Según Chen et al. (2012), los métodos de detección de cambios orientados a objetos se pueden clasificar en cuatro grupos diferentes: (i) detección de cambios mediante comparación objeto a objeto; (ii) detección de cambios mediante comparación post-clasificación de objetos; (iii) detección de cambios multitemporal directo; y (iv) métodos híbridos de detección de cambios.

Los métodos de cambios mediante comparación objeto a objeto son aquellos que, de la misma forma que en los métodos a nivel de píxel, se realiza una comparación directa entre cada uno de los objetos de la imagen. Esto se realiza mediante una superposición espacial de los objetos y el posterior análisis de sus valores espectrales o de sus características de forma y textura. La principal ventaja de este tipo de métodos de detección de cambios es la propia comparación directa que se realiza entre los objetos. Normalmente, todos los objetos se extraen mediante métodos de segmentación de imagen, y los pasos a seguir para la detección de cambios, como por ejemplo el método de diferencias simples, son similares a los pasos seguidos en los métodos de detección basados en píxeles (Gong et al., 2008; Miller et al., 2005). No obstante, estos métodos presentan ciertos inconvenientes. Como en el caso de los métodos de tipo binario a nivel de píxel, la selección de un umbral con el que definir si ha habido cambio o no resulta complicada, y puede generar errores tanto por exceso como por defecto en la detección de los objetos de cambio. Otro de los inconvenientes que presenta este método es, al realizar la segmentación de 
imágenes por separado, los objetos segmentados pueden presentar cambios en su forma y dimensión, por lo que resulta muy complicado encontrar la correspondencia espacial objeto a objeto entre imágenes de diferentes épocas de estudio o incluso la generación de polígonos astillas (McDermid et al., 2008). Los posibles errores que se cometan al realizar la correspondencia entre objetos afectarán directamente en los resultados de detección de cambios.

En contraste con los métodos de comparación objeto a objeto, los métodos de detección de cambios mediante comparación post-clasificación son capaces de indicar la dirección del cambio (tipo de cambio). Estos métodos detectan los cambios en el paisaje mediante el análisis de la clase a la que pertenecen los objetos en las diferentes fechas de estudio, sin necesidad de realizar una comparación directa de los valores espectrales o de textura de los objetos (Durieux et al., 2008; Laliberte et al., 2004; Walter, 2004). Dentro de estos métodos, se encuentra el método de post-clasificación, en el que se clasifican los objetos de las diferentes fechas por separado y se comparan las clases resultantes de la clasificación para cada uno de los objetos estudiados. Cabe destacar que el principal problema que presentan estos métodos es la propagación de errores, tanto en la segmentación de las imágenes (cuando proceda) como en los errores cometidos en las clasificaciones. Además, como en el caso anterior, resulta difícil realizar la correspondencia entre objetos de épocas diferentes al generar la segmentación de imágenes por separado, pudiendo obtener objetos de forma y tamaño diferentes para cada una de las épocas de estudio. Para solucionar el problema de la segmentación, existen diversos trabajos en los que se consideran objetos con forma y dimensiones constantes para las diferentes épocas de estudio, en donde los objetos son definidos mediante los límites de parcelas contenidas en una base de datos vectorial (Hermosilla et al., 2012).

En los métodos de detección de cambios multitemporal directos, se intenta evitar y eliminar los errores de generación y correspondencia de objetos relacionados con la segmentación de imágenes de fechas diferentes por separado. Así, estos métodos realizan una combinación de imágenes de diferentes fechas de estudio para generar una única segmentación y obtener directamente objetos de cambio y no cambio (Bontemps et al., 2008; Desclée et al., 2006). Una única segmentación combinando todas las imágenes de diferentes fechas de estudio facilita el método de detección de cambios ya que genera objetos de tamaño, forma y posición geográfica constantes. Dentro de estos métodos se encuentra el método de clasificación multitemporal directa, en el cual se combinan imágenes de diferentes épocas de estudio para conseguir una clasificación en la que se obtienen directamente los resultados de cambio y de no cambio. 
Como último grupo de métodos de detección de cambios a nivel de objeto están los métodos híbridos, que combinan tanto procedimientos a nivel de objeto como a nivel de píxel. Este enfoque parte de la idea de que la información de cambio debe derivarse de los píxeles, y que la metodología a nivel de objetos se debe aplicar posteriormente para conseguir una mejor extracción de los resultados de cambios. Así, diferentes autores han empleado estos métodos para generar imágenes de diferencias a nivel de píxel para su posterior segmentación y clasificación de objetos de cambio y no cambio (Al-Khudhairy et al., 2005; Carvalho et al., 2001; McDermid et al., 2008; Yu et al., 2004). De esta forma, los métodos híbridos reducen satisfactoriamente errores en la detección de cambios además de evitar los errores de correspondencia en la comparación de objetos o la generación de polígonos astilla. Ya que en los métodos híbridos de detección de cambios intervienen muchos pasos, se desconoce la influencia de las diferentes combinaciones entre métodos a nivel de píxel y a nivel de objeto sobre los resultados finales de detección de cambios.

\subsubsection{Extracción de información/atributos a nivel de objeto}

Para poder clasificar un objeto, es necesario disponer de una serie de variables o características descriptivas que cuantifiquen de forma numérica las propiedades de dicho objeto, de forma que se puedan utilizar para la asignación de dicho objeto a una clase temática.

Guyon y Elisseeff (2003) consideran las características descriptivas como aquellas características derivadas de variables crudas, representando estas variables la información contenida en las imágenes obtenidas por sensores remotos. En este trabajo, la extracción de características descriptivas se basa en la obtención de información derivada de datos, elaborados o no, de modo que las características a nivel de píxel son reemplazadas por otras que representan al objeto completo (Hermosilla, 2011).

Existen diversos trabajos centrados en la extracción de características que posteriormente son empleados con diferentes propósitos, como extraer información a partir de perfiles de densidad en alturas para análisis de la vegetación (Estornell et al., 2011; Velázquez-Martí et al., 2010), extracción de rugosidad del terreno para estimar flujos hídricos (Colmenárez et al., 2010), o combinación de imágenes y datos LiDAR para clasificaciones urbanas (Hermosilla et al., 2010), agrícolas (Recio et al., 2006) y forestales (Ruiz et al., 2016).

De los trabajos realizados se deduce el gran potencial de estas técnicas si se consiguen integrar adecuadamente en los procesos de actualización cartográfica. 
Además de las tradicionales características espectrales, de forma y de textura (Benz et al., 2004; Haralick et al., 1973) extraídas de objetos, otro tipo de características tridimensionales, características estructurales derivadas de funciones geoestadísticas y características de fragmentación, pueden ser extraídas de otros tipos de datos y de imágenes. En la Tabla 1.2 se agrupan las características que se describen a continuación en función de la fuente de datos de las que se derivan.

\begin{tabular}{|c|c|}
\hline Datos & Tipo de características \\
\hline \hline Derivadas de datos LiDAR & Tridimensionales \\
\hline \hline Derivadas de imágenes & Espectrales, forma, textura y derivadas de funciones geoestadísticas \\
\hline \hline Derivadas de imágenes y datos LiDAR & Fragmentación \\
\hline
\end{tabular}

Tabla 1.2: Tipos de características extraídos por objeto en función de los datos empleados.

\subsubsection{Información tridimensional derivada de datos LiDAR}

Cada vez más, la información proporcionada por los sensores LiDAR está siendo empleada para la clasificación de coberturas y usos del suelo y reconocimiento de objetos. Esto es debido principalmente a las características derivadas de las alturas que aporta este sensor. La tecnología LiDAR añade una nueva dimensión a las clasificaciones de usos del suelo diferenciando entre elementos que presentan cierta altura respecto al suelo, como son los edificios y los árboles, con respecto de los elementos a nivel de suelo (Yan et al., 2015). Estos valores de altura derivados del LiDAR han demostrado tener una importancia para la detección y delineación de elementos elevados independientemente de los entornos en los que han sido empleados (entornos urbanos o espacios naturales) (Hartfield et al., 2011; Priestnall et al., 2000).

Existen estudios orientados a objeto que han utilizado datos LiDAR para la clasificación de coberturas y usos del suelo. Chen y Gao (2014) emplean los datos LiDAR en forma de modelos digitales para la segmentación y posterior clasificación de coberturas de suelo en zonas urbanas utilizando características de altura e intensidad. Im et al. (2008) también emplean únicamente los datos LiDAR para la segmentación y clasificación de usos del suelo de los objetos segmentados.

En términos generales, los datos LiDAR han sido ampliamente empleados combinando información tridimensional con información multiespectral sobre diferentes entornos urbanos, (Awrangjeb et al., 2013; Hermosilla et al., 2010; Rottensteiner et al., 2007; Sohn y Dowman, 2007), suburbanos (Parent et al., 2015), agrícolas (Arroyo et al., 2010) o zonas forestales (Holmgren et al., 2008; Hudak et al., 2009; Ruiz et al., 2016). La in- 
formación LiDAR se complementa con la información espectral obtenida por sensores de satélites o sensores aéreos de forma que los dos sistemas encuentran un beneficio mutuo. En este sentido, los datos LiDAR proporcionan información tridimensional que no proporcionan los sensores espectrales, mientras que los sensores espectrales proporcionan información espectral no contenida en los datos tridimensionales.

La práctica más extendida de uso del LiDAR pasa por la interpolación de la nube de puntos para la generación de modelos digitales de superficie y modelos digitales del terreno, que combinados con información espectral, hace que la clasificación de ciertas clases resulte más fácil reduciendo la confusión e incrementando la separabilidad entre ellas (Brennan y Webster, 2006; Hartfield et al., 2011; Yan et al., 2015). Estos modelos tridimensionales también han sido empleados para la clasificación de áreas forestales combinando dichos modelos con información de intensidades (Pippuri et al., 2016).

Parent et al. (2015) proponen un método completamente automático que combina métodos a nivel de píxel y objeto para la extracción de coberturas del suelo basándose en características derivadas de LiDAR y características espectrales. La estrategia seguida es la de clasificar cada una de las coberturas del suelo por separado empleando el retorno LiDAR y características espectrales para identificar, mediante umbrales, aquellos píxeles que potencialmente pertenezcan a una cobertura dada. Tras la clasificación, los píxeles resultantes se agrupan en objetos basándose en reglas de contigüidad. La clasificación de todas las coberturas se combina en una única imagen para obtener el mapa final de coberturas de suelo.

Antonarakis et al. (2008); Arroyo et al. (2010); Huang et al. (2013) también emplean el mismo enfoque orientado a objetos mediante segmentación y clasificación empleando los datos LiDAR combinados con información espectral en la clasificación de coberturas y usos del suelo.

En cuanto a la detección de cambios, los datos LiDAR se han empleado fundamentalmente para detección de edificios y actualización de bases de datos en zonas urbanas (Chen y Gao, 2014; Hermosilla et al., 2010; Vu et al., 2004a; Zhou et al., 2004, 2008). En los procedimientos para la actualización de bases de datos se genera un modelo digital de superficies normalizado (MDSn), calculado mediante la resta entre un modelo digital de superficie (MDS) y un modelo digital del terreno (MDT). Gracias al modelo de superficie normalizado es posible la extracción de los edificios, que comparándolos con la cartografía existente, permite detectar los cambios producidos en cuanto a demoliciones y nuevas edificaciones (Champion et al., 2010). Este proceso también se puede realizar comparando datos LiDAR multitemporales entre dos fechas diferentes (Vu et al., 2004b). 
Otro procedimiento de detección de cambios que emplea datos LiDAR incluye alguna modificación, como es la clasificación de elementos directamente sobre la nube de puntos. La nube se clasifica diferenciando entre puntos terreno y puntos objeto obteniendo los puntos pertenecientes a los edificios. Una vez extraídos los edificios, se comparan con la cartografía existente y se calculan las diferencias (Vosselman et al., 2004). Este método se considera como una primera aproximación para la detección de cambios orientado a objeto ya que emplea únicamente elementos pertenecientes a edificios. En este trabajo nos centramos en las características que se pueden extraer de los modelos digitales generados a partir de datos LiDAR.

\subsubsection{Información derivada de imágenes}

\section{Características espectrales, de textura y de forma}

Las características espectrales proporcionan información sobre la respuesta espectral de los píxeles que componen la imagen, la cual viene dada en función de los tipos de cobertura, estados fisiológicos de las plantas, materiales de construcción, etc. (Recio, 2009). La información espectral es el tipo de información básica proporcionada por las imágenes de sensores remotos. Al extraer este tipo de información a nivel de objeto se puede obtener un conjunto de estadísticos como son la media aritmética, la desviación típica, el máximo, el mínimo, el rango, etc. de los valores espectrales de los píxeles contenidos en el objeto (Ruiz et al., 2011).

Las características de textura aportan información acerca de la distribución espacial de los valores de intensidad en la imagen. Existen diversas técnicas de análisis de texturas que han sido empleadas para extracción de este tipo de características: métodos estadísticos, como la matriz de co-ocurrencias de niveles de gris (MCNG) (Haralick et al., 1973), técnicas de filtrado como los filtros de energía (Laws, 1985), o los filtros Gabor (Jain y Farrokhnia, 1991), métodos basados en la descomposición wavelets (Mallat, 1989), etc.

Smits y Annoni (1999) proponen un método para la actualización de bases de datos de ocupación del suelo empleando imágenes pancromáticas de sensores satelitales de alta resolución. Mediante procesos de segmentación de la imagen de texturas (calculando la MCNG) obtenida a partir de la imagen pancromática, se identifican los nuevos límites de regiones urbanas e industriales, que son comparadas con los polígonos existentes en la base de datos previa y son actualizadas siguiendo las especificaciones del Corine Land Cover. Huang et al. (2008) también extrae la matriz de co-ocurrencias de una imagen pancromática del sensor SPOT5, en donde la imagen de texturas se combina 
junto con la información espectral en una clasificación supervisada para la obtención de las coberturas del suelo.

He et al. (2011) también emplean tanto la información espectral como de textura para estudios de clasificación y detección de cambios en usos del suelo en zonas periurbanas con imágenes Landsat-5 TM. Aquí, se generan imágenes de textura por cada una de las bandas espectrales de las dos épocas, y se calculan dos imágenes de magnitud de cambios mediante el análisis del vector de cambios (Johnson y Kasischke, 1998), una espectral y otra de texturas. Estas imágenes de magnitud se combinan en una única imagen de dos bandas, la cual se emplea en el método de clasificación para la obtención de los píxeles de cambio.

Las características de forma describen las propiedades geométricas de un objeto, así como la complejidad de su contorno. Las características de forma básicas son el área y el perímetro de los objetos. A parte de estas dos características básicas, se pueden obtener otros descriptores de forma, como el índice de compacidad, índice de forma e índice de dimensión fractal (Bogaert et al., 2000; Krummel et al., 1987), siendo entre estos el índice de forma el más conocido. Para el cálculo de los parámetros de forma es necesario que los objetos estén definidos, o bien por métodos de segmentación de la imagen o bien por una capa vectorial, como en el caso de las parcelas. En esta tesis, al emplear límites de parcelas definidos por una capa vectorial y considerar que las parcelas se mantienen constantes, las características de forma también se mantendrán constantes, por lo que no serán indicadores de cambio en este caso. A pesar de ello, este tipo de características ayudan a la eliminación de errores en la base de datos vectorial identificando polígonos cuña, o para identificar elementos pertenecientes a calles y carreteras debido a su forma característica (Benz et al., 2004; Gil-Yepes et al., 2013).

Estos tres tipos de características forman un grupo muy efectivo para la clasificación de objetos, y se han empleado junto con otro tipo de características en diversos estudios para la clasificación de usos del suelo (Petropoulos et al., 2011; Powers et al., 2015; Recio et al., 2006; Yu et al., 2008). Los cambios en los usos del suelo están asociados a cambios tanto en la respuesta espectral como en la distribución espacial de los valores de reflectancia, es por esto que estas características siguen siendo empleadas en estudios de clasificación y detección de cambios.

\section{Características derivadas de funciones geoestadísticas}

Las características de las funciones geoestadísticas derivadas de imágenes aportan información sobre la distribución espacial de los elementos de las imágenes. La caracterización de patrones regulares espacialmente resulta interesante en la clasificación 
de coberturas o usos del suelo agrícolas donde existen marcos de plantación regulares (Balaguer-Beser et al., 2013; Ruiz et al., 2007). Una de las funciones geoestadísticas más extendidas en el mundo de la teledetección es el semivariograma (Atkinson y Lewis, 2000).

En años recientes, el semivariograma se ha hecho un hueco dentro del análisis en los procesos de clasificación orientados a objetos (Van der Meer, 2012). Berberoglu et al. (2000) empleaba el semivariograma para la extracción de información de texturas para clasificación por píxel que derivaba en una clasificación orientada a objeto cuando combinaba los píxeles clasificados con los límites de las parcelas. En Berberoglu et al. (2000) la información extraída del semivariograma es una imagen de texturas obtenida mediante el cálculo de la varianza y semivarianza sobre la imagen espectral

Las características derivadas del semivariograma han sido empleadas para clasificaciones a nivel de objeto en zonas agrícolas (Recio et al., 2011, 2006; Ruiz et al., 2007). Xie et al. (2008) emplearon valores discretos de semivarianza del semivariograma a diferentes distancias para proporcionar características de textura para clasificación por objeto de polígonos generados por segmentación. Balaguer et al. (2010) obtuvieron altas fiabilidades de clasificación empleando características derivadas del semivariograma en parcelas rurales. En Hermosilla et al. (2012) se emplearon características extraídas del semivariograma con características espectrales, de forma y de textura para un problema de detección de cambios en áreas periurbanas con paisajes heterogéneos. En ambos casos, las características extraídas del semivariograma, son parámetros obtenidos de las funciones del semivariograma para cada una de las parcelas de estudio, considerando parámetros como la pendiente, ratios entre valores de semivarianza a diferentes distancias del origen, posición de los máximos y mínimos relativos, entre otras.

Yue et al. (2013) emplearon características del semivariograma para mejorar las fiabilidades de una clasificación orientada a objeto con imágenes QuickBird, siendo estas características los valores de semivarianza del objeto, la media y desviación de dichos valores y el gradiente del semivariograma a tres distancias del origen diferentes. Powers et al. (2015) usaron características del semivariograma para detectar perturbaciones de tipo industrial en áreas forestales. Balaguer et al. (2010) y Wu et al. (2015) demostraron que se podían obtener mejores resultados de clasificación basada en objetos de usos del suelo combinando características derivadas del semivariograma con información espectral, con respecto a la combinación de características derivadas de la matriz de co-ocurrencias de niveles de gris (MCNG) e información espectral. Balaguer-Beser et al. (2013) estudiaron la heterogeneidad de la distribución de árboles en plantacio- 
nes, utilizando un conjunto de parámetros extraídos del semivariograma experimental, y mostraron la habilidad de las características del semivariograma para describir patrones espaciales de los cultivos. En todos estos últimos trabajos, las características empleadas son las características propuestas en Balaguer et al. (2010), con parámetros derivados de las funciones de semivariograma como por ejemplo, valores de semivarianza a diferentes distancias dentro de la función, ratios entre dichos valores, distancia desde el origen a la que se encuentran los valores extremos de la función del semivariograma, el valor de la pendiente al principio de la función, etc.

El semivariograma ha demostrado tener un gran potencial en estudios de clasificación al permitir caracterizar la estructura interna de los objetos, pudiendo diferenciar entre varios tipos de clases y coberturas de usos del suelo. En este sentido, las funciones geoestadísticas permiten relacionar la distribución espacial de los elementos contenidos en los objetos de estudio. Es por esto que este tipo de información resulta interesante para estudios de detección de cambios, ya que si se detecta un cambio dentro de la estructura interna del objeto entre dos fechas diferentes, se podría detectar el cambio en la cobertura o uso del suelo.

\section{Extracción de información de regiones de sombra}

En la literatura, se pueden encontrar diferentes métodos para la eliminación de sombras sobre imágenes. Algunos de estos estudios eliminan las sombras directamente sobre las imágenes obtenidas por sensores remotos (Arbel y Hel-Or, 2011; Liu y Yamazaki, 2012; Tsai, 2006); en otros, las sombras son eliminadas tras la clasificación de las imágenes sobre los mapas de coberturas (Song et al., 2014; Van de Voorde et al., 2007; Zhou et al., 2009).

Shu y Freeman (1990) hacen una revisión de varios métodos de detección y eliminación de sombras sobre imágenes, entre los que se encuentran la eliminación mediante máscaras, fusión de datos de diferentes fuentes y realce radiométrico. La eliminación mediante mascaras consiste básicamente en detectar las zonas de sombras y enmascararlas, y de esta forma prescindir de ellas para el estudio. La fusión de datos de diferentes fuentes se basa en reemplazar los píxeles que se sitúan en zona de sombra por píxeles procedentes de otra imagen de una época diferente. En cuanto al realce radiométrico emplea el método de ecualización de histogramas o "histogram matching", en el que los valores del histograma en las zonas de sombra se ecualizan para ajustarse lo máximo posible al histograma de las zonas sin sombra. Así mismo, tras la aplicación del realce, realiza un nuevo ajuste empleando los histogramas de las zonas vecinas a las sombras para que coincidan entre ellas con el fin de minimizar las diferencias radiométricas alre- 
dedor de los bordes de las sombras. Para conseguir esto, estudia tres métodos diferentes: transformación en escala de grises algebraica, ecualización de los histogramas y transformación o ajuste de media y desviación, siendo esta última la que mejores resultados obtiene.

En otros trabajos, se han empleado otro tipo de metodologías para la eliminación de sombras, como el método de índices invariantes de color (Tsai, 2006), la corrección gamma, ajustes de histogramas y correlación lineal para imágenes por satélite de alta resolución, como Ikonos y QuickBird, obteniendo los mejores resultados empleando la correlación lineal (Sarabandi et al., 2004).

Además de los métodos citados anteriormente, se pueden encontrar otro tipo de técnicas de corrección mediante ratios, como los utilizados en Yamazaki et al. (2009) y Kouchi y Yamazaki (2007), en donde se toman muestras de las zonas de sombra y no sombra de un mismo tipo de superficie, y se realiza una regresión lineal por cada una de las bandas tanto espectrales como pancromática. La relación que se obtiene entre las muestras se emplea para la corrección del brillo de los píxeles de sombra. Arbel y Hel-Or (2011) emplean una corrección suponiendo que las intensidades en las zonas de sombra y no sombra son similares, por lo que a partir de muestras de sombra y no sombra, generan una máscara de intensidades por cada banda de la imagen para aplicar el realce sobre los valores a las zonas de sombra. Una vez aplicada la corrección, se realiza un ajuste general para conseguir una correcta visualización de toda la imagen.

En los últimos años, se han aplicado estas técnicas de realce no sólo a nivel de píxel sino también a nivel de objeto. En Liu y Yamazaki (2012) se realiza una segmentación con el fin de clasificar la imagen en objetos sombra y no sombra mediante una umbralización del histograma. Así mismo, los objetos sombra son categorizados en tres clases diferentes en función de lo oscura que es la sombra con el fin de aumentar la precisión a la hora de aplicar el ajuste. Una vez se obtienen los objetos categorizados en niveles de sombra, se vuelve a realizar una segmentación. Tras obtener los nuevos objetos sombra, se realiza la corrección mediante métodos lineales como en Dare (2005) y Sarabandi et al. (2004). Luus et al. (2013) emplean un método de segmentación mediante texturas para la detección de las sombras. La corrección de estas se realiza mediante un realce de los valores de intensidad obtenido mediante la diferencia de la intensidad media global y de la correspondiente media global de la intensidad de la región en sombra.

Por otra parte, las sombras también pueden ser eliminadas no para la corrección de la imagen sino tras la clasificación de la imagen, y asignar una clase a cada una de las regiones en sombra. Van de Voorde et al. (2007) clasifican una imagen QuickBird inclu- 
yendo una clase para las sombras. Los píxeles clasificados como sombras son de nuevo reclasificados en función de su posición y en función de la información de pertenencia del clasificador con la segunda clase más probable. Para esto, se emplea un clasificador de redes neuronales, tomando muestras de entrenamiento y como clase de muestra la segunda clase más probable de cada píxel comparándolas con muestras visuales.

De la misma forma que para la corrección de las imágenes, hay otros métodos que segmentan la imagen, como en Zhou et al. (2009), que emplean el software eCognition para la segmentación y clasificación. Además, comparan varias metodologías para clasificar las sombras en imágenes de alta resolución como la combinación de información espectral con información espacial, restauración de sombras previo a la clasificación mediante realce radiométrico por correlación lineal y fusión de datos multifuente como apoyo en la clasificación. En uno de los métodos estudiados, tras la segmentación y clasificación de la imagen mediante eCognition, se toman los objetos en sombra empleando umbrales y los diferencia entre sombras altas y bajas introduciendo información espacial del modelo digital LiDAR. Combinan esta información con umbrales NDVI para separar las sombras de los edificios de las generadas por los árboles y luego las clasifican en usos del suelo. Al igual que en Song et al. (2014), emplean umbrales para la detección y clasificación de las sombras combinándolas con filtros morfológicos de apertura y cierre.

\subsubsection{Información derivada de imágenes y de datos LiDAR}

\section{Características de fragmentación}

Las características de fragmentación, o métricas de paisaje (landscape metrics), son características que se emplean para cuantificar o medir la estructura del paisaje, entendiendo como paisaje el tipo de coberturas existentes y la distribución espacial de estas dentro de un área determinada (Herold y Menz, 2000; McGarigal et al., 2014). Este tipo de características o indicadores, desarrollados dentro del campo de las ciencias medioambientales, han sido principalmente empleados como un valioso recurso para estudios de paisaje con respecto a sostenibilidad ecológica (Frohn, 1998), y son uno de los métodos más populares para cuantificar los patrones que se pueden encontrar en el paisaje a pesar de sus inconvenientes como la dependencia de la escala o su difícil interpretabilidad, entre otras (Gustafson, 1998; Uuemaa et al., 2013).

Una de las herramientas más extendidas para el cálculo de estos indicadores es el software Fragstats (McGarigal et al., 2014), que extrae características de fragmentación de imágenes de mapas de coberturas del suelo. Otra herramienta más reciente es Indi- 
FRAG (Sapena y Ruiz, 2015b), que aborda la extracción de este tipo de indicadores sobre mapas de coberturas de tipo vectorial.

Las características de fragmentación se consideran de gran importancia debido a su interés en estudios ecológicos, socio-económicos y en la gestión del territorio, y su análisis puede proporcionar las claves para un desarrollo territorial más equilibrado (Salinas, 2010). Además, han sido empleadas en un amplio abanico de estudios medioambientales, como estudios de degradación y erosión de suelos (Lesschen et al., 2008), predicción de escorrentía (Lin et al., 2007), estudios sobre fauna (Guillemain et al., 2008; Tsachalidis y Hadjisterkotis, 2008) planificación estratégica para la gestión ambiental (Musacchio y Coulson, 2001; Saura y Torné, 2009), cambios en usos del suelo, etc. (Zaragozí et al., 2012). Muchas de estas aplicaciones provienen de las ciencias medioambientales, pero también han sido desarrolladas otro tipo de aplicaciones geográficas aprovechando las ventajas de las características de fragmentación.

La integración de este tipo de características con datos de teledetección y sistemas de información geográficos pueden ayudar en el análisis de diferentes dimensiones estructurales como localización, distribución, tamaño, forma y disposición de los diferentes elementos o coberturas en diversos estudios sobre usos del suelo. También proporcionan información que se puede integrar con los sistemas de información geográfica y bases de datos, lo que permite localizar y seleccionar zonas de gran interés ecológico de manera más efectiva además de la ayuda en la toma de decisiones y medidas de gestión adecuadas.

Una gran variedad de características han sido propuestas y aplicadas principalmente en áreas urbanas, como características que miden la fragmentación, (Kane et al., 2014; Zhang et al., 2012), la complejidad de las formas (Wu et al., 2011) o la heterogeneidad (Taubenböck y Kraff, 2014).

Otros estudios se han centrado en la detección de cambios, como el de Herold et al. (2002a), que emplean una metodología calculando indicadores de fragmentación sobre imágenes espaciales para la descripción de estructuras en usos del suelo urbanos y la detección de cambios por el crecimiento de este. Malinverni (2011) obtiene mapas de detección de cambios de usos del suelo para la valoración de daños tras el terremoto de Haití en 2010, empleando imágenes de satélite y SIG. Sapena y Ruiz (2015a), estudian los cambios morfológicos y las tendencias de crecimiento en regiones urbanas extrayendo indicadores de fragmentación multitemporales de mapas de coberturas de suelo en formato vectorial de dos fechas diferentes.

Existen otros estudios en los que se han empleado estas características desde el punto 
de vista del análisis de imágenes orientado a objetos, en los que las características de fragmentación se extraen de objetos de la imagen segmentada en estudios de usos del suelo (Herold et al., 2002a; Kane et al., 2014; Zaragozí et al., 2012). Al emplear el análisis orientado a objeto, se pueden diferenciar niveles o jerarquías (Addink et al., 2007; Benz et al., 2004) para el cálculo de características, ya sean las características propias de cada objeto, o las características de las coberturas existentes dentro de cada uno de ellos. Sapena y Ruiz (2015b) hacen esta distinción entre superobjetos y objetos sobre zonas urbanas, en las que los superobjetos son las manzanas y los objetos son las parcelas urbanas contenidas dentro de las manzanas. Las características son empleadas para la clasificación de usos del suelo de la zona urbana de Valencia.

En Jacquin et al. (2008) se busca una metodología para cartografiar la expansión urbana empleando técnicas de clasificación y análisis de imágenes orientados a objetos. Los objetos son generados y clasificados en diferentes usos del suelo mediante la segmentación de imágenes por satélite incluyendo como parámetros para la clasificación las características de fragmentación.

Van der Kwast et al. (2011) diseñan un método de reclasificación de zonas urbanas mediante el cual un mapa de coberturas del suelo generado a partir de una clasificación por píxel de imágenes de satélite, es reclasificado a partir de un conjunto de reglas obtenidas en función de la distribución espacial y tamaño de los objetos contenidos en el paisaje.

Silva et al. (2008) proponen un método para la detección de indicadores de cambio sobre una base de datos de imágenes de satélite. En un primer paso, se definen los tipos de patrones espaciales asociados a un cierto tipo de cambio. Después, se generan objetos homogéneos mediante la segmentación de las imágenes de satélite empleando la información espectral. Para cada segmento, se calculan las diferentes características de fragmentación y estas se emplean en su clasificación para la identificación de los cambios. De esta forma, los descriptores que han sido extraídos de las imágenes de satélite son asociados a diferentes tipos de cambios de usos del suelo relacionados con diferentes factores sociales.

Las características de fragmentación son capaces de proporcionar información sobre la estructura del paisaje pudiendo cuantificar y medir los diversos elementos que configuran dicho paisaje. Estas características se han empleado con diversos propósitos como se ha visto en los estudios citados anteriormente. Tanto la posibilidad de empleo a nivel de objeto como su uso en métodos de clasificación de usos del suelo, hacen que estas características puedan proporcionar información relevante para el estudio de análisis 
de cambios de usos del suelo con respecto a estructuras del paisaje tanto naturales como artificiales (Herold et al., 2002b). En esta tesis, se pretende emplear este tipo de características para describir los cambios en las coberturas y usos del suelo de los objetos de estudio asociados a los cambios que se producen en las métricas al producirse un cambio entre las coberturas estudiadas en fechas diferentes.

\subsubsection{Discusión de antecedentes}

A pesar de que los métodos vistos en los apartados 1.2.1 y 1.2.2 detecten los cambios e identifiquen las nuevas clases y coberturas del suelo en los objetos de estudio, la metodología de actualización sigue requiriendo de procesos de fotointerpretación realizados por un operario para la asignación final de la clase o cobertura tanto a nivel de píxel como a nivel de objeto.

Diversos tipos de características se han utilizado en los procesos de clasificación y detección de cambios, siendo las características espectrales las más comunes en estos estudios. Otras características, como las de textura y forma también forman parte, a día de hoy, del conjunto básico de características extraídas de imágenes empleadas en estudios de clasificación a nivel de objeto.

Otros sensores, como el LiDAR, proporcionan información sobre la altura de los objetos situados en la superficie terrestre. Esta información puede ser extraída a nivel de objeto, adquiriendo características tridimensionales que han sido empleadas en numerosos estudios de detección, segmentación, clasificación e identificación de objetos como árboles o edificios, así como de detección de cambios.

La mayor parte de los trabajos revisados tienen un factor en común, y es que las características empleadas para las clasificaciones o en los métodos de detección de cambios no proporcionan una dimensión temporal, y se basan principalmente en el análisis independiente de imágenes. Muchos de los estudios se limitan a proporcionar información temporal a aquellos objetos analizados mediante diferencias espectrales derivadas de las imágenes en dos o más épocas de estudio en diferentes entornos agrícolas, (Berberoglu y Akin, 2009; Chen et al., 2012; He et al., 2011; Löw et al., 2015), forestales (Bontemps et al., 2008; Hermosilla et al., 2015; Tortini et al., 2015) y urbanos (Du et al., 2015; Gamanya et al., 2009; Hebel et al., 2013; Zhou et al., 2008), por lo que existe un vacío en cuanto a la extracción y generación de características temporales se refiere.

En esta tesis se pretende desarrollar una metodología de detección de cambios que utilice un conjunto de características que tengan sentido temporal, mediante el cual, un 
único grupo de características generado a partir de datos de dos épocas distintas, pueda caracterizar los cambios de cobertura o uso del suelo de un mismo objeto en las dos fechas de estudio. 



\section{Capítulo 2}

\section{Objetivos y estructura de la tesis}

\subsection{Objetivos}

El principal objetivo de esta tesis es el de desarrollar una metodología integrada de procesado digital de imágenes de alta resolución y de datos LiDAR, conducente a la extracción de características cuantitativas a nivel de objeto (parcelas) y subobjetos (elementos interiores) que permitan su caracterización para la asignación de un tipo de uso o cobertura del suelo orientada a la detección de cambios. En este trabajo se han empleado datos públicos adquiridos a partir del Plan Nacional de Ortofotografía Aérea (PNOA) y del Plan Nacional de Teledetección (PNT), enmarcados dentro del Plan Nacional de Observación del Territorio (PNOT), a disposición de todas las administraciones y entidades públicas españolas. Con esto, se quiere demostrar una de las muchísimas utilidades y posibilidades de los datos geoespaciales públicos, en este caso en concreto, para la detección de cambios y la actualización de bases de datos cartográficas de usos del suelo.

Para alcanzar este objetivo general, este estudio se ha centrado en el planteamiento de los siguientes objetivos específicos:

- Analizar los métodos de detección de cambios basados en imágenes y datos LiDAR, con el planteamiento de trabajar a nivel de objeto. La aplicación de estas metodologías se debe centrar en la detección de cambios entre imágenes y en la actualización de bases de datos cartográficas.

- Definir y extraer características con información temporal orientadas a la detección de cambios. De esta forma, se pretende obtener un conjunto de características que aporten información en sí mismas sobre la posibilidad de existencia de 
cambios.

- Estudiar la aplicabilidad de las características extraídas con información temporal sobre diferentes entornos paisajísticos, analizando el comportamiento de los diferentes tipos de características en diversas áreas de estudio, como en zonas urbanas, periurbanas y agrícolas, e identificar aquellas características con las que se obtienen mejores resultados en las diferentes áreas.

- Evaluar estadísticamente los métodos empleados para la asignación de tipos de usos del suelo y la detección de cambios y evaluar la efectividad de las características propuestas en la metodología de detección de cambios.

- Definir una metodología de detección de cambios para la actualización de bases de datos tras el análisis de resultados de esta tesis, que integre el procesado de imágenes de alta resolución espacial y datos LiDAR.

\section{2. $\quad$ Estructura de la tesis}

La tesis está dividida en 6 capítulos, un apartado de bibliografía y dos apéndices.

El Capítulo 1 contiene la presentación y justificación de este trabajo, donde se realiza una revisión del estado del arte de las metodologías de detección de cambios, de las técnicas de análisis de imágenes orientadas a objeto y de los diferentes tipos de características empleadas para clasificación de coberturas y usos del suelo y detección de cambios.

En el Capítulo 2 se definen los objetivos de esta tesis.

En el Capítulo 3 se presentan las zonas de estudio sobre las que se han realizado los ensayos de este trabajo, se muestran sus características y se describen los datos disponibles con su preprocesado.

En el Capítulo 4 se describe y se desarrolla la metodología de este trabajo. Este capítulo está divido en dos grandes apartados: conceptos teóricos y ensayos.

Dentro de los conceptos teóricos se describen los diferentes métodos de detección de cambios y algoritmos que se emplearán en los diversos ensayos de selección de características, clasificaciones y detección de cambios. En segundo lugar, se presentan los distintos tipos de características, así como la forma en la que se obtienen y se extraen a nivel de objeto o parcela. Además, se describe la manera de proveer a las características con información temporal. En tercer lugar se describe la forma de evaluación de los ensa- 
yos de clasificación y detección de cambios mediante métodos estadísticos, como son las matrices de confusión e indicadores de detección y de calidad.

En el apartado de ensayos, se describen las clases de usos de suelo y de cambios que se emplean en los métodos de clasificación y de detección de cambios en las dos zonas de estudio. Posteriormente, se describen los estudios realizados con los diferentes tipos de características. En total, se han realizado 4 ensayos diferentes: uno por cada grupo de características propuesto para la detección de cambios (características LiDAR, características derivadas de funciones geoestadísticas, y características de fragmentación a nivel de objeto y subobjeto), más un último ensayo en el que se comparan todos los grupos de características y se realiza un estudio en el que se simula la actualización de una base de datos, en la que el uso de suelo no actualizado (o clase previa), es conocido y se utiliza en el proceso de detección de cambios.

En el Capítulo 5 se recogen y analizan los resultados obtenidos en los diferentes ensayos descritos en el capítulo anterior, y se incluye una sección de discusión general de los resultados obtenidos en los ensayos.

En el Capítulo 6 se comentan las conclusiones obtenidas en esta tesis así como las líneas futuras de investigación.

En el Apéndice A se mencionan las publicaciones científicas derivadas de esta tesis realizadas por el autor.

En el Apéndice B se muestra la lista de acrónimos de las diferentes características estudiadas en este trabajo. 



\section{Capítulo 3}

\section{Zonas de estudio y datos empleados}

\subsection{Zonas de estudio}

Se han empleado dos zonas diferentes para el desarrollo de esta tesis. La primera zona se corresponde con la zona norte de la ciudad de Valencia, en el propio municipio de Valencia además de la comarca de L'Horta Nord con un área aproximada de 5.100 hectáreas y coordenadas X e Y ETRS89 UTM 30N máximas de 730.100 m; 4.384 .500 m y mínimas de 719.700 m; 4.373.800 m. Este área periurbana de Valencia consta de áreas urbanas densas en las que se han producido durante los últimos años movimientos de expansión, eliminando edificaciones antiguas, construyendo nuevas y reduciendo el área agrícola e industrial situada en la periferia. La comarca de L'Horta Nord tiene un gran significado histórico, al formar parte de la comarca de L'Horta de Valencia antes de su división en las actuales comarcas de L'Horta Nord, Sud, Oest y la ciudad de Valencia, debido al gran crecimiento demográfico y urbano general de las localidades que formaban parte de ella. L'Horta de Valencia se caracteriza por su minifundismo, fruto de su antigüedad y de las múltiples particiones hereditarias y por una rotación de cultivos dentro del año agrícola que permiten obtener dos y hasta tres cosechas al año (Piqueras Haba, 1999). Las parcelas son principalmente de tipo citrícola y hortofrutícola, además de huertos familiares de pequeño tamaño. La orografía de la región es generalmente llana sin cambios bruscos de pendiente, que junto con el clima, hace de esta región una zona óptima para la plantación de cultivos y huerta.

La segunda zona de estudio está situada en la zona norte de la Región de Murcia, en la comarca de la Vega Alta del Segura en los municipios de Abarán, Blanca y Ulea. Tiene una superficie aproximada de 8.150 hectáreas y coordenadas X e Y ETRS89 UTM 


\section{Zonas de estudio y datos empleados}

30N máximas de 655.300 m; 4.234 .900 m y mínimas de 643.900 m; 4.225 .900 m, sobre la que se extienden grandes plantaciones agrícolas. Esta región se caracteriza por una dinámica agrícola de regadío pronunciada, susceptible de grandes cambios debido a la eliminación y regeneración de cultivos en parcelas de gran tamaño como son arranques y nuevas plantaciones en cultivos de tipo leñoso, siendo los cambios relacionados con edificios casi inexistentes. La orografía de la región es accidentada debido a su cercanía a la Sierra de la Pila, por lo que se encuentran parcelas de estudio de pendiente variable.

En las Figuras 3.1 y 3.2 se puede ver la situación y los detalles respectivamente de las zonas de estudio de Valencia y Murcia.

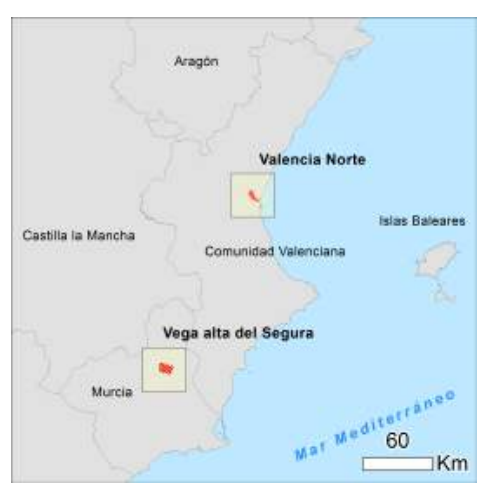

(a) Localización de las zonas de estudio

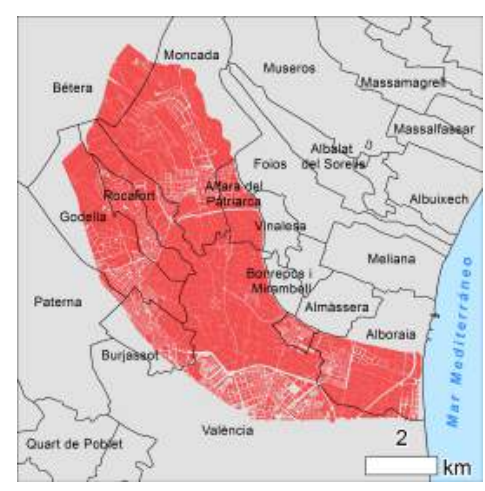

(b) Localización de la zona de Valencia

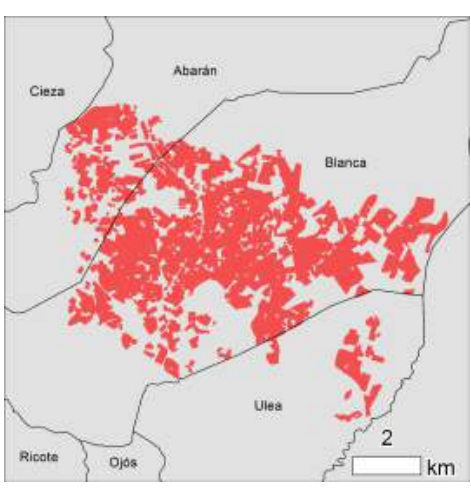

(c) Localización de la zona de Murcia

Figura 3.1: Localización de las zonas de estudio.

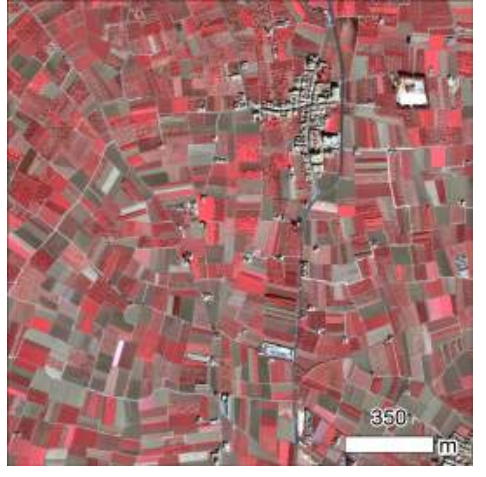

(a) Detalle de la zona de Valencia

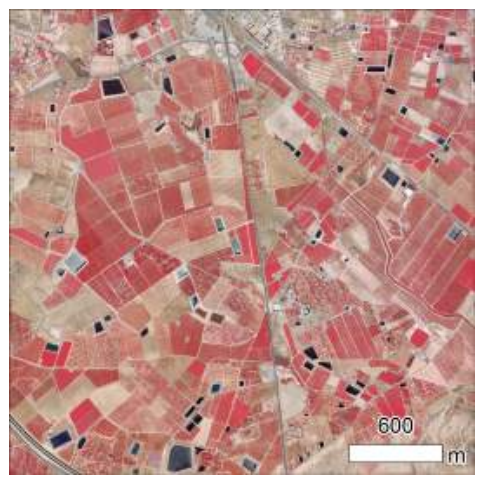

(b) Detalle de la zona de Murcia

Figura 3.2: Detalles de las zonas de estudio en falso color infrarrojo. 


\subsection{Datos}

Se pueden diferenciar tres tipos de datos con los que se ha trabajado: imágenes multiespectrales de alta resolución, datos de tipo tridimensional, como son datos LiDAR y modelos digitales del terreno, y cartografía catastral de tipo vectorial.

Dentro de las imágenes multiespectrales se pueden diferenciar dos tipos de imágenes dependiendo del tipo de sensor: sensor satelital y sensor aerotransportado. Para la zona de Valencia se ha empleado una imagen ortorrectificada generada a partir de una imagen QuickBird adquirida en febrero de 2004 con 1 banda pancromática y 4 bandas espectrales con resolución radiométrica de 11 bits/píxel. Las bandas multiespectrales y pancromática se fusionaron empleando el método basado en la transformación de componentes principales (Chavez et al., 1991; Zhang y Mishra, 2012), en el que se sustituye el primer componente principal por la imagen pancromática, seguido de la transformación inversa de componentes principales, consiguiendo una imagen con una resolución espacial de 0,6 metros píxel para las cuatro bandas espectrales (IR, R, G y B).

Además de la imagen QuickBird para la zona de Valencia, se utilizaron ortoimágenes aéreas adquiridas en agosto de 2006 y 2008 dentro del marco del Plan Nacional de Ortofotografía Aérea (PNOA) (Arozarena et al., 2008), con una resolución espacial de 0,5 metros/píxel, una resolución radiométrica de 8 bits/píxel y 3 bandas espectrales (IR, R, G). Estas imágenes fueron ortorrectificadas y georreferenciadas, las bandas multiespectrales y pancromática fueron fusionadas y se generaron mosaicos y ajustes radiométricos como parte del programa PNOA. Para la zona de Murcia se tiene este mismo tipo de imagen para los años 2007 y 2009 proporcionadas por la Consejería de Agricultura y Agua de la Región de Murcia (CARM) con información multiespectral (IR, R, G, B).

Los datos de tipo tridimensional LiDAR de la zona de Valencia fueron adquiridos en diciembre de 2003 por un sensor Optech ALTM-2033 (Airborne Laser Scanner Terrain Mapper) por encargo de la Confederación Hidrográfica del Júcar. Los datos LiDAR presentaban una distribución regular en forma de malla con una densidad de $1 \mathrm{punto} / \mathrm{m}^{2}$. Además de la propia nube de puntos, se proporcionaron los modelos digitales de superficie (MDS) y del terreno (MDT) corregidos de errores empleando técnicas de edición manual. Sobre esta misma zona de estudio se obtuvieron en septiembre de 2009 datos LiDAR empleando un sensor RIEGL LMS-Q680 con una densidad nominal de 0,5 puntos $/ \mathrm{m}^{2}$ también dentro del programa PNOA.

Para la zona de Murcia no se dispone de información tridimensional, lo que impide realizar cierta clase de estudios en los que interviene este tipo de información. 


\section{Zonas de estudio y datos empleados}

Los datos vectoriales de los que se disponen en la zona de Valencia son los mapas catastrales generados por la Dirección General de Catastro de España para zonas rústicas y urbanas en sus divisiones a nivel de subparcelas y parcelas, respectivamente. La escala nominal es de 1:2.000 para la cartografía catastral rústica y 1:1.000 para la urbana. Para la zona de Murcia se dispone de cartografía rústica en formato vectorial con las subparcelas agrícolas a escala 1:2.000 proporcionada por la Consejería de Agricultura y Agua de la Región de Murcia. La unidad elemental empleada en este trabajo se ha definido combinando las subparcelas catastrales rústicas y las parcelas catastrales urbanas. En ambos casos, nos referimos a ellas como parcelas.

La Tabla 3.1 recoge un resumen de los datos empleados en esta tesis.

\begin{tabular}{|c|c|c|}
\hline Zona & Datos & Características \\
\hline \multirow{7}{*}{ Valencia } & Imagen QuickBird & $\begin{array}{l}\text { Adquisición: Febrero } 2004 \\
\text { Resolución espacial: } 0,6 \mathrm{~m} / \text { píxel } \\
\text { Resolución radiométrica: } 11 \text { bits } \\
\text { Bandas : IR, R, G, B }\end{array}$ \\
\hline & Ortoimágenes PNOA & $\begin{array}{l}\text { Adquisición: Agosto } 2006 \text { y } 2008 \\
\text { Resolución espacial: } 0,5 \mathrm{~m} / \text { píxel } \\
\text { Resolución radiométrica: } 8 \text { bits } \\
\text { Bandas IR, R, G }\end{array}$ \\
\hline & $\begin{array}{l}\text { Datos LiDAR } 2003 \\
\text { (Por encargo de la Confederación } \\
\text { Hidrográfica del Júcar) }\end{array}$ & $\begin{array}{l}\text { Adquisición: Diciembre } 2003 \\
\text { Sensor: Optech ALTM } 2033 \\
\text { Densidad nominal: } 1 \text { punto } / \mathrm{m}^{2}\end{array}$ \\
\hline & MDT 2003 & $\begin{array}{l}\text { Producto derivado vuelo LiDAR } 2003 \\
\text { Resolución espacial: } 0,5 \mathrm{~m}\end{array}$ \\
\hline & MDS 2003 & $\begin{array}{l}\text { Producto derivado vuelo LiDAR } 2003 \\
\text { Resolución espacial: } 0,5 \mathrm{~m}\end{array}$ \\
\hline & Datos LiDAR PNOA 2009 & $\begin{array}{l}\text { Adquisición: Agosto } 2009 \\
\text { Sensor: RIEGL LMS-Q680 } \\
\text { Densidad nominal: 0,5 puntos } / \mathrm{m}^{2} \\
\text { Densidad real media: } 0,8 \text { puntos } / \mathrm{m}^{2}\end{array}$ \\
\hline & Cartografía & $\begin{array}{l}\text { Parcelario catastro rústica } 1: 2.000 \\
\text { Parcelario catastro urbano: } 1: 1.000\end{array}$ \\
\hline \multirow[t]{2}{*}{ Murcia } & Ortoimágenes PNOA & $\begin{array}{l}\text { Adquisición: Agosto } 2007 \text { y } 2009 \\
\text { Resolución espacial: } 0,5 \text { m/píxel } \\
\text { Resolución radiométrica: } 8 \text { bits } \\
\text { Bandas IR, R, B }\end{array}$ \\
\hline & Cartografía & Parcelario catastro rústica 1:2.000 \\
\hline
\end{tabular}

Tabla 3.1: Resumen de datos empleados para el estudio.

La Figura 3.3 y Figura 3.4 muestran unos ejemplos de los tipos de datos que se tiene de las zonas de Valencia y Murcia respectivamente. 


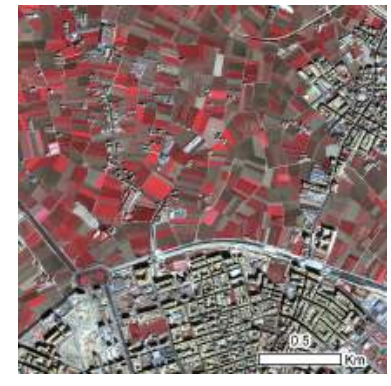

(a)

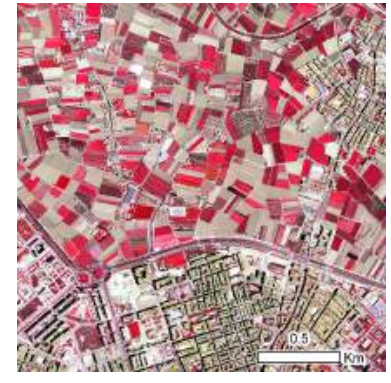

(b)

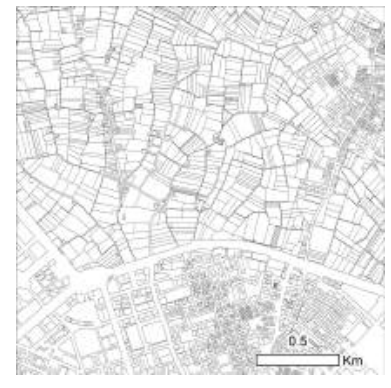

(c)

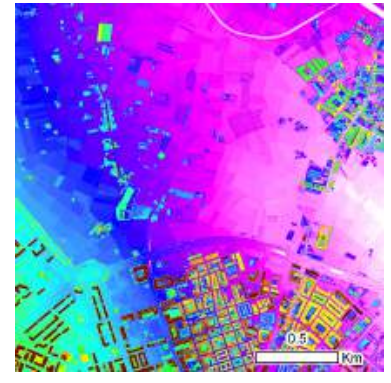

(d)

Figura 3.3: Detalle de datos de la zona de Valencia. (a) imagen QuickBird 2004, (b) imagen PNOA 2008 , (c) parcelario urbano y rústico y (d) modelo digital de superficies.

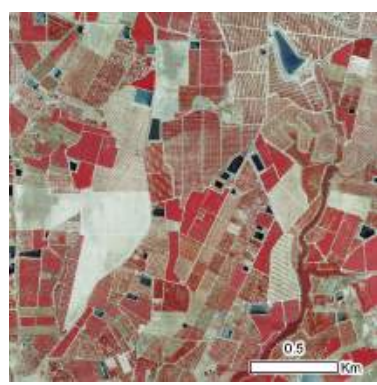

(a)

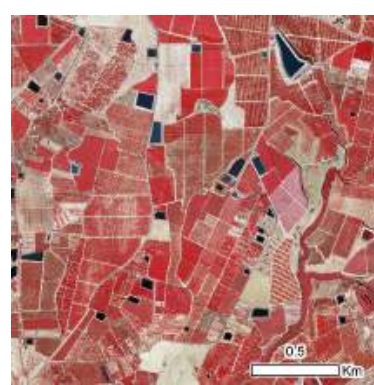

(b)

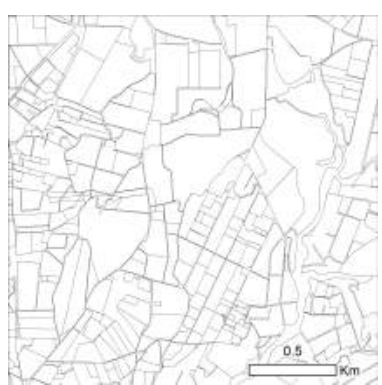

(c)

Figura 3.4: Detalle de datos de la zona de Murcia: (a) imagen PNOA 2007, (b) imagen PNOA 2009 y (c) parcelario rústico. 


\subsection{Pre-procesado de los datos}

La imagen QuickBird de la zona de Valencia se remuestreó a 0,5 metros de tamaño de píxel con el fin de tener todos los datos de la misma zona de estudio a una misma resolución espacial. Así mismo, se llevó a cabo un ajuste radiométrico entre las imágenes empleando el método de regiones pseudoinvariantes utilizando la imagen QuickBird como referencia para el ajuste. Este método consiste en la selección de zonas comunes e invariantes en tiempo para la definición de una función de normalización basada en la media y la desviación típica de los valores radiométricos en ambas fechas (Chen et al., 2005; Schott et al., 1988; Yuan y Elvidge, 1996). Se realizó el mismo procesamiento de ajuste radiométrico para las imágenes de la zona de Murcia utilizando las imágenes de 2007 como referencia.

En cuanto al MDT y al MDS de la zona de Valencia de 2003, también se remuestrearon con un tamaño de píxel igual a 0,5 metros para poder superponer las imágenes multiespectrales con este modelo, además de poder superponerlo con los modelos generados mediante LiDAR.

El preprocesado de la información vectorial del conjunto de parcelas, tanto de la zona de Valencia como la de Murcia, consistió en la eliminación de aquellas parcelas de forma anómala, como por ejemplo, polígonos cuña o polígonos demasiado estrechos. La selección de parcelas aptas para el estudio se realizó a partir del área y del índice de forma o shape index (Forman y Godron, 1986; McGarigal y Marks, 1995), que relaciona la superficie del objeto con el perímetro. Cuanto mayor sea el perímetro con respecto a la superficie, mayor será el índice de forma. Se seleccionaron parcelas con una superficie superior a $250 \mathrm{~m}^{2}$ y un índice de forma inferior a 4, asegurando así un tamaño y una compacidad que permitieran extraer características de los objetos de manera fiable.

\subsubsection{Procesado de los datos LiDAR para la generación de los modelos digitales del terreno}

Como parte del preprocesado de los datos, se generaron los modelos digitales para la época de 2009. Los modelos del terreno y superficie de 2009 se calcularon empleando la nube de puntos LiDAR PNOA de 2009. Estos modelos se calcularon utilizando el algoritmo iterativo de medias descrito en Estornell et al. (2011). Este algoritmo está basado en la selección de puntos de mínima altura y eliminación de puntos pertenecientes a elementos que están situados sobre el terreno, como los edificios y la vegetación. Para esto, 
el algoritmo genera un primer MDT a partir de una primera selección de puntos mínimos en un área determinada. Tras la generación del primer MDT, el algoritmo realiza una nueva búsqueda de puntos de altura mínima en zonas menores de búsqueda. Los puntos seleccionados en este paso se comparan con el MDT obtenido inicialmente. Aquellos puntos que presenten una altura mayor a un valor umbral definido al compararlos con el MDT, son eliminados. El MDT obtenido tras el proceso iterativo de selección de puntos mínimos es más preciso que las versiones iniciales del modelo calculado, ya que consigue eliminar elementos no pertenecientes a la clase suelo.

Tras el cálculo de los MDS de 2003 y 2009 a partir de la nube de puntos LiDAR y el MDT de 2009, se calcularon los MDSn o modelos de superficie normalizados mediante la resta entre los MDS y los MDT de sus respectivas épocas. De esta forma se elimina la influencia del terreno sobre las alturas de los elementos contenidos en las parcelas.

La Figura 3.5 muestra los diferentes productos obtenidos a partir de la nube de puntos LiDAR. La Figura 3.5a se corresponde con la interpolación de la nube de puntos para la obtención del modelo digital de superficies o MDS; la Figura 3.5b se corresponde con el modelo digital del terreno o MDT calculado a partir del algoritmo de Estornell et al. (2011); y la Figura 3.5c se corresponde al modelo digital de superficies normalizado (MDSn) obtenido a partir de la resta de los dos modelos anteriores.

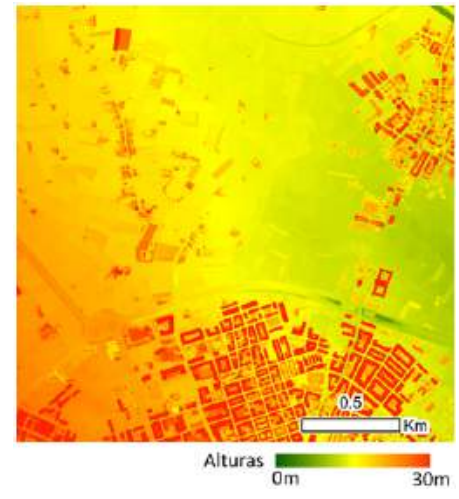

(a) MDS

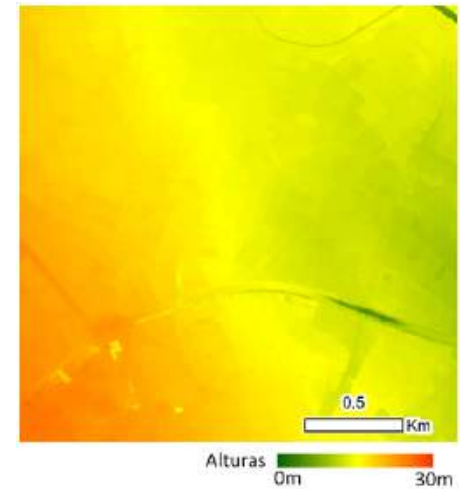

(b) MDT

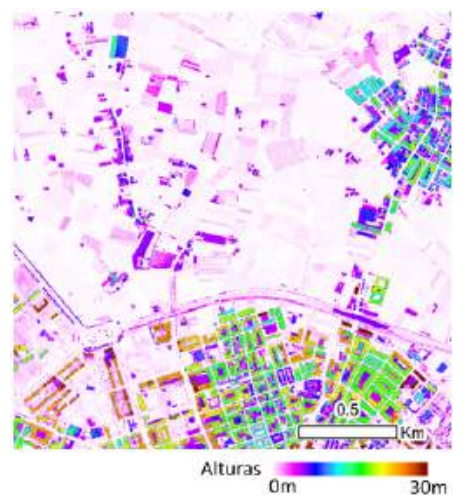

(c) MDSn

Figura 3.5: Modelos digitales obtenidos a partir de datos LiDAR. 



\section{Capítulo 4}

\section{Metodología}

En este capítulo de metodología se pueden diferenciar dos partes: conceptos teóricos y descripción de los ensayos realizados. En los conceptos teóricos se introducen los métodos de clasificación y detección de cambios que han sido empleados en esta tesis y utilizados en el apartado de ensayos. Así mismo se presentan los diferentes tipos de características empleadas y la forma de su extracción a nivel de objeto o parcela. Las características que se describen están agrupadas en: (i) características espectrales, de textura y de forma, considerando este grupo como el conjunto básico de características; (ii) características tridimensionales derivadas de datos LiDAR; (iii) características geoestadísticas derivadas del semivariograma, semivariograma cruzado y codispersión; y (iv) características de fragmentación. Como última sección de conceptos teóricos, se describe la metodología seguida para la evaluación de los resultados de clasificación y detección de cambios.

En la parte de ensayos se describen, en un primer lugar, las clases de usos de suelo y clases de cambio empleadas en los diferentes ensayos para cada una de las zonas de estudio. Posteriormente se describen los estudios que han sido realizados para la detección de cambios de usos del suelo en entornos agrícolas y peri-urbanos. En cada ensayo se describen las pruebas hechas con los diferentes grupos de características y la naturaleza de los experimentos con las correspondientes fases de selección de características, clasificaciones y detección de cambios, clases empleadas, obtención de resultados, etc. En total, se realizan cuatro ensayos diferentes, uno por cada tipo de características estudiado, más un último ensayo en el que se muestra la metodología propuesta de detección de cambios y actualización de bases de datos, en la cual se usan las características resultantes de los ensayos anteriores y se comparan los resultados para ver cómo se mejora la clasificación incluyendo en el estudio los nuevos conjuntos de características propuestos en este trabajo. 


\subsection{Conceptos teóricos}

\subsubsection{Métodos de detección de cambios y clasificadores}

\subsubsection{Métodos de detección de cambios}

En este trabajo, los métodos de detección de cambios empleados se enfocan sobre el análisis de imágenes basados en objetos (OBIA), en el que los píxeles no son estudiados individualmente, si no que se combinan en grupos homogéneos (objetos) y estudiados en conjunto (Walter, 2004).

A continuación se muestran los diferentes métodos de detección de cambios que han sido empleados en este trabajo.

\subsection{Diferencias simples}

Singh (1989) y Lunetta y Elvidge (1999) describen el método de diferencias simples como una diferencia entre imágenes, y actualmente se considera como uno de los métodos clásicos de detección de cambios orientado a píxel. La diferencia de imágenes consiste en la sustracción de una imagen de una época posterior sobre otra imagen de una época anterior píxel a píxel y su posterior umbralización, siendo un método simple y de fácil significado. Para el correcto funcionamiento de este método, es necesario un correcto ajuste radiométrico entre las imágenes. El principal inconveniente que presenta este método es que sus resultados no indican entre qué tipos de clases o coberturas han ocurrido los cambios, por lo que el método carece de información direccional. No obstante, sí que proporciona información sobre la magnitud de los cambios. Además, la obtención de resultados no requiere un nivel de procesamiento elevado, pudiendo procesar imágenes de gran tamaño de forma sencilla. En este trabajo se emplea este método de forma indirecta, es decir, no se emplea como método de detección de cambios en sí, sino que se emplea para obtener productos derivados con carácter temporal que se utilizarán en otros métodos de detección de cambios. Al aplicar este método a nivel de objeto, las diferencias se realizan no sobre los píxeles de la imagen sino sobre las características extraídas de cada objeto, por lo que se obtienen características con un significado temporal. Otra forma de aplicar este método a nivel de objeto, es realizar la diferencia entre imágenes píxel a píxel y posteriormente extraer las características de dicha imagen de diferencias para cada uno de los objetos de estudio. 


\subsection{Método de post-clasificación}

El método de post-clasificación está basado en clasificaciones de imágenes independientes identificándose el tipo de cambio producido entre las fechas de estudio (Lunetta y Elvidge, 1999). En este método, dos imágenes se clasifican independientemente para conseguir los mapas temáticos de fechas diferentes y posteriormente se comparan entre sí para detectar los cambios entre ellos (Tewkesbury et al., 2015). La principal ventaja de este método es que se pueden conocer las diferentes transiciones o tipos de cambio de forma explícita, sin tener que realizar un estudio de las zonas para identificar los tipos de cambio a detectar. Además, ya que los mapas de clasificaciones se generan de manera independiente, la normalización radiométrica no resulta crucial (Coppin et al., 2004).

El principal problema que presenta este método, además del elevado coste temporal para la selección de las diferentes muestras de entrenamiento y la clasificación de dos imágenes por separado, es la propagación de errores cometidos en las clasificaciones sobre la detección final de cambios, lo que resulta en una reducción de la fiabilidad en la detección.

En este método orientado a objetos, los objetos, o parcelas, son clasificados empleando la información extraída de ellos en las diferentes fechas de estudio. Tras obtener los objetos clasificados en las dos fechas, las clases de los objetos son comparadas detectando así los cambios. En la Figura 4.1 se muestra el flujo de trabajo que se emplea en el método de post-clasificación para la detección de cambios.

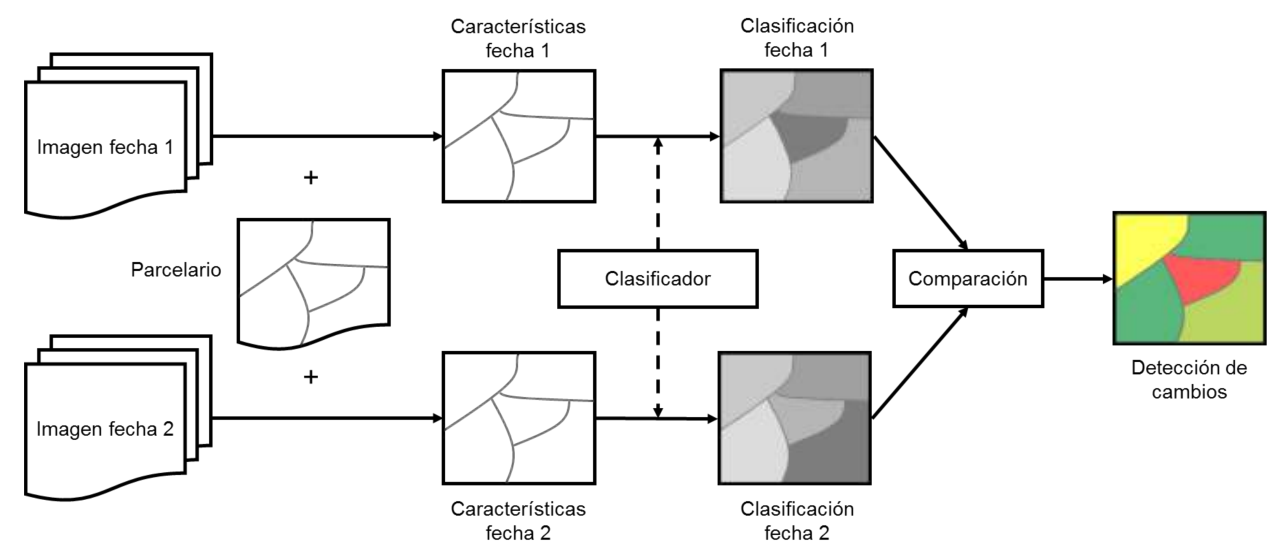

Figura 4.1: Flujo de trabajo del método de post-clasificación para la detección de cambios. 


\subsection{Método de clasificación directa}

Otro de los métodos basados en algoritmos clasificadores es el método de clasificación directa. En este método, se combinan imágenes de fechas diferentes para generar, mediante un único proceso de clasificación, un mapa en el que se muestran las transiciones entre usos o coberturas del suelo, mostrando así los cambios. La combinación de imágenes se realiza generando una nueva imagen compuesta por las múltiples bandas de las imágenes originales de cada fecha de estudio. Esta nueva imagen es la que se introduce en el clasificador cuyas bandas se emplean como información para generar la clasificación (Lunetta y Elvidge, 1999; Tewkesbury et al., 2015).

La principal ventaja de este método es que solo requiere de una clasificación para detectar los tipos de cambios. Por otra parte, se debe realizar una comparación de imágenes de ambas fechas y seleccionar las clases de estudio de tal forma que indiquen el cambio producido entre las dos fechas, por lo que el principal inconveniente de este método, es que se deben conocer a priori los tipos de cambio existentes o directamente centrar el estudio sobre tipos de cambio concretos.

Los enfoques más habituales para aplicar esta metodología a nivel de objeto son: en el primer caso, (Figura 4.2), se combinan las imágenes mediante la resta entre bandas de las imágenes correspondientes a las diferentes épocas de estudio, y posteriormente, se extraen las características descriptivas de cada uno de los objetos. Estas características son utilizadas para la clasificación directa con la que se obtiene el mapa final con las clases de cambio y no cambio.

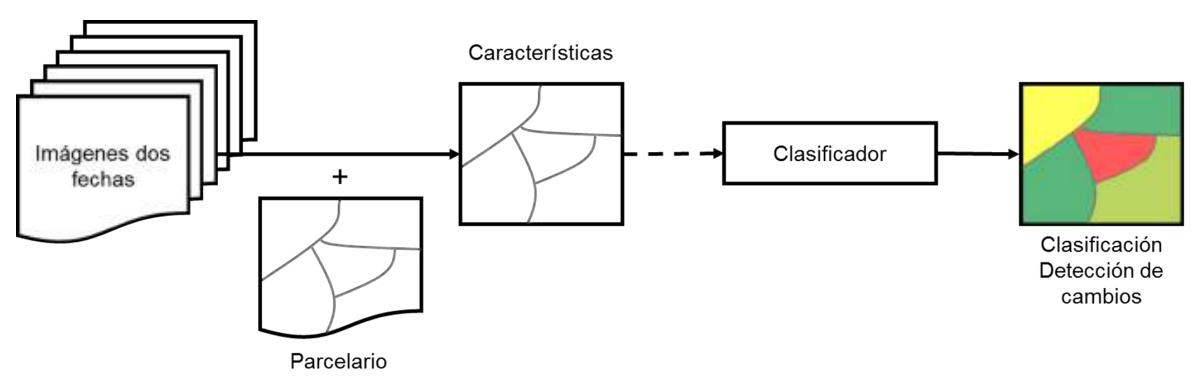

Figura 4.2: Flujo de trabajo del método de clasificación directa para la detección de cambios mediante combinación de imágenes.

En el segundo caso (Figura 4.3), se extraen las características a nivel de objeto de las fechas de estudio por separado, en donde los objetos son clasificados empleando al mismo tiempo las características extraídas de las diferentes fechas de estudio, diferenciando en una única clasificación los objetos de cambio de los de no cambio. Este caso permite la 
posterior combinación y generación de nuevos conjuntos de características con significado temporal.

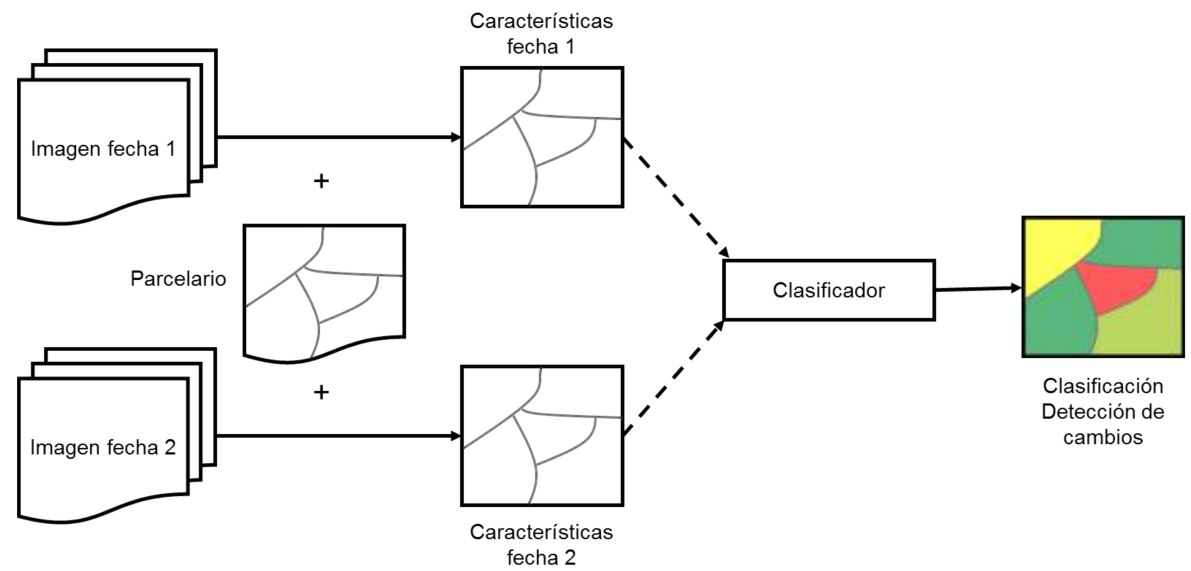

Figura 4.3: Flujo de trabajo del método de clasificación directa para la detección de cambios mediante extracción de características de estudio por separado.

\subsubsection{Algoritmos clasificadores}

La clasificación se puede definir como: (i) la definición de categorías o clases de objetos, o (ii) como la asignación o distribución de objetos individuales a estas categorías o clases (Tso y Mather, 2009). Aplicado a imagen digital, la clasificación basada en píxeles es el proceso por el que se asigna a un píxel de una imagen multiespectral una de las categorías de la leyenda, generalmente sobre la base de similitudes entre los valores numéricos que las definen (Chuvieco, 1996).

En primer lugar, del análisis de las imágenes se extraen las características descriptoras de las diferentes clases a identificar. A continuación se comparan las características del total de elementos en las imágenes con las características obtenidas en el paso anterior. Por último, cada uno de los elementos que forman la imagen, píxeles individuales o grupos de ellos, se asignan a la clase correspondiente en función de su semejanza con las características que definen el total de las categorías.

La clasificación de imágenes es un proceso complejo que requiere considerar numerosos factores. Los pasos principales en la clasificación de imágenes incluyen la definición de la leyenda, el preprocesado de la imagen, la selección de muestras de aprendizaje, la extracción de características, la selección y aplicación de un método de clasificación adecuado, el postprocesado de la clasificación y la evaluación de la precisión obtenida. 
En general, los métodos de clasificación de imágenes se pueden agrupar en métodos supervisados o no supervisados, paramétricos y no paramétricos, clasificadores duros o blandos, o por píxel, subpíxel o por objetos (Lu y Weng, 2007). La agrupación en métodos supervisados o no supervisados se realiza en función del nivel de intervención del usuario en la selección de muestras de entrenamiento necesarias para obtener las características descriptivas de cada clase. Otra agrupación es la de métodos paramétricos o no paramétricos, en función de la distribución de los datos empleados. Por ejemplo, un clasificador paramétrico se basa en la función de probabilidad estadística de cada clase, asumiendo que los datos siguen una distribución normal, mientras que el clasificador no paramétrico asume una función de probabilidad desconocida, por lo que no emplea métodos estadísticos para calcular la separabilidad entre clases. La agrupación de clasificadores duros o blandos considera si el resultado de la asignación de una clase es final o por el contrario si proporciona un nivel de similitud o probabilidad por cada clase. El último tipo de agrupación se realiza en función de la unidad básica de estudio, si es un píxel, un subpíxel o un objeto compuesto por más de un píxel (Tewkesbury et al., 2015).

Para solucionar el problema de clasificación, existen diferentes métodos y algoritmos clasificadores como son el análisis discriminante, los árboles de decisión, el algoritmo random forest, el método de máxima probabilidad, el algoritmo ISODATA, etc. A continuación se describen los diferentes algoritmos empleados.

\subsection{Clasificación ISODATA}

El algoritmo ISODATA es un método de clasificación no supervisado que calcula las medias de cada clase uniformemente distribuidas en el espacio e iterativamente agrupa los píxeles restantes usando técnicas de mínima distancia (Tou y Gonzalez, 1974). Cada iteración recalcula las medias y reclasifica los píxeles con respecto a las nuevas medias. El método ISODATA consiste en los siguientes pasos: establecer los parámetros iniciales, distribuir el número de clases que deseamos clasificar entre los centroides de las agrupaciones existentes o clústeres, eliminar los segmentos menores al número mínimo indicado, actualizar el centroide de los clústeres, calcular la distancia media de las muestras en el dominio clúster, calcular la distancia media global de la muestra desde los respectivos centroides de los clústeres, encontrar el vector de desviaciones estándar y obtener el valor máximo del vector, deshacer los clústeres previamente calculados y volver a rehacer los clústeres de acuerdo con los nuevos vectores calculados. El método ISODATA se encuentra descrito en Cihlar et al. (2000). 


\subsection{Análisis discriminante}

El análisis discriminante es un método estadístico en el que se usan combinaciones lineales de variables para distinguir entre dos o más categorías de los casos de estudio. Las variables discriminan entre los grupos los diferentes casos y predicen a qué categoría o grupo pertenece un caso basándose en los valores de estas variables (Duda et al., 2001; Saraf y Cracknell, 1989). En otras palabras, el análisis discriminante busca las relaciones que existen entre las variables de estudio que mejor discriminan las clases a diferenciar. Este método genera funciones discriminantes usando las variables que mejor describen cada clase con una cierta probabilidad (Tabachnick y Fidell, 1989). En los estudios realizados en este trabajo se emplea el análisis discriminante lineal paso a paso o forward stepwise para la selección de variables previa a estudios de clasificación y de detección de cambios. Este procedimiento va introduciendo las variables de estudio de una en una para la generación de las reglas de clasificación. El método empleado para la selección del orden de las variables es el F-value o valor F, que indica el nivel de significación de una variable dentro del propio conjunto de variables de estudio. A mayor valor de F, mayor significación de la variable.

\subsubsection{3 Árboles de decisión}

Un árbol de decisión es un diagrama de flujo, con estructura de un árbol, consistente en 3 elementos básicos: el nodo raíz, el nodo interno, y el nodo de hojas. El mayor elemento o nodo principal es la raíz, y el elemento final son los nodos de las hojas. Lo nodos entre la raíz y las hojas son los nodos internos. Cada nodo interno se corresponde con un test sobre un atributo, y cada rama representa un resultado de dicho test. Cada nodo de cada hoja contiene una clase. El clasificador de árboles de decisión empleado en estos ensayos es el J48, implementado en el software WEKA (Witten et al., 2011) y basado en el algoritmo C4.5 de árboles de decisión. El algoritmo de árboles de decisión divide la muestra de entrenamiento usando condiciones exclusivas para generar grupos homogéneos que pertenezcan a una única clase (Quinlan, 1993; Witten et al., 2011). Los árboles de decisión han sido ampliamente utilizados en el mundo de la teledetección para diversos estudios de clasificación (Colditz, 2015; Du et al., 2015; Im et al., 2008; Powers et al., 2015).

Para la generación de las reglas de clasificación de árboles de decisión se emplearon métodos de poda. La poda permite incrementar la fiabilidad de la clasificación y optimizar la estructura del árbol reduciendo el número de nodos del árbol, y por lo tanto, 
controlando el tamaño de este evitando árboles complejos y sobreajustes a las muestras de entrenamiento.

Se han empleado dos métodos de poda: la post-poda (post-prunning) - que depende del valor del factor o nivel de confianza -; y la pre-poda (pre-prunning) - que depende del número mínimo de elementos o casos por nodo (Patel y Upadhyay, 2012; Witten et al., 2011). En la post-poda el árbol de decisión se genera antes de empezar a podar las ramas. La post-poda elimina las partes que tienen una menor capacidad de predicción yendo hacia atrás desde las ramas hacia las raíces. Empezando en cada nodo final del árbol u hojas, se calcula la suma ponderada del error de todas las hojas de la rama que se está podando. Si el error calculado en la rama es mayor que el error estimado, la rama se poda. El valor del error de la rama se controla mediante el valor del factor de confianza, cuyo rango va desde 0 a 1 . Un factor de confianza menor indica mayor simplicidad del árbol. Con la pre-poda se decide cuándo se ha de parar el crecimiento de la rama en el proceso de generación del árbol de decisión. El parámetro del mínimo número de casos por nodo define el número mínimo de objetos que deben contener los últimos nodos de la rama (las hojas), lo que limita el grado en el que el árbol se adapta a los datos iniciales. En cada nodo intermedio en el árbol de decisión, el número mínimo de casos de entrenamiento debe seguir como mínimo a dos de las ramas (Patel y Upadhyay, 2012). Cuanto mayor es el valor de este parámetro, más generales son las reglas del árbol. Estos dos parámetros evitan el sobreajuste del árbol a la muestra de entrenamiento. La poda es especialmente importante cuando las muestras de entrenamiento contienen errores o anomalías, y ayuda a mantener el comportamiento general del conjunto de reglas del árbol.

\subsubsection{Extracción de características a nivel de objeto}

\subsubsection{Extracción de características espectrales, de forma y de textura}

Para la extracción de los diferentes conjuntos de características, que se mencionan a continuación, se ha empleado el programa FETEX 2.0. descrito en Ruiz et al. (2011). FETEX es un software de extracción de características de imágenes a nivel de objeto, en el cual se introduce las imágenes y el conjunto de parcelas en formato vectorial ESRI shapefile para el cálculo de las características. FETEX fue diseñado originalmente para trabajar con bases de datos de usos y coberturas de suelo y ayudar en los procesos de clasificación de parcelas ya existentes.

El grupo de características espectrales se calcula a partir de los valores de intensidad 
relacionados con la respuesta espectral de cada una de las bandas de la imagen. Se consideran parte de este grupo los valores de cualquier tipo de ratio entre bandas u otros índices, como por ejemplo el índice de vegetación de diferencias normalizado o NDVI. En concreto este último también es calculado por FETEX. El conjunto de características extraídas por banda espectral que forma parte de la imagen y del índice NDVI está compuesto por los valores de media, desviación estándar, mínimo, máximo, rango, sumatorio y moda de los píxeles contenidos dentro de la parcela de estudio.

La media de los niveles digitales de los píxeles se obtiene mediante la fórmula de la media aritmética (4.1):

$$
\bar{x}=\frac{1}{n} \sum_{i=1}^{n} x_{i}
$$

donde $n$ es el número total de píxeles que componen el objeto y $x_{i}$ es el valor de intensidad del píxel $i$.

La desviación típica se obtiene mediante (4.2).

$$
\sigma=\sqrt{\frac{1}{n-1} \sum_{i=1}^{n}\left(x_{i}-\bar{x}\right)^{2}}
$$

El NDVI o índice de vegetación de diferencia normalizada se relaciona con la densidad, estado y vigor de la vegetación, siendo su fórmula (4.3).

$$
N D V I=\frac{I R-R}{I R+R}
$$

donde $R$ representa la banda espectral del rojo e $I R$ la del infrarrojo cercano.

Al trabajar a nivel de parcela, este grupo de características se extraen únicamente sobre el conjunto de píxeles que componen dicha parcela, y se obtiene un único valor por característica extraída. Este conjunto de características espectrales resultan de gran utilidad para la distinción y caracterización de elementos homogéneos (Ruiz et al., 2011), como son parcelas de suelo arable o suelo desnudo, cultivos herbáceos, etc.

Por otro lado se extraen las características de forma, que aportan información sobre la complejidad de la forma que presentan las parcelas. Están basadas en ratios entre área y perímetro de las propias parcelas, y son extraídos directamente de la geometría de los polígonos contenida en los datos vectoriales que definen las parcelas de estudio. Las características extraídas son el índice de forma o "shape index", dimensión fractal, 
ambas descritas en Krummel et al. (1987); McGarigal et al. (2014); McGarigal y Marks (1995), y la compacidad, descrita por Bogaert et al. (2000).

El índice de forma describe la similitud de la forma de un objeto con un cuadrado y se obtiene de acuerdo al cociente adimensional expresado en (4.4).

$$
\text { Índice de forma }=\frac{\text { Perímetro }}{4 \sqrt{\text { Área }}}
$$

El valor del índice de forma varía entre 1 e infinito, donde 1 es el valor correspondiente a un objeto ideal cuadrado. Cuanto menos compacta sea la forma del objeto, mayor será el valor del índice de forma.

La dimensión fractal expresa la complejidad de los polígonos a partir de un cociente entre perímetro y superficie (Krummel et al., 1987) de acuerdo con la expresión (4.5).

$$
\text { Dimensión fractal }=2 \frac{\log \left(\frac{\text { Perímetro }}{4}\right)}{\log (\text { Área })}
$$

La compacidad de un objeto se suele medir con el ratio superficie/perímetro que es adimensional (Bogaert et al., 2000) (4.6).

$$
\gamma_{1}=\frac{\text { Área }}{\text { Perímetro }^{2}}
$$

Dado que el círculo es el objeto más compacto, se puede modificar el índice anterior de modo que el resultado sea la unidad para las formas circulares y obtener la expresión 4.7 .

$$
\text { Compacidad }=\frac{2 \sqrt{\pi \cdot \text { Área }}}{\text { Perímetro }}
$$

El índice de compacidad varía entre 0 y 1 , siendo 0 el valor correspondiente a un objeto lineal y 1 el de un objeto circular.

Las características de forma ayudan a la clasificación y detección de cierto tipo de parcelas como polígonos urbanos, o viviendas, diferentes parcelas agrícolas y otros elementos como son las carreteras, cauces y ríos, debido a la forma que presentan dichos elementos sobre la superficie terrestre caracterizados de maneras diferentes por las características de forma.

El último conjunto de características de este apartado son las características de 
textura. Las características de textura aportan información sobre la distribución espacial de los valores de intensidad o distribución de niveles de gris de una determinada región dentro de la imagen. Son especialmente útiles para caracterizar zonas o elementos en la imagen con carácter espectral heterogéneo, en los que el uso de la información espectral resulta insuficiente para dicha caracterización. Las características de textura se calcularon basándose en los vecindarios de cada uno de los píxeles que componen la imagen. Existe un amplio conjunto de técnicas para la extracción de características de textura, como son los métodos estadísticos tales como la matriz de co-ocurrencias de niveles de gris (MCNG) descrito en Haralick et al. (1973), técnicas de filtrado como los filtros de energía (Laws, 1985) o los filtros Gabor (Jain y Farrokhnia, 1991), métodos basados en la descomposición wavelet (Mallat, 1989), etc.

En este estudio se extrajeron las características de textura empleando FETEX, que permite extraer diferentes conjuntos de características de este tipo. Del mismo modo que en el caso de las características espectrales, las características de textura se extrajeron por objeto o parcela, obteniendo un único valor por parcela para característica extraída. La banda empleada para la obtención de las características de textura es la banda del rojo, considerada como la banda que mayor contraste presenta, en términos de reflectancia, entre suelo y vegetación en comparación con el resto de bandas de la imagen (Ghulam et al., 2007).

La textura puede caracterizarse en términos de la cuantía e intensidad de bordes por unidad de área. Una transición brusca en los niveles de gris de una imagen alrededor de un píxel dado puede detectarse comparando por pares los valores de los vecindarios del píxel. FETEX extrae la media y la desviación de la fórmula de densidad de bordes de un objeto empleando la expresión propuesta por Sutton y Hall (1972), donde $g$ se considera en función de la distancia $d$ entre los píxeles de una imagen $I$ en un vecindario N., (4.8).

$$
\begin{aligned}
g(d) & =\sum_{(i, j) \in N}|I(i, j)-I(i+d, j)|+|I(i, j)-(i-d, j)| \\
& +|I(i, j)-I(i+d, j)|+|I(i, j)-(i-d, j)|
\end{aligned}
$$

En los ensayos realizados en esta tesis se ha considerado una distancia de 1 píxel para la extracción de las características de los objetos de estudio y la obtención de la media y la desviación típica como características extraídas de la fórmula de intensidad de bordes. 
Otro grupo de características de textura extraídas por FETEX es el conjunto descrito en Haralick et al. (1973), basado en la matriz de co-ocurrencias de los niveles de gris (MCNG). Este conjunto de características también es conocido como las características del histograma de segundo orden de los valores de intensidad de la imagen. Además de estos valores, como son el contraste, uniformidad, entropía, varianza, covarianza, momento diferencial inverso (IDM) y correlación, FETEX también extrae las características de primer orden del histograma. Los estadísticos de primer orden obtenidos a partir del histograma de frecuencias de los niveles de gris son la curtosis y la asimetría o skewness. La curtosis indica el grado de apuntamiento de una distribución estadística de frecuencias, suponiendo una distribución normal, y se obtiene mediante la fórmula 4.9:

$$
\text { Curtosis }=\frac{1}{n} \sum_{i=1}^{n}\left(\frac{\left(x_{i}-\bar{x}\right)}{\sigma}\right)^{4}-3
$$

Por otro lado, el skewness o coeficiente de asimetría, determina si una distribución es simétrica alrededor del nivel digital de máxima frecuencia suponiendo también una distribución normal. Valores positivos indican que la distribución está desplazada hacia la derecha con una mayor cola hacia la derecha del máximo. Valores negativos indican que la distribución está desplazada hacia la izquierda, con una forma más prolongada hacia ese lado del máximo. El valor de la asimetría se obtiene mediante la fórmula 4.10:

$$
\text { Skewness }=\frac{1}{n} \sum_{i=1}^{n}\left(\frac{\left(x_{i}-\bar{x}\right)}{\sigma}\right)^{3}
$$

La matriz de co-ocurrencias se calcula midiendo la frecuencia que tiene un nivel de gris con otro nivel de gris con el que guarda una relación espacial específica a una cierta distancia y en una dirección determinada. Esta matriz de frecuencias es simétrica y se presenta en función de la relación angular entre píxeles vecinos, así como de la distancia entre ellos. En la fórmula de la matriz MCNG (4.11) $p(i, j)$ representa las frecuencias relativas de los niveles de gris $i$ y $j$, tomando los píxeles dos a dos y separados una distancia $d$ según una dirección dada. $N_{g}$ son los niveles de gris o niveles de intensidad en la imagen. Cuanto mayores sean los valores de su diagonal principal más homogénea será la textura que representa la matriz, mientras que cuanto más repartidos estén los valores fuera de la diagonal más heterogénea será.

$$
p(i, j)=\frac{P(i, j)}{\sum_{i=0}^{N_{g}-1} \sum_{j=0}^{N_{g}-1} P(i, j)}
$$


La MCNG permite caracterizar la organización espacial de los niveles de gris de un patrón de textura, si bien, no puede recoger los aspectos de forma de las primitivas de nivel de gris, por lo que no es adecuada para texturas formadas por patrones de grandes dimensiones o primitivas extensas. Una vez formada la MCNG de una imagen, la caracterización de los niveles de gris y de sus patrones se consigue mediante la extracción de 7 variables estadísticas de segundo orden, propuestas por Haralick et al. (1973), que describen las propiedades de varianza, contraste, uniformidad, entropía, momento diferencia inverso, momento producto y correlación.

La varianza mide la heterogeneidad, es decir, la variabilidad de las intensidades en la imagen y aumenta su valor cuando los niveles de gris difieren de la media. La varianza viene descrita por la expresión 4.12:

$$
\sum_{i=0}^{N_{g}-1} \sum_{j=0}^{N_{g}-1}(i-\mu)^{2} \cdot p(i, j)
$$

El contraste establece la diferencia de la frecuencia entre valores altos y bajos del nivel de gris. Está directamente relacionado con la frecuencia espacial de la imagen. Valores altos del contraste son indicativos de la existencia de muchos valores fuera de la diagonal principal de la matriz 4.13.:

$$
\sum_{i=0}^{N_{g}-1} \sum_{j=0}^{N_{g}-1}(i-j)^{2} \cdot p(i, j)
$$

La uniformidad mide la homogeneidad de la textura de la imagen. Los valores más altos corresponden a distribuciones espaciales de los niveles de gris casi constantes (4.14):

$$
\sum_{i=0}^{N_{g}-1} \sum_{j=0}^{N_{g}-1} p(i, j)^{2}
$$

La entropía mide la aleatoriedad, complejidad o desorden en la distribución de la intensidad en una imagen (4.15):

$$
-\sum_{i=0}^{N_{g}-1} \sum_{j=0}^{N_{g}-1} p(i, j) \cdot \log [p(i, j)]
$$

El momento de diferencia inverso (IDM) está inversamente relacionado con el contraste. Valores altos indican que la frecuencia de ocurrencia en la imagen de niveles 
de intensidad similares es elevada, discriminando zonas de variación de niveles de gris entre píxeles (4.16):

$$
\sum_{i=0}^{N_{g}-1} \sum_{j=0}^{N_{g}-1} \frac{p(i, j)}{1+(i-j)^{2}}
$$

La covarianza es una medida de homogeneidad local. Valores positivos altos indican una mayor probabilidad de que se den juntos en la imagen valores de intensidad similar. Por el contrario, valores negativos son propios de imágenes donde los píxeles vecinos difieren mucho en su nivel de gris (4.17):

$$
-\sum_{i=0}^{N_{g}-1} \sum_{j=0}^{N_{g}-1}(i-\mu) \cdot(j-\mu) \cdot p(i, j)
$$

La correlación equivale al momento producto normalizado con respecto a la varianza (4.18):

$$
\frac{\sum_{i=0}^{N_{g}-1} \sum_{j=0}^{N_{g}-1}(i-\mu) \cdot(j-\mu) \cdot p(i, j)}{\sum_{i=0}^{N_{g}-1} \sum_{j=0}^{N_{g}-1}(i-\mu)^{2} \cdot p(i, j)}
$$

Desde el punto de vista práctico, uno de los problemas que presenta la clasificación de imágenes mediante información o variables de textura es la presencia de errores significativos en las zonas frontera entre clases, debido precisamente a que el valor de cada píxel depende de la distribución de valores de su vecindario, tal y como se recoge en otros trabajos (Ferro y Warner, 2002; Ruiz et al., 2002). La utilización del enfoque por objeto elimina el error que se produce al obtener la MCNG para cada píxel en un vecindario ya que, en su cálculo, sólo se consideran aquellos píxeles pertenecientes al objeto, con lo que se evita la inclusión de píxeles exteriores al mismo.

En lugar de calcular una MCNG para cada uno de los píxeles pertenecientes a un objeto y posteriormente obtener la media aritmética de las 7 variables explicadas y así obtener las 7 características correspondientes al polígono, se ha calculado una única MCNG para cada polígono (Balaguer et al., 2010) considerando la frecuencia relativa entre cada par de píxeles separados una distancia de 1 píxel y en las cuatro direcciones siguientes: $0^{\circ}, 45^{\circ}, 90^{\circ}$ y $135^{\circ}$.

El conjunto total de características espectrales, de forma y de textura extraídas se muestra en la Tabla 4.1. 


\begin{tabular}{|c|c|}
\hline Tipo & Características \\
\hline \multirow{7}{*}{ Espectrales } & Media \\
\hline & Desviación \\
\hline & Mínimo \\
\hline & Máximo \\
\hline & Rango \\
\hline & Sumatorio \\
\hline & Mayoría \\
\hline \multirow{5}{*}{ Forma } & Índice de forma \\
\hline & Compacidad \\
\hline & Dimensión fractal \\
\hline & Área \\
\hline & Perímetro \\
\hline \multirow{11}{*}{ Textura } & Contraste \\
\hline & Uniformidad \\
\hline & Entropía \\
\hline & Varianza \\
\hline & Covarianza \\
\hline & Momento de diferencia inverso \\
\hline & Correlación \\
\hline & Curtosis \\
\hline & Skewness \\
\hline & Media de intensidad de bordes \\
\hline & Desv. Típica de intensidad de bordes \\
\hline
\end{tabular}

Tabla 4.1: Lista de características espectrales, forma y textura extraídas a nivel de parcela. Nota: las características espectrales se extraen para todas las bandas espectrales que componen la imagen además del NDVI. 
Estos grupos de características se emplean en diferentes ensayos y experimentos a lo largo de este trabajo, y se consideran como el grupo básico de características.

Como se ha comentado anteriormente, en este estudio se ha empleado el método clásico de detección de cambios de diferencias simples para obtener características a nivel de objeto que aporten información temporal. Para ello, se han realizado las diferencias entre las características de tipo multiespectral y textura de una imagen en una época posterior, menos las características obtenidas de una imagen sobre las mismas parcelas de una época anterior. De esta forma, se obtiene un único valor por cada una de las variables existentes en cada parcela, describiendo así la variación de la parcela entre las dos épocas de estudio. Debido a la propia naturaleza de las características de forma, invariables en ambas épocas de estudio obtenidas a partir de la geometría de las parcelas, las diferencias no se aplican para este conjunto de características.

\subsubsection{Extracción de características derivadas de datos LiDAR}

La extracción de características tridimensionales derivadas de datos LiDAR se realiza orientada a objetos, de forma similar a las características espectrales empleando FETEX, en el que el parcelario se utiliza para la definición de objetos, extrayendo las estadísticas de media, desviación y valores máximos y mínimos de los valores de alturas de los modelos digitales. En función del método de detección de cambios que se emplee, se extraerán las características de dos formas diferentes.

La primera forma es extraer las características de los MDSn de las dos fechas de estudio por separado. Con esta extracción, se obtendrán dos grupos de características pertenecientes a fechas diferentes para un mismo conjunto de parcelas de estudio, y se emplean cuando se utiliza el método de post-clasificación para la detección de cambios.

En la segunda forma, se pretende que el grupo de características tridimensionales tengan significado temporal, por lo que se puede aplicar el mismo método de diferencias simples sobre las características tridimensionales de las dos fechas que se ha aplicado a las características espectrales y de textura, o bien obtener las diferencias entre los MDSn de ambas fechas y posteriormente realizar la extracción de características a nivel de objeto. En este caso se ha considerado realizar la segunda opción. Las características extraídas del modelo de diferencias son: la media, la desviación típica, y los valores máximos y mínimos de los valores de altura de los píxeles contenidos dentro de cada una de las parcelas de estudio. Estas características se emplean en el método de clasificación directa de detección de cambios. 
En la Figura 4.4 se pueden observar ejemplos de los MDSn en las dos épocas de estudio y la diferencia entre ellos.

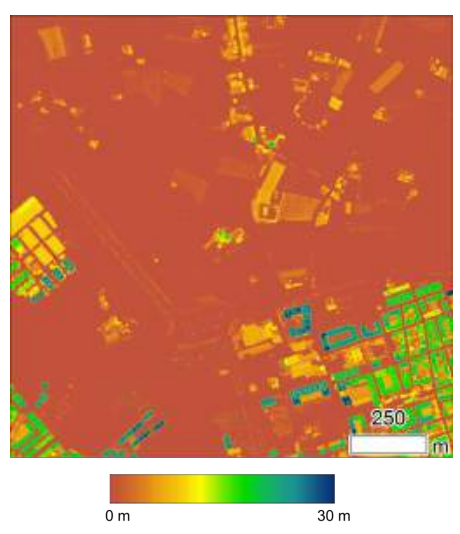

(a) MDSn 2003

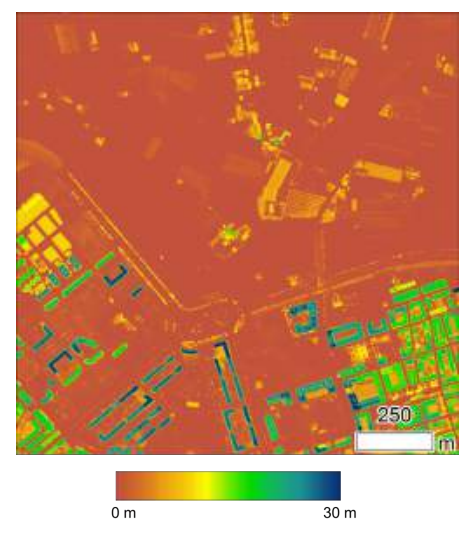

(b) MDSn 2009

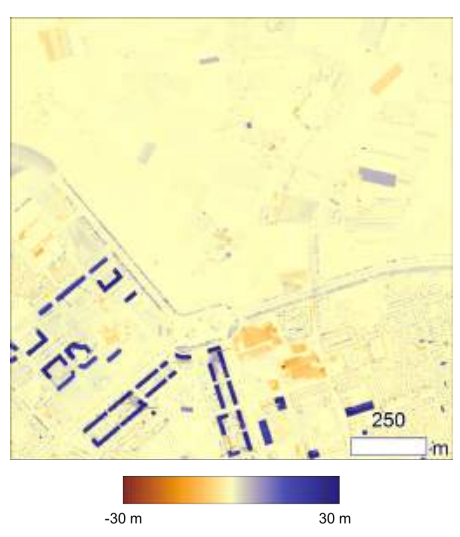

(c) Diferencia entre MDSn

Figura 4.4: Detalles de los modelos digitales de superficie normalizados de 2003, 2009 y diferencias entre modelos.

\subsubsection{Extracción de características derivadas de funciones geoestadísticas}

En este apartado se describen las características derivadas de funciones geoestadísticas. Estas características aportan información acerca de la distribución espacial del contenido de las parcelas describiendo la regularidad o irregularidad en la disposición de los elementos u objetos presentes en las parcelas de estudio, lo que resulta de gran utilidad para la detección de patrones y marcos de plantación, por ejemplo. El conjunto de características que se emplea en este trabajo se extrae a partir de la función del semivariograma.

La función del semivariograma relaciona la semivarianza con la separación espacial y proporciona una descripción concisa e imparcial de la escala y el patrón de la variabilidad espacial (Curran, 1988). La semivarianza se define como la mitad de la media de la raíz cuadrada de las diferencias entre los valores separados por un lag, en el que dicho lag es un vector definido por una distancia y una dirección (Atkinson y Lewis, 2000). La función de la semivarianza presenta la siguiente ecuación (4.19):

$$
\gamma(\vec{h})=\frac{1}{2 N(\vec{h})} \sum_{i=1}^{N(\vec{h})}\left[z\left(x_{i}\right)-z\left(x_{i}-\vec{h}\right)\right]^{2}
$$

En la que $z\left(x_{i}\right)$ es el valor de la variable en la posición $x_{i}, \vec{h}$ la separación entre 
elementos en una dirección dada, y $N(\vec{h})$ el número de pares de datos en las posiciones $x_{i}$ y $x_{i}+\vec{h}$ en una única banda para una parcela determinada.

Según la propia definición, los valores de la función del semivariograma se corresponden con una única dirección. Para el cálculo del semivariograma omnidireccional, FETEX obtiene la media de todas las funciones del semivariograma empleando seis direcciones diferentes (de $0^{\circ}$ a $150^{\circ}$ con pasos de $30^{\circ}$ ). Para evitar ningún tipo de tendencia o información sesgada en la calidad de la detección de patrones durante el análisis direccional, el valor del ángulo con el que se comienza el análisis a partir del píxel inicial en cada parcela es aleatorio. Además se aplica a cada una de las curvas calculadas un filtro gaussiano con una distancia igual a tres posiciones para suavizar su forma y eliminar ruido o fluctuaciones experimentales. El resultado obtenido a partir de este semivariograma permite cuantificar la asociación espacial de los valores de intensidad de los píxeles de una banda de la imagen. Además mide el grado de correlación espacial entre estos (Ruiz et al., 2011).

El comportamiento de la función del semivariograma dependerá de la distribución de los valores de intensidad de los píxeles de la parcela de estudio. En parcelas homogéneas los valores del semivariograma aumentan cuando aumenta la distancia $h$ o lag. Cuando los elementos dentro de la parcela se encuentran distribuidos con un patrón regular, el semivariograma muestra un comportamiento cíclico conocido como efecto agujero (Pyrcz y Deutsch, 2003), típico de las parcelas agrícolas de leñosos, como pueden ser los cítricos, en la que los árboles están distribuidos según un marco de plantación regular. En la Figura 4.5 se muestra un ejemplo de parcelas con sus usos del suelo y el semivariograma asociado a dicho uso.

De estos semivariogramas se puede extraer un conjunto de características que describe su comportamiento en función de la distancia a lo largo del semivariograma. Ya que la forma del semivariograma depende de la clase o contenido de la parcela, estas características ayudan a su caracterización, facilitando la distinción de patrones de plantación regulares y por lo tanto, aportando información clave para distinguir la clase a la que pertenecen. El conjunto de características extraídas del semivariograma se describe en Balaguer et al. (2010). La Tabla 4.2 recoge la lista de estas características diferenciadas según la distancia o zona del semivariograma de donde son extraídas.

Este conjunto de características ha sido empleando en diferentes trabajos como los de Cabrera-Barona et al. (2016); Dunwoody et al. (2013); Gil-Yepes et al. (2013); Hermosilla et al. (2012); Löw et al. (2013); Ruiz et al. (2016, 2007), en los que las características de estructura se utilizan en métodos de clasificación. 

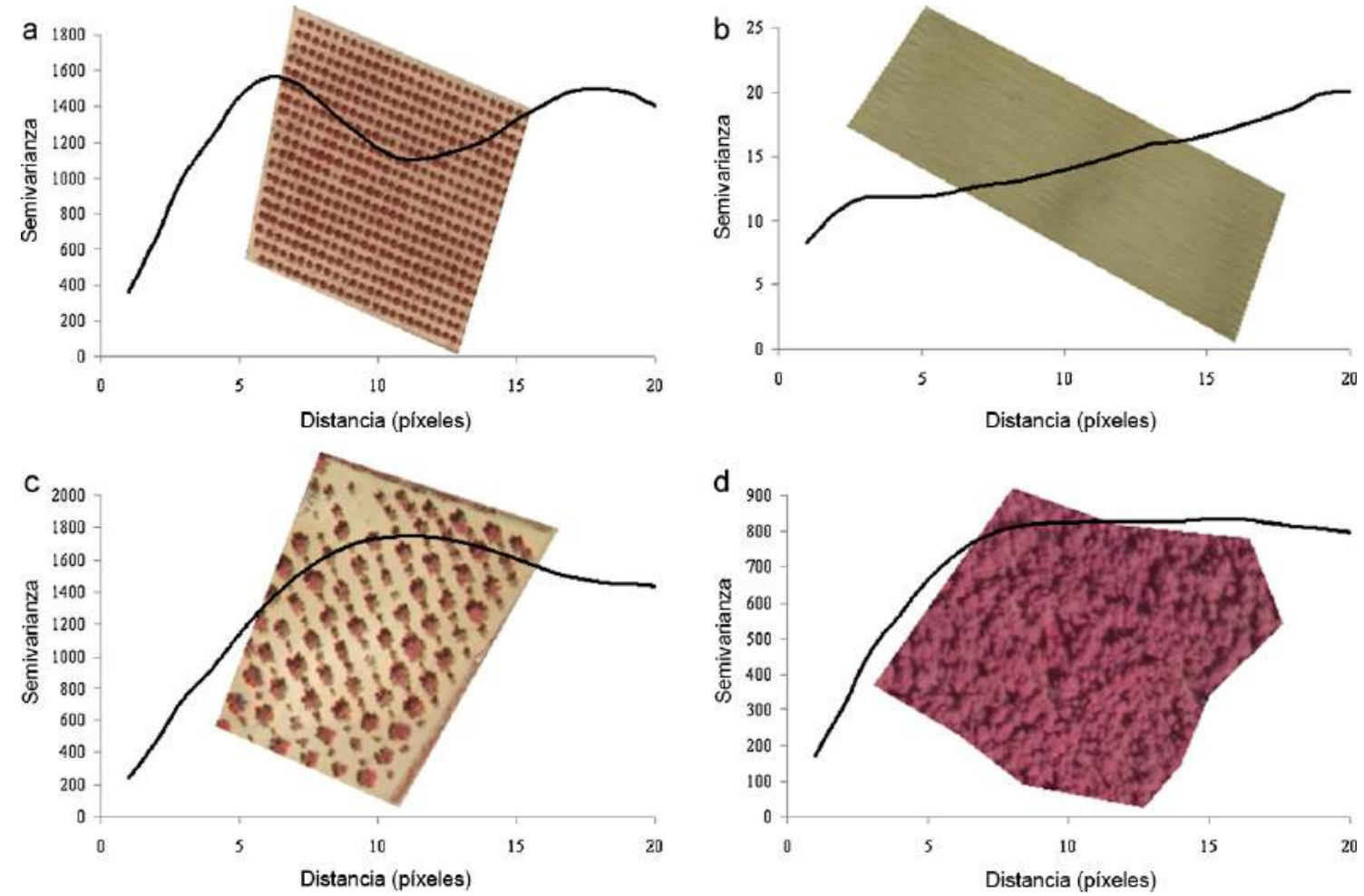

Figura 4.5: Parcelas con diferentes usos del suelo y sus respectivos semivariogramas experimentales superpuestos. En el eje de abscisas se encuentra la distancia entre píxeles o lag, y los valores de semivarianza en el eje de ordenadas. Parcelas de (a) cítricos, (b) terreno arable, (c) algarrobos y (d) bosque (Ruiz et al., 2011). 


\begin{tabular}{|c|c|c|c|}
\hline \multicolumn{2}{|c|}{ Tipo } & Nombre & Descripción \\
\hline \multirow{14}{*}{ 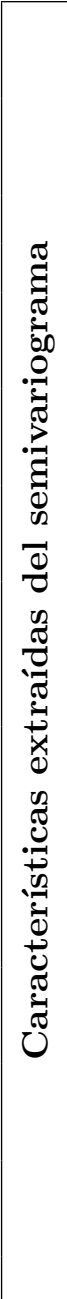 } & \multirow{4}{*}{$\begin{array}{c}\text { Parámetros cercanos al } \\
\text { origen }\end{array}$} & RVF & $\begin{array}{l}\text { Ratio entre el valor total de la varianza y el } \\
\text { semivariograma en el primer lag. }\end{array}$ \\
\hline & & $\mathrm{RSF}$ & $\begin{array}{l}\text { Ratio entre los valores de semivarianza entre } \\
\text { el segundo y el primer lag. }\end{array}$ \\
\hline & & FDO & Primera derivada cercana al origen. \\
\hline & & SDT & Segunda derivada en el tercer lag. \\
\hline & \multirow{7}{*}{$\begin{array}{l}\text { Parámetros empleando los } \\
\text { valores hasta el primer } \\
\text { máximo }\end{array}$} & FML & $\begin{array}{l}\text { Valor del lag donde se encuentra el primer } \\
\text { máximo. }\end{array}$ \\
\hline & & MFM & $\begin{array}{l}\text { Media de los valores del semivariograma } \\
\text { hasta el primer máximo. }\end{array}$ \\
\hline & & VFM & $\begin{array}{l}\text { Varianza de los valores del semivariograma } \\
\text { hasta el primer máximo. }\end{array}$ \\
\hline & & DMF & $\begin{array}{l}\text { Diferencia entre la media de los valores del } \\
\text { semivariograma hasta el primer máximo y la } \\
\text { semivarianza en el primer lag. }\end{array}$ \\
\hline & & $\mathrm{RMM}$ & $\begin{array}{l}\text { Ratio entre la semivarianza en el primer } \\
\text { máximo local y la media de los valores del } \\
\text { semivariograma hasta el primer máximo. }\end{array}$ \\
\hline & & $\mathrm{SDF}$ & $\begin{array}{l}\text { Diferencia de segundo orden entre el primer } \\
\text { lag y el primer máximo. }\end{array}$ \\
\hline & & $\mathrm{AFM}$ & $\begin{array}{l}\text { Área entre el valor del semivariograma en el } \\
\text { primer lag y el primer máximo. }\end{array}$ \\
\hline & \multirow{3}{*}{$\begin{array}{l}\text { Parámetros de los valores } \\
\text { que van desde el primer } \\
\text { máximo hasta el segundo } \\
\text { máximo }\end{array}$} & DMS & $\begin{array}{l}\text { Distancia entre la posición del primer } \\
\text { máximo local y el segundo máximo. }\end{array}$ \\
\hline & & DMM & $\begin{array}{l}\text { Distancia entre el primer máximo y el } \\
\text { primer mínimo. }\end{array}$ \\
\hline & & $\mathrm{HA}$ & Área del efecto agujero. \\
\hline
\end{tabular}

Tabla 4.2: Lista de características extraídas del semivariograma (Balaguer et al., 2010). 


\subsection{Funciones de semivariograma cruzado y codispersión}

En este apartado se describen las características aplicadas y validadas por primera vez en estudios de teledetección y procesado digital de imágenes publicadas en el artículo de Gil-Yepes et al. (2016) derivado de esta tesis.

El semivariograma cruzado es una extensión del semivariograma que permite el análisis simultáneo de dos variables continuas (Wackernagel, 2003). Para este estudio en concreto, $z_{j}\left(x_{i}\right)$ representa el valor del píxel en la banda roja de una parcela en una época $t=t_{j}$. Considerando $z_{j}(x)$ y $z_{j}(x+\vec{h})$ dos valores $z_{j}$ en las posiciones $x$ y $x+\vec{h}$ donde la distancia entre ellos es $\vec{h}$ y siendo $z_{j}$ y $z_{k}$ los valores en las imágenes de una parcela en los tiempos $t=t_{j}$ y $t=t_{k}$ respectivamente, el semivariograma cruzado se define como (4.20):

$$
\gamma_{j k}(\vec{h})=\frac{1}{2 N(\vec{h})} \sum_{i=1}^{N(\vec{h})}\left[z_{j}\left(x_{i}\right)-z_{j}\left(x_{i}+\vec{h}\right)\right]\left[z_{k}\left(x_{i}\right)-z_{k}\left(x_{i}+\vec{h}\right)\right]
$$

Sólo los píxeles dentro de una parcela son considerados para el cálculo del semivariograma cruzado. Además, para cada una de las variables continuas del semivariograma cruzado, se emplea información de imágenes de fechas diferentes. De esta forma, el semivariograma cruzado permite combinar información de dos fechas y así poder obtener características temporales derivadas de su función (Gil-Yepes et al., 2016). Del mismo modo que la función del semivariograma, el semivariograma cruzado tiene un comportamiento direccional, por lo que para la obtención del semivariograma cruzado omnidireccional se emplea el mismo procedimiento de cálculo de medias en diferentes direcciones aleatorias con pasos de $30^{\circ}$ (Ruiz et al., 2011).

La codispersión (Wackernagel, 2003) se obtiene a partir de los valores del semivariograma cruzado $\gamma_{j k}(\vec{h})$ y los valores de los semivariogramas de las dos variables que intervienen en el semivariograma cruzado $\gamma_{j}(\vec{h})$ y $\gamma_{k}(\vec{h})(4.21)$ :

$$
v_{j k}(\vec{h})=\frac{\gamma_{j k}(\vec{h})}{\sqrt{\gamma_{j}(\vec{h}) \cdot \gamma_{k}(\vec{h})}}
$$

Los valores de la codispersión $v_{j k}(\vec{h})$ pueden ser interpretados como un índice de correlación que indica la similitud entre dos semivariogramas y por lo tanto, entre las variables que se emplean para calcularlo. Los cambios en las parcelas entre las fechas 
$t=t_{j}$ y $t=t_{k}$ serán más evidentes cuando el valor de la codispersión se acerque a cero, lo que implica una menor correlación entre ellos y mayor distinción entre cambios. Los valores de la codispersión en parcelas de no cambio es diferente de cero. Debido a que el semivariograma cruzado se calcula empleando los mismos datos que se emplean para el cálculo del semivariograma, el rango de valores de la codispersión oscila entre -1 y 1.

El semivariograma cruzado y la codispersión son funciones decrecientes de la distancia $\vec{h}$ cuando $z_{j}$ y $z_{k}$ presentan una correlación negativa, y se pueden obtener valores tanto positivos como negativos en diferentes distancias de la parcela, caracterizando dos estructuras espaciales diferentes. Por ejemplo, puede haber funciones en las que inicialmente sus valores decrezcan y luego aumenten a distancias mayores.

El semivariograma (4.19) y el semivariograma cruzado (4.20), tiene un comportamiento direccional, lo que significa que la distancia del lag aumenta en una dirección determinada. Para obtener las características derivadas de los semivariogramas, el cálculo se realiza en $n$ lags, $\left\{h_{1}, h_{2}, \cdots, h_{n}\right\}$ siendo $h_{i}=\left\|\vec{h}_{i}\right\|$.

El intervalo empleado entre dos lags (h) en este estudio para el cálculo de las funciones de semivariograma cruzado y codispersión es de 1 píxel, por lo que la distancia del lag es igual al tamaño del píxel $(0,5 \mathrm{~m})$. El motivo para usar un único píxel como distancia de lag es obtener el mayor nivel de detalle en el semivariograma cruzado experimental y codispersión ya que se desea analizar toda la respuesta de las funciones.

Las funciones del semivariograma cruzado y codispersión proporcionan información temporal ya que para su obtención se emplean dos variables, o imágenes en este caso, de dos épocas diferentes. La extracción y estudio de las características temporales se centra principalmente, a diferencia con las características no temporales, en el estudio de parámetros que puedan ser de utilidad para la detección de cambios en el tiempo y no únicamente en la clasificación unitemporal de usos del suelo de las parcelas, por lo que el estudio de las características extraídas del semivariograma cruzado y de la codispersión resulta muy interesante.

\subsection{Características bitemporales derivadas del semivariograma cruza- do}

Las variables extraídas del semivariograma cruzado están basadas en las características extraídas del semivariograma descritas en Balaguer et al. (2010) (Tabla 4.2). Debido a la naturaleza de estas características, algunas de ellas no han sido consideradas. En particular, el semivariograma cruzado puede tener un comportamiento decreciente o valores 
negativos, lo que hace que el cálculo de ciertas de las características sea innecesario.

Las características extraídas del semivariograma cruzado que son consideradas para el estudio se muestran en la Tabla 4.3, en la que también se pueden apreciar las fórmulas para su obtención.

Algunas de las variables del semivariograma cruzado, como se ha comentado, pueden tener valores positivos o negativos. Este es el caso de la derivada en el origen (CS_FDO). $\mathrm{Su}$ signo indica si el semivariograma tiene una forma creciente o decreciente en el primer lag. Si el semivariograma cruzado empieza con valores negativos: $\gamma_{j k}\left(h_{3}\right)<\gamma_{j k}\left(h_{2}\right)<$ $\gamma_{j k}\left(h_{1}\right)<0$, entonces se define $h_{\max 1}=0$, por lo que $h_{\max 1}<h_{\min 1}$ en todos los casos y CS_DMM $<0$. Además, se define CS_MFM $=$ CS_VFM $=0$.

\begin{tabular}{|c|c|}
\hline Descripción & Fórmula \\
\hline \multicolumn{2}{|l|}{ Posición de valores concretos } \\
\hline Posición del primer máximo local & CS_SMAX1 $=h_{\max 1}$ \\
\hline Posición del primer mínimo local & CS_SMIN1 $=h_{\min 1}$ \\
\hline \multicolumn{2}{|l|}{ Parámetros cercanos al origen } \\
\hline Primera derivada cerca del origen & CS_FDO $=\frac{\gamma_{j k}\left(h_{2}\right)-\gamma_{j k}\left(h_{1}\right)}{h_{2}-h_{1}}$ \\
\hline \multicolumn{2}{|l|}{ Parámetros sobre el primer máximo } \\
\hline $\begin{array}{l}\text { Media de los valores del semivariograma } \\
\text { hasta el primer máximo }\end{array}$ & $\mathrm{CS \_ MFM}=\gamma_{j k \max 1}^{\operatorname{mean}}=\frac{1}{\max 1} \sum_{i=1}^{n} \gamma_{j k}\left(h_{i}\right)$ \\
\hline $\begin{array}{l}\text { Varianza de los valores del semivariograma } \\
\text { cruzado hasta el primer máximo }\end{array}$ & $\mathrm{CS} \_\mathrm{VFM}=\frac{1}{\max 1} \sum_{i=1}^{n}\left(\gamma_{j k}\left(h_{i}\right)-\gamma_{j k \max 1}^{\operatorname{mean}}\right)^{2}$ \\
\hline \multicolumn{2}{|l|}{$\begin{array}{l}\text { Parámetros entre el primer y segundo } \\
\text { máximo }\end{array}$} \\
\hline $\begin{array}{l}\text { Distancia entre el primer y segundo } \\
\text { máximo }\end{array}$ & CS_DMM $=h_{\max 1}-h_{\min 1}$ \\
\hline
\end{tabular}

Tabla 4.3: Características extraídas del semivariograma cruzado siendo: $h_{\max 1}$ el $l a g$ donde se localiza el primer máximo relativo del semivariograma cruzado, $h_{\min 1}$ donde se localiza el primer mínimo relativo, y $\gamma_{j k}\left(h_{i}\right)$ el valor del semivariograma cruzado en el lag $h_{i}$.

\subsection{Características bitemporales derivadas de la codispersión}

Del mismo modo que en el semivariograma y semivariograma cruzado, se ha extraído un conjunto de variables que describen la forma de la función de codispersión en función de los valores del lag. Las variables extraídas son las siguientes: la media de los valores absolutos de la codispersión (CO_MEAN); la desviación estándar de los valores de codispersión (CO_STD); la posición del primer máximo relativo (CO_SMAX1); y la posición y el valor del primer mínimo relativo (CO_SMIN1 y CO_MIN1). Estas variables y sus fórmulas se muestran en la Tabla 4.4. 


\begin{tabular}{|l|l|}
\hline \multicolumn{1}{|c|}{ Descripción } & \multicolumn{1}{c|}{ Fórmula } \\
\hline \hline Parámetros a lo largo de la función & CO_MEAN $=v_{j k}^{\text {mean }}=\frac{1}{n} \sum_{i=1}^{n}\left|v_{j k}\left(h_{i}\right)\right|$ \\
\hline $\begin{array}{l}\text { Media absoluta de los valores de } \\
\text { codispersión }\end{array}$ & CO_STD $=v_{j k}^{\text {mean }}=\frac{1}{n} \sum_{i=1}^{n}\left(v_{j k}\left(h_{i}\right)-v_{j k}^{\text {mean }}\right)^{2}$ \\
\hline $\begin{array}{l}\text { Desviación estándar de los valores de } \\
\text { codispersión }\end{array}$ & CO_SMAX1 $=h_{\text {max } 1}$ \\
\hline Posición de valores concretos & CO_SMIN1 $=h_{\text {min } 1}$ \\
\hline Posición del primer máximo local. & \\
\hline Posición del primer mínimo local. & CO_VMIN1 $=v_{j k}\left(h_{m i n 1}\right)$ \\
\hline Valores concretos & \\
\hline Valor del primer mínimo local. & \\
\hline
\end{tabular}

Tabla 4.4: Características extraídas de la codispersión siendo: $n$ el número de lags de estudio, $\nu_{j k}\left(h_{i}\right)$ el valor de la codispersión en el lag $h_{i}, h_{\max 1}$ el lag donde se localiza el primer máximo relativo de la función de codispersión, y $h_{\min 1}$ donde se localizad el primer mínimo relativo.

Las variables CO_SMIN1 y CO_SMAX1 se calculan considerando un vecindario lineal igual a 5 lags de distancia alrededor de cada $h_{i}$, como en Balaguer et al. (2010), y se definen como la posición del lag del primer mínimo y máximo relativo de los valores de la codispersión $\left(h_{\min } \mathrm{y} h_{\max }\right.$ respectivamente). Existen dos casos especiales para los valores de estas variables de codispersión. Cuando la función de codispersión tiene tendencia ascendente continua desde el origen hasta $h_{n}$ que es el mayor lag, no existe un máximo relativo y por lo tanto $h_{\max 1}=h_{n}$. Lo mismo ocurre si no existe mínimo relativo. En este caso, el mínimo relativo es $h_{\min 1}=h_{n}$. Si la codispersión empieza con valores negativos, $v_{j k}\left(h_{3}\right)<v_{j k}\left(h_{2}\right)<v_{j k}\left(h_{1}\right)<0$, entonces el primer valor relativo corresponde a un mínimo y se define $h_{\max 1}=0$, por lo que $h_{\max 1}<h_{\min 1}$.

\subsubsection{Extracción de características de fragmentación}

Las características de fragmentación se emplean para cuantificar o medir la estructura del paisaje o distribución espacial de las coberturas existentes dentro de un área determinada (McGarigal et al., 2014). En este estudio se ha planteado la extracción de características e índices de fragmentación de paisaje aplicados a nivel de parcela, de manera que se puedan caracterizar dichas parcelas en función de las características de sus elementos internos o subobjetos pertenecientes a diferentes coberturas de suelo.

El conjunto de indicadores o características extraídos se agruparon siguiendo dos criterios diferentes: (i) en función de escala o nivel de característica que describe; y (ii) en función del tipo de información o propiedad de los objetos y subobjetos (Figura 4.6).

En función de la escala o nivel de detalle, se pueden diferenciar dos tipos diferentes 
de características: a nivel de parcela o características propias de cada objeto de estudio (características a nivel objeto o nivel parcela); y a nivel de los subobjetos y su tipo de cobertura contenidos dentro de cada parcela (características de cobertura, subobjeto o subparcela).

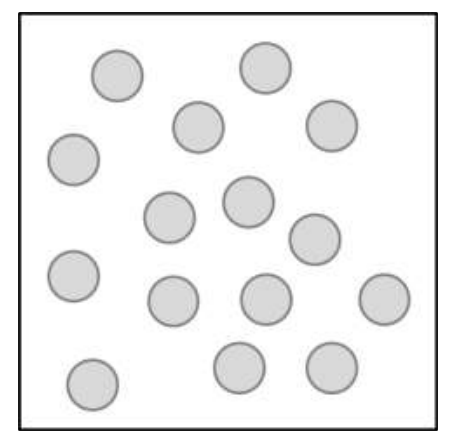

(a) Características a nivel de parcela.

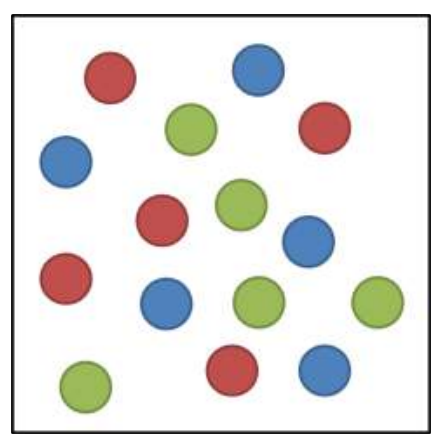

(b) Características de cobertura.

Figura 4.6: Clasificación de características siguiendo el criterio de escala.

La agrupación según el tipo de información o propiedad se divide en: indicadores de área y perímetro, forma, contraste, agregación y diversidad. La Tabla 4.5 muestra las características extraídas en este estudio.

La mayoría de características de fragmentación se obtienen a partir del software Fragstats descrito en McGarigal et al. (2014), y para su extracción, es necesario el cálculo de unos mapas de coberturas básicas. Estos mapas de coberturas se generan a partir de los datos tridimensionales e imágenes QuickBird y PNOA. Una vez generados estos, las características son obtenidas mediante código generado en IDL que, invocando a Fragstats, extrae los indicadores tanto a nivel de parcela como de cobertura de la zona de estudio utilizando el parcelario en formato vectorial para la delimitación de los objetos.

Existen otros trabajos en los que se ha realizado la extracción de indicadores de fragmentación no sobre los mapas de coberturas sino a partir de datos vectoriales tanto para las parcelas como para las coberturas. Así mismo, se han generado diferentes herramientas, además de Fragstats, para la extracción de varios indicadores de fragmentación (Ebert y Wade, 2004; Lang y Tiede, 2003; Sapena y Ruiz, 2015b; Vogt et al., 2007).

En la siguiente sección se describe el conjunto de indicadores extraídos en función de la información que proporcionan. 


\begin{tabular}{|c|c|c|}
\hline Tipo y Nombre & Código & Escala \\
\hline \multicolumn{3}{|l|}{ Área y Perímetro } \\
\hline Área de cobertura & $\mathrm{CA}$ & Clase \\
\hline Porcentaje de cobertura & PLAND & Clase \\
\hline Índice de mayor objeto & LPI & Clase \\
\hline Suma total de bordes & TE & Objeto y Clase \\
\hline Densidad de bordes & ED & Clase \\
\hline Estadísticos de área de los objetos & AREA & Clase \\
\hline Densidad de árboles & DA & Clase \\
\hline \multicolumn{3}{|l|}{ Forma } \\
\hline Índice de forma & SHAPE & Clase \\
\hline Dimensión fractal perímetro-área & PAFRAC & Clase \\
\hline Ratio perímetro-área & PARA & Clase \\
\hline Índice fractal & FRAC & Clase \\
\hline Círculo circunscrito & CIRCLE & Clase \\
\hline Índice de contigüidad & CONTIG & Clase \\
\hline \multicolumn{3}{|l|}{ Contraste } \\
\hline Índice de contraste de bordes & ECON & Objeto \\
\hline Índice de contraste total de bordes & TECI & Objeto \\
\hline Contraste ponderado de densidad de bordes & CWED & Objeto \\
\hline \multicolumn{3}{|l|}{ Agregación } \\
\hline Índice de contagio & CONTAG & Objeto \\
\hline Índice de agregación & $\mathrm{AI}$ & Objeto \\
\hline Tamaño efectivo de malla & MESH & Objeto \\
\hline Índice de división & SPLIT & Objeto \\
\hline Distancia euclídea entre elementos vecinos & ENN & Clase \\
\hline Número de elementos & NP & Clase \\
\hline Densidad de elementos & $\mathrm{PD}$ & Clase \\
\hline \multicolumn{3}{|l|}{ Diversidad } \\
\hline Índice de diversidad de Shannon & SHDI & Objeto \\
\hline Índice de uniformidad de Shannon & SHEI & Objeto \\
\hline Índice de diversidad de Simpson & SIDI & Objeto \\
\hline Índice de uniformidad de Simpson & SIEI & Objeto \\
\hline Densidad de riqueza de elementos & PRD & Objeto \\
\hline Riqueza del tipo de elementos & PR & Objeto \\
\hline Densidad riqueza árboles & DRA & Clase \\
\hline Índice de fragmentación & IFFR & Objeto \\
\hline Índice de fragmentación total absoluta & IFFA & Objeto \\
\hline Densidad-diversidad & DD & Objeto \\
\hline
\end{tabular}

Tabla 4.5: Características de fragmentación. 


\subsection{Indicadores de área y perímetro}

Como su nombre indica, este conjunto de características aporta información acerca del área y del perímetro de los objetos, y se han obtenido características tanto a nivel de objeto como a nivel de clase. La característica obtenida a nivel de objeto es la suma total de bordes (TE - total edge), que cuantifica en metros la suma de los perímetros de todos los subobjetos existentes dentro de la parcela. En la expresión de TE (4.22) $e_{i k}$ es la longitud total en metros del perímetro de los subobjetos contenidos en la parcela y $n$ el número de subobjetos.

$$
T E=\sum_{k=1}^{n} e_{i k}
$$

Para el conjunto de características extraídas a nivel de clase se tiene: el área de clases (CA - class area) (4.23), que indica el área que ocupa cada una de las diferentes clases existente en la parcela de estudio; el porcentaje de clases (PLAND - percentage of landscape) (4.24), que indica el porcentaje de área existente de cada clase en la parcela; el indice de mayor objeto (LPI - largest patch index), que cuantifica el porcentaje del área total que ocupa el mayor elemento de cada clase en la parcela; la suma total de bordes (TE - total edge), que al igual que en las características a nivel de objeto, indica el valor total del perímetro de los elementos existentes de cada clase dentro de la parcela; la densidad de bordes (ED - edge density) (4.25) de cada clase contenida en la parcela; y finalmente, los estadísticos de área de los subobjetos (AREA-MN y SD), que son la media y la desviación típica del área de los subobjetos por clase existentes en la parcela.

$$
\begin{gathered}
C A=\sum_{j=1}^{n} a_{i j}\left(\frac{1}{10000}\right) \\
P L A N D=\frac{\sum_{j=1}^{n} a_{i j}}{A}(100) \\
L P I=\frac{\max \left(a_{i j}\right)}{A}(100) \\
E D=\frac{\sum_{k=1}^{n} e_{i k}}{A}(10000)
\end{gathered}
$$

En las expresiones de (4.23), (4.24), (4.25) y (4.26), $a_{i j}$ es el área en metros cuadrados de la cobertura de estudio, $e_{i k}$ es la longitud total en metros del perímetro de los 
subobjetos $(n)$ contenidos en la parcela y $A$ es el área total de la parcela.

Además, también se ha generado un índice a nivel de clase para una única cobertura de estudio. Este índice es la densidad de árboles (DA). Este índice ha sido empleado en otros estudios empleando la cobertura de tipo edificio o urbano como en Colaninno et al. (2011); Romano et al. (2010); Sapena y Ruiz (2015b). La expresión de DA se muestra en la ecuación (4.27) donde $a_{j}$ es el área en metros cuadrados de los subobjetos de cobertura de árboles, $n$ es el número de árboles y $A$ es el área total de la parcela.

$$
D A=\frac{\sum_{j=1}^{n} a_{j}}{A}
$$

\subsection{Indicadores de forma}

Los indicadores de forma calculados proporcionan información de la geometría de los subobjetos contenidos en las parcelas de estudio. Todos los indicadores de forma han sido calculados a nivel de clase para cada una de las coberturas existentes dentro de las parcelas. Las características descriptivas de clase relacionadas con la forma son: la media y la desviación típica de la dimensión fractal perímetro-área (PAFRAC-MN y SD - perimeter-area fractal dimension), que refleja la complejidad de las formas de los subobjetos contenidos en las parcelas independientemente del tamaño de estos; la media y desviación del ratio perímetro-área (PARA-MN y SD - perimeter-area ratio), que es una medida más sencilla de medir la complejidad de las formas, pero presenta el problema que varía según el tamaño de los elementos de la parcela; la media y desviación del índice de forma (SHAPE-MN y SD - shape index), considerando como el indicador de forma más sencillo para medir la complejidad de las formas de los objetos y subobjetos; la media y desviación del índice fractal (FRAC-MN y SD - fractal index), que indica la dimensión fractal de los subobjetos contenidos en la parcela; la media y desviación del círculo circunscrito (CIRCLE-MN y SD - related rircumscribing circle), que aporta información sobre la elongación de los subobjetos de una clase existentes dentro de la parcela (Baker y Cai, 1992); y finalmente, la media y desviación del indice de contigüidad (CONTIGMN y SD - contiguity index), basado en la conectividad espacial o contigüidad de los subobjetos de una clase dentro de la parcela, proporcionando un indicador relacionado con la configuración de los bordes y por lo tanto, de la forma (LaGro, 1991).

En las siguientes expresiones de PAFRAC (4.28), PARA (4.29), SHAPE (4.30), FRAC (4.31) y CIRCLE (4.32), $a_{i j}$ es el área en metros cuadrados de los $n$ subobjetos de estudio, $a_{i^{j}}^{s}$ es el área en metros cuadrados del menor subobjeto en la parcela 
de estudio, $p_{i j}$ es la longitud en metros del perímetro de los subobjetos y $n_{i}$ el número de subobjetos pertenecientes a una misma cobertura.

$$
\begin{aligned}
& P A F R A C=\frac{\frac{2}{\left[n_{i} \sum_{i=1}^{n}\left(\ln p_{i j} \cdot \ln a_{i j}\right)\right]-\left[\left(\sum_{i=1}^{n} \ln p_{i j}\right)\left(\sum_{i=1}^{n} \ln p_{i j}\right)\right]}}{\left(n_{i} \sum_{j=1}^{n} \ln p_{i j}^{2}\right)-\left(n_{i} \sum_{j=1}^{n} \ln p_{i j}\right)^{2}} \\
& P A R A=\frac{p_{i j}}{a_{i j}} \\
& S H A P E=\frac{p_{i j}}{4 \sqrt{a_{i j}}} \\
& F R A C=\frac{2 \ln \left(0,25 p_{i j}\right)}{\ln a_{i j}} \\
& C I R C L E=1-\frac{a_{i j}}{a_{i j}^{s}}
\end{aligned}
$$

En la ecuación de contigüidad CONTIG (4.33), $c_{i j r}$ es el valor de contigüidad del píxel $r$ en el subobjeto $i j, v$ la suma de los valores en una ventana de $3 \times 3$ píxeles y $a_{i j}$ es el área en metros cuadrados de los subobjeto de estudio.

$$
\text { CONTIG }=\frac{\left[\frac{n_{i} \sum_{r=1}^{z}\left(c_{i j r}\right)}{a_{i j}^{*}}\right]-1}{v-1}
$$

\subsection{Indicadores de contraste}

Para el cálculo de los indicadores de contraste, es necesario introducir una matriz de pesos en la que cada peso corresponde a la magnitud del borde o contraste entre las diferentes coberturas de suelo. En este estudio se ha considerado el mismo peso para todos los bordes entre las diferentes coberturas.

Se han calculado varios indicadores basados en el contraste entre bordes que se refieren a la magnitud de la diferencia entre elementos adyacentes de diferentes tipos de coberturas a nivel de parcela. Los primeros indicadores son la media y desviación típica del indice de contraste de bordes (ECON-MN y SD - edge contrast index), que mide el grado de contraste entre bordes de los subobjetos de la parcela y sus vecinos inmediatos. ECON es un índice relativo, por lo que dado un borde o una densidad de bordes, mide 
el contraste con respecto de ese borde o esa densidad. Valores altos de ECON, independientemente del tamaño de los subobjetos, indican un contraste elevado. Por esto mismo, existe otro índice en el que interviene tanto el total de bordes de la parcela como su densidad, y ese es el indice del contraste total de bodes (TECI - total edge contrast index), que cuantifica el valor ECON como un porcentaje. El valor de TECI es cero cuando los únicos bordes que se encuentran en la parcela son los propios límites de esta. Su valor aumenta en cuanto aumenta el número de bordes de los subobjetos o el contraste entre ellos. Como última característica de contraste, se calcula el contraste ponderado de densidad de bordes (CWED - contrast-weighted edge density), que normaliza los bordes por unidad de área para facilitar la comparación entre parcelas de diferentes tamaños. $\mathrm{Su}$ valor se comporta de la misma manera que el indicador TECI, con la diferencia de que los valores pueden superar el valor de 100 al ser TECI expresado en un porcentaje.

En la ecuación de ECON (4.34), $p_{i j k}$ es la longitud del borde del subobjeto $i j$ adyacente al subobjeto de cobertura $k, d_{i k}$ los pesos introducidos como contraste entre bordes entre las coberturas $i$ y $k, p_{i j}$ es la longitud del perímetro del subobjeto $i j$ y $n$ el número de subobjetos.

$$
E C O N=\frac{\sum_{k=1}^{n}\left(p_{i j r} \cdot d_{i k}\right)}{p_{i j}}(100)
$$

En la ecuación de TECI (4.35), $e_{i k}$ es la longitud total del borde en metros entre subobjetos de coberturas $i$ y $k, e_{i k}^{*}$ es la longitud total en metros entre subobjetos y coberturas $i$ y $k$ incluyendo los bordes de la parcela de estudio, $d_{i k}$ los pesos introducidos como contraste entre bordes entre las coberturas $i$ y $k$ y $n$ y $q$ el número de subobjetos de cada cobertura.

$$
T E C I=\frac{\sum_{k=1}^{n}\left(e_{i k} \cdot d_{i k}\right)}{\sum_{k=1}^{q}\left(e_{i k}\right)}(100)
$$

En la expresión de CWED (4.36), $e_{i k}$ es la longitud total del borde en metros entre subobjetos de coberturas $i$ y $k, d_{i k}$ los pesos introducidos como contraste entre bordes entre las coberturas $i$ y $k, A$ es el área total de la parcela y $n$ el número de subobjetos.

$$
C W E D=\frac{\sum_{k=1}^{n}\left(e_{i k} \cdot d_{i k}\right)}{A}(10000)
$$




\subsection{Indicadores de agregación}

Estos indicadores hacen referencia a la tendencia que siguen los tipos de elementos a ser agregados espacialmente o "textura", en la que se pueden diferenciar varios conceptos como dispersión, dispersión entre tipologías, subdivisión y aislamiento. El concepto de dispersión se refiere a la distribución espacial de los elementos dentro de la parcela sin distinción entre las clases que intervienen en esta distribución, mientras que la dispersión entre tipologías se refiere a la distribución y "mezcla" espacial de cada uno de los elementos existentes dentro de la parcela teniendo en cuenta su clase o cobertura. La dispersión entre tipologías indica únicamente el patrón con el que se repite la adyacencia entre coberturas sin tener en cuenta el tamaño, contigüidad o dispersión de los elementos. La subdivisión está relacionada con la dispersión, pero esta indica el número diferente de subobjetos que existen en la parcela. De la misma forma, el aislamiento está relacionado con la subdivisión, pero este indica el grado de separación de los subobjetos de la parcela.

Un indicador relacionado tanto con la dispersión como con la dispersión entre tipologías, es el Índice de contagio (CONTAG - contagion index), basado en la probabilidad de encontrar un elemento de una cobertura al lado de otro con otra cobertura diferente (O’Neill et al., 1988). Este ha sido ampliamente utilizado en trabajos medioambientales ya que parece que resume correctamente el agrupamiento general sobre mapas categóricos. El índice CONTAG se extrae a nivel de parcela y se muestra en la expresión (4.37), en donde $P_{i}$ es la proporción de la parcela ocupada por una cobertura $i, g_{i k}$ el número de adyacencias entre píxeles de las cobertura $i$ y $k$, y $n$ el número de coberturas existentes en la parcela.

$$
\operatorname{CONTAG}=\left[1+\frac{\sum_{i=1}^{n} \sum_{k=1}^{n}\left[P_{i} \cdot \frac{g_{i k}}{\sum_{k=1}^{n} g_{i k}}\right] \cdot\left[\ln \left(P_{i} \cdot \frac{g_{i k}}{\sum_{k=1}^{n} g_{i k}}\right)\right]}{2 \ln (n)}\right](100)
$$

Otra característica relacionada con la dispersión obtenida a nivel de objeto es el índice de agregación (AI - aggregation index), calculado como un porcentaje basado en el ratio del número total de adyacencias entre el número máximo de adyacencias posibles (He et al., 2000). El valor es 0 cuando no existen adyacencias entre coberturas en la parcela (cuando la cobertura está completamente disgregada), y 100 cuando la cobertura está completamente agregada. La expresión de AI se muestra en la ecuación (4.38), donde $g_{i i}$ 
es el número de adyacencias entre píxeles de una misma cobertura $i$ y $n$ el número de coberturas.

$$
A I=\left[\sum_{i=1}^{n}\left(\frac{g_{i i}}{\max \left(g_{i i}\right)}\right) P_{i}\right](100)
$$

El tamaño efectivo de malla (MESH - effective mesh size), que se basa en la distribución del área acumulada de una cobertura, se interpreta como el tamaño de los elementos de una cobertura cuando la parcela se divide en $S$ partes, siendo $S$ el valor del índice de división (SPLIT - splitting index). El índice de división se calcula a partir del área total de la parcela al cuadrado dividido entre el sumatorio de las áreas al cuadrado de los diferentes elementos de cada una de las clases que existen dentro de la parcela. Las características MESH y SPLIT se obtienen a nivel objeto. En las expresiones de MESH (4.39) y SPLIT (4.40), $a_{j}$ es el área en metros cuadrados de los subobjetos de estudio, $A$ el área total de la parcela de estudio en metros cuadrados y $n$ el número de subobjetos.

$$
\begin{aligned}
& \text { MESH }=\frac{\sum_{j=1}^{n} a_{j}^{2}}{A} \\
& \text { SPLIT }=\frac{A^{2}}{\sum_{j=1}^{n} a_{j}^{2}}
\end{aligned}
$$

La distancia euclídea entre elementos vecinos (ENN - euclidean nearest neighbor distance) es la forma más simple de medir el aislamiento entre los subobjetos de la parcela, y se calcula obteniendo la distancia euclídea entre subobjetos o elementos desde los puntos más cercanos entre ellos. Esta característica se obtiene únicamente a nivel de clase, y su expresión se muestra en (4.41), donde $h_{i j}$ es la distancia en metros desde un subobjeto $i$ de la cobertura hasta el subobjeto vecino más cercano $j$ de la misma cobertura.

$$
E N N=h_{i j}
$$

Se han obtenido indicadores relacionados con la cantidad de subobjetos que existen dentro de la parcela. Estos son el número de elementos (NP - number of patches) y densidad de elementos (PD - patch density), ambos calculados a nivel de clase indicando el número de subobjetos y densidad de cada una de las coberturas de estudio. En las expresiones de NP (4.42) y PD (4.43), $n_{i}$ indica el número de subobjetos pertenecientes 
a la cobertura $i$ y $A$ el área total de la parcela de estudio en metros cuadrados.

$$
\begin{gathered}
N P=n_{i} \\
P D=\frac{n_{i}}{A}(10000)(100)
\end{gathered}
$$

\subsubsection{5 Índices de diversidad}

Los índices de diversidad están relacionados con la riqueza y uniformidad de las diferentes coberturas que existen, en este caso, dentro de la parcela. La riqueza se refiere al número de coberturas que hay, mientras que la uniformidad se refiere a la distribución del área entre las diferentes coberturas. Este tipo de variables sólo se calcula a nivel de parcela salvo excepción.

Algunos de los índices que se presentan a continuación son más sensibles o bien a la riqueza o bien a la uniformidad, como por ejemplo el índice de diversidad de Shannon (SHDI - Shannon's diversity index), que es más sensible a la riqueza, mientras que en el indice de diversidad de Simpson (SIDI - Simpson's diversity index) tiene más peso la diversidad. En las expresiones SIDI (4.44) y SHDI (4.45), $P_{i}$ es la proporción de la parcela ocupada por una cobertura $i$, siendo $n$ el número de coberturas existentes en la parcela.

$$
\begin{gathered}
S I D I=1-\sum_{i=1}^{n} P_{i}^{2} \\
S H D I=-\sum_{i=1}^{n}\left(P_{i} \cdot \ln \left(P_{i}\right)\right)
\end{gathered}
$$

El índice de diversidad de Shannon SHDI es el índice de diversidad más extendido y su valor representa la cantidad de "información" por cobertura en este caso. La magnitud absoluta de este índice realmente no es significativa, por lo que se suele emplear de forma relativa para comparar dos áreas diferentes o el mismo elemento en épocas diferentes, y por tanto puede ser muy útil a la hora de detectar cambios. Por el contrario, el índice de Simpson SIDI es menos sensible a la presencia de diferentes clases y es más intuitivo. $\mathrm{Su}$ valor representa la probabilidad de que dos objetos cualesquiera seleccionados aleatoriamente sean de diferente clase, por lo que a mayor valor, mayor probabilidad de que 
dos elementos aleatoriamente seleccionados pertenezcan a clases diferentes. Siendo este una probabilidad, puede interpretarse tanto de forma absoluta como relativa. Para este índice existe una modificación, el índice de diversidad de Simpson modificado (MSIDI - modified Simpson's diversity index), que elimina la interpretación intuitiva del índice de Simpson (SIDI) como una probabilidad y transforma el índice SIDI en un índice del mismo tipo que el índice de Shannon (SHDI).

La regularidad mide el otro aspecto relacionado con la diversidad existente en la parcela, siendo esta la distribución del área entre las diferentes clases. El índice de uniformidad de Shannon (SHEI - Shannon's evenness index) y el indice de uniformidad de Simpson (SIEI - Simpson's evenness index) aíslan el efecto de uniformidad de la influencia de la riqueza de los índices previamente mencionados (McGarigal et al., 2014). Esta uniformidad se expresa como el nivel observado de diversidad dividido entre la diversidad máxima posible para la riqueza de una clase dada. El mayor nivel de diversidad se alcanza para cualquier nivel de riqueza cuando existe la misma distribución de áreas entre las diferentes coberturas. En los índices SHEI (4.46) y SIEI (4.47), $P_{i}$ es la proporción de la parcela ocupada por una cobertura $i$ y $n$ el número de coberturas existentes en la parcela.

$$
\begin{gathered}
S H E I=\frac{-\sum_{i=1}^{n}\left(P_{i} \cdot \ln \left(P_{i}\right)\right)}{\ln (n)} \\
S I E I=\frac{1-\sum_{i=1}^{n} P_{i}^{2}}{1-\left(\frac{1}{n}\right)}
\end{gathered}
$$

La riqueza de tipo de elementos (PR - patch richness) obtiene el número de coberturas que hay dentro de la parcela y no se ve afectada por la abundancia relativa de cada cobertura o de su distribución espacial. La versión estandarizada de este indicador es la densidad de riqueza de tipo de elementos (PRD - patch richness density), que facilita su interpretación a la hora de comparar diferentes parcelas. La estandarización se realiza por unidad de área. Exclusivamente para la cobertura de árbol, se ha calculado la densidad de riqueza de árboles (DRA) que relaciona el número de árboles dentro de una parcela con la superficie de dicha parcela. Este es el único índice de diversidad que ha sido aplicado a nivel de clase. En las expresiones de PRD (4.48) y DRA (4.49), $m$ es el número de coberturas existentes en la parcela, $A$ el área total de la parcela de estudio y $n_{i}$ el número de subobjetos pertenecientes a la cobertura de árboles $i$ existentes dentro 
de la parcela de estudio.

$$
\begin{gathered}
P R D=\frac{n_{i}}{A}(10000)(100) \\
D R A=\frac{n_{i}}{A}
\end{gathered}
$$

El indice de fragmentación funcional relativa (IFFR) obtiene el nivel de fragmentación dentro del perímetro de la parcela de estudio en relación con las áreas funcionales o coberturas. El índice de fragmentación funcional absoluta (IFFA) calcula el nivel de integración funcional (subobjetos en función a la cobertura a la que pertenezcan) y estructural (parcela) del perímetro (Marinescu y Avram, 2012; Sapena y Ruiz, 2015b).

Las expresiones de IFFR (4.50) e IFFA (4.51) se encuentran a continuación, donde $n_{j}$ es el número total de coberturas dentro de la parcela de estudio, $p_{i}$ el perímetro de los subobjetos de la cobertura $i$ y $P$ el perímetro total de la parcela.

$$
\begin{aligned}
& I F F R=\frac{4-n_{j}}{4-1} \\
& I F F A=\frac{P}{\sum_{i=1}^{m} p_{i}}
\end{aligned}
$$

La diversidad depende en cierta medida del tamaño de la unidad en la que se mide sin considerar la densidad, por lo que para eliminar el efecto de la escala, se realiza una normalización añadiendo el dato del volumen (Escolano, 2009). Este índice se conoce como densidad-diversidad DD (4.52), donde $k$ es el número de coberturas y $a_{i k}$ el área de los subobjetos de la cobertura $k$ en la parcela de estudio $i$.

$$
D D=\sum_{k} \frac{a_{i k}}{\max \left(a_{i k}\right)}
$$




\subsubsection{Métodos de evaluación de las clasificaciones y detección de cambios}

\subsubsection{Evaluación de clasificaciones a nivel de píxel}

La evaluación de los resultados de las clasificaciones se realiza mediante una matriz de confusión. En esta matriz, se comparan los resultados de la clasificación con las clases reales de las parcelas de estudio. La fiabilidad global de la clasificación se calcula mediante el valor de la suma de los píxeles correctamente clasificados dividido entre el número total de píxeles clasificados. A partir de esta matriz de confusión, también se calculan las fiabilidades de usuario y productor para cada una de las clases de estudio. Estas fiabilidades miden los errores por exceso y por defecto respectivamente (Congalton, 1991). La fiabilidad del productor indica la probabilidad de que un píxel perteneciente a una clase haya sido clasificado correctamente mediante la relación de los píxeles correctamente asignados a una clase y los píxeles totales existentes de esa clase. La fiabilidad del usuario indica la probabilidad de que un píxel clasificado en la imagen corresponda a esa clase en la realidad, relacionando los píxeles correctamente asignados a una clase con los píxeles totales clasificados como esa clase.

\subsubsection{Evaluación de clasificaciones a nivel de objeto}

Para la evaluación de las diferentes clasificaciones a nivel de objeto se ha empleado el método de validación cruzada. En este método todas las parcelas de estudio se introducen en el clasificador y se dividen aleatoriamente en $k$ subconjuntos iguales, también denominados folds. Cada subconjunto contiene el mismo número de parcelas, pero el número de las diferentes clases que contiene puede ser variable. Luego, las parcelas contenidas en $k-1$ subconjuntos se emplean como muestras de entrenamiento para la generación de las reglas de clasificación. Las parcelas del último subconjunto o fold que queda fuera se emplean como muestras de evaluación mediante el cual se obtienen los errores de la clasificación. Esta operación se repite $k$ veces dejando fuera un subconjunto diferente cada vez. Finalmente, se calcula la media de los errores del clasificador a lo largo de todas las iteraciones. La ventaja de este método es que permite emplear todo el conjunto de parcelas en las que se conoce la clase a la que pertenecen, maximizando la eficiencia en el número de muestras disponible.

Del mismo modo que en la evaluación de la clasificación a nivel de píxel, para la clasificación a nivel de objeto se calcula la matriz de confusión, en la que se comparan 
las clases asignadas a los objetos en la clasificación con las clases reales de los objetos y se obtienen las diferentes fiabilidades: fiabilidad global, fiabilidad de productor y fiabilidad de usuario.

\subsubsection{Evaluación de la detección de cambios}

Para la evaluación de la detección de cambios también se emplea una matriz de confusión (Tabla 4.6), donde los resultados de la clasificación son comparados con las clases reales de las parcelas de estudio (Congalton, 1991). La fiabilidad global de la detección de cambios se obtiene mediante la suma de los cambios (VP - verdaderos positivos) y los no cambios (VN - verdaderos negativos) correctamente detectados. Además, permite calcular los siguientes indicadores: errores detectables o falsos positivos (FP) -parcelas de no cambio clasificadas como cambios-; y errores indetectables o falsos negativos (FN) -parcelas de cambio clasificadas como no cambio. En general, en los procesos de actualización de bases de datos las parcelas detectadas como cambios se revisan manualmente, por lo que los FP son detectados durante esta revisión. Las parcelas clasificadas como no cambio no son revisadas, por lo que los FN no son detectados.

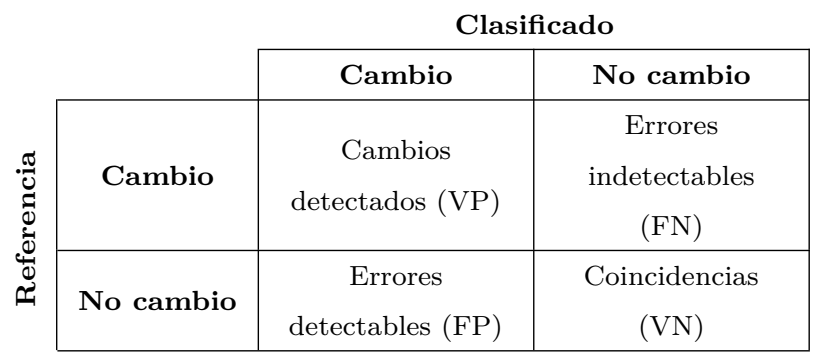

Tabla 4.6: Matriz de confusión de detección de cambios.

A partir de la matriz de confusión de cambios (Tabla 4.6) se calculan otros dos indicadores: el porcentaje de detección, que expresa el porcentaje de parcelas de cambio correctamente detectadas; y el porcentaje de calidad (4.22), que aporta información sobre la calidad absoluta de la detección y localización de cambios. El porcentaje de calidad es un indicador muy estricto ya que para obtener un $100 \%$ de calidad se deben detectar todos los cambios sin incluir ningún elemento que no sea cambio (ningún falso positivo) (Jin y Davis, 2005). Las fórmulas del porcentaje de detección y el porcentaje de calidad se muestran en las expresiones (4.21) y (4.22) respectivamente. 


$$
\begin{gathered}
P D=100 \cdot V P /(V P+F N) \\
P C=100 \cdot V P /(V P+F P+F N)
\end{gathered}
$$

\subsubsection{Evaluación de parámetros de poda mediante curvas ROC}

Las gráficas de curvas ROC (Receiver Operating Characteristics graph) es una técnica de visualización, organización y selección de clasificadores basada en el rendimiento de estos (Bradley, 1997; Fawcett, 2006; Marrocco et al., 2008; Metz, 1979; Provost y Fawcett, 2001). Los gráficos ROC son gráficos bidimensionales en los cuales las tasas de verdaderos positivos (VP) se dibujan en el eje Y de la gráfica y la tasa de falsos positivos (FP) se dibujan en el eje X, de esta forma, se representan las ventajas y desventajas relativas entre costes (falsos positivos) y beneficios (verdaderos positivos). Esto permite a la curva ROC medir la habilidad del clasificador para obtener resultados positivos, comparando el ratio de VP con el ratio de FP.

Una de las ventajas de las curvas ROC es que no dependen del número de muestras por clase. En muchos casos reales siempre hay un mayor número de casos negativos (parcelas de no cambio en este caso) que de casos positivos, especialmente en estudios de detección de cambios. Es por esto que las curvas ROC pueden ayudar en la selección de parámetros de clasificación (o del propio clasificador) sin tener en consideración la tasas de detección de cambios en una base de datos o en una zona de estudio concreta. El área cubierta bajo la función de la curva ROC o AUC (area under ROC curve) es el indicador que se ha analizado para la selección de los parámetros. La principal función del AUC es seleccionar el clasificador óptimo y los parámetros de clasificación en cuanto a parámetros de poda se refiere. Cuanto mayor es el valor de AUC, mejor es el rendimiento del clasificador. Las curvas ROC calculadas en este estudio se obtuvieron mediante WEKA (Witten et al., 2011). 


\subsection{Descripción de los ensayos realizados}

\subsubsection{Clases de usos de suelo y clases de cambio empleadas en los métodos de clasificación y detección de cambios}

\subsubsection{Descripción de las clases de usos del suelo y las clases de cambio para la zona de Valencia}

Las diferentes clases relativas a los usos del suelo definidas en la zona de estudio de Valencia se pueden ver en la Figura 4.7. Estas clases son: terreno arable (4.7a); terreno cultivado (4.7b); cultivo arbóreo (4.7c); terreno yermo (4.7d), edificio industrial (4.7e); edificio de tipo urbano (4.7f); y edificio de tipo rural (4.7g). Algunas de estas clases son generalizaciones o agrupaciones de las clases del SIOSE. Esta generalización fue considerada para mejorar el método de detección de cambios debido a la poca representatividad de algunos de los cambios en la zona de estudio.

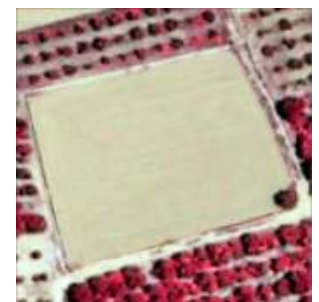

(a) Terreno arable

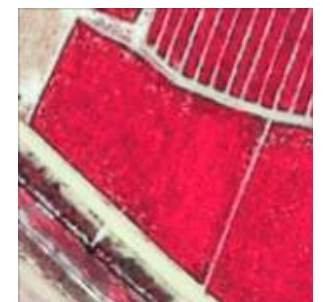

(b) Terreno cultivado

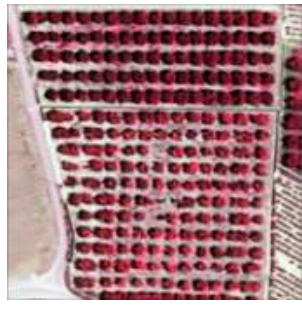

(c) Cultivo arbóreo

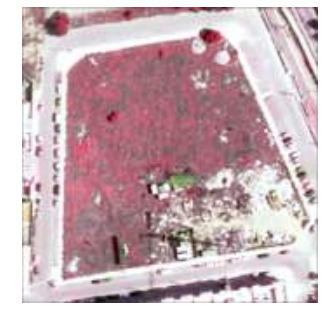

(d) Terreno yermo

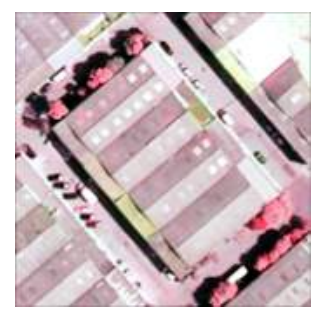

(e) Edificio industrial

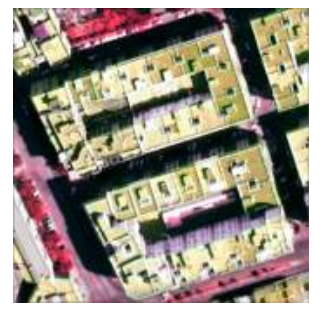

(f) Edificio urbano

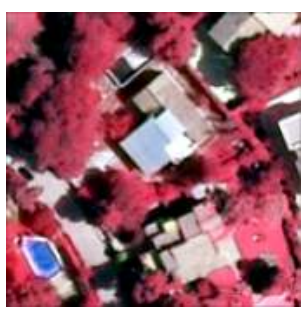

(g) Edificio rural

Figura 4.7: Clases de usos de suelo existentes en la zona de Valencia. (Detalles sobre imágenes PNOA 2008 - composición falso color infrarrojo).

Las clases de terreno arable, terreno cultivado y cultivo arbóreo están enmarcadas dentro del tipo de coberturas simples del SIOSE. El terreno arable forma parte de los terrenos cultivados de tipo barbecho o en transición entre cultivos, sin ningún tipo de cobertura vegetal sobre ellos. La clase de terreno cultivado se corresponde con los cultivos herbáceos, con cultivos principalmente de hortalizas, tubérculos para consumo humano 
y forrajeros. El cultivo arbóreo se corresponde con la clase de cultivos leñosos, predominando en la zona de Valencia la clase de frutales de tipo cítrico. La clase de terreno yermo se emplea en aquellos casos de terrenos agrícolas de abandono definitivo y/o expropiados para la construcción de infraestructuras urbanas y para suelos no edificados como solares o parcelas sin edificar. La clase de edificio urbano es una generalización de las clases urbanas de casco, con edificios aislados e históricos, situados dentro de áreas urbanas. La clase de edificio rural se corresponde con la generalización de viviendas unifamiliares adosadas y aisladas y la clase de huerta familiar, muy típicas en las zonas rurales de Valencia. El principal tipo de construcción son los edificios de tipo chalet unifamiliar, con jardín o zona dedicada al cultivo para el autoconsumo. El edificio industrial es una cobertura genérica con superficies artificiales en las que existen instalaciones destinadas a la obtención, elaboración, transformación, reparación, almacenamiento y distribución de productos.

Se ha definido otro conjunto de clases que muestran tipos de cambio. Este grupo se emplea en métodos de cambio por clasificación directa, en los que es necesario introducir al algoritmo clasificador clases de cambio. El conjunto de tipos de cambio está representado en la Figura 4.8 con ejemplos que reflejan el cambio entre diferentes usos de suelo en dos fechas de estudio diferentes. 


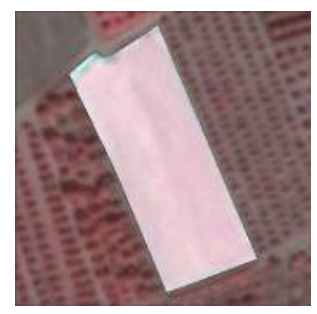

(a) Clase arable en 2004

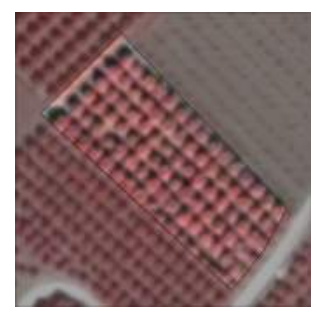

(e) Clase árboles en 2004

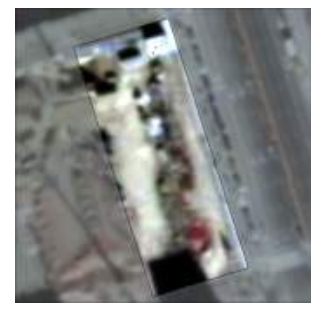

(i) Clase yermo en 2004

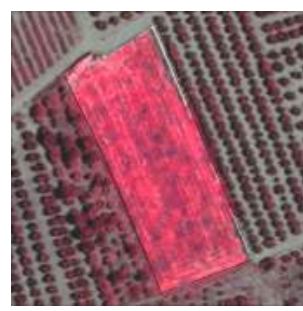

(b) Clase cultivado en 2008

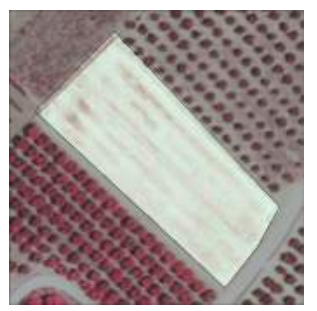

(f) Clase arable en 2008

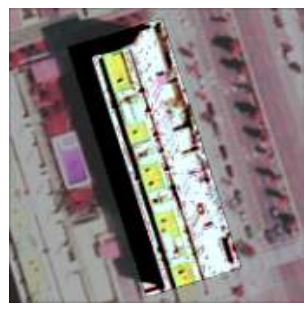

(j) Clase ed. urbano en 2008

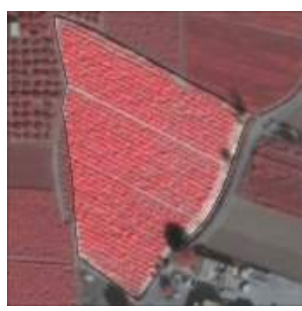

(c) Clase cultivado en 2004

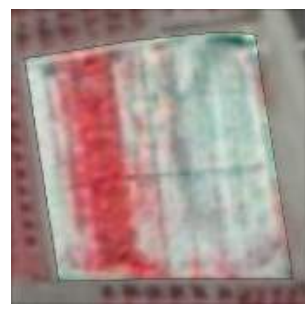

(g) Clase arable en 2004

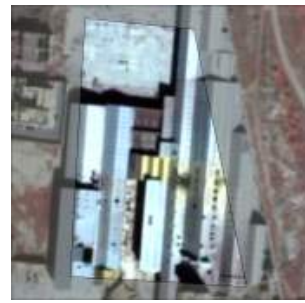

(k) Clase ed. industrial en 2004

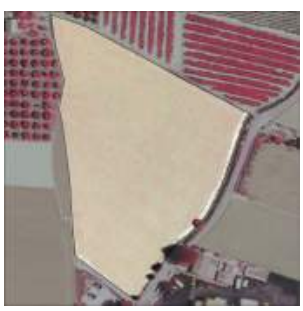

(d) Clase arable en 2008

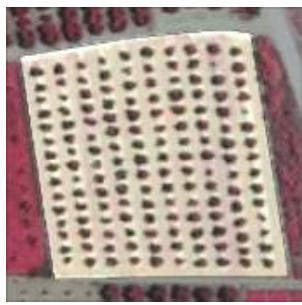

(h) Clase árboles en 2008

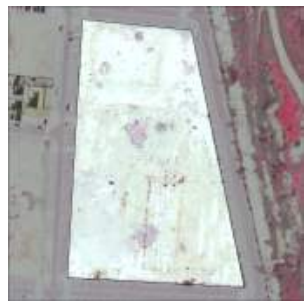

(1) Clase yermo en 2008

Figura 4.8: Ejemplos de parcelas con clases de cambio: cultivo 1 (CC1) con suelo arable en 2004 (a), y suelo cultivado en 2008 (b); cultivo 2 (CC2) con suelo cultivado en 2004 (c), y suelo arable en 2008 (d); arranques (ARR) con árboles en 2004 (e), y suelo arable en 2008 (f); nuevas plantaciones (NPL) con suelo arable en 2004 (g), y árboles en 2008 (h); nuevos edificios (NED) con suelo yermo en 2004

(i), y edificio urbano en 2008 (j); demoliciones (DEM) con edificio industrial en 2004 (k), y suelo yermo en 2008 (l). 
Los tipos de cambio que se observan en la Figura 4.8 son: cambios en cultivos, en los que el uso de suelo cambia de terreno arable a terreno cultivado (CC1) y viceversa (CC2); arranques (ARR), con cambio de cultivos arbóreos a terreno arable o terreno cultivado; nuevas plantaciones (NPL), con cambio de terreno arable o terreno cultivado a cultivo arbóreo; nuevos edificios (NED), con cambio de uso de suelo en el que no existen edificios a uso de suelo con edificio (ya sea edificio urbano, rural o industrial); y demoliciones (DEM), con cambio de edificio urbano o industrial a terreno yermo. La Figura 4.9 muestra un esquema de las diferentes combinaciones entre usos y clases que han sido empleadas en este trabajo para definir los tipos de cambios. Se han considerado únicamente estas opciones no por la imposibilidad de transición entre los diferentes usos o coberturas, sino porque no se observaron otros tipos de cambio en la zona de estudio de Valencia.
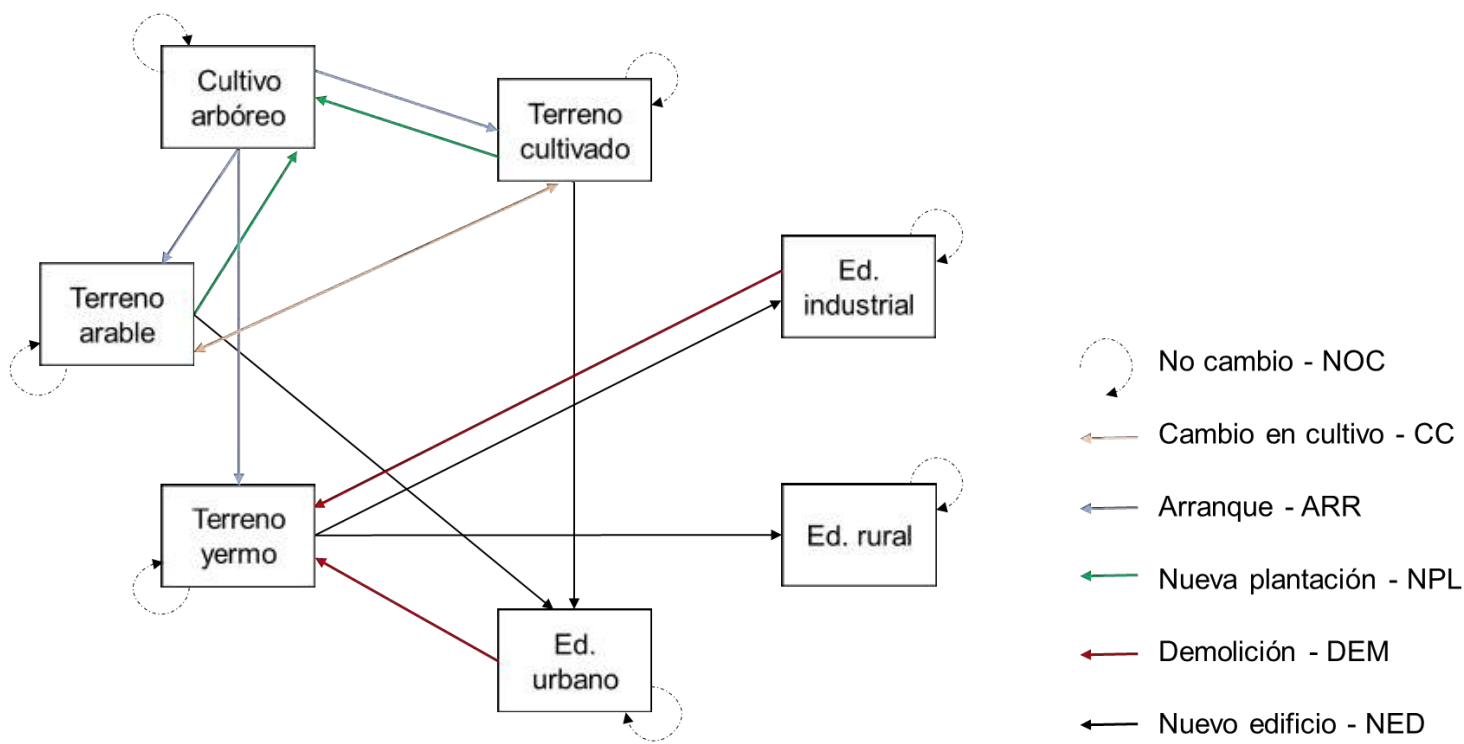

Figura 4.9: Diagrama de cambios entre usos del suelo existentes en la zona de estudio de Valencia.

Los usos del suelo han sido asignados a cada una de las parcelas de estudio (tanto de entrenamiento como de evaluación) mediante interpretación visual en las dos fechas de estudio. Existen varias alternativas para la selección de muestras de entrenamiento, como la selección de muestras con áreas proporcionales para cada una de las clases, o la selección de muestras proporcional a las clases de estudio. En estudios previos, Colditz (2015) recomienda una selección de muestras de entrenamiento con proporciones de área similares para cada una de las clases para la clasificación por árboles de decisión. Jin et al. (2014) recomiendan la distribución proporcional de las muestras con el propósito de aumentar la fiabilidad global y reducir los errores de clasificación en áreas urbanas. 
En ambos casos se considera que el método de selección de muestras de entrenamiento depende del tipo de estudio a realizar. En nuestro caso, se han seguido dos criterios: la representatividad en el número de parcelas por clase, y homogeneidad en la distribución espacial de las parcelas (Chatfield, 1991). De esta forma se ha evitado la toma de información sesgada en la selección de parcelas para cada una de las clases. En la Tabla 4.7 se recoge el número total de parcelas de estudio para las clases de usos de 2004 y 2008. En la Tabla 4.8 se recoge el número de parcelas de estudio para las clases de cambio. La tasa de cambio de la zona de estudio es del $23 \%$.

\begin{tabular}{|c|c|}
\hline \multicolumn{2}{|c|}{ Clase de usos de suelo 2004 } \\
\hline Clase & Número de parcelas \\
\hline Arable & 263 \\
\hline Cultivado & 214 \\
\hline Árboles & 311 \\
\hline Yermo & 187 \\
\hline Ed. Industrial & 129 \\
\hline Ed. Rural & 133 \\
\hline Ed. Urbano & 735 \\
\hline Total & $\mathbf{1 9 7 2}$ \\
\hline
\end{tabular}

\begin{tabular}{|c|c|}
\hline \multicolumn{2}{|c|}{ Clase de usos de suelo 2008} \\
\hline Clase & Número de parcelas \\
\hline Arable & 268 \\
\hline Cultivado & 200 \\
\hline Árboles & 255 \\
\hline Yermo & 165 \\
\hline Ed. Industrial & 122 \\
\hline Ed. Rural & 133 \\
\hline Ed. Urbano & 829 \\
\hline Total & $\mathbf{1 9 7 2}$ \\
\hline
\end{tabular}

Tabla 4.7: Número de parcelas de cada clase de usos de suelo en 2004 y 2008.

\begin{tabular}{|c|c|}
\hline \multicolumn{2}{|c|}{ Clases de cambio } \\
\hline \hline Clase & Número de parcelas \\
\hline No cambio & 1506 \\
\hline Cambio en cultivo 1 - CC1 & 96 \\
\hline Cambio en cultivo 2 - CC2 & 95 \\
\hline Arranques - ARR & 101 \\
\hline Nuevas plantaciones - NPL & 50 \\
\hline Nuevos edificios - NED & 108 \\
\hline Demoliciones - DEM & 16 \\
\hline Total & $\mathbf{1 9 7 2}$ \\
\hline
\end{tabular}

Tabla 4.8: Número de parcelas de cada clase de cambio. 


\subsubsection{Descripción de las clases de usos del suelo y las clases de cambio para la zona de Murcia}

Para la zona de Murcia, el estudio se ha centrado en usos de suelo agrícola arable (Figuras 4.10d, 4.10e) y plantaciones de cultivos leñosos o árboles (Figuras 4.10a, 4.10b, 4.10c y 4.10f) con los que se ha definido únicamente tres tipos de clases de cambio: parcelas de no cambio (Figuras 4.10a y 4.10b); arranques (Figuras 4.10c y 4.10d); y nuevas plantaciones (Figuras 4.10e y 4.10f). Las parcelas de no cambio son aquellas parcelas que presentan un mismo uso de suelo en las dos épocas de estudio. Las parcelas de arranques se corresponden a un uso del suelo de tipo cultivo leñoso o árboles en la primera época y uso de tipo arable en la segunda época. Por el contrario, las parcelas de nuevas plantaciones presentan en la primera época el uso del suelo arable, y cultivo leñoso en la segunda época.

Del mismo modo que para la zona de Valencia, los usos del suelo y las clases de cambio han sido asignados a las parcelas mediante interpretación visual, y se han seguido los mismos criterios de representatividad y homogeneidad para la selección de las parcelas de estudio. El número de parcelas empleado en este estudio se muestra en la Tabla 4.9 , siendo NOC parcelas de no cambio, ARR parcelas de arranques y NPL parcelas de nuevas plantaciones. La tasa de cambio de la zona de estudio es del $18 \%$.

\begin{tabular}{|c|c|}
\hline Nombre & Número \\
\hline \hline No cambio - NOC & 1193 \\
\hline Arranques - ARR & 151 \\
\hline Nuevas plantaciones - NPL & 115 \\
\hline Total & 1459 \\
\hline
\end{tabular}

Tabla 4.9: Número de parcelas correspondientes a cada clase de estudio. 


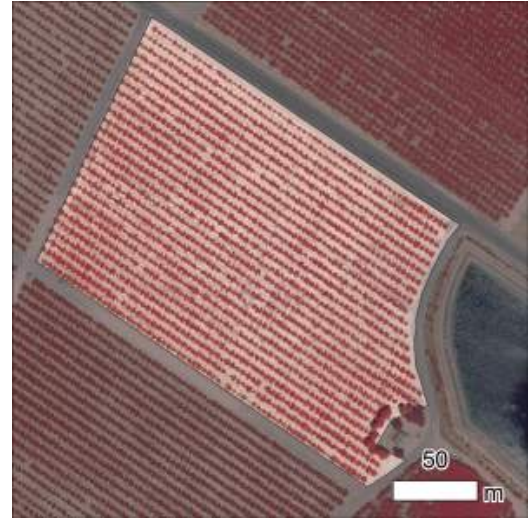

(a) Uso de suelo árboles en 2007

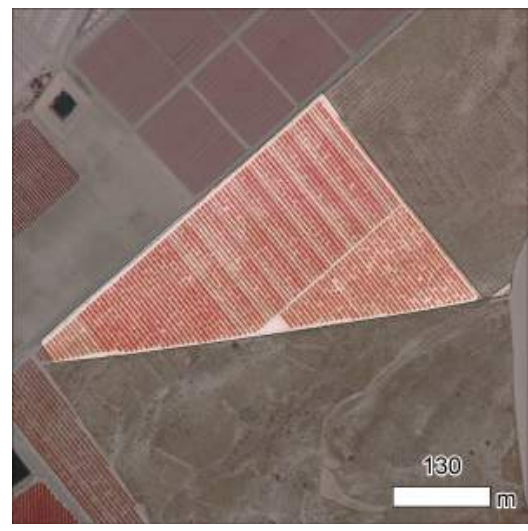

(c) Uso de suelo árboles en 2007

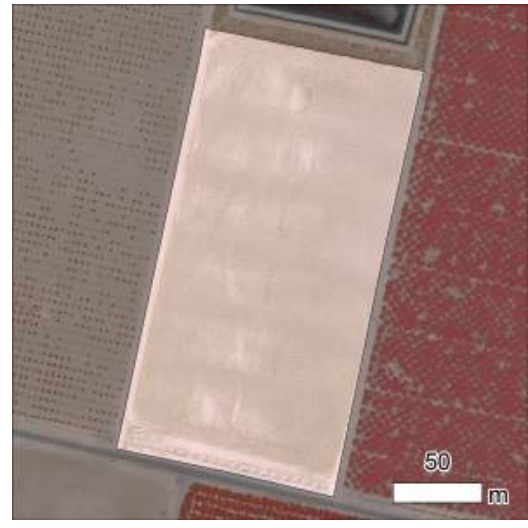

(e) Uso de suelo arable en 2007

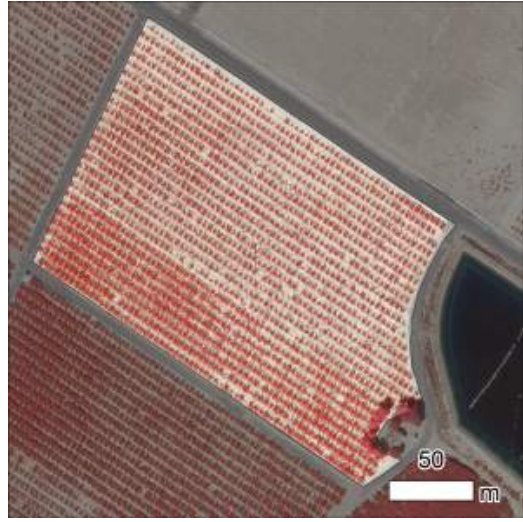

(b) Uso de suelo árboles en 2009

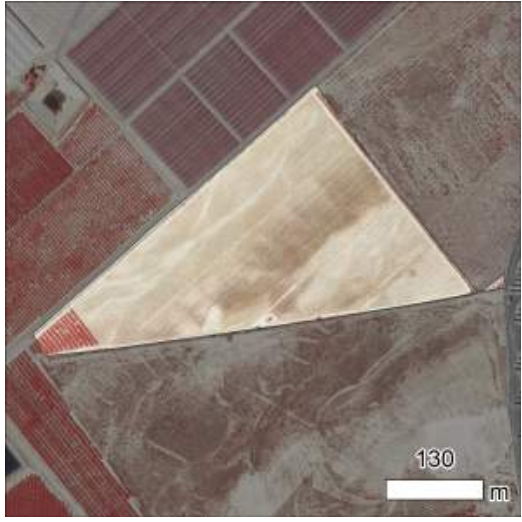

(d) Uso de suelo arable en 2009

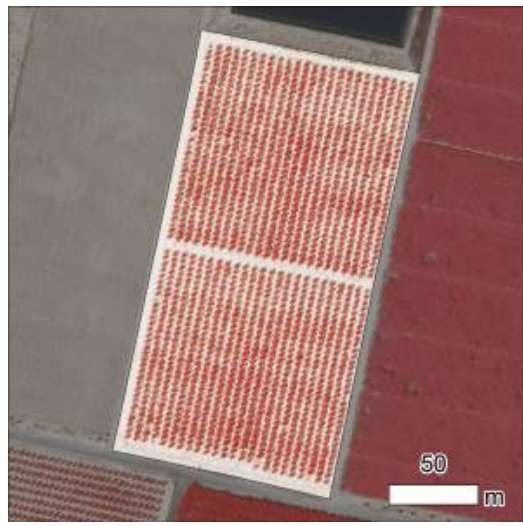

(f) Uso de suelo árboles en 2009

Figura 4.10: Ejemplos de parcelas con clase de: no cambio (NOC) con uso de suelo de árboles en 2007 (a); y en 2009 (b); arranques (ARR) con uso de suelo de árboles en 2007 (c); y suelo arable en 2009 (d); nuevas plantaciones (NPL) con uso de suelo arable en 2007 (e); y uso de suelo árboles en 2009 (f). 


\subsubsection{Ensayo I. Análisis y estudios de clasificación empleando las características extraídas de datos LiDAR}

La zona de estudio sobre la que se ha realizado el análisis de características tridimensionales extraídas de datos LiDAR es la zona de Valencia. En este estudio se extraen las características tridimensionales a partir de los modelos digitales derivados de los datos LiDAR (en concreto del modelo digital de superficies normalizado) (Capítulo 3.3.1). Con el fin de poder analizar más a fondo este conjunto de características, se han planteado dos ensayos utilizando dos métodos diferentes de detección de cambios: el método de post-clasificación (Ensayo I-A) y el método de clasificación multitemporal directa (Ensayo I-B). Las Figuras 4.11 y 4.12 muestran los esquemas de los ensayos I-A y I-B. Dependiendo del método utilizado para la detección de cambios se han extraído las características de forma diferente y se han utilizado clases de estudio diferentes. Este ensayo se plantea con el propósito de analizar la importancia de las características tridimensionales para la detección de cambios relacionados con usos y coberturas que presentan una componente de altura. En la Tabla 4.10 se puede ver un resumen de los dos ensayos realizados empleando características tridimensionales extraídas de datos LiDAR.

\begin{tabular}{|c|c|c|}
\cline { 2 - 3 } \multicolumn{1}{c|}{} & Ensayo I-A & \multicolumn{2}{c|}{ Ensayo I-B } \\
\hline \hline Zona de estudio & Valencia & Valencia \\
\hline \hline Metodología & \multicolumn{2}{|c|}{} \\
\hline Características empleadas & Espectrales, textura, forma y tridimensionales & Espectrales, textura, forma y tridimensionales \\
\hline Clases de estudio & Clases de usos del suelo & Clases de cambio \\
\hline Algoritmos empleados & Árboles de decisión J48 & Árboles de decisión J48 \\
\hline Métodos de detección de cambios & Post-clasificación & Clasificación directa \\
\hline Métodos de evaluación & Matrices de confusión & Matrices de confusión \\
\hline
\end{tabular}

Tabla 4.10: Descripción de los ensayos realizados utilizando características tridimensionales.

Los objetivos de estos ensayos son:

- Analizar el comportamiento de las características tridimensionales en los métodos de clasificación y detección de cambios.

- Definir las clases de cambio y no cambio que se ven afectadas al emplear las características tridimensionales.

- Comparar los métodos de detección de cambios. 


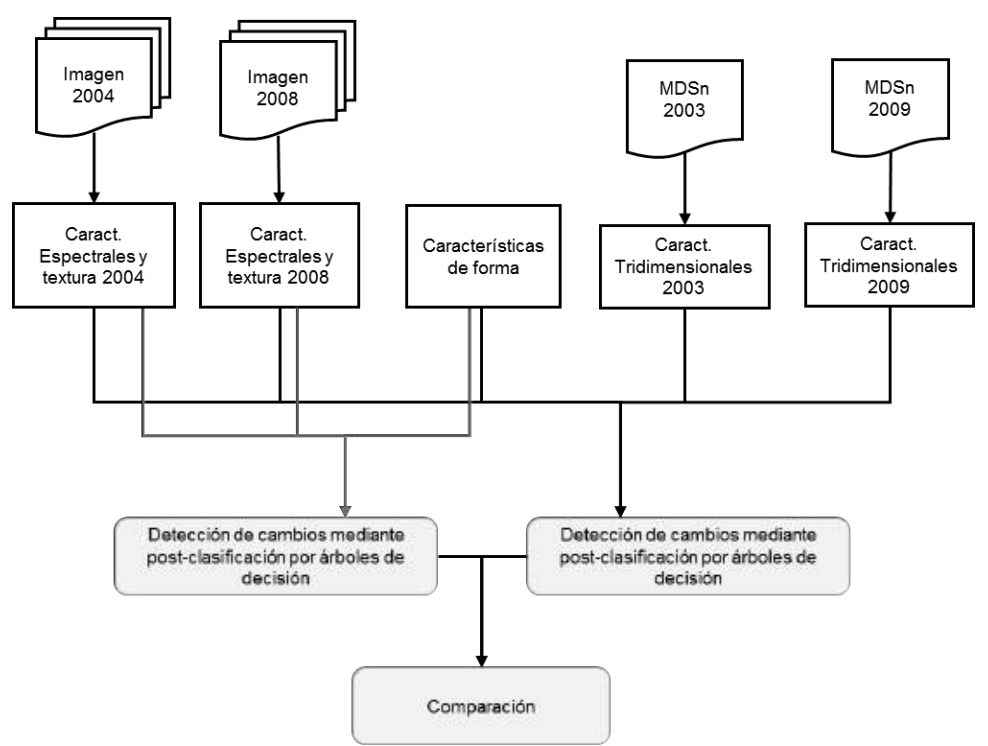

Figura 4.11: Esquema general del Ensayo I-A de detección de cambios con características espectrales, de textura, forma y tridimensionales.

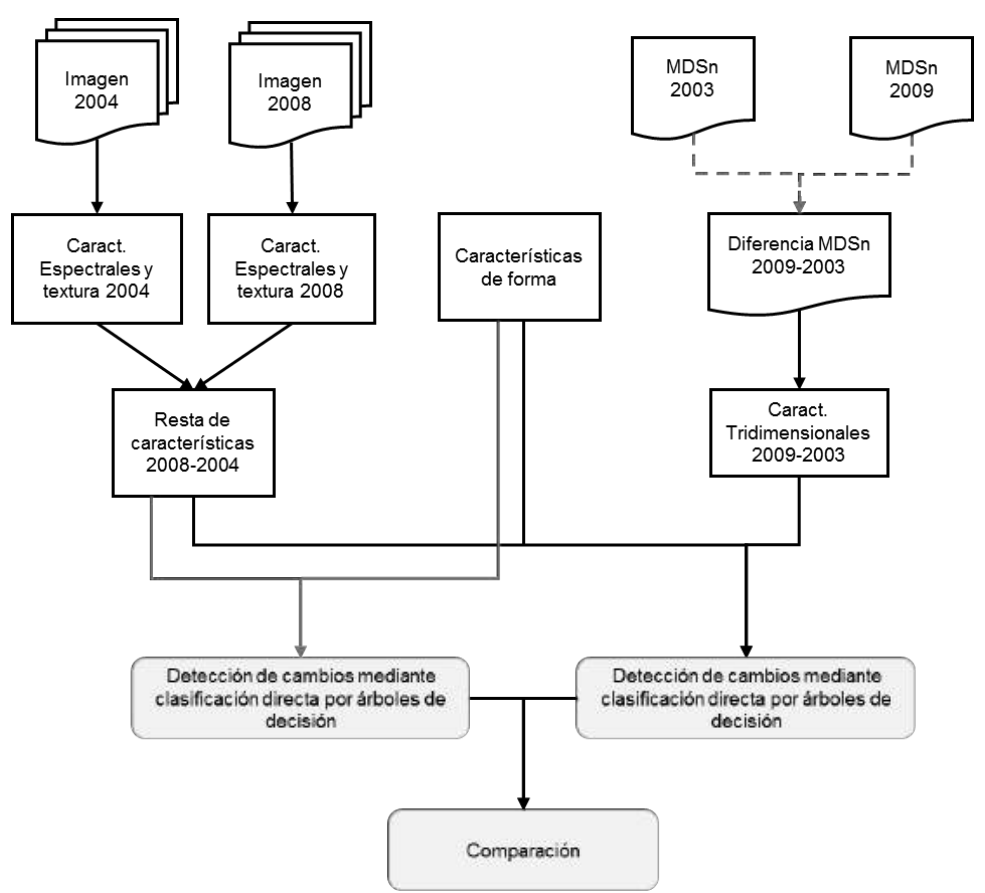

Figura 4.12: Esquema general del Ensayo I-B de detección de cambios con características espectrales, de textura, forma y tridimensionales. 


\subsubsection{Ensayo I.A. Efecto de las características tridimensionales en méto- dos de detección de cambios orientados a objetos basados en post- clasificación de imágenes}

Las características tridimensionales extraídas de datos LiDAR para el estudio de cambios mediante post-clasificación son: la media, la desviación típica, y los valores máximos y mínimos de los valores de altura. Estos valores son extraídos a partir de los píxeles pertenecientes al MDSn de las parcelas de estudio de ambas épocas. Las características tridimensionales se han calculado mediante el software FETEX 2.0 (Ruiz et al., 2011).

En este método se comparan los resultados de clasificación de las dos fechas de estudio para obtener los resultados de detección de cambios. La comparación entre dichas clasificaciones sigue las condiciones del diagrama de la Figura 4.9. En caso de haberse detectado un cambio entre dos clases que no está indicado en el diagrama, se considera como un error por exceso.

Con el fin de analizar y comprender mejor el comportamiento de las características tridimensionales, se han realizado dos post-clasificaciones diferentes: una empleando los conjuntos de características básicas (espectrales, textura y forma); y otra añadiendo a este conjunto el grupo de características tridimensionales. Además, debido a la propia naturaleza del método, es posible hacer la comparación entre las clasificaciones de usos del suelo en las diferentes fechas de estudio, lo que permite un mejor análisis tanto de las características como de las clasificaciones.

En primer lugar se realiza la extracción de las características a nivel de objeto obtenidas utilizando FETEX 2.0 - sobre la imagen QuickBird de 2004 y el parcelario de la zona de estudio. El conjunto de parcelas de estudio junto con sus características es introducido en el algoritmo clasificador de árboles de decisión. El resultado obtenido es un mapa de clasificación a nivel de objeto con los usos del suelo de cada una de las parcelas. Posteriormente, se realiza este mismo procedimiento con la imagen PNOA de 2008 para obtener el mapa de usos del suelo de la segunda fecha.

Como se ha comentado antes, este procedimiento se repite dos veces: incluyendo y no incluyendo el conjunto de características tridimensionales. El clasificador empleado es el de árboles de decisión J48, y se han evaluado las clasificaciones empleando validación cruzada con 10 subgrupos o folds. Las fiabilidades globales y de productor y usuario se han obtenido para cada clasificación y cada clase estudiada. Como último paso y con el fin de detectar los cambios de usos del suelo, se comparan ambas clasificaciones de 
2004 y 2008, siendo parcelas de cambio aquellas que presentan clases diferentes entre las dos fechas estudiadas. La detección de cambios se ha evaluado empleando la matriz de confusión agrupando las parcelas en cambios y no cambios, permitiendo obtener los porcentajes de detección de calidad para cada caso de detección de cambios. Los resultados del estudio mediante post-clasificaciones se recogen en la sección 5.1.1.

Cabe destacar que, a la hora de la extracción de las características derivadas de datos LiDAR, se han encontrado discrepancias entre algunas de las parcelas debido al desfase temporal entre las fechas de adquisición de datos. Así, se han detectado parcelas en las que existen elementos altos, como pueden ser árboles o invernaderos, y que no se corresponden con las imágenes espectrales. Estos ejemplos se pueden ver en las Figuras 4.13 y 4.14. Este desfase temporal existente entre los datos LiDAR y las imágenes espectrales implica la generación de errores directamente relacionados con los errores en los estudios de clasificación y detección de cambios. Estas parcelas con desfase no se han empleado en las muestras de evaluación.

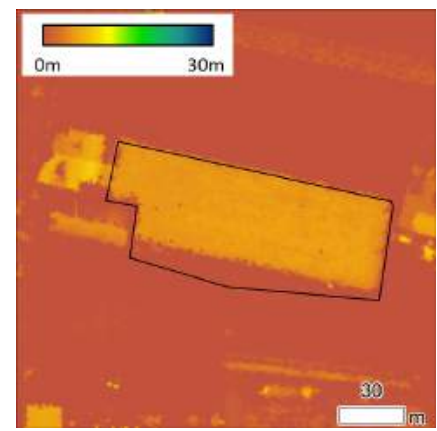

(a) MDS normalizado derivado de datos LiDAR.

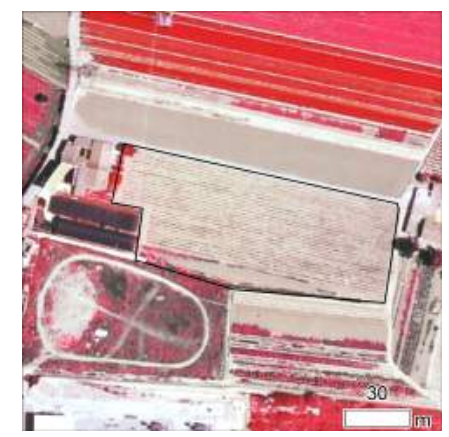

(b) Imagen PNOA en falso color infrarrojo

Figura 4.13: Desfase temporal entre toma de datos LiDAR e imágenes espectrales (ejemplo 1).

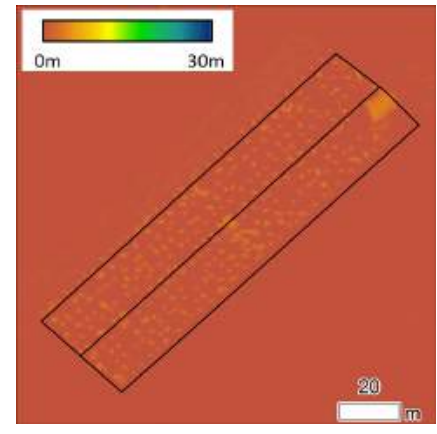

(a) MDS normalizado derivado de datos LiDAR.

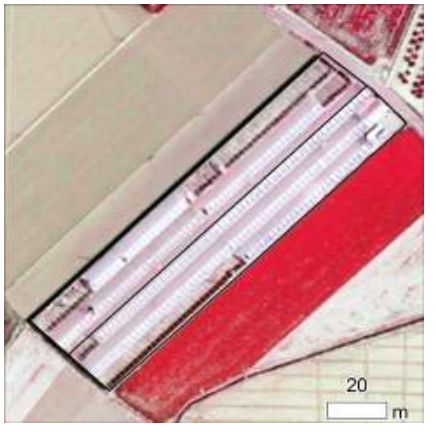

(b) Imagen PNOA en falso color infrarrojo

Figura 4.14: Desfase temporal entre toma de datos LiDAR e imágenes espectrales (ejemplo 2). 


\subsubsection{Ensayo I.B. Clasificación directa orientada a objetos empleando ca- racterísticas tridimensionales con significado temporal}

En el método de detección de cambios por clasificación directa, se ha de introducir información correspondiente a las dos épocas de estudio en una misma clasificación. Si se emplease todo el conjunto de características (espectrales, textura, forma y tridimensionales) extraídas a nivel de objeto por cada imagen de las dos fechas de estudio, el número de características introducido en el clasificador sería enorme. Es por esto que, con el fin de poder reducir el número de características por parcela, se ha planteado el uso de características que contengan carácter temporal combinando la información extraída de las características de ambas imágenes mediante el método de diferencias simples.

En este ensayo se han realizado dos clasificaciones directas diferentes: la primera empleando las características espectrales y textura usando simples diferencias, más las características de forma; y la segunda, agregando a este conjunto las características tridimensionales extraídas a partir del modelo de diferencias de los MDS normalizados.

Las clases empleadas en esta clasificación son las clases pertenecientes al conjunto de clases de cambio. Los resultados de ambas clasificaciones son comparados para observar la influencia de las características tridimensionales sobre este método de detección de cambios. Para las clasificaciones se utiliza el algoritmo de árboles de decisión y los resultados se evalúan empleando el método de validación cruzada con 10 subconjuntos o folds. Para la evaluación de la detección de cambios se agrupan las clases de cambio en una única clase y se obtiene la matriz de confusión de cambios, lo que permite calcular los porcentajes de calidad y de detección para los dos casos estudiados, además de fiabilidades y errores por exceso y defecto. Los resultados de este estudio se recogen en la sección 5.1.2.

\subsubsection{Ensayo II. Estudio de detección de cambios empleando nuevas características bitemporales derivadas de funcio- nes geoestadísticas}

En este apartado se describe el estudio realizado para la validación del nuevo conjunto de características extraídas del semivariograma cruzado y de la codispersión para un problema concreto de detección de cambios (Ensayo II-A). El estudio de cambios se ha realizado sobre los datos de la zona de Murcia, en la que se ha centrado el problema de detección de cambios relacionado con parcelas de cultivos leñosos en dos fechas 
diferentes. En el estudio se combinan variables de tipo espectral (resta de los valores de media y desviación del NDVI las dos épocas de estudio) con las variables de estructura (6 características correspondientes al semivariograma cruzado y 5 a la codispersión), las cuales son extraídas de la banda roja de las imágenes. Se emplea esta banda debido a que la banda del rojo es la banda que presenta un mayor contraste, en términos de reflectancia, entre el suelo y vegetación (Ghulam et al., 2007). Con este estudio se pretende demostrar que las características del semivariograma cruzado y codispersión proporcionan información adicional sobre los cambios estructurales de las parcelas directamente relacionados con los cambios en los usos del suelo. Como parte del estudio, se describe la selección de variables realizada, el método de clasificación orientado a objeto empleado junto con el cálculo de la detección de cambios, la forma de evaluación de los resultados y la selección de parámetros de poda del clasificador de árboles de decisión mediante curvas ROC. Como ensayo adicional (Ensayo II-B), se ha realizado una clasificación directa utilizando características espectrales y características derivadas del semivariograma. Estos resultados son comparados con los resultados de la clasificación obtenidos utilizando la selección de características de semivariograma cruzado y codispersión. En la Figura 4.15 se muestra un esquema general de este estudio. 


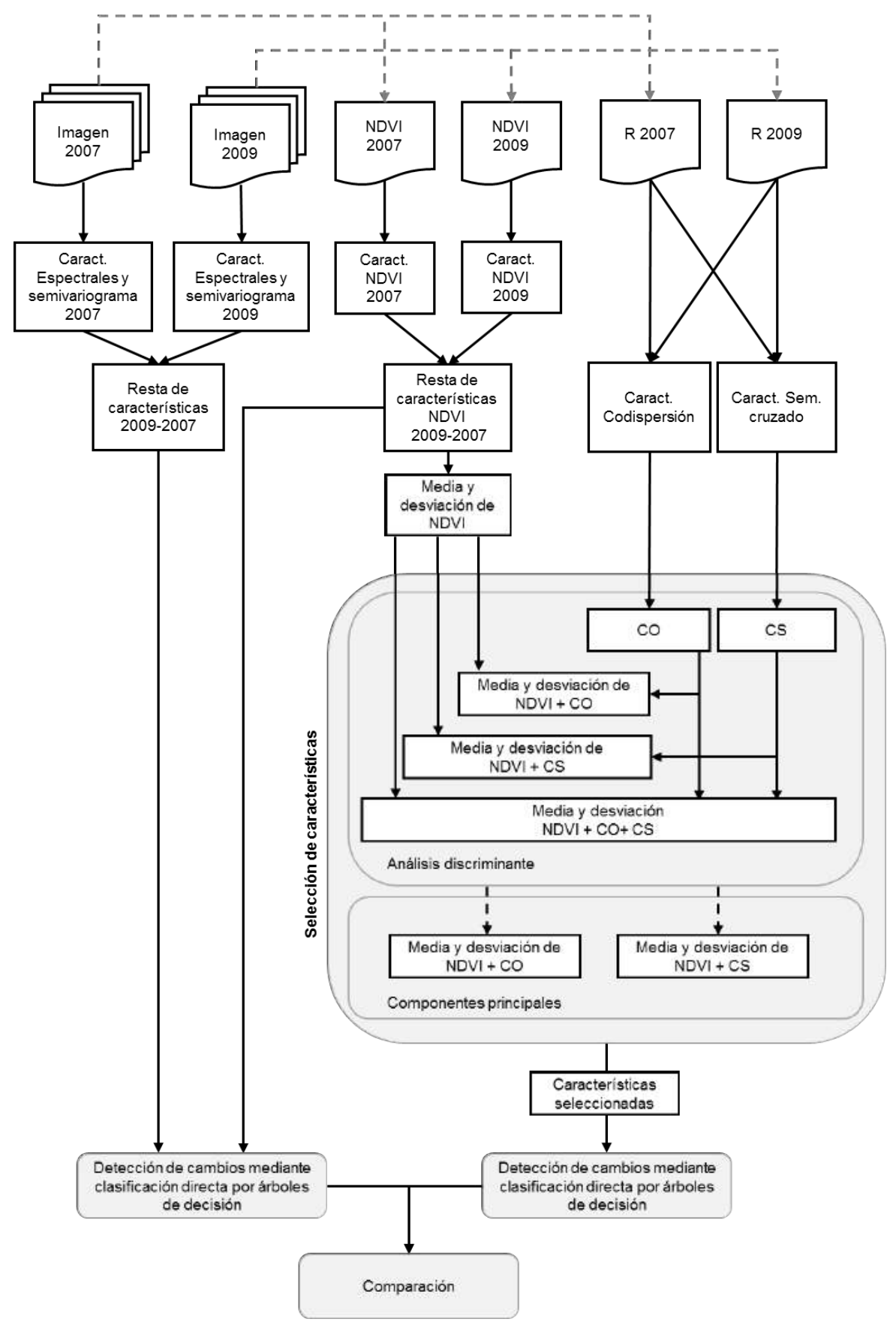

Figura 4.15: Esquema general del Ensayo II de detección de cambios con características derivadas del semivariograma cruzado y codispersión, en donde R 2007 es la banda del rojo de la imagen PNOA de 2007, R 2009 es la banda del rojo de la imagen del PNOA de 2009, CO son las características extraídas de la codispersión y CS son las características extraídas del semivariograma cruzado. 
En la Tabla 4.11 se puede ver un resumen de los ensayos realizados en este estudio en el que se emplean características derivadas de la codispersión y semivariograma cruzado así como diferencias entre características derivadas del semivariograma y diferencias entre características espectrales.

\begin{tabular}{|c|c|c|}
\cline { 2 - 3 } \multicolumn{1}{c|}{} & Ensayo II - A & \multicolumn{2}{c|}{ Ensayo II - B } \\
\hline \hline Zona de estudio & Murcia & Murcia \\
\hline \hline Metodología & NDVI, codispersión y semivariograma cruzado & Espectrales y semivariograma \\
\hline Características empleadas & Clases de cambio & Clases de cambio \\
\hline Clases de estudio & Clasificación directa & Árboles de decisión J48 \\
\hline Algoritmos empleados & Árboles de decisión J48 y análisis discriminante paso a paso & Clasificación directa \\
\hline Métodos de detección de cambios & Matrices de confusión y curvas ROC & Matrices de confusión \\
\hline Métodos de evaluación & &
\end{tabular}

Tabla 4.11: Características generales de los ensayos realizados utilizando características de codispersión, semivariograma cruzado y semivariograma.

Los objetivos de estos ensayos son:

- Analizar el comportamiento del nuevo conjunto de características derivadas de la codispersión y semivariograma cruzado en los diferentes tipos de clases de cambios estudiados.

- Seleccionar un conjunto de características capaz de identificar los cambios estructurales de las parcelas relacionados con los usos del suelo.

- Seleccionar un conjunto de parámetros de poda adecuado para el clasificador de árboles de decisión empleando el grupo de características seleccionado.

- Analizar la información proporcionada por el nuevo conjunto de características en comparación con las características derivadas del semivariograma.

Los resultados de este estudio de cambios se pueden ver en el Capítulo 5 de resultados en el apartado 5.2.

\subsubsection{Análisis de las funciones geoestadísticas y selección de variables de diferencias de NDVI, semivariograma cruzado y codispersión}

Se ha realizado un estudio del conjunto de variables de diferencias de NDVI, semivariograma cruzado y codispersión con el fin de seleccionar aquel conjunto de características que mejor describa las clases de estudio para la detección de cambios además de eliminar información redundante. Las características que intervienen en el estudio son: la resta 
de los valores de media y desviación de valores de NDVI en las dos fechas de estudio (un total de 2 características); las características extraídas del semivariograma cruzado (6 características); y las características extraídas de la codispersión (5 características). El número total de características estudiadas es de 13. El estudio de selección de variables se ha realizado mediante análisis discriminante lineal paso a paso y el análisis de componentes principales.

El estudio de análisis discriminante se ha realizado por grupos de características por separado - espectrales, semivariograma cruzado y codispersión-, y combinaciones entre los grupos, asignando en todos los casos la misma probabilidad a las diferentes clases de estudio independientemente del número de casos por clase. Con esto se pretende evitar cualquier tipo de sesgo debido al elevado número de parcelas de no cambio existente en la muestra. Las fiabilidades de cada clase y la fiabilidad global obtenida por el análisis discriminante lineal paso a paso se han empleado para analizar lo que aporta cada una de las variables en la clasificación en cada uno de los pasos.

El análisis de componentes principales se ha empleado para agrupar e interpretar características que proporcionan información similar y así detectar información redundante contenida en las características estudiadas. Calculando los componentes principales sobre el conjunto completo de características a estudiar, la mayor parte de variabilidad de los datos se concentra en los primeros componentes principales calculados. La visualización de las características proyectadas sobre los planos de estos nuevos componentes ayuda a la comprensión y discriminación de redundancias en la información (Balaguer et al., 2010). Aquellas características que estén en una misma zona o región sobre la proyección de dos dimensiones generada por dos componentes principales, tendrán valores similares sobre los vectores de los componentes principales, por lo que tendrán información en común. Además de las proyecciones de los componentes, se ha calculado la matriz de correlación para asistir al estudio de selección de características.

El conjunto de características resultante tras la selección de variables se empleó para los ensayos de clasificación para la detección de cambios.

Los resultados de la selección de características se pueden observar en el apartado 5.2.2 del Capítulo 5 de resultados. 


\subsubsection{Ensayo II.A. Clasificación directa orientada a objetos empleando las nuevas características geoestadísticas bitemporales}

Primero se realizan las clasificaciones empleando los tres grupos de características independientemente: características derivadas del semivariograma cruzado, características de codispersión y características espectrales de NDVI. Luego se generan todas las combinaciones posibles entre los grupos para estudiar el comportamiento de las características estructurales cuando se combinan con información espectral NDVI. Se ha realizado un total de 7 clasificaciones directas agrupando los distintos conjuntos de características previos a la selección de variables. La Tabla 4.12 muestra la matriz de clasificaciones, en la que cada celda se corresponde con una clasificación, en la que se cuantifica el número de características empleadas dependiendo de la combinación de los grupos de características estudiados.

\begin{tabular}{|c|c|c|}
\hline Clasificación & Características & Número \\
\hline \hline Espectral & NDVI & 2 \\
\hline CO & Codispersión & 5 \\
\hline CS & Sem. Cruzado & 6 \\
\hline Espectral + CO & NDVI + Codispersión & 7 \\
\hline Espectral + CS & NDVI + Sem. Cruzado & 8 \\
\hline CO + CS & Codispersión + Sem. Cruzado & 11 \\
\hline Espectral + CO + CS & NDVI + Sem. Cruzado + Codispersión & 13 \\
\hline
\end{tabular}

Tabla 4.12: Combinación y número de características empleadas en clasificaciones directas mediante árboles de decisión.

Tras el estudio de selección de variables mediante análisis discriminante, las características de la codispersión y semivariograma cruzado que hayan sido predichas como más discriminantes, se usan para las nuevas clasificaciones. Estas se combinan con las características NDVI y se selecciona el menor conjunto de características que mayor fiabilidad obtiene en la clasificación.

En este estudio sólo se ha empleado el clasificador de árboles de decisión ya que el objetivo principal del estudio es analizar el poder discriminante de las variables. Además, se han probado y comparado diferentes parámetros de poda (prunning) para el algoritmo clasificador con el conjunto final de características seleccionado. Los parámetros de poda ensayados son: el factor de confianza, con valores de 0,$1 ; 0,25 ; 0,50 ; 0,75$ y 0,95 ; y el número mínimo de casos por hoja con valores 1, 2, 3 y 4. Los parámetros de poda se han evaluado a partir de los gráficos de curvas ROC, variando los valores de estos dos parámetros y dejando el número de folds y semillas fijos. 
Para la evaluación de los resultados se emplea el método de validación cruzada dividiendo la muestra en 10 subconjuntos iguales o folds. Cada subconjunto consta de aproximadamente 146 parcelas. Los resultados obtenidos se presentan en una matriz de confusión (Congalton, 1991), por la cual se obtiene la fiabilidad global, la fiabilidad de productor y la fiabilidad de usuario (Sección 4.1.3.2).

Los resultados de detección de cambios se obtienen a partir de la matriz de confusión de cambios y los porcentajes de calidad y detección (Sección 4.1.3.3).

Para la evaluación de los parámetros de poda, empleados en la clasificación directa de detección de cambios con la selección final de características, se han empleado los gráficos con curvas ROC.

\subsubsection{Ensayo II.B. Comparación de detección de cambios mediante dife- rencias entre variables espectrales y geoestadísticas}

Los resultados de detección de cambios obtenidos mediante el conjunto de características NDVI, semivariograma cruzado y codispersión seleccionado, son comparados con una clasificación y detección de cambios empleando un conjunto de variables obtenidas a partir de las diferencias entre las características espectrales y las características derivadas de los semivariogramas de las dos épocas. Para la obtención de estas características, se realizan las simples diferencias entre valores de una misma variable obtenida en las dos épocas de estudio sobre una misma parcela.

El número total de características obtenidas para este estudio son: 35 características espectrales ( 7 por banda espectral de la Tabla 4.1, más 7 características derivadas del NDVI) y 14 características derivadas del semivariograma (Tabla 4.2), un total de 49 características. Las características son introducidas en el algoritmo clasificador de árboles de decisión y se obtienen las matrices de confusión y de detección de cambios. Los resultados de esta clasificación se pueden observar en el apartado 5.2.4 del Capítulo 5 de resultados.

\subsubsection{Ensayo III. Análisis de características de fragmentación}

En este apartado se recoge el estudio realizado sobre las características de fragmentación. El estudio se ha realizado sobre la zona de Valencia debido a la disponibilidad de datos espectrales y datos LiDAR, necesarios para la generación de los mapas de cobertura. 
En un primer lugar se describe el estudio de características realizado sobre un conjunto de parcelas sintéticas. De esta forma se analizó el comportamiento de las características de fragmentación sobre un entorno controlado. Este análisis permitió reducir el número de características y hacer una selección previa para el estudio de detección de cambios.

Tras el estudio de parcelas sintéticas, se describe el proceso de generación de los mapas de coberturas necesarios para la extracción de las características a nivel de objeto. Como fase final del ensayo, se describe el método de clasificación y evaluación para la detección de cambios. La Figura 4.16 muestra un esquema del ensayo III.

En este ensayo se desea conseguir un conjunto de características que describan los subobjetos y que puedan emplearse para detectar cambios en las parcelas de estudio.

En la Tabla 4.13 se puede ver una síntesis de la zona de estudio y métodos empleados en este ensayo.

\begin{tabular}{|c|c|}
\cline { 2 - 2 } \multicolumn{1}{c|}{} & Ensayo III \\
\hline \hline Zona de estudio & Valencia \\
\hline \hline Metodología & Fragmentación y NDVI \\
\hline Características empleadas & Clases de cambio \\
\hline Clases de estudio & Clasificación directa \\
\hline Algoritmos empleados & Árboles de decisión J48, ISODATA y análisis discriminante paso a paso \\
\hline Métodos de detección de cambios & Matrices de confusión \\
\hline Métodos de evaluación & \\
\hline
\end{tabular}

Tabla 4.13: Características generales del ensayo realizado utilizando características de fragmentación.

Los objetivos generales del ensayo III son:

- Analizar el comportamiento de las características de fragmentación según el número y tipo coberturas existentes dentro de las parcelas de estudio.

- Estudiar y seleccionar un conjunto de características de fragmentación a nivel de objeto y subobjeto para estudios de detección de cambios. 


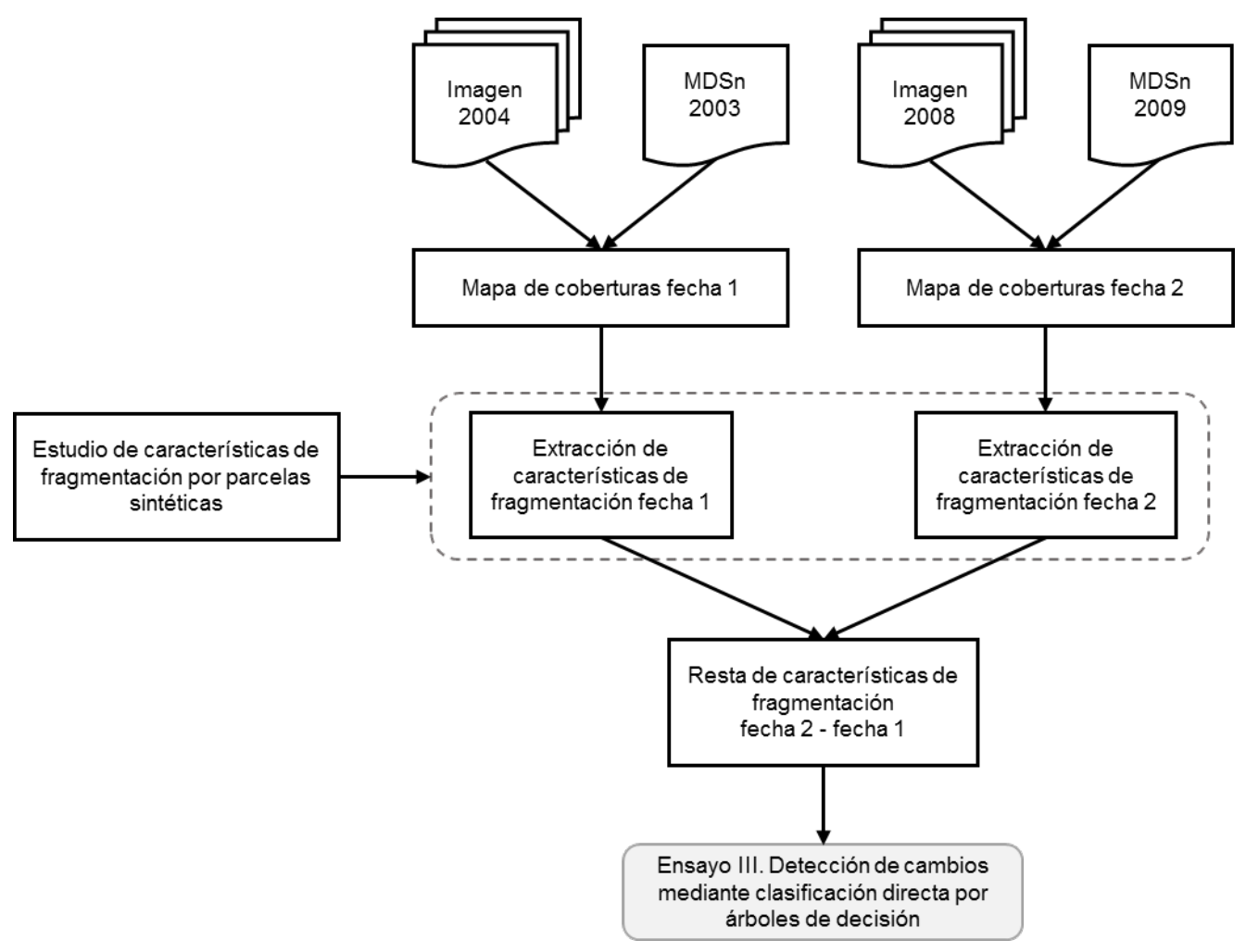

Figura 4.16: Esquema general del Ensayo III de detección de cambios con características de fragmentación.

\subsubsection{Estudio de características de fragmentación sobre parcelas sintéti- cas}

El objetivo de este estudio es reducir el número de características de fragmentación mediante una selección previa de las características más eficaces para describir las diferentes clases de estudio. Para esto, se ha analizado el comportamiento de las características mediante un conjunto de parcelas sintéticas. Las parcelas sintéticas son parcelas ideales en las que sus elementos presentan formas, distribuciones y límites regulares, que intentan describir los rasgos más característicos de cada uno de los tipos de clases de parcelas. Este conjunto de parcelas sintéticas permite un mayor control y un análisis detallado de las características de fragmentación. Los tipos de clases empleados para este estudio son las mismas clases de usos del suelo definidas en el apartado 4.2.1.1, empleando los tipos básicos de coberturas de suelo: suelo desnudo, vegetación, árboles y edificios.

En la Figura 4.17 se puede observar un conjunto de parcelas sintéticas (Grupo A) en las que se muestran varios tipos de parcelas de árboles con distribución regular y de 
diferentes tamaños 4.17 (a, b, c, d), plantones 4.17 (c), y parcelas mixtas 4.17 (d, e) en las que en la mitad de la parcela o bien no hay árboles o bien hay plantones. Y por último, otro tipo de árboles en los que se puede distinguir su alineación 4.17 (f), pero resulta imposible diferenciar donde empieza o acaba cada árbol. También se ha considerado otro tipo de parcelas con una disposición de árboles irregular y de diferentes tamaños 4.17 (h), y otro tipo de parcelas con coberturas mixtas 4.17 (g, j, k, l) con coberturas o elementos de cultivo, árboles y edificios.

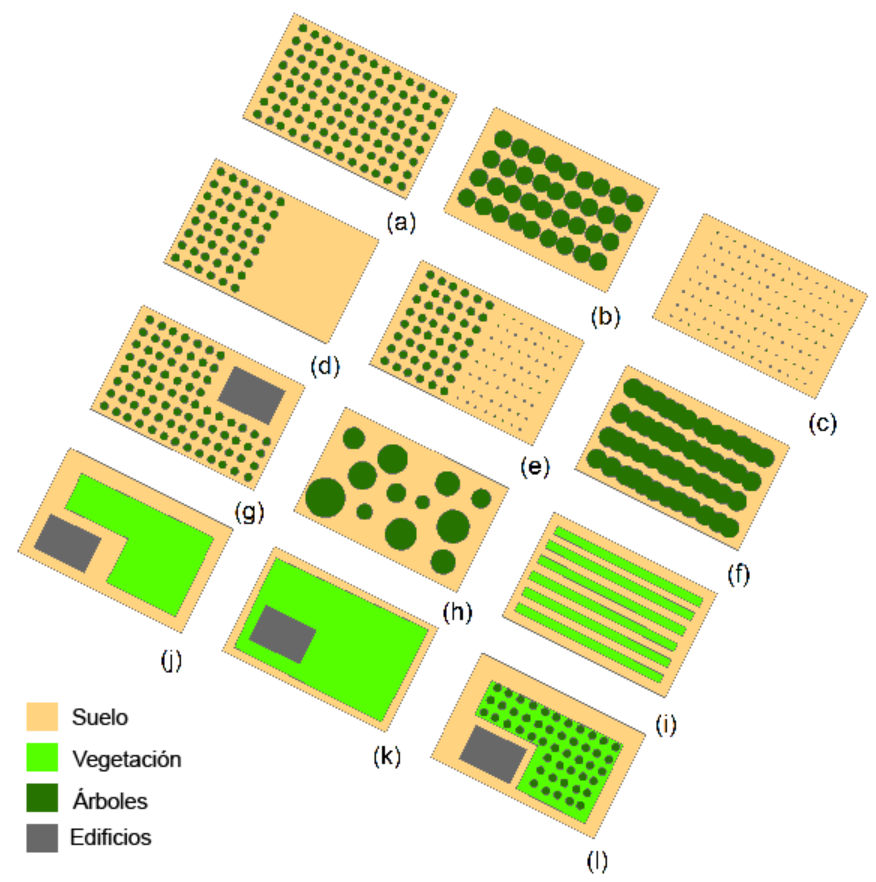

Figura 4.17: Grupo A de parcelas sintéticas.

Además, para poder realizar una mejor interpretación de cierto número de características que pueden ayudar al análisis de edificios existentes en las parcelas de estudio, se ha generado otro conjunto de parcelas sintéticas (Grupo B) relacionadas únicamente con edificios (Figura 4.18), en las que se puede diferenciar edificios de diferentes tamaños y formas. 


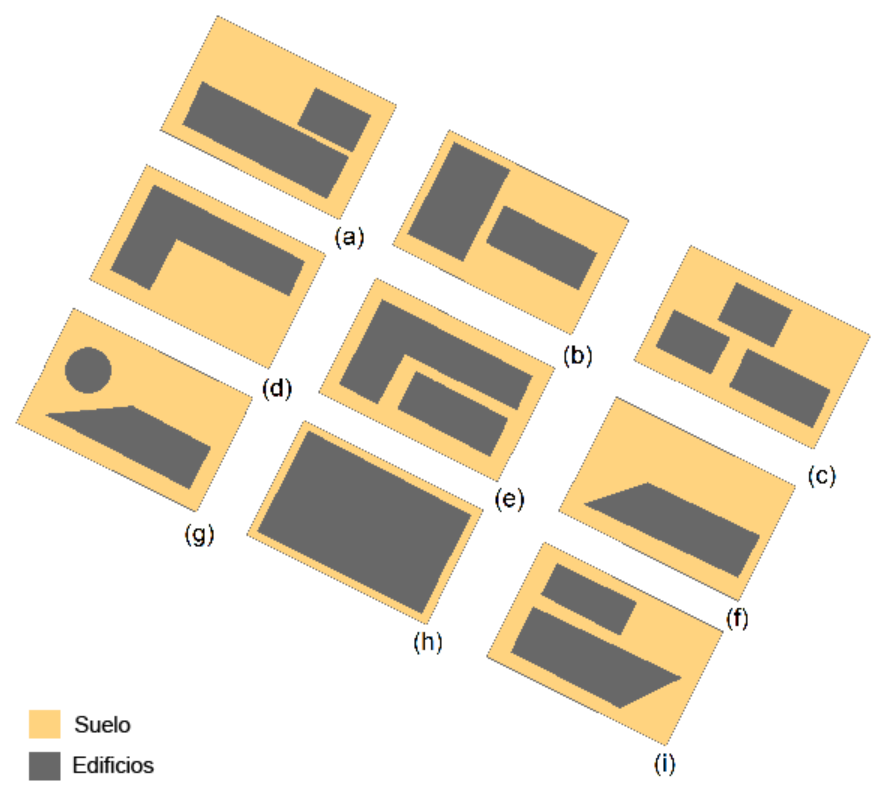

Figura 4.18: Grupo B de parcelas sintéticas.

\subsubsection{Parcelas sintéticas vs. parcelas reales}

Las parcelas sintéticas, como se ha comentado, son parcelas ideales cuyos elementos o subobjetos formados por diferentes coberturas de suelo, tienen formas, distribuciones y límites geométricos regulares. Las parcelas reales, no tienen coberturas de suelo homogéneas o límites entre cubiertas bien definidos, lo que dificulta la distinción entre las clases. Además, a estos inconvenientes hay que añadir posibles errores en el proceso de generación de los mapas de coberturas, debidos, o bien a errores en la clasificación o a limitaciones debidas a los datos de estudio. El estudio de las características se ha realizado distinguiendo entre dos tipos de parcelas según su contenido y se ha diferenciado entre parcelas de uso agrícola y parcelas edificadas.

\subsection{Parcelas de uso agrícola}

Existen principalmente tres tipos de parcelas agrícolas: cultivadas, en las que la cobertura predominante es vegetación de tipo herbáceo; arables, en las que predomina el suelo desnudo; y arbóreas, en la que se presenta básicamente cobertura de árboles.

Tanto en las parcelas cultivadas como arables, muchas veces resulta difícil detectar 
si se ha producido un cambio o no. Esto se debe a que estas dos coberturas se pueden manifestar en la parcela de manera no homogénea y en diversas ocasiones se encuentran mezcladas entre sí. Por este motivo, son frecuentes los errores de clasificación entre parcelas de ambas clases. Se espera que a pesar de los posibles errores cometidos en la generación del mapa de usos del suelo, las características de fragmentación ayuden a la correcta clasificación de las parcelas de estudio.

Por otro lado están las parcelas con cultivos arbóreos. En las parcelas reales, por ejemplo parcelas de naranjos, la disposición de los árboles nunca es perfecta como en el caso de las parcelas sintéticas. Además, existen casos en los que algunas de las parcelas están peor cuidadas que otras, por lo que entre filas de árboles, no hay suelo desnudo sino vegetación, lo que dificulta la clasificación de dichas parcelas si no se emplea información tridimensional. En el caso en el que el espacio entre árboles sea suelo desnudo, resultará más fácil la clasificación de las parcelas.

\subsection{Parcelas edificadas}

Las parcelas de edificios que se pueden encontrar son básicamente tres: edificios rurales (denominados de esta forma ya que están situados fuera de zonas urbanas) ya sean adosados o aislados, edificios urbanos y edificios industriales. Generalmente, en los tres tipos existe un solo edificio por parcela, especialmente en las parcelas industriales y urbanas. En estas dos últimas tipologías es común que el edificio abarque, si no toda, la mayor parte de la parcela. Por esto mismo es de esperar que, mediante las características de fragmentación resulte difícil diferenciar entre estas dos clases ya que tienen el mismo tipo de cobertura y una distribución y extensión sobre la parcela similares.

En el caso de los edificios rurales, es posible que existan varios edificios con tamaños diversos dentro de una parcela, pero no es de esperar un número elevado de estos. Estas parcelas pueden llegar a compartir varias coberturas de tipos de suelo, por lo que resultaría menos complicado diferenciarlas de las parcelas industriales y/o urbanas.

Las parcelas sintéticas se han generado en un principio con un único edificio, ya que en las parcelas que están siendo estudiadas no se ha diferenciado ninguna parcela en la que exista más de un edificio, lo que no indica que no se pueda dar el caso. Sin embargo, para poder estudiar las características de fragmentación extraídas más a fondo, se ha optado por introducir un conjunto de parcelas con más de un edificio en ellas además de diferentes formas (Grupo B) (Figura 4.18). 


\subsubsection{Generación de mapas de coberturas para la extracción de caracte- rísticas de fragmentación}

La generación de los mapas de coberturas del suelo se ha realizado con el propósito de describir las coberturas básicas que constituyen las parcelas. Las características de fragmentación no pueden ser extraídas directamente de los píxeles de las imágenes sino a partir de agrupaciones de píxeles. Los mapas de coberturas se han generado mediante la clasificación a nivel de píxel de las imágenes aéreas y satelitales y de modelos digitales de superficie normalizados. La zona sobre la cual se han generado es la zona de estudio de Valencia debido a la disponibilidad de datos LiDAR, con la consiguiente mejora de la fiabilidad en la clasificación.

La clasificación de coberturas básicas consta de los siguientes pasos: (i) generación de máscaras binarias; (ii) clasificación no supervisada, (iii) asignación de coberturas de suelo a las clases de la clasificación no supervisada, (iv) clasificación de sombras y (v) filtrado morfológico. Tras la obtención de los mapas de coberturas se realiza una evaluación a nivel de píxel.

\subsection{Generación de las máscaras binarias y mapas de coberturas básicas}

El primer paso consiste en la generación de máscaras binarias combinando información espectral y del MDSn. Las máscaras generadas se corresponden con las zonas de sombra y con las coberturas de suelo desnudo, vegetación, árboles y edificios.

Para la selección de las zonas de sombra y no sombra se genera una imagen de intensidades obtenida a partir de los valores de la media de las bandas espectrales de la imagen de estudio (IR, R, G, B para la imagen QuickBird de 2004, e IR, R y G para la imagen PNOA de 2008). En cada una de estas imágenes se toman muestras de dos regiones de interés (ROI) diferentes en las que se distinguen los píxeles pertenecientes a las zonas de sombra y zonas de no sombra. Suponiendo que los niveles digitales de las dos ROIs siguen una distribución normal, el valor umbral se obtiene automáticamente calculando el punto de intersección entre las dos distribuciones. Para la generación de la máscara derivada del MDSn, se divide la imagen en regiones con alturas mayores y menores a 1 metro. Se selecciona este valor umbral debido a que se considera que la altura mínima de los árboles es de 1 metro en la zona de estudio, así se separan los elementos con cierta altura, como los árboles y los edificios, de los elementos que no poseen altura, como el suelo o la vegetación. Previo a la generación de las máscaras de alturas, los MDSn son filtrados mediante el algoritmo de media ponderada inversa a la 
distancia espectral (Recio, 2009). La siguiente máscara se obtiene mediante el NDVI, que se emplea para separar elementos pertenecientes a la vegetación y árboles, de los elementos de suelo y de los edificios. Aquí, se sigue el mismo procedimiento que para la generación de la máscara de sombras, tomando muestras de dos ROIs en las que se distinguen los píxeles pertenecientes a árboles y a vegetación, de los píxeles de suelo desnudo y de edificios. Como en el caso anterior de sombras, el valor umbral se calcula automáticamente.

Combinando las máscaras obtenidas anteriormente se obtienen máscaras binarias para toda la zona de trabajo correspondientes a las cinco coberturas básicas estudiadas sombras, suelo desnudo, vegetación, árboles y edificios -. La obtención de cada cobertura se realiza mediante la combinación de las máscaras de la siguiente manera: las sombras se obtienen directamente con la máscara de intensidades de las regiones de sombra, mientras que sobre aquellas zonas de no sombra se calculan las máscaras correspondientes a las coberturas de suelo, vegetación, árboles y edificios; el suelo desnudo se obtiene tras la combinación de zonas de no sombra, valores bajos de NDVI y la máscara con valores inferiores a 1 metro del MDSn; la vegetación se obtiene empleando la máscara de no sombra con valores altos de NDVI y valores inferiores a 1 metro del MDSn; los edificios se obtienen mediante la máscara de no sombra, valores inferiores al umbral de NDVI y valores superiores a 1 metro de MDSn; los árboles se obtienen combinando la máscara de no sombra con las máscaras de valores elevados de NDVI y valores superiores a 1 metro del MDSn. La Figura 4.19 muestra un esquema del uso las máscaras binarias para la generación de los mapas de coberturas básicas. En la Figura 4.20 se puede ver un detalle de los mapas de coberturas básicas generados mediante máscaras para las dos fechas de estudio. 


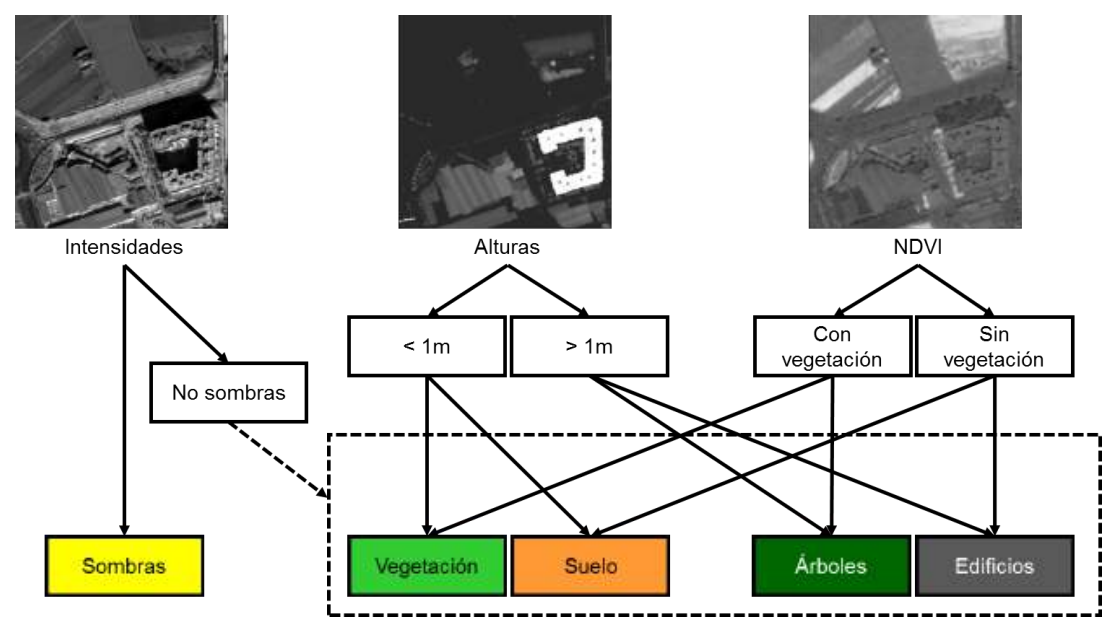

Figura 4.19: Detalle de la generación de los mapas de coberturas básicas empleando información espectral de intensidades y de NDVI e información de alturas del MDSn.

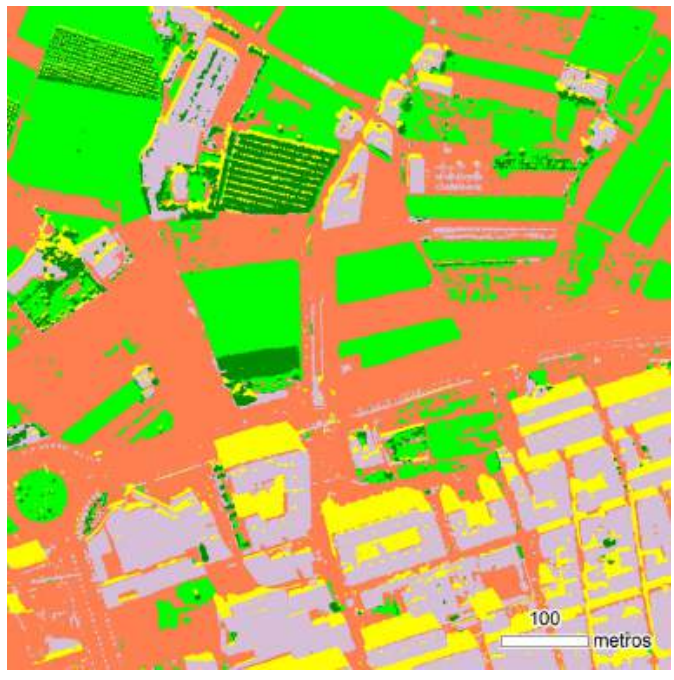

(a) 2004 .

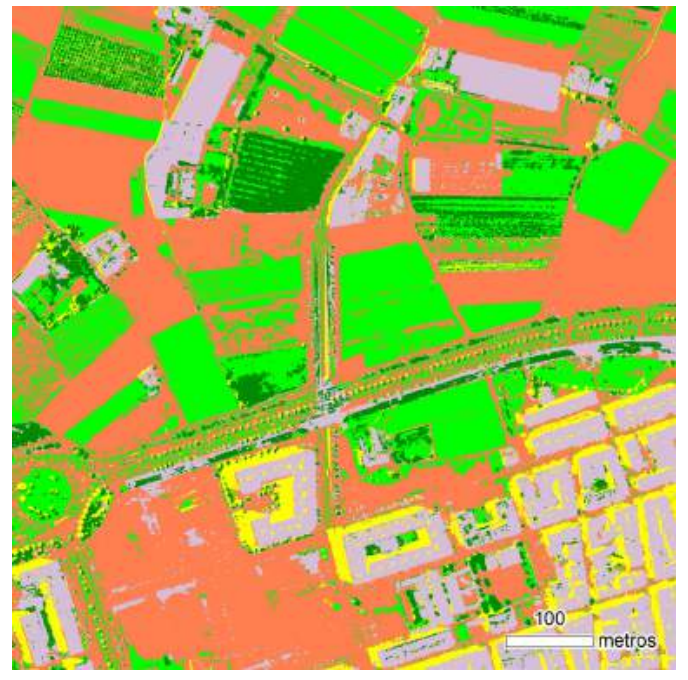

(b) 2008 .

$\square$ Suelo desnudo $\square$ Vegetación $\square$ Edificios $\square$ Arboles $\square$ Sombras

Figura 4.20: Detalles de los mapas de coberturas básicas generados para las dos épocas de estudio. 


\subsection{Clasificación no supervisada y asignación de coberturas}

En este paso se ha realizado una clasificación no supervisada empleando las bandas espectrales de cada una de las imágenes más los modelos digitales de superficie normalizados. El objetivo de la clasificación no supervisada es crear un conjunto de objetos espectralmente homogéneos. El método que se emplea para la clasificación no supervisada es el algoritmo ISODATA. Los parámetros que se definen para la clasificación son; un mínimo de 5 clases hasta un máximo de 15, un máximo de 10 iteraciones con un umbral de cambio del $5 \%$ y un mínimo de 50 píxeles por clase.

Para cada una de las fechas de estudio se generan dos clasificaciones no supervisadas empleando las bandas espectrales de cada una de las imágenes y las máscaras de los MDSn, obteniendo así una clasificación para elementos de altura menor a 1 metro y otra clasificación para elementos de altura mayor a 1 metro. En la Figura 4.21 se muestra un detalle de las clasificaciones no supervisadas de elementos de menor y mayor altura para una de las épocas de estudio.

Los elementos resultantes de las clasificaciones no supervisadas se comparan con los mapas de coberturas básicas generados del paso anterior con el fin asignar a cada uno de los objetos generados una cobertura básica final. La cobertura que mayor superficie presenta en los objetos de una misma clase no supervisada es la asignada a dicha clase. En la Figura 4.22 se muestra un esquema del proceso seguido para la generación de los mapas de coberturas empleando las clasificaciones no supervisadas y el mapa de coberturas básicas.

Para aquellas clases que presentan aproximadamente el mismo valor de ocupación por dos coberturas, se realiza una asignación a nivel de objeto, tratando a cada objeto de esa clase como una entidad independiente y asignándole una cobertura en función de sus valores medios del MDSn y NDVI. Después de asignar una cobertura a todos los objetos no clasificados se procede con la asignación de coberturas a las zonas de sombra. 


\section{Metodología}

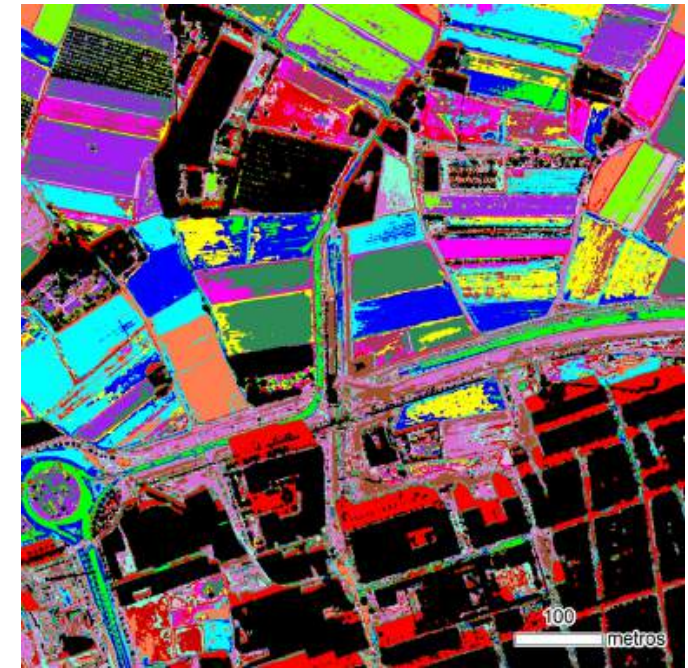

(a) Clasificación de elementos bajos (cada color se corresponde con cada una de las clases de menor altura resultantes de la clasificación no supervisada).

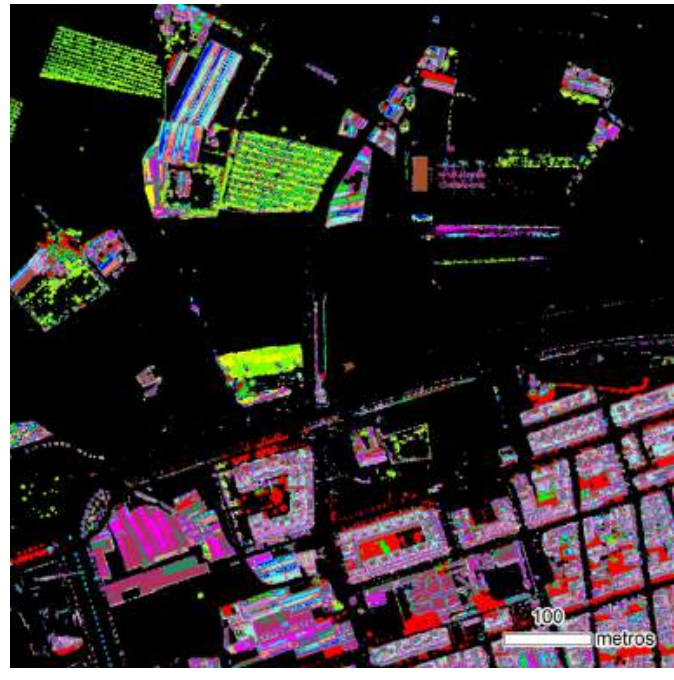

(b) Clasificación de elementos altos (cada color se corresponde con cada una de las clases de mayor altura resultantes de la clasificación no supervisada).

Figura 4.21: Detalles del mapa de clasificación no supervisada por el método ISODATA de la imagen QuickBird de 2004.

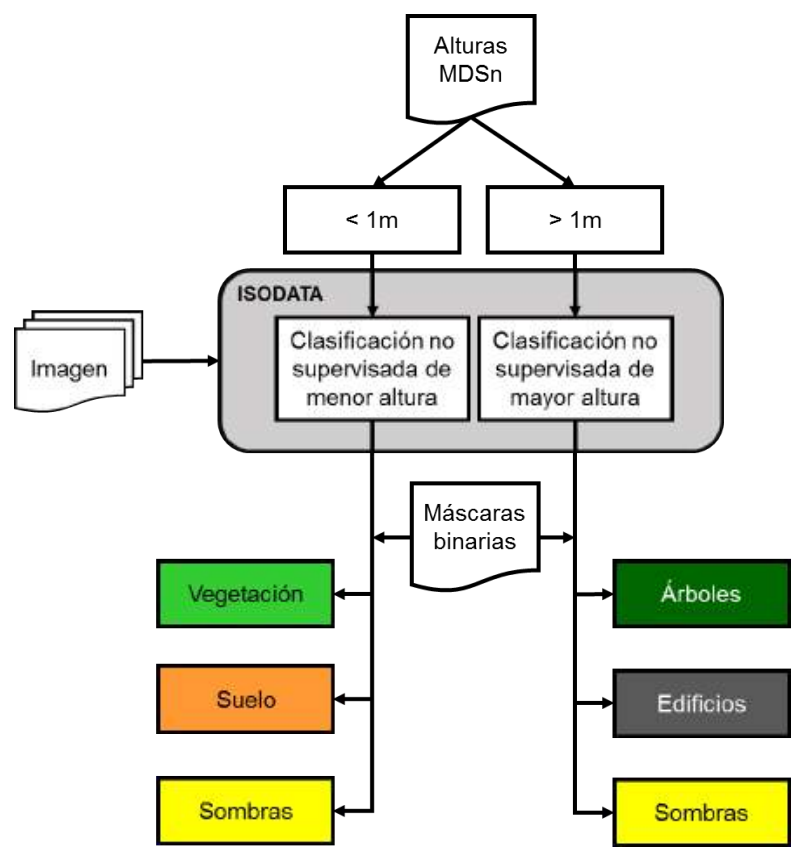

Figura 4.22: Detalle de la generación de los mapas de coberturas mediante la clasificación no supervisada y las máscaras binarias. 


\subsection{Clasificación de zonas de sombras}

El procedimiento empleado para la clasificación de las zonas de sombra es muy similar al proceso inicial de generación de las máscaras binarias. Tras la asignación de coberturas al resultado de la clasificación no supervisada, los píxeles asignados a la clase de sombra son reclasificados en sombras altas y bajas empleando la información espacial proveniente de los MDSn como en Zhou et al. (2009). A partir de una umbralización del NDVI mediante muestras de vegetación tomadas sobre las sombras de las imágenes, se generan máscaras en las que se puede distinguir entre zonas con vegetación de zonas sin vegetación. Los píxeles de "sombras altas" con vegetación son reclasificados como árboles, y los que no presentan vegetación, como edificios. Los píxeles de "sombras bajas" son reclasificados como vegetación para aquellos píxeles con un NDVI superior al umbral fijado, y como suelo para aquellos que no tienen vegetación. En la Figura 4.23 se muestra un ejemplo de la eliminación de sombras sobre un detalle del mapa de coberturas para la fecha de 2004.

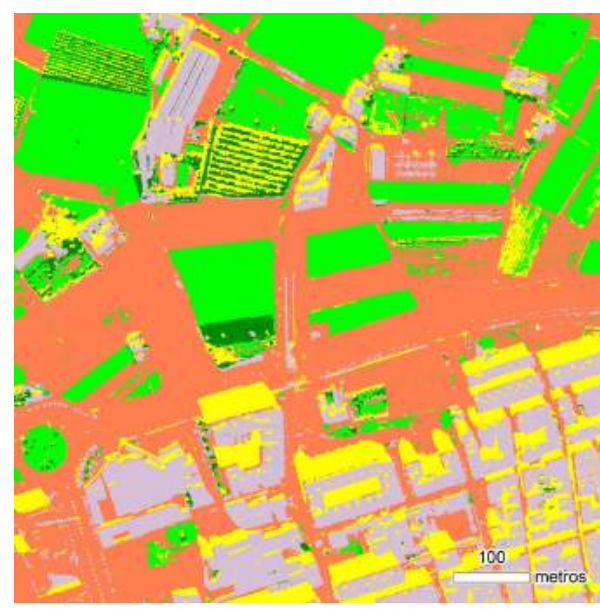

(a) Sombras sin eliminar.

Suelo desnudo

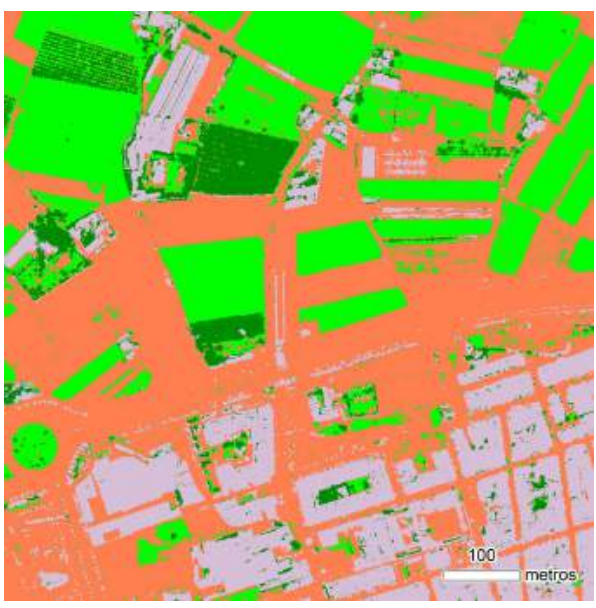

(b) Sombras eliminadas.

Figura 4.23: Detalle de mapa de coberturas de 2004 antes y después de la eliminación de sombras.

\subsection{Filtrado del mapa de coberturas}

Tras la eliminación de las sombras, el mapa de coberturas se filtra en busca de elementos clasificados como edificios y, mediante un estudio de tamaño, forma y compacidad, los píxeles pertenecientes a esos elementos son reclasificados, reduciendo así errores en esta clase. La selección de los parámetros se realiza de forma empírica. A las agrupaciones de edificios menores de 100 píxeles cuyo valor de índice de forma es superior a 1,1 y 


\section{Metodología}

con una compacidad menor a 5, se les reasigna una nueva cobertura dependiendo de la clase de los píxeles que tiene a su alrededor. Generalmente, la clase reasignada a estos elementos es la clase árbol debido a la altura que tienen los píxeles.

Tras el filtrado de edificios, al mapa de coberturas se le vuelven a aplicar dos filtros diferentes: un primer filtro de moda y posteriormente un filtro de apertura. El filtro de moda se aplica para suavizar los resultados de la imagen y eliminar píxeles aislados eligiendo el valor más frecuente en la ventana empleada para el filtro. Se ha optado por elegir un tamaño de ventana de 3x3 para no reducir el tamaño de los elementos más pequeños y evitar generalizaciones. Tras el filtrado de moda se emplea un filtro de apertura con un tamaño de ventana de 5x5. El filtro de apertura consiste en la combinación de un filtro de erosión y otro de dilatación para romper pequeñas conexiones que puedan existir entre elementos y posteriormente eliminar protuberancias. Del mismo modo, también se consideró aplicar un filtro de cierre de $5 \times 5$ consistente en la combinación de, en primer lugar un filtro de dilatación seguido de una erosión. Con este filtro se consigue eliminar agujeros internos de los objetos y espacios inconexos. Tras evaluar los resultados de los filtros se selección el filtro de apertura, ya que este, mantiene la estructura de los árboles dentro de las parcelas. Al aplicar el filtro de cierre, se pierde el espacio que existe entre las hileras de árboles y por lo tanto la estructura que siguen en la parcela. En la Figura 4.24 se puede observar un ejemplo.

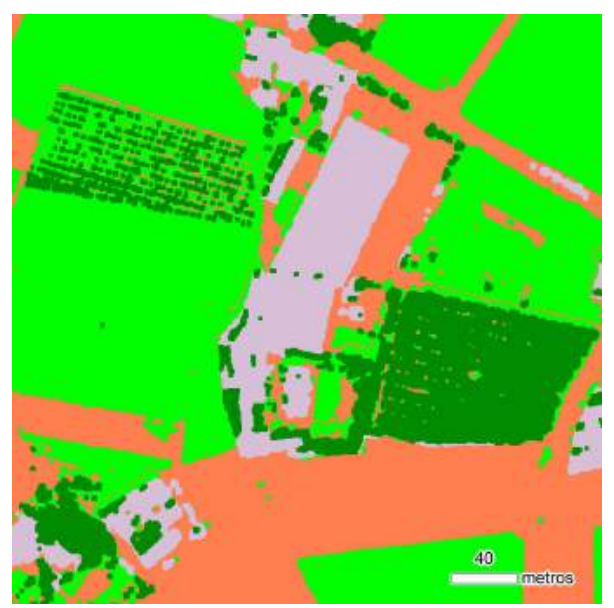

(a) Filtrado morfológico de apertura

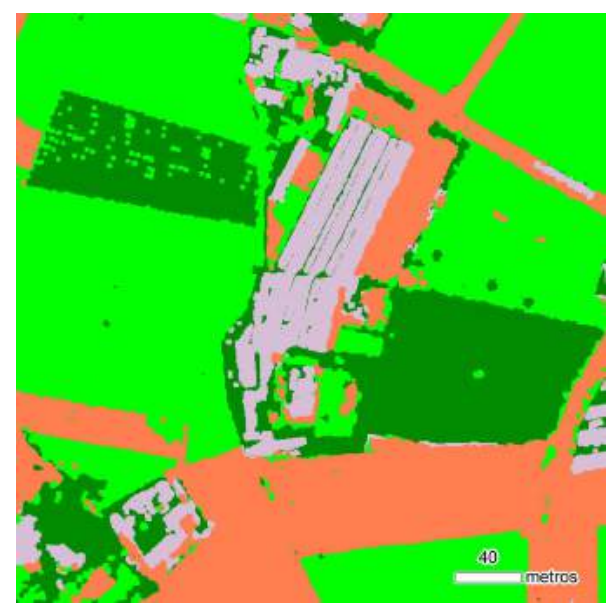

(b) Filtrado morfológico de cierre Edificios Árboles

Figura 4.24: Ejemplo de mapa de coberturas de imagen QuickBird con filtrado morfológico de apertura y cierre con ventana de $5 \times 5$ píxeles. 


\subsection{Evaluación de los mapas de coberturas}

Tras la generación y filtrado de los mapas de coberturas, se ha realizado una evaluación de estos. Se han hecho cuatro evaluaciones diferentes: una por cada imagen clasificada (QuickBird de 2004 y PNOA de 2008) y otras dos sobre las zonas de sombra también en las dos imágenes de las dos fechas.

Para la evaluación se han escogido mediante fotointerpretación diferentes regiones de interés o muestras "verdad terreno" de todas las coberturas estudiadas. Estas muestras se han comprado con los mapas de coberturas a nivel de píxel mediante una matriz de confusión, y se ha obtenido la fiabilidad global de toda la clasificación así como las fiabilidades de productor y de usuario por cada una de las coberturas estudiadas.

Para la evaluación de la asignación de clases a las zonas de sombra se ha empleado este mismo procedimiento. La diferencia entre la evaluación de sombras y los mapas de coberturas es que para la selección de las muestras "verdad terreno", se ha realizado una interpretación de las zonas de sombra con ayuda de imágenes PNOA de 2006, en las que existe una menor presencia de sombras, y un realce de las sombras en las dos fechas de 2004 y 2008.

\subsubsection{Estudios de detección de cambios mediante clasificación directa em- pleando características de fragmentación}

En este apartado se ha realizado el estudio de detección de cambios empleando las características de fragmentación sobre el conjunto de parcelas de Valencia mediante el método de clasificación directa orientada a objeto empleando árboles de decisión.

El conjunto de características preseleccionado en el estudio de características mediante parcelas sintéticas se ha extraído de los mapas de coberturas generados para las dos épocas. Con el fin de dotar de significado temporal a las características de fragmentación y reducir el número a introducir en el clasificador, se ha realizado la diferencia entre las características de las dos épocas de estudio.

Tras haber realizado una primera selección de características de fragmentación en el estudio de características sobre las parcelas sintéticas, se ha llevado a cabo una nueva selección empleando análisis discriminante paso a paso y matriz de correlaciones. Tras este análisis, se han hecho varias pruebas de clasificación mediante árboles de decisión probando diferentes combinaciones de características. La combinación que mejor resultados obtiene se ha empleado para el estudio de detección de cambios. 
La evaluación de los resultados se realiza utilizando el método de validación cruzada, como en casos anteriores, dividiendo la muestra en 10 subconjuntos iguales. Con los resultados obtenidos se ha generado la matriz de confusión y se ha obtenido la fiabilidad global, la fiabilidad de productor y la fiabilidad de usuario. A partir de estos resultados, se ha calculado la matriz de confusión de cambios junto con los porcentajes de calidad y de detección. Los resultados de este ensayo están en el Apartado 5.3.

\subsubsection{Ensayo IV. Análisis de características temporales para la detección de cambios}

En este último ensayo se han escogido las variables seleccionadas a lo largo de los ensayos anteriores para la detección y evaluación de cambios sobre la zona de Valencia. El estudio consiste en introducir en el clasificador los diferentes tipos de características uno a uno generando diferentes grupos de características y ver cómo evolucionan los resultados mediante clasificación directa empleando árboles de decisión. Los grupos de características se muestran en la Tabla 4.14, en donde se puede observar los tipos de características que componen cada grupo.

\begin{tabular}{|c|c|c|c|c|c|c|c|c|}
\hline & \multicolumn{7}{|c|}{ Tipo de características empleadas } \\
\hline & & Espectral & Textura & Forma & Tridimensional & Geoestadísticas & Fragmentación & Clase previa \\
\hline \multirow{5}{*}{ Grupo } & Grupo A & $\mathrm{X}$ & $\mathrm{X}$ & $\mathrm{X}$ & & & & \\
\hline & Grupo B & $\mathrm{X}$ & $\mathrm{X}$ & $\mathrm{X}$ & $\mathrm{X}$ & & & \\
\hline & Grupo C & $\mathrm{X}$ & $\mathrm{X}$ & $\mathrm{X}$ & $\mathrm{X}$ & $\mathrm{X}$ & & \\
\hline & Grupo D & $\mathrm{X}$ & $\mathrm{X}$ & $\mathrm{X}$ & $\mathrm{X}$ & $\mathrm{X}$ & $\mathrm{X}$ & \\
\hline & Grupo E & $\mathrm{X}$ & $\mathrm{X}$ & $\mathrm{X}$ & $\mathrm{X}$ & $\mathrm{X}$ & $\mathrm{X}$ & $\mathrm{X}$ \\
\hline
\end{tabular}

Tabla 4.14: Grupos de características generados.

Como caso final, se ha considerado que los cambios son estudiados sobre una base de datos cartográfica en la que se conoce las clases previas de cada uno de los parcelas de la base de datos. Existen diversos estudios en los que se ha combinado análisis de imágenes con información extraída de bases de datos cartográficas (Gilichinsky y Peled, 2014; Hoffer, 1975; Peled, 1994; Recio et al., 2011; Walter, 2004). Del mismo modo, se pretende combinar las características extraídas por métodos de análisis de imágenes a nivel de objeto (espectrales, textura, forma, tridimensionales, geoestadísticas y de fragmentación) para la clasificación, junto con la información de la clase previa de usos del suelo de los objetos como si de una base de datos cartográfica se tratase para la detección de cambios.

En estudios recientes se ha utilizado, como en este caso, la información contenida en bases de datos de usos del suelo con el fin de detectar cambios en dichas bases de 
datos, (Gilichinsky y Peled, 2014; Gladstone et al., 2012; Recio et al., 2011), comparando esta información con los resultados de clasificación de imágenes. Hoffer (1975) utilizó la información contenida en una base de datos como información adicional en estudios de clasificación. Un caso más actualizado es el de Recio et al. (2011), en el que se realizó un estudio sobre el efecto que tenía la inclusión de información de usos del suelo de fechas anteriores como una característica descriptiva más para la clasificación orientada a objetos aplicado en métodos de post-clasificación, obteniendo altos porcentajes de errores indetectables cuanto mayor era la fiabilidad de la base de datos.

Al emplear el método de clasificación directa, se parte de la ventaja de que al introducir información sobre las dos épocas de estudio a la vez, los posibles errores contenidos en la base de datos sobre la clase previa, no afectan del mismo modo que si se tratase del método de post-clasificación. En cambio, si se emplease el método de post-clasificación únicamente empleando la clase previa como clase inicial, los posibles errores en la base de datos se verían reflejados directamente en las fiabilidades de clasificación y detección de cambios.

En la Tabla 4.15 se puede ver una síntesis de los métodos del ensayo IV realizado.

\begin{tabular}{|c|c|}
\cline { 2 - 2 } \multicolumn{1}{c|}{} & Ensayo IV \\
\hline \hline Zona de estudio & Valencia \\
\hline \hline Metodología & \\
\hline Características empleadas & Selección de características de ensayos previos \\
\hline Clases de estudio & Clases de cambio \\
\hline Algoritmos empleados & Árboles de decisión J48 \\
\hline Métodos de detección de cambios & Clasificación directa \\
\hline Métodos de evaluación & Matrices de confusión \\
\hline
\end{tabular}

Tabla 4.15: Características generales del ensayo realizado empleando el conjunto total de características.

Los objetivos generales del ensayo IV son:

- Analizar y comparar los diferentes grupos de características empleados en este trabajo.

- Testear una metodología de detección de cambios mediante características temporales combinadas con información de bases de datos de ocupación del suelo. 



\section{Capítulo 5}

\section{Resultados}

En este capítulo se muestran los resultados de los ensayos realizados para la detección de cambios empleando las diferentes características extraídas descritas en el apartado de metodología.

Los resultados están separados por ensayos realizados sobre dos zonas de estudio diferentes. Para los ensayos realizados en la zona de estudio de Valencia, se ha utilizado el conjunto de características no temporales, entre las que se encuentran las características de fragmentación y tridimensionales. Para la obtención de estas es necesaria información espacial procedente de los modelos digitales de superficie. Para los ensayos realizados en la zona de Murcia, se han empleado las variables temporales. Debido a la naturaleza agrícola de la zona de Murcia, los estudios de variables temporales se han centrado en las características de estructura interna de las parcelas.

En el primer ensayo se emplean los métodos de post-clasificación y clasificación directa para la detección de cambios empleando el conjunto de características clásicas (espectrales, textura y forma) y características tridimensionales sobre la zona de Valencia.

El segundo ensayo se centra en la zona de Murcia, en el que se analiza el nuevo conjunto de características derivadas del semivariograma cruzado y codispersión y se realiza el estudio de detección de cambios empleando el método de clasificación directa. Además, se comparan estos resultados con los resultados de detección de cambios obtenidos mediante características derivadas del semivariograma.

En el tercer ensayo se realiza el estudio de características de fragmentación sobre la zona de Valencia, en donde se estudia el comportamiento de las características mediante el conjunto de parcelas sintéticas y, posteriormente, se generan y se evalúan los mapas 
de coberturas de las dos fechas de estudio. El estudio de detección de cambios utilizando características de fragmentación se realiza mediante el método de clasificación directa.

En el último ensayo se comparan los resultados de clasificación y detección de cambios mediante clasificación directa de los diferentes grupos de características estudiados y seleccionados a lo largo de esta tesis.

\subsection{Resultados del ensayo I. Análisis y estudios de clasificación de las características extraídas de datos LiDAR}

En este apartado se recogen los resultados obtenidos durante el estudio de las características extraídas de los modelos digitales LiDAR. En un primer lugar se muestran los resultados obtenidos empleando el método de post-clasificación, en el cual se comparan las clasificaciones de dos fechas de estudio y la detección de cambios con y sin características tridimensionales (Ensayo I.A). En segundo lugar, se muestran los resultados del método de clasificación directa con y sin características tridimensionales (Ensayo I.B). En la Figura 5.1 se muestra el esquema de los dos subensayos realizados como parte del ensayo I.

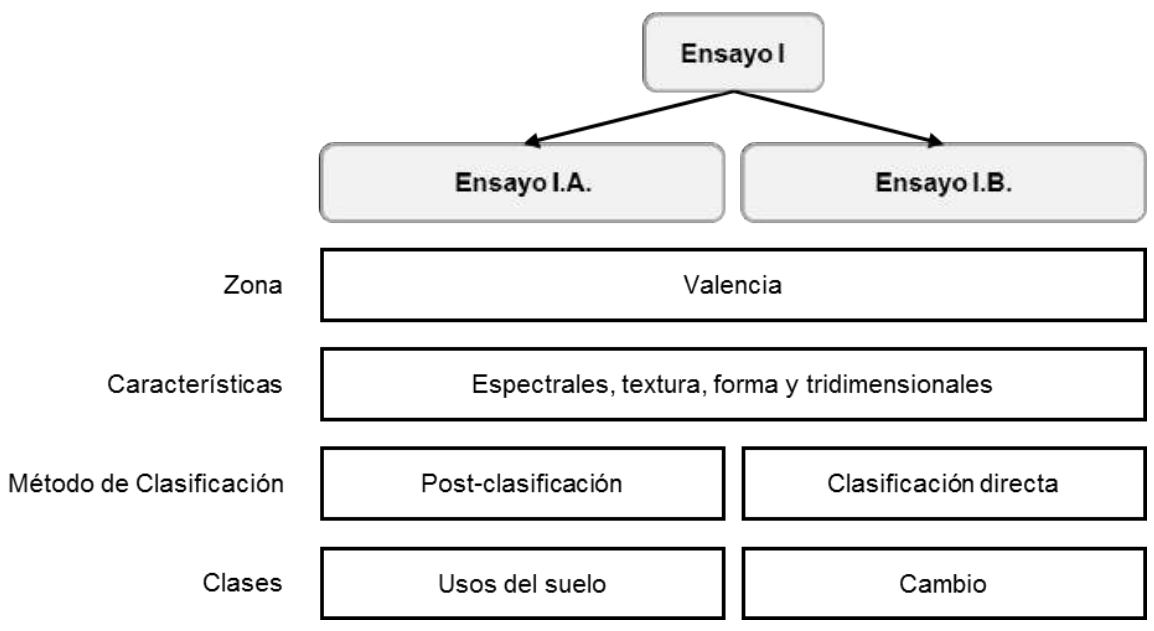

Figura 5.1: Esquema del Ensayo I. 


\subsubsection{Resultados del ensayo I.A. Efecto de las característi- cas tridimensionales en métodos de detección de cam- bios orientados a objetos basados en post-clasificación de imágenes}

En las Figuras 5.2 y 5.3 se pueden observar las gráficas de fiabilidades de productor y usuario para cada una de las clases estudiadas para las clasificaciones de 2004 y 2008 así como las matrices de confusión, empleando y no empleando características tridimensionales junto con las características espectrales, de forma y de textura. Los resultados sin características tridimensionales muestran valores altos de fiabilidades de productor y usuario en ambas clasificaciones. Existen excepciones como la clase yermo, en la que hay cierta confusión debido a la propia naturaleza y variabilidad de la clase, y entre las clases de edificios rurales e industriales con edificios urbanos. Estos errores de confusión son más notables en la clasificación empleando la imagen del PNOA de 2008.

$\mathrm{Al}$ incluir en las clasificaciones las características tridimensionales las fiabilidades de usuario y productor aumentan notablemente en ambas fechas. El aumento de las fiabilidades es más destacado en las clases de edificio rural e industrial y en la clase yermo, clases que presentaban confusión entre ellas. A pesar de haber mejorado considerablemente, la clase yermo es la clase que presenta las menores fiabilidades.

Las características tridimensionales aportan información sobre las alturas existentes en las parcelas, beneficiando principalmente a las clases de árboles y edificios y reduciendo la confusión con otras clases y entre ellas mismas. Estas características aumentan las fiabilidades de usuario y productor de las clases de estudio además de las fiabilidades globales de las clasificaciones. Los valores de fiabilidad global de las clasificaciones se pueden observar en la Figura 5.4, en la que las fiabilidades aumentan en más de un $5 \%$ al emplear las características tridimensionales.

Tras la obtención de los resultados de las clasificaciones, las clases resultantes de 2004 se comparan con las de 2008 para obtener los cambios empleando el diagrama de cambios de la Figura 4.9. Estos a su vez se comparan con las referencias y se calculan las matrices de confusión de la detección de cambios. En las gráficas de la Figura 5.5 se muestran las fiabilidades de las clases de cambio obtenidas con el método de post-clasificación al comparar los cambios calculados con las parcelas de referencia además de las matrices de confusión generadas. 

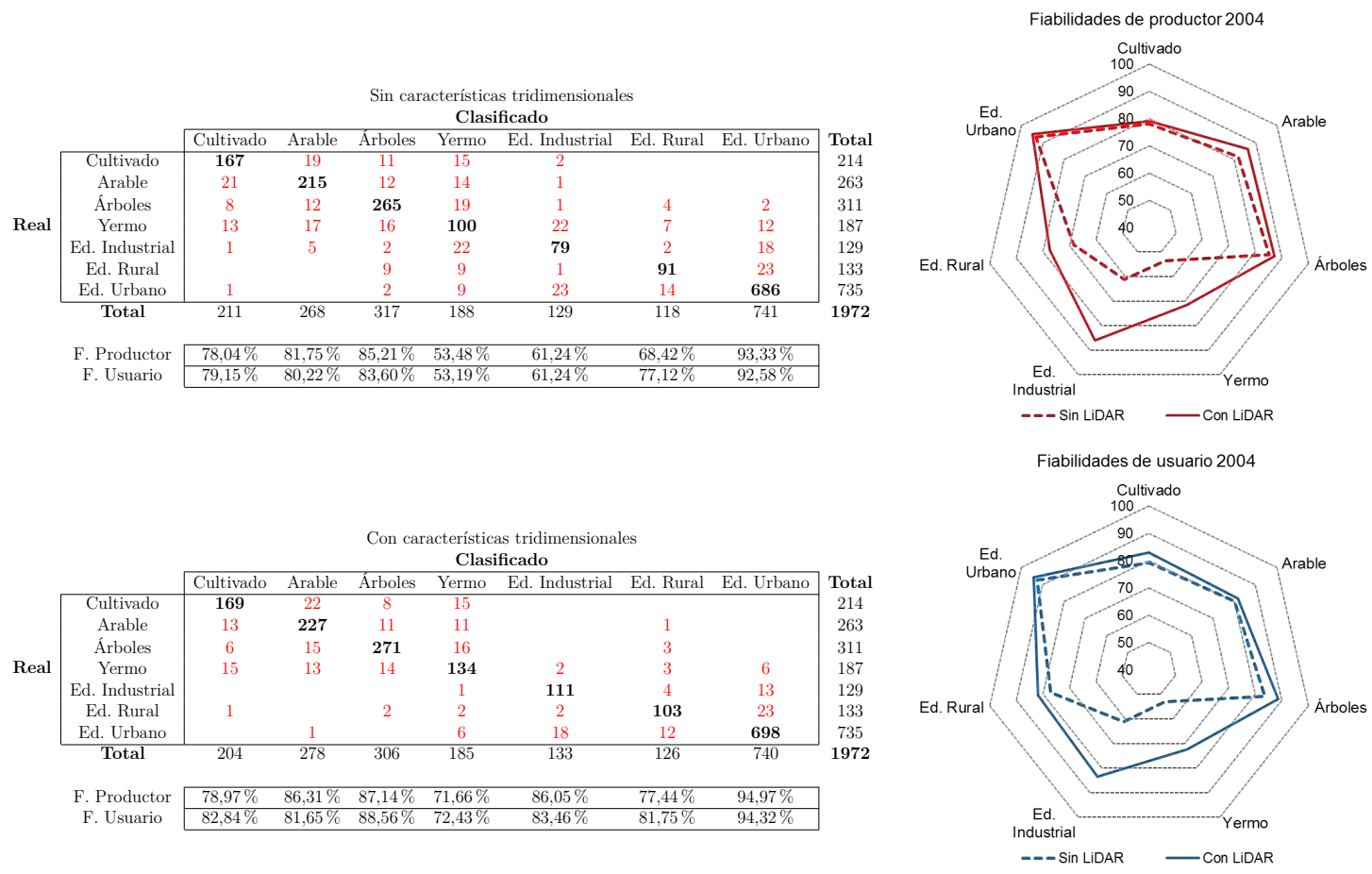

Figura 5.2: Matrices de confusión de clasificaciones mediante árboles de decisión de la imagen QuickBird de 2004 empleando y sin emplear características tridimensionales derivadas de datos LiDAR y gráficas comparativas de fiabilidades de productor y usuario.

$\mathrm{Al}$ analizar las fiabilidades obtenidas en las clases de cambio por el método de postclasificación se observa que se produce una mejora general en todos los tipos de cambio excepto en la clase de terreno arable a terreno cultivado (CC1), en la que los resultados de fiabilidad disminuyen ligeramente. Aquellas clases relacionadas con edificios, como las demoliciones (DEM) y nuevos edificios (NED), aumentan sus fiabilidades considerablemente, así como las nuevas plantaciones (NPL).

Los resultados generales de los cambios se muestran en la Figura 5.6, obtenidos mediante la matriz de confusión de cambios comparando valores antes y después de incluir las características tridimensionales en el estudio. 


\subsection{Resultados del ensayo I. Análisis y estudios de clasificación de las características extraídas de datos LiDAR}
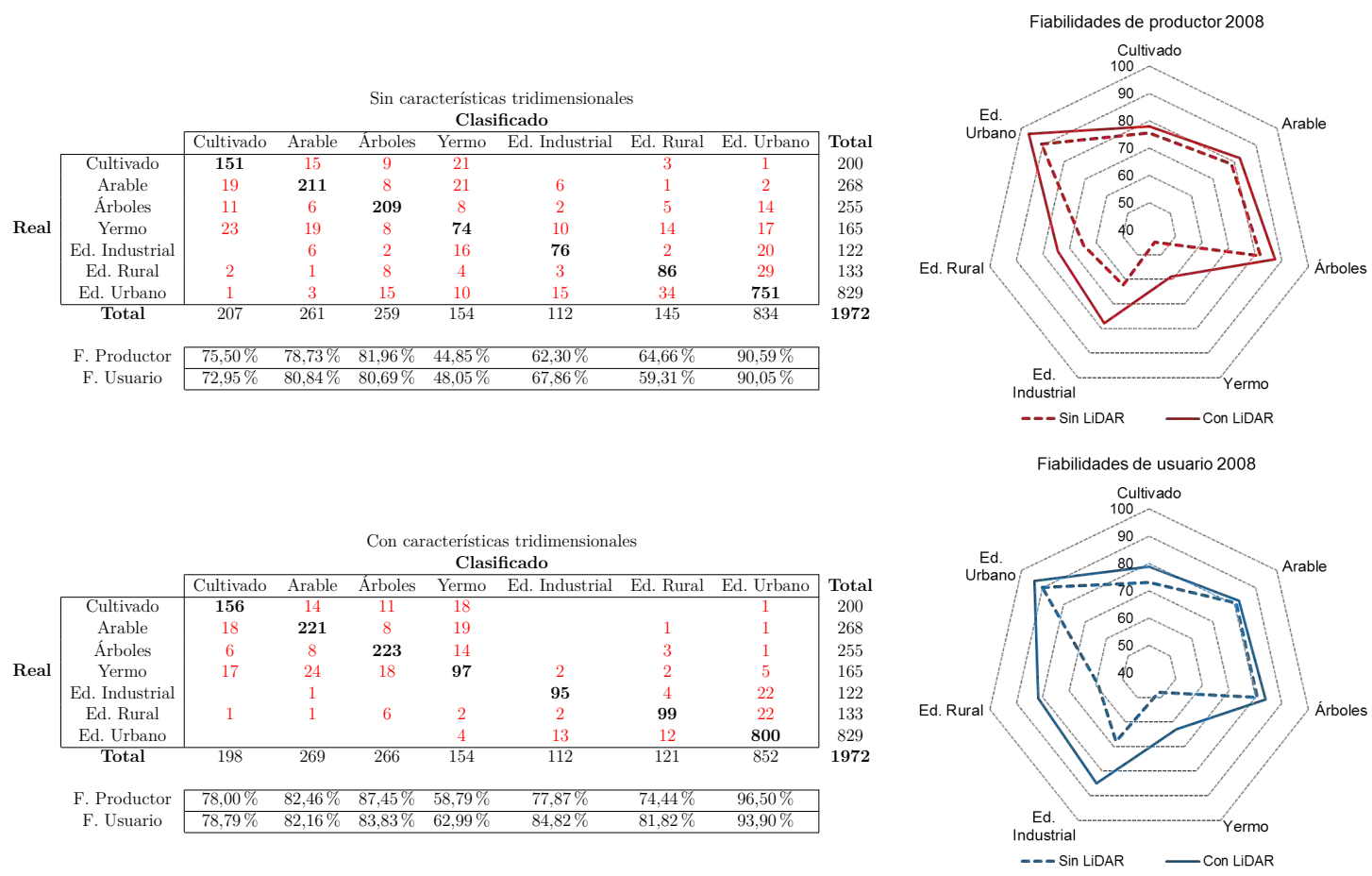

Figura 5.3: Matrices de confusión de clasificaciones mediante árboles de decisión de la imagen PNOA de 2008 empleando y sin emplear características tridimensionales derivadas de datos LiDAR y gráficas comparativas de fiabilidades de productor y usuario.

\section{Fiabilidades globales de clasificación}

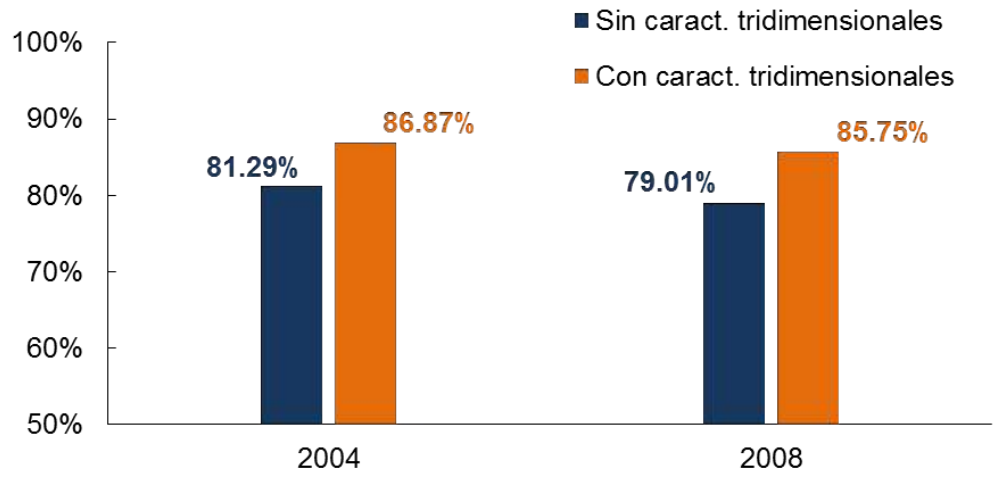

Figura 5.4: Fiabilidades globales de las clasificaciones de 2004 y 2008 empleando y sin emplear características tridimensionales. 

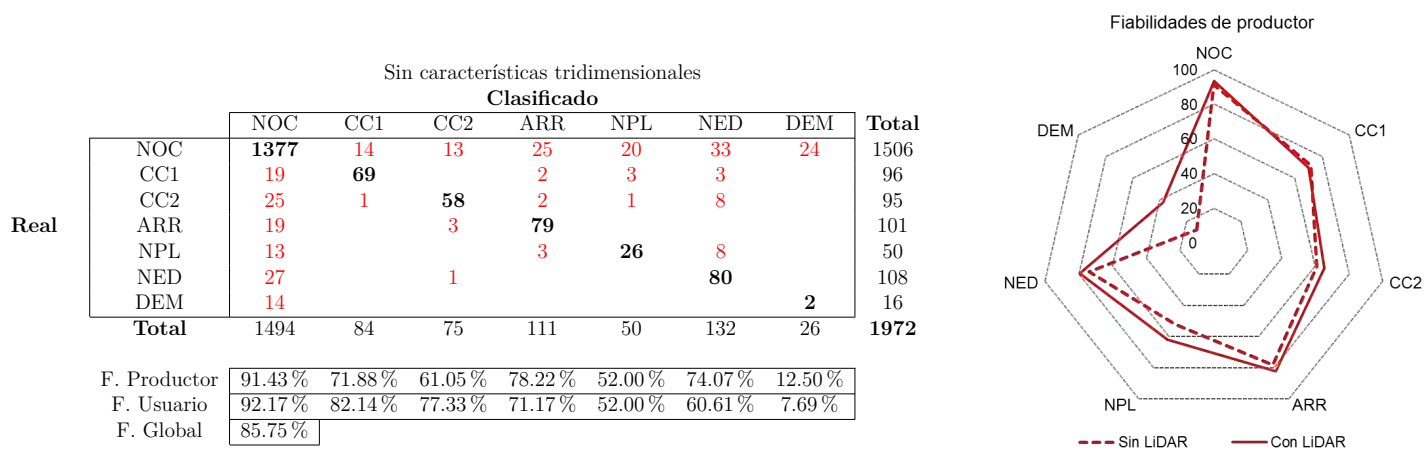

--- Sin LIDAR —CON LIDAR

Fiabilidades de usuario
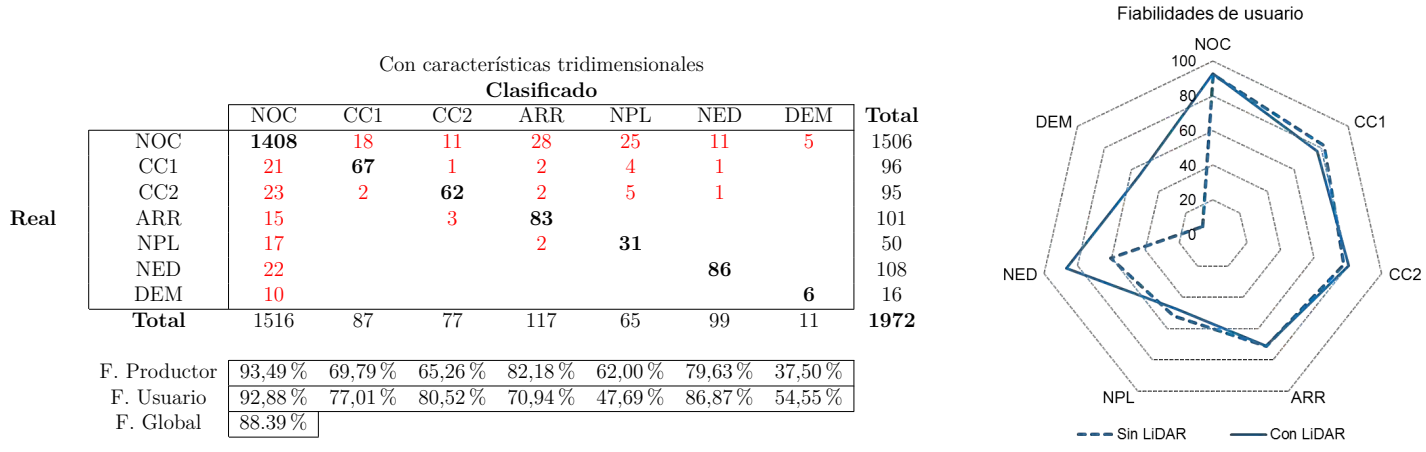

Figura 5.5: Matrices de confusión de la detección de cambios por el método de post-clasificación empleando y sin emplear características tridimensionales derivadas de datos LiDAR y gráficas comparativas de fiabilidades de productor y usuario (siendo NOC la clase de no cambio, CC1 la clase de terreno arable a terreno cultivado, $\mathrm{CC} 2$ la clase de terreno cultivado a terreno arable, ARR arranques, NPL nuevas plantaciones, NED nuevos edificios y DEM demoliciones).

En la gráfica de fiabilidades de la detección de cambios (Figura 5.6) se puede observar que al incluir las características tridimensionales se obtienen resultados ligeramente más elevados tanto para las parcelas de cambio como para las parcelas que no han cambiado (coincidencias). También se ha reducido el número de errores por defecto y por exceso. Centrando los resultados en las parcelas de cambio, no se ha producido una mejora considerable en la detección de cambios, ya que los valores de cambios detectados y errores por defecto son parecidos en ambos casos, pero se ha conseguido reducir el número de errores por exceso -falsos positivos- y clasificarlos correctamente como coincidencias, lo que hace aumentar también la fiabilidad total del método de detección de cambios.

Los porcentajes de detección y calidad obtenidos sin emplear las características tridimensionales son $74,89 \%$ y 58,66\% respectivamente, mientras que al emplear características tridimensionales los valores obtenidos son $76,82 \%$ y $63,48 \%$. Tanto el porcentaje de detección como el de calidad han aumentado al incluir las características tridimensionales en el método, especialmente la calidad en la detección. 


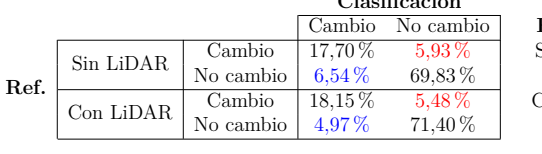

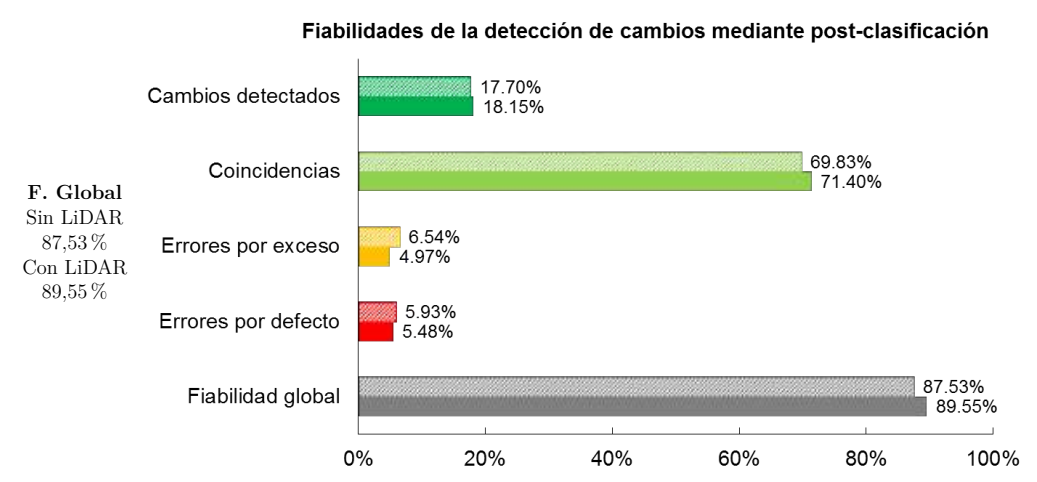

Figura 5.6: Matrices de confusión de detección de cambios por el método de post-clasificación empleando y no empleando características tridimensionales derivadas de datos LiDAR y gráfica de fiabilidades globales de las detecciones de cambio empleando características tridimensionales (relleno sólido) y sin emplear características tridimensionales (relleno tramado).

A pesar de que las características tridimensionales mejoran ligeramente los resultados de clasificación y detección de cambios, los errores por exceso siguen siendo elevados $(4,97 \%)$. Sobre estos errores de detección de cambios también están contemplados los errores producidos en las clasificaciones, debido a que en el método de post-clasificación se arrastran los de las clasificaciones a los resultados finales de detección de cambios. Es por esto que se ha realizado el mismo estudio de detección de cambios empleando el método de detección de cambios por clasificación directa y así observar si se mejoran los resultados de detección.

\subsubsection{Resultados Ensayo I.B. Clasificación directa orientada a objetos empleando características tridimensionales con significado temporal}

Las clases empleadas para la clasificación en este método son las clases de cambio, por lo que se obtuvieron los resultados de la detección de cambios al realizar la clasificación agrupando las clases de cambios. En la Figura 5.7 se pueden ver las fiabilidades de productor y usuario de las clases de estudio de la clasificación directa. Los valores de fiabilidad tanto de productor como de usuario aumentan para todas las clases al incluir las características tridimensionales empleando este método, especialmente las clases relacionadas con edificios. Las matrices de confusión de las clasificaciones directas empleando y sin emplear características tridimensionales, se pueden ver en la Figura 5.7. 

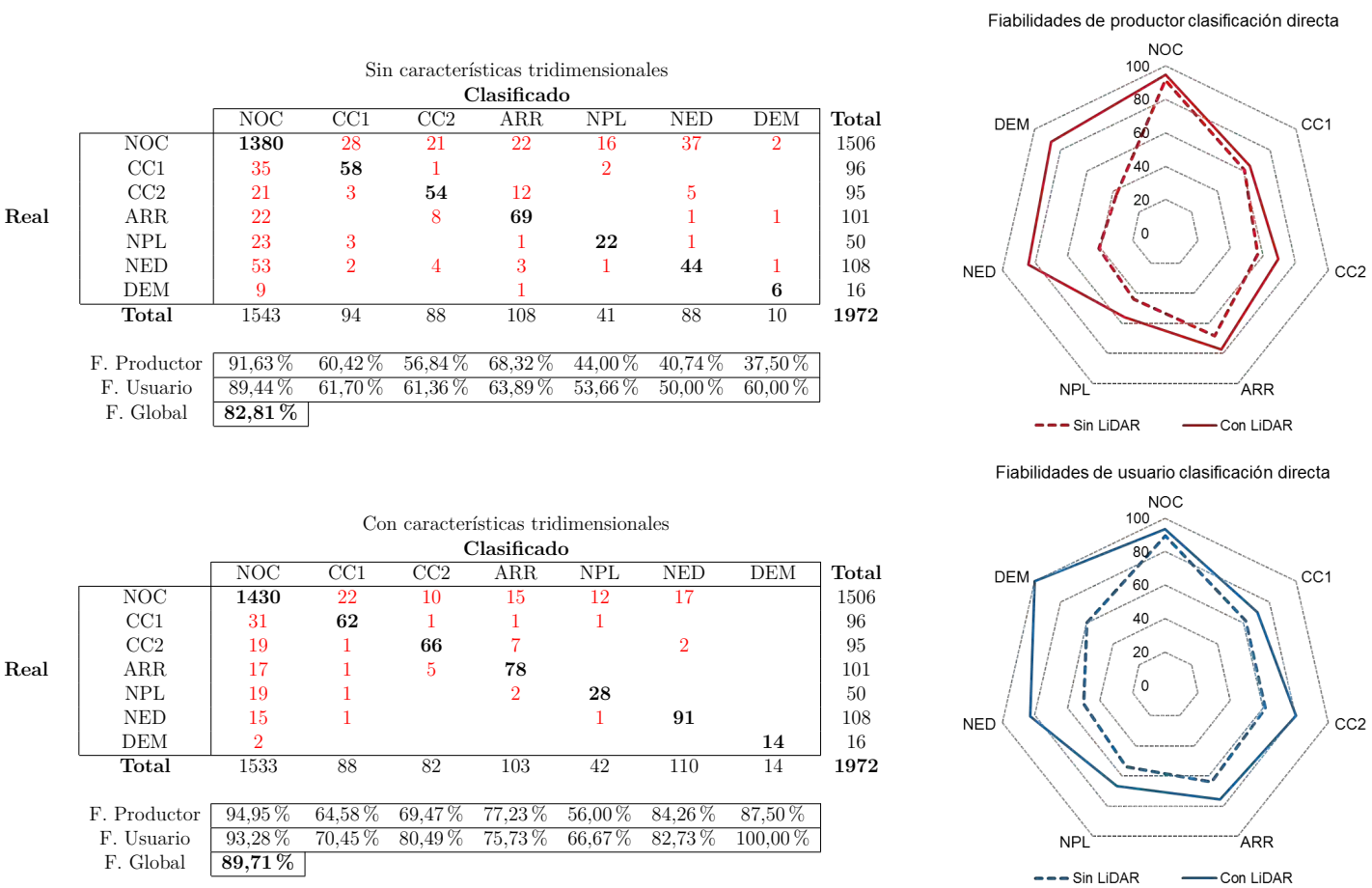

Figura 5.7: Matrices de confusión de clasificaciones directas empleando y sin emplear características tridimensionales derivadas de datos LiDAR y gráficas comparativas de fiabilidades de productor y usuario (siendo NOC la clase de no cambio, CC1 la clase de terreno arable a terreno cultivado, CC2 la clase de terreno cultivado a terreno arable, ARR arranques, NPL nuevas plantaciones, NED nuevos edificios y DEM demoliciones).

En la Figura 5.8 se pueden observar los resultados de detección de cambios obtenidos a partir de la matriz de confusión de cambios usando el método de clasificación directa. La inclusión de las características tridimensionales afecta en gran medida a la clasificación directa reduciendo el número de errores y aumentando las detecciones y coincidencias, lo que resulta en un aumento de un $85,34 \%$ hasta un $90,92 \%$ en la fiabilidad global del sistema. Los porcentajes de detección y de calidad para este método son $65,02 \%$ y $51,18 \%$ cuando no se emplean características tridimensionales, y del 77,90\% y 66,97\% respectivamente cuando se emplea este tipo de características.

Si se comparan estos resultados con el método de post-clasificación, se puede observar que se obtiene un ligero aumento en la fiabilidad global con el método de clasificación directa debido a que se reducen los errores por exceso, aumentando el número de coincidencias detectadas. El número de cambios detectados apenas aumenta, sin conseguir una reducción significativa en el número de errores por defecto. A pesar de ello, en la clasificación directa empleando características tridimensionales, se obtienen mejores resultados en aquellas clases en las que las alturas de los elementos son cruciales para 


\subsection{Resultados del ensayo I. Análisis y estudios de clasificación de las características extraídas de datos LiDAR}

su clasificación, como los edificios y los árboles. En las clases de nuevos edificios y demoliciones se ha conseguido aumentar la detección de cambios y reducir errores tanto por exceso como por defecto. Las clases de arranques y nuevas plantaciones son algo más complicadas debido a la variabilidad de las clases y usos de suelo que intervienen en estos cambios. Aun así, sus fiabilidades aumentan al emplear las características tridimensionales. En el estudio, los peores resultados se obtienen en las clases de nuevas plantaciones y cambios en cultivos de tipo 1 (CC1 - de arable a cultivado), con valores de fiabilidad de productor del 56,00\% y 64,58\% y fiabilidad de usuario del $66,67 \%$ y $70,45 \%$ sin utilizar y utilizando características tridimensionales, respectivamente.

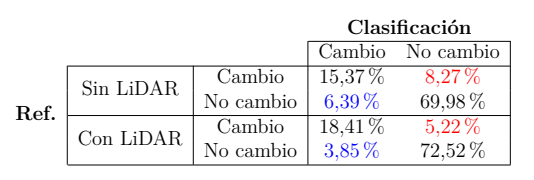

$$
\begin{gathered}
\text { F. Global } \\
\text { Sin LiDAR } \\
85,34 \% \\
\text { Con LiDAR } \\
90,92 \%
\end{gathered}
$$

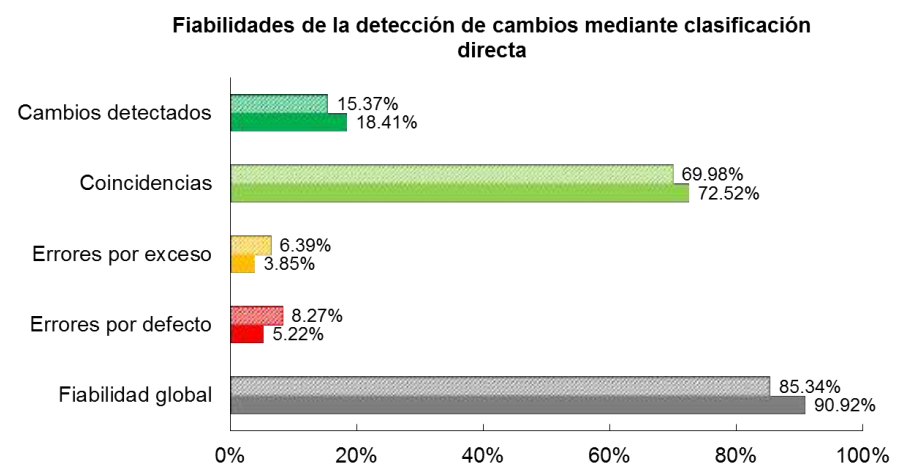

Figura 5.8: Matrices de confusión de detección de cambios por clasificación directa empleando y no empleando características tridimensionales derivadas de datos LiDAR y gráfica de fiabilidades globales de las detecciones de cambio empleando características tridimensionales (relleno sólido) y sin emplear características tridimensionales (relleno tramado).

A pesar de no existir una diferencia entre resultados notable al emplear diferentes metodologías de detección de cambios, los valores de clasificación directa muestran una reducción de los errores en la detección de cambios, especialmente en los errores por exceso y un aumento en las coincidencias. 


\subsection{Resultados del ensayo II. Estudio de detección de cambios empleando nuevas características bi- temporales derivadas de funciones geoestadísti- cas}

En este apartado se muestran los resultados obtenidos del estudio de características derivadas de la codispersión y semivariograma cruzado. Este estudio de detección de cambios está descrito en el Capítulo 4 de la Metodología, sección 4.2.3. Primero se ha descrito y analizado el comportamiento de las funciones del semivariograma cruzado y codispersión para la detección de cambios a nivel de objetos. Tras analizar el comportamiento de estas funciones, se ha realizado la selección de variables mediante análisis discriminante y componentes principales. Una vez realizada la selección de variables, se ha llevado a cabo la clasificación y se han obtenido los resultados de detección de cambios (Ensayo II.A) Los resultados obtenidos tras el análisis del comportamiento de las funciones, la selección de características y detección de cambios se han publicado en el artículo Gil-Yepes et al. (2016). Como estudio final se han comparado la clasificación y detección de cambios de estas nuevas variables con la clasificación y detección de cambios empleando diferencias simples entre variables espectrales y variables derivadas de los semivariogramas de las dos fechas de estudio (Ensayo II.B). En la Figura 5.9 se muestra un resumen de los subensayos pertenecientes al ensayo II.

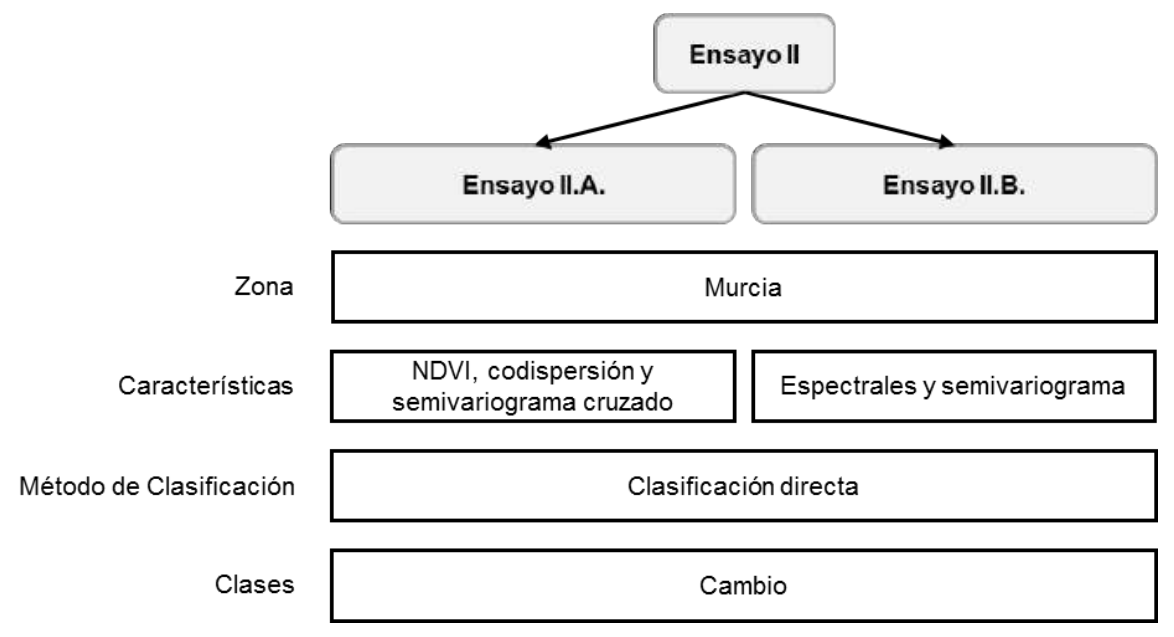

Figura 5.9: Esquema del Ensayo II. 
5.2 Resultados del ensayo II. Estudio de detección de cambios empleando nuevas características bitemporales derivadas de funciones geoestadísticas

\subsubsection{Resultados del análisis del comportamiento de las fun- ciones geoestadísticas a nivel de objeto para la detección de cambios}

En las parcelas con clase de no cambio el semivariograma cruzado y la codispersión se comportan de manera similar al semivariograma (Figura 5.10a y 5.10b). Los semivariogramas de las parcelas que tienen un patrón de plantación de árboles muestran un comportamiento cíclico. Por el contrario, los semivariogramas que representan superficies homogéneas (como por ejemplo, el uso del suelo arable), crecen desde el primer lag hasta el primer máximo, a partir del cual los valores de la semivarianza se estabilizan (Figuras 5.10c y 5.10e). Además, los valores de codispersión en parcelas que presentan cambio tienen un valor absoluto menor que las parcelas de no cambio. La forma que presentan las funciones del semivariograma cruzado y de la codispersión varían dependiendo del tipo de cambio (Figura 5.10d y 5.10f).

El comportamiento cíclico de las parcelas de no cambio (Figura 4.10a y 4.10b) se puede diferenciar en ambos, semivariograma cruzado (Figura 5.10b) y semivariogramas de las dos fechas (Figura 5.10a). En estas parcelas los valores de codispersión son diferentes de 0, especialmente a media y larga distancia (Figura 5.10b), lo que implica cierta correlación entre los valores de los niveles digitales en las dos épocas.

En la Figura 5.10c se muestran los semivariogramas de la clase de arranques para el caso de las Figuras 4.10c y 4.10d. En el semivariograma de la primera fecha se puede diferenciar el comportamiento cíclico típico de parcelas con árboles dispuestos en hileras. En la segunda fecha, los valores de la semivarianza son menores y la forma de la gráfica del semivariograma muestra un comportamiento lineal creciente sin ningún valor de máximo o mínimo local. Estas diferencias entre los semivariogramas también se pueden distinguir en las funciones del semivariograma cruzado y la codispersión (Figura 5.10d). Los valores del semivariograma cruzado son considerablemente menores en las parcelas de cambio que en las de no cambio. Esto tiene un efecto en la pendiente del primer lag y también en los valores de media y desviación estándar del semivariograma cruzado hasta el primer máximo. Todos los valores de codispersión son cercanos a 0 para todas las distancias de lag, lo que indica una baja correlación entre los valores de la banda del rojo de la parcela entre las dos épocas y por lo tanto, la existencia de cambios dentro de la parcela. 


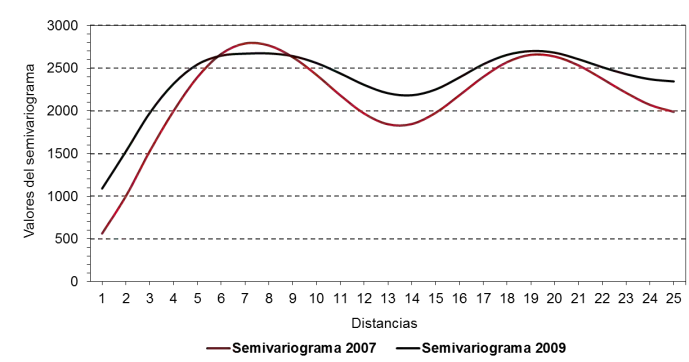

(a) Gráfica de los semivariogramas pertenecientes a una parcela de la clase de no cambio en 2007 y 2009.

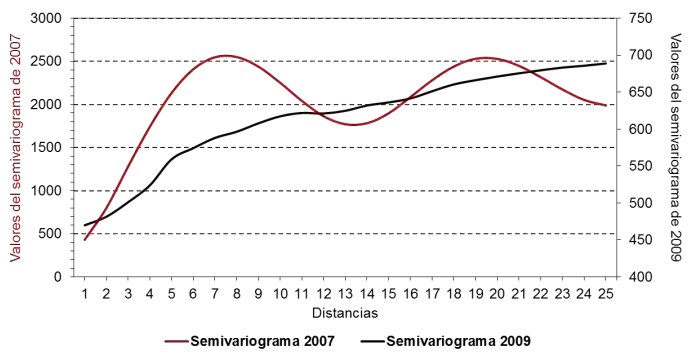

(c) Gráfico multieje de los valores del semivariograma de 2007 (izquierda) y de 2009 (derecha) para una parcela de la clase de arranques.

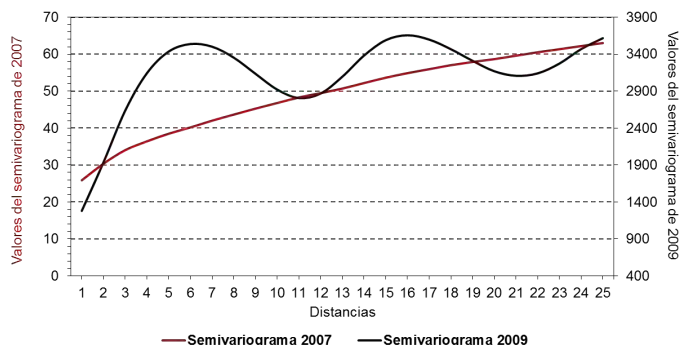

(e) Gráfico multieje de los valores del semivariograma de 2007 (izquierda) y de 2009

(derecha) para una parcela de la clase de nuevas plantaciones.

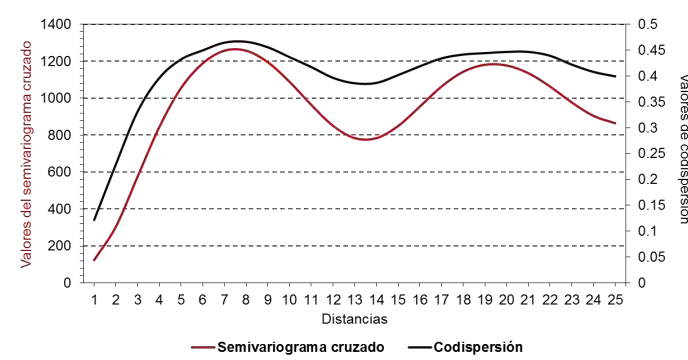

(b) Gráfico multieje de valores de semivariograma cruzado (izquierda) y valores de codispersión (derecha) de una parcela de clase de no cambio.

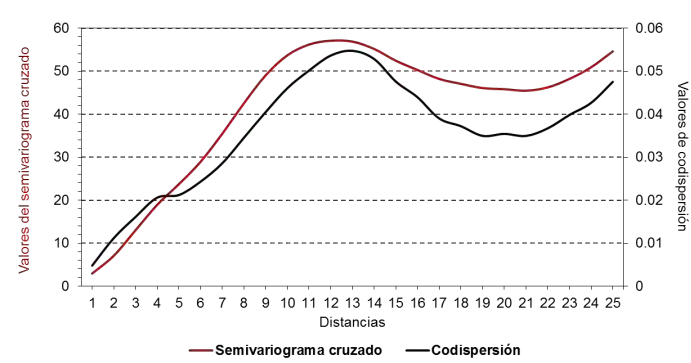

(d) Gráfico multieje de los valores del semivariograma cruzado (izquierda) y valores de codispersión (derecha) para una parcela de la clase de arranques.

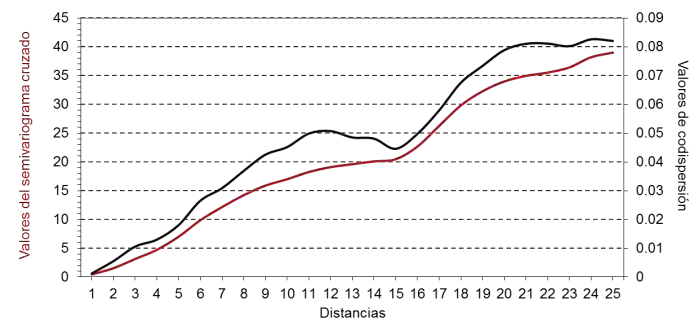

(f) Gráfico multieje de los valores del semivariograma cruzado (izquierda) y valores de codispersión (derecha) para una parcela de la clase de nuevas plantaciones.

Figura 5.10: Semivariogramas, semivariograma cruzado y codispersión de las parcelas de ejemplo de la Figura 4.10. 
Como en el caso anterior de cambio para la clase de arranques, las parcelas con clase de nuevas plantaciones (Figura 4.10e y 4.10f), presentan valores de semivariograma cruzado menores (Figura 5.10f), pero en este caso, pierde el comportamiento cíclico y muestra una pendiente creciente. Los valores de codispersión también son menores a 0.1 (Figura 5.10f).

\subsubsection{Resultados de selección de variables de diferencias de NDVI, semivariograma cruzado y codispersión}

La Figura 5.11 representa los valores de correlación entre las diferentes variables estudiadas en forma de matriz de colores. En esta matriz, los colores más oscuros se corresponden con valores de correlación elevados, mientras que los colores más claros representan valores bajos de correlación. En la matriz obtenida para el conjunto de características del semivariograma cruzado y codispersión (Figura 5.11), se destaca la alta correlación existente entre algunas de estas características, mostrando por ejemplo, una fuerte relación entre varias características del semivariograma cruzado: la primera derivada cerca del origen (CS_FDO), los valores de media hasta el primer máximo (CS_MFM), y los valores de varianza hasta el primer máximo (CS_VFM). La información obtenida en los lags cercanos al origen de la función está contenida en estas tres características. Valores elevados de semivariograma cruzado genera valores elevados de la pendiente cerca del origen y un incremento de los valores de media y desviación hasta el primer máximo. Estas características mantienen una gran correlación con los valores de media y desviación estándar de la codispersión (CO_MEAN y CO_STD) y con el valor de la codispersión en el primer mínimo local (CO_VMIN1). Además, también hay una alta correlación entre la posición del primer máximo local del semivariograma cruzado (CS_SMAX1) y la distancia entre el primer máximo y el primer mínimo del semivariograma cruzado (CS_DMM); y entre la posición del máximo local (CO_SMAX1) y la posición del primer mínimo local (CO_SMIN1) de la codispersión. Esto es debido a similitudes entre las funciones del semivariograma cruzado y la codispersión, especialmente en las parcelas de no cambio. 


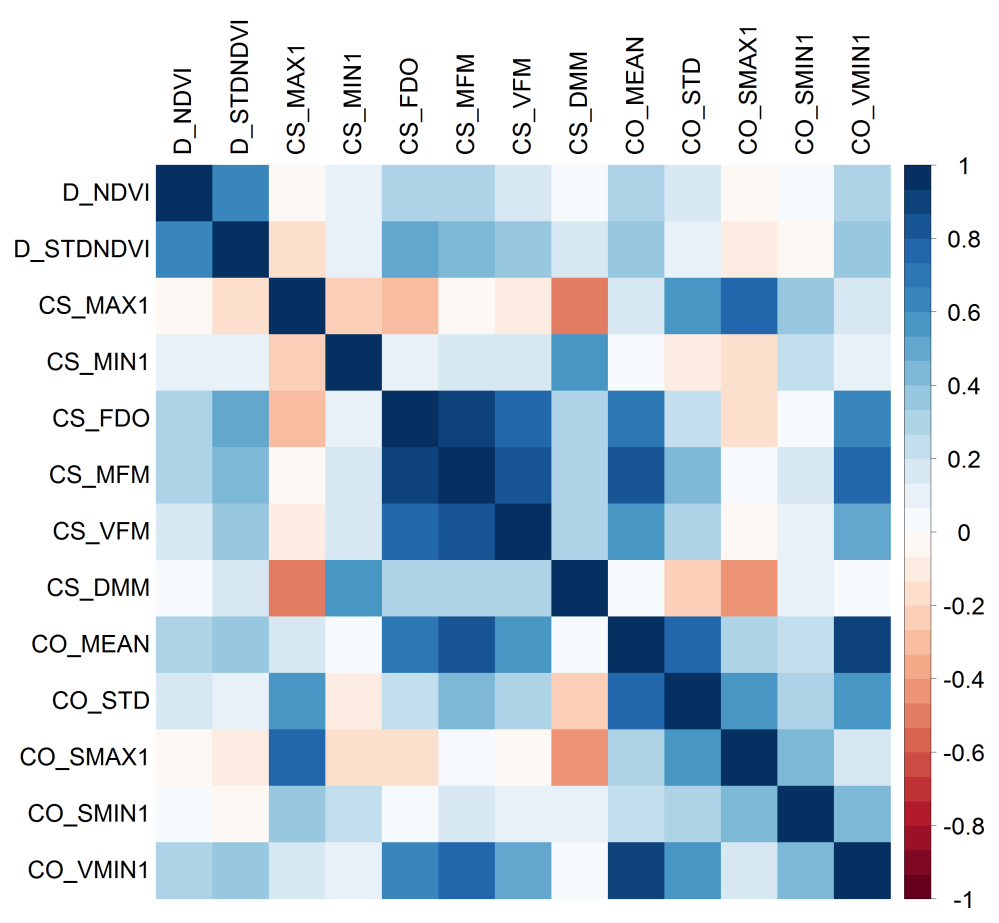

Figura 5.11: Matriz de valores de correlación entre variables espectrales, codispersión y semivariograma cruzado. Los valores de mayor magnitud con colores más oscuros (azul oscuro y rojo oscuro) representan una mayor correlación.

\subsubsection{Resultados de la selección de variables del semivariograma cruzado}

La Figura 5.12 muestra la fiabilidad global y por clases obtenida con el análisis discriminante paso a paso a partir de las características del semivariograma cruzado. El valor de la fiabilidad global está directamente relacionada con la clase de no cambio debido a que esta es la clase que mayor frecuencia presenta. Los valores de la fiabilidad de los resultados obtenidos para las otras dos clases de estudio son bastante irregulares y dependientes de las características introducidas en cada paso del análisis discriminante.

La clase de arranques obtiene la mayor fiabilidad al introducir la primera característica en el sistema, que es la media de los valores del semivariograma cruzado hasta el primer máximo (CS_MFM). Esta característica permite distinguir entre la clase de no cambio y arranques. Cuando se incluye la varianza de los valores hasta el primer máximo (CS_VFM), aumenta la fiabilidad de la clase de no cambios pero disminuye la fiabilidad de la detección de arranques. Al incluir la distancia entre el primer máximo y el primer mínimo (CS_DMM), mejora la fiabilidad de nuevas plantaciones. Al introducir el resto de características, aumentan la confusión entre las clases de arranques y 


\subsection{Resultados del ensayo II. Estudio de detección de cambios empleando nuevas características bitemporales derivadas de funciones geoestadísticas}

nuevas plantaciones. A pesar de ello, la clase de no cambio es la que obtiene mayores fiabilidades.

Fiabilidades análisis discriminante - Semivariograma cruzado

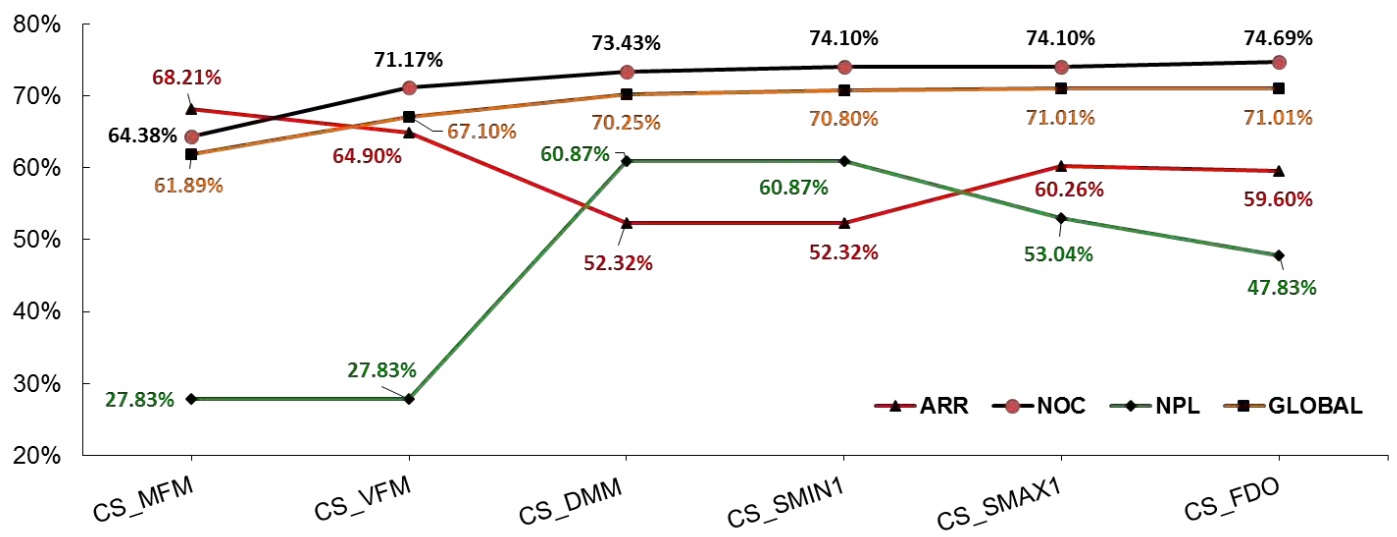

Figura 5.12: Fiabilidad global y fiabilidades predichas por clases de las variables del semivariograma cruzado empleando análisis discriminante paso a paso (siendo NOC la clase de no cambio, ARR arranques y NPL nuevas plantaciones). Características añadidas en orden de izquierda a derecha.

La Figura 5.13 muestra las fiabilidades del análisis discriminante cuando se emplean las características espectrales junto con las características del semivariograma cruzado. Las dos características espectrales son seleccionadas en los dos primeros pasos del análisis. Al incluir la media de los valores hasta el primer máximo del semivariograma cruzado (CS_MFM), se obtienen fiabilidades superiores al $80 \%$ para todas las clases de estudio. De esta forma disminuye la confusión entre la clase de no cambios y nuevas plantaciones que se produce cuando únicamente se usan las dos variables espectrales.

La Figura 5.14 representa la proyección de las características espectrales y del semivariograma cruzado sobre los planos de los componentes principales. Los tres primeros componentes principales explican casi el $80 \%$ de la información que aportan las características espectrales y del semivariograma cruzado. El análisis de componentes principales muestra 4 grupos diferentes en los planos estudiados. El primer grupo contiene la distancia entre el primer máximo y primer mínimo (CS_DMM) y la posición del primer mínimo (CS_SMIN1). Estas características muestran una gran correlación en la Figura 5.11, y debido a que la diferencia entre el máximo y el mínimo es seleccionada entre las dos primeras características que forman parte del sistema en el análisis discriminante, la posición del primer mínimo (CS_SMIN1) es eliminada directamente del estudio. El segundo grupo está compuesto por la derivada en el origen (CS_FDO), la varianza de los valores del semivariograma cruzado hasta el primer máximo (CS_VFM), y la media de 


\section{Resultados}

los valores hasta el primer máximo (CS_MFM). Estas características presentan valores de alta correlación entre sí (Figura 5.11) y debido a que la media de los valores hasta el primer máximo fue la primera característica incluida en el análisis discriminante tras las características espectrales, las otras dos características son rechazadas para el estudio. El tercer grupo está compuesto por las características espectrales. La característica de la situación del primer máximo (CS_SMAX1) es independiente en el primer plano, pero no tanto en el segundo. Esta característica es la sexta incluida en el análisis discriminante y está relacionada con otras características como CS_FDO, CS_VFM y CS_MFM, apareciendo cercana a estas en el CP 2-3, por lo que incluye información redundante al sistema. Por esta razón esta característica es rechazada para el estudio.

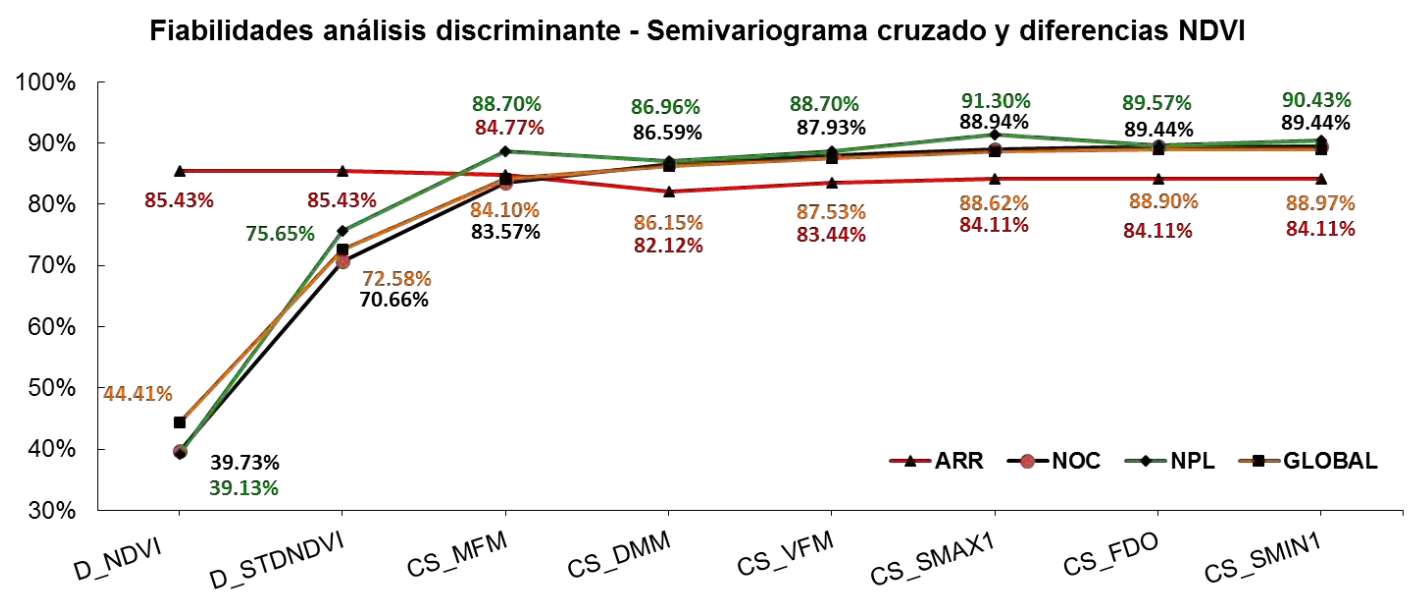

Figura 5.13: Fiabilidad global y fiabilidades predichas por clases de las variables del semivariograma cruzado y características espectrales empleando análisis discriminante paso a paso (siendo NOC la clase de no cambio, ARR arranques y NPL nuevas plantaciones). Características añadidas en orden de izquierda a derecha.

Tras el análisis de los resultados, las únicas características del semivariograma cruzado seleccionadas para la clasificación y detección de cambios son el valor de la media hasta el primer máximo (CS_MFM) y la diferencia entre el primer máximo y mínimo (CS_DMM). 


\subsection{Resultados del ensayo II. Estudio de detección de cambios empleando nuevas características bitemporales derivadas de funciones geoestadísticas}

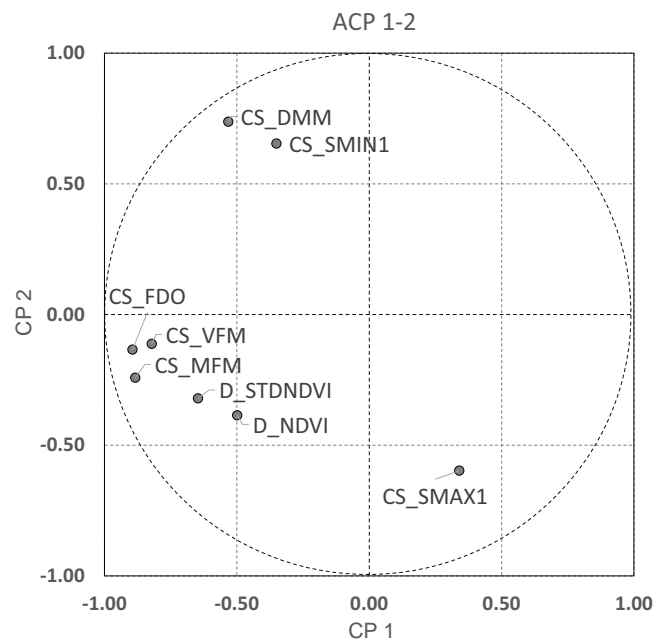

(a) Plano componentes principales (CP) 1 y 2 .

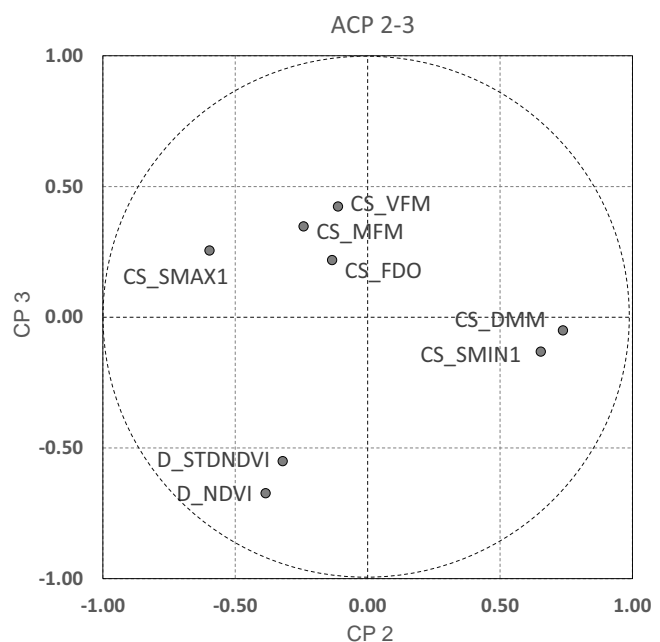

(b) Plano componentes principales (CP) 2 y 3.

Figura 5.14: Análisis de componentes principales (ACP) de características espectrales y semivariograma cruzado.

\subsubsection{Resultados de la selección de variables de codispersión}

La figura 5.15 muestra los valores de fiabilidad global y fiabilidades por clase obtenidas mediante análisis discriminante paso a paso de las características extraídas de la codispersión. El orden de la selección de variables va de izquierda a derecha.

El valor de la media de la codispersión (CO_MEAN) y la desviación estándar (CO_STD) son las dos primeras características que se introducen en el sistema, consiguiendo una fiabilidad global elevada (76,56\%). Cuando se incluyen más características en el sistema, la fiabilidad global disminuye ligeramente. El mismo comportamiento se puede observar en las fiabilidades de las parcelas de no cambio.

En la clase de nuevas plantaciones se obtienen las menores fiabilidades cuando se emplean las dos primeras variables seleccionadas. Esto es debido a la confusión que existe entre esta clase y la clase de arranques. Las nuevas plantaciones obtienen una mayor fiabilidad cuando se utilizan las 5 variables alcanzando un valor próximo al $66 \%$. Cuando se incluyen más de dos características en el sistema, la fiabilidad de la clase de nuevas plantaciones mejora al mismo tiempo que la fiabilidad de los arranques disminuye, generando confusión entre las dos clases. Por ejemplo, la Figura 5.10f muestra falsos valores de mínimos y máximos relativos, lo que puede generar confusión entre ambas clases.

La Figura 5.16 muestra las fiabilidades del análisis discriminante al incluir las características espectrales en el estudio. La primera característica que se introduce en el 


\section{Resultados}

sistema es la media de las diferencias de NDVI, y la segunda la media de los valores de la codispersión. Esta última característica dispara las fiabilidades de las clases de no cambio y de nuevas plantaciones. Cuando se incluye la desviación estándar de las diferencias de NDVI aumentan las fiabilidades de las tres clases de estudio. Tras incluir estas tres variables en el sistema, las fiabilidades se estabilizan salvo por pequeñas variaciones que se consideran irrelevantes para el sistema. Se puede observar que las fiabilidades obtenidas con las características de la codispersión son mayores que las fiabilidades obtenidas con las características del semivariograma cruzado.

Fiabilidades análisis discriminante - Codispersión

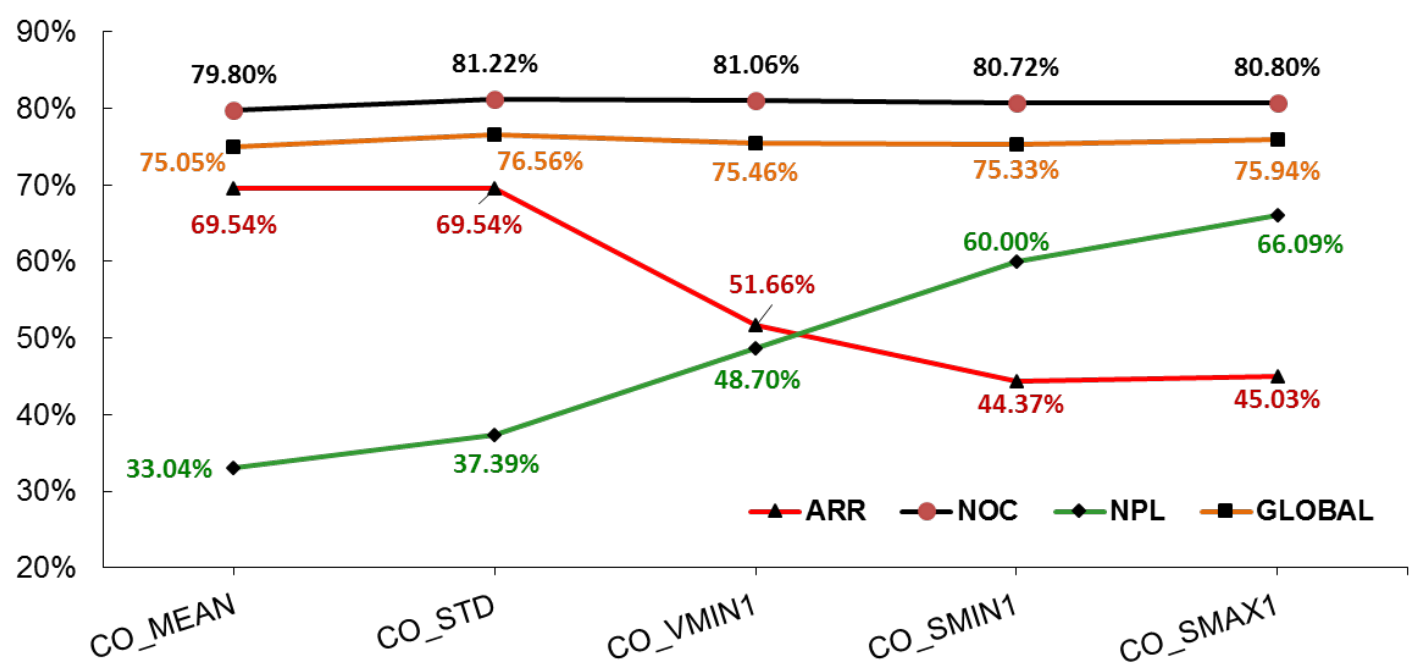

Figura 5.15: Fiabilidad global y fiabilidades predichas por clases de las variables de la codispersión empleando análisis discriminante paso a paso (siendo NOC la clase de no cambio, ARR arranques y

NPL nuevas plantaciones). Características añadidas en orden de izquierda a derecha.

La Figura 5.17 muestra las características espectrales y de codispersión proyectadas sobre los planos definidos por los tres primeros componentes principales. Estos tres componentes contienen el $80 \%$ de la varianza de los datos. En la Figura 5.17a se pueden diferenciar cuatro agrupaciones de características: la media de los valores de codispersión (CO_MEAN) y el valor de la codispersión en el primer mínimo (CO_VMIN1) forman parte de un grupo; la desviación estándar de los valores de codispersión (CO_STD) se puede considerar como independiente; la posición del valor de la codispersión del primer mínimo local (CO_SMIN1) y la posición del primer máximo (CO_SMAX1) forman parte de otro grupo; las características espectrales forman el cuarto grupo. La media de los valores de codispersión y el valor del primer mínimo pertenecen a un mismo grupo ya que proporcionan información similar con valores cercanos a cero en las parcelas 


\subsection{Resultados del ensayo II. Estudio de detección de cambios empleando nuevas características bitemporales derivadas de funciones geoestadísticas}

de cambio. Las características de las posiciones de los mínimos y máximos también contienen información similar, ya que presentan valores cercanos entre sí en un número elevado de parcelas.

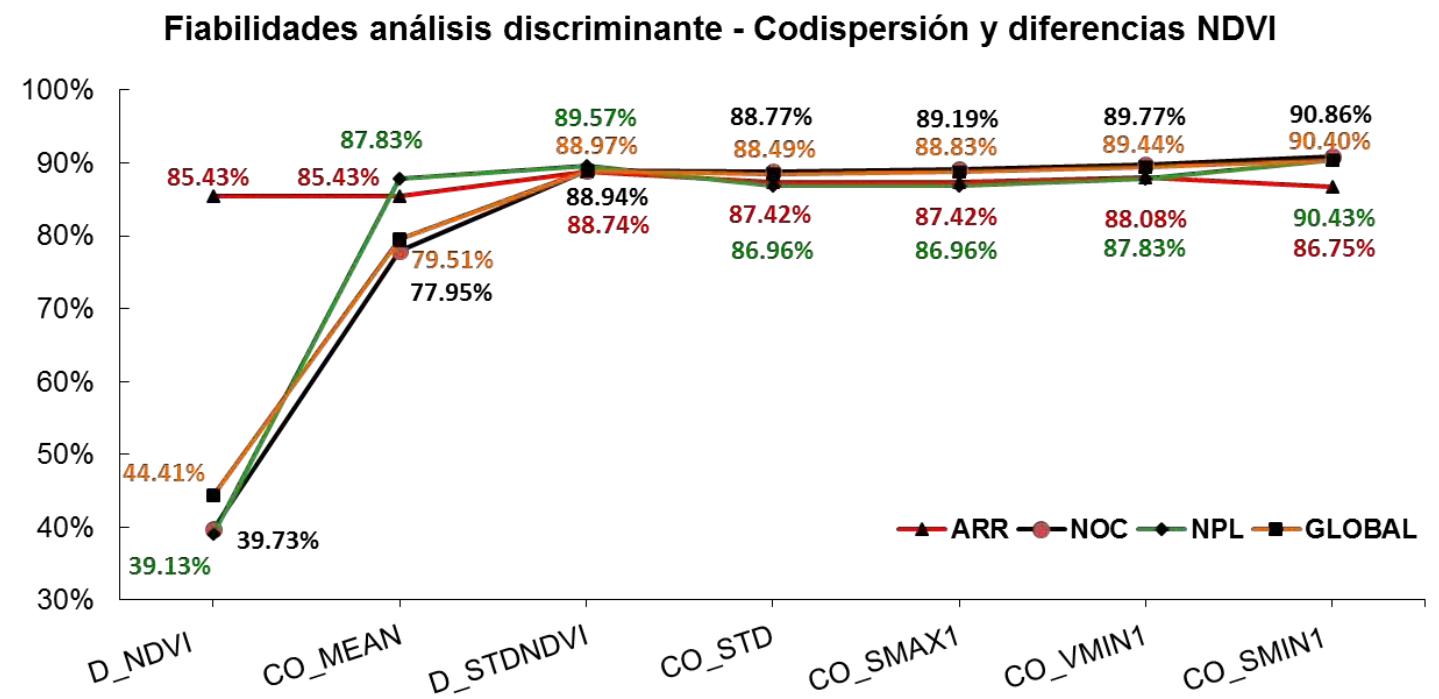

Figura 5.16: Fiabilidad global y fiabilidades predichas por clases de las variables de la codispersión y características espectrales empleando análisis discriminante paso a paso (siendo NOC la clase de no cambio, ARR arranques y NPL nuevas plantaciones). Características añadidas en orden de izquierda a derecha.

De acuerdo a los valores de correlación representados en la Figura 5.11, la desviación estándar de los valores de codispersión (CO_STD) tiene una gran correlación con la media de los valores de la codispersión (CO_MEAN), así como valores de correlación superiores a 0,4 con el resto de las características de la codispersión.

Las características espectrales son independientes de las características de la codispersión en los planos de los componentes 2-3 y 1-2. De acuerdo con estos resultados, se ha seleccionado la media de los valores de la codispersión (CO_MEAN) para el estudio de clasificación ya que ha sido la primera característica seleccionada por el análisis discriminante. El resto de características presentan altas correlaciones con esta característica y entre ellas mismas al interpretar la matriz de correlaciones y el análisis de componentes principales, siendo parte del mismo grupo en las diferentes proyecciones. A pesar de esto, la desviación estándar de los valores de codispersión (CO_STD) también resulta interesante para el estudio a pesar de tener alta correlación con la media de los valores de codispersión. La característica de la desviación estándar pertenece a diferentes grupos en los las proyecciones 1-2 y 2-3 de los componentes principales, y es la segunda característica seleccionada en el análisis discriminante. CO_SMIN1 y CO_SMAX1 


\section{Resultados}

tienen una correlación superior a 0,4 con la característica CO_STD aun perteneciendo a grupos diferentes en el análisis de componentes principales. Ambas características son rechazadas ya que aportan menor cantidad de información en la clasificación mediante análisis discriminante (figura 5.16).

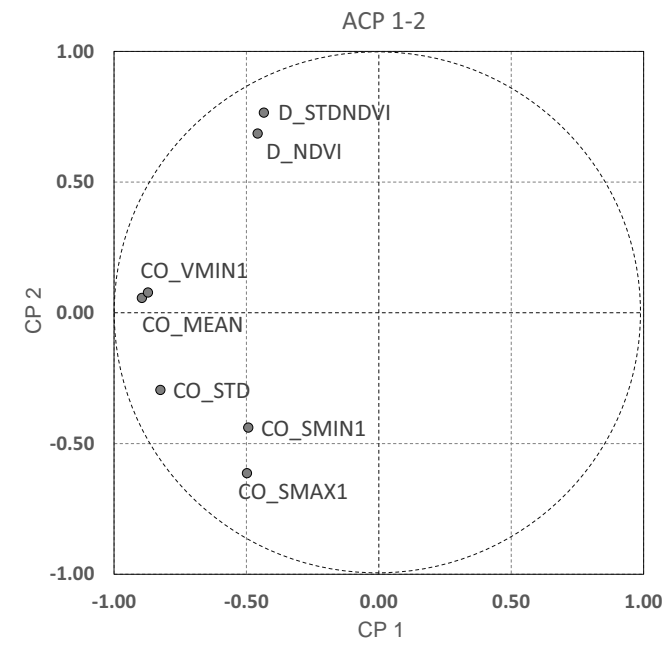

(a) Plano componentes principales (CP) 1 y 2 .

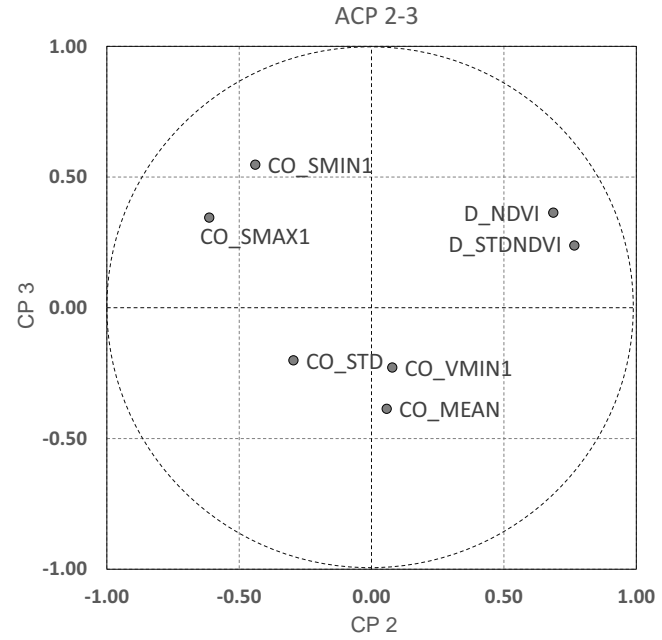

(b) Plano componentes principales (CP) 2 y 3

Figura 5.17: Análisis de componentes principales (ACP) de características espectrales y semivariograma cruzado.

Las características de codispersión pueden explicar información adicional sobre la estructura espacial de las parcelas, información que no aportan las características espectrales. Es por esto que los resultados muestran una gran complementariedad entre la codispersión y las características espectrales. El valor de la media de los valores de codispersión (CO_MEAN) y la desviación estándar (CO_STD) son seleccionadas para el estudio de clasificación y detección de cambios, siendo las características más representativas del grupo de características de codispersión.

\subsubsection{Resultados de clasificación de grupos de características por árboles de decisión}

La figura 5.18 muestra la fiabilidad global cuando se emplean árboles de decisión para la clasificación de diferentes combinaciones de grupos de características. Los grupos individuales de características descriptivas obtienen menores fiabilidades que cuando se combinan los diferentes grupos. La combinación de los grupos de codispersión y semivariograma cruzado no muestran una gran mejora con respecto a las clasificaciones de grupos simples, lo que indica que ambos grupos contienen información redundante. 


\subsection{Resultados del ensayo II. Estudio de detección de cambios empleando nuevas características bitemporales derivadas de funciones geoestadísticas}

Cuando se combinan las características de codispersión o semivariograma cruzado con el grupo de características espectrales, se obtienen fiabilidades superiores al $92 \%$. Combinando los tres grupos de estudio se obtiene la mayor fiabilidad, pero la diferencia con respecto a la combinación de las características de codispersión con las espectrales no es muy notable.

Como era de esperar, las diferencias de NDVI aportan información relevante para la detección de cambios en las clases estudiadas. En las parcelas sin cambio, las medias de los valores de NDVI deben ser similares en las dos fechas, por lo que al realizar la diferencia entre ellas, los valores de dichas diferencias de NDVI deben ser cercanos a cero. Al haber obtenido los valores de NDVI mediante la resta de la media de NDVI de la segunda época (NDVI\#2) menos la media de NDVI de la primera época (NDVI\#1), valores positivos de NDVI están asociados a cambios en las parcelas de nuevas plantaciones, mientras que valores negativos de NDVI están asociados a cambios de arranques. La diferencia de media en parcelas de nuevas plantaciones es positiva debido al incremento de los valores de NDVI en la parcela de la segunda fecha. A pesar de esto, hay casos en los que parcelas de árboles tienen valores bajos de NDVI, concretamente en aquellas parcelas de nuevas plantaciones en las que los árboles son muy jóvenes y tienen una copa reducida. En estos casos, las diferencias de media de NDVI también son cercanas a cero, lo que introduce cierta confusión entre la distinción de parcelas de no cambio y nuevas plantaciones. Lo mismo sucede con la desviación estándar de NDVI, que tiene valores elevados en parcelas con árboles y valores menores en parcelas arables. En la práctica, las diferencias entre valores de desviación de NDVI entre las dos fechas no es exactamente cero, y esto genera confusión entre parcelas de no cambio y parcelas de nuevas plantaciones. Este comportamiento se ve reflejado en los valores de fiabilidad obtenidos durante el análisis de selección de variables, con altas fiabilidades en arranques y valores bajos para las clases de no cambio y nuevas plantaciones. A pesar de obtener buenos resultados empleando características espectrales de NDVI, estas características introducen confusión entre las clases de estudio.

Las características de semivariograma cruzado y codispersión obtienen valores elevados de fiabilidad en las clasificaciones mediante árboles de decisión, lo que indica que son relevantes para la distinción entre las clases de cambios y no cambio estudiadas. Estas características proporcionan información sobre los cambios en la estructura interna de las parcelas, lo que no ocurre con las características espectrales, y reducen la confusión entre las clases de estudio.

La figura 5.19 muestra la fiabilidad global de la clasificación directa empleando ár- 


\section{Resultados}

boles de decisión cuando se realizan diferentes combinaciones entre las características resultantes del análisis de variables. Las características del semivariograma cruzado y codispersión obtienen altas fiabilidades cuando se combinan con las características espectrales, obteniendo valores superiores al $92 \%$ (Figura 5.19 A, B C y D).

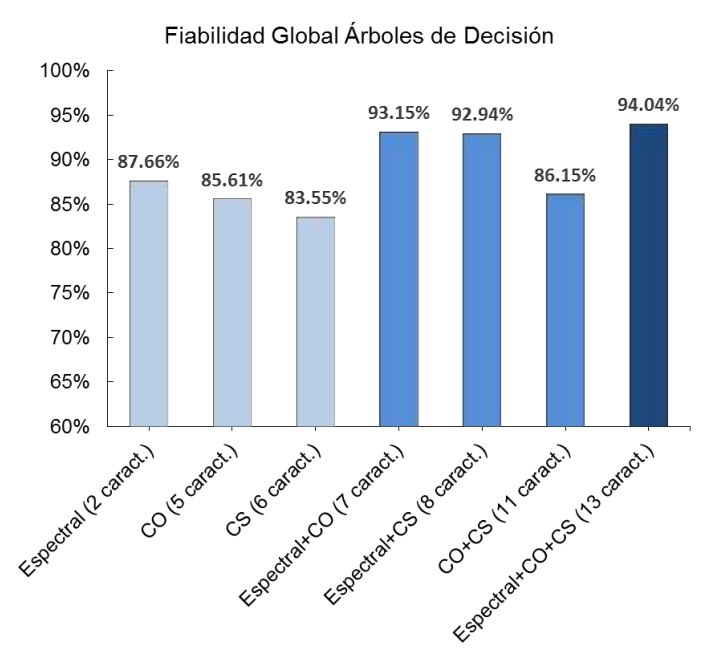

Figura 5.18: Fiabilidades globales de la clasificación mediante árboles de decisión empleando diferentes combinaciones de grupos de características.

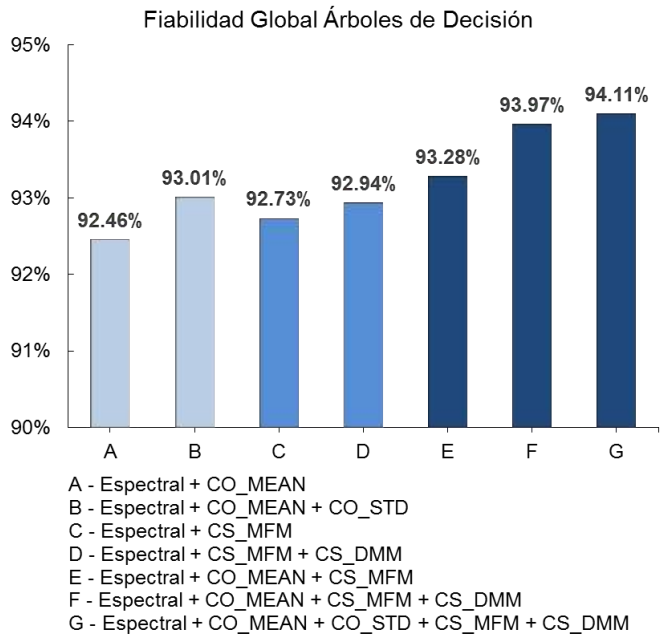

Figura 5.19: Fiabilidades globales de la clasificación mediante árboles de decisión empleando diferentes combinaciones de características seleccionadas.

Cuando se combinan las características del semivariograma cruzado junto con las características de codispersión y características espectrales, se obtienen las mayores fiabilidades con porcentajes superiores al $93 \%$ (Figura 5.19 E, F y G), a pesar de que las diferencias entre las fiabilidades no sean mayores al $1 \%$.

Las características del grupo E son las que se emplean para el ajuste de los parámetros de poda en los árboles de decisión y, por lo tanto, se emplean también para el estudio final de detección de cambios. Se ha seleccionado este grupo ya que es el que menor número de características contiene en comparación con los grupos F y G, e incluye una combinación de los tres grupos de características sin una reducción significativa de la fiabilidad en la clasificación.

\subsubsection{Ajuste de los parámetros de poda de los árboles de decisión}

Para optimizar la detección de cambios mediante clasificación directa por árboles de decisión, se ha realizado una selección de parámetros de poda del clasificador (coeficiente 


\subsection{Resultados del ensayo II. Estudio de detección de cambios empleando nuevas características bitemporales derivadas de funciones geoestadísticas}

de confianza y número mínimo de instancias) empleando las curvas ROC. El valor que ha sido estudiado en estas curvas es el área debajo de la curva ROC (AUC). A mayor valor de AUC, mejor solución de clasificación.

La figura 5.20 muestra los valores de AUC en función del coeficiente de confianza y el número mínimo de instancias. Los resultados revelan que las fiabilidades obtenidas no muestran grandes diferencias a la hora de seleccionar diferentes parámetros, lo que indica que el clasificador funciona correctamente y que los parámetros de poda para este caso, no tienen un efecto relevante. A pesar de esto, se pueden distinguir pequeñas variaciones en los valores del AUC dependiendo de los parámetros empleados y de las clases de estudio. El valor del mínimo número de instancias que mejores resultados obtiene es 4 , y alcanza su máximo con valores de coeficiente de confianza igual a 0,75 , donde el valor de la AUC se estabiliza. Por lo tanto, estos valores son los que se usan para la detección de cambios mediante clasificación directa.

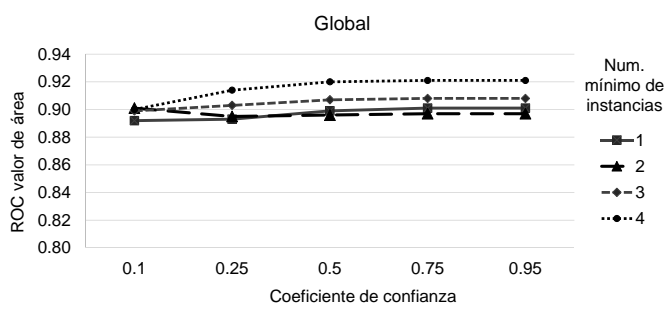

(a) Fiabilidad Global.

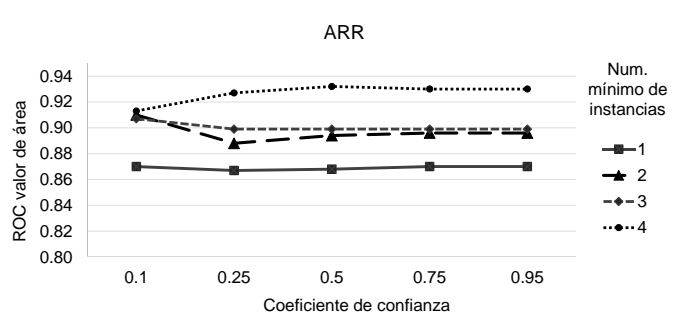

(c) Fiabilidad de la clase de arranques (ARR).

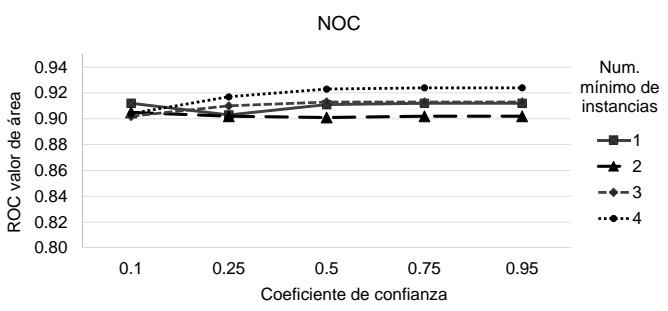

(b) Fiabilidad de la clase de no cambio (NOC).

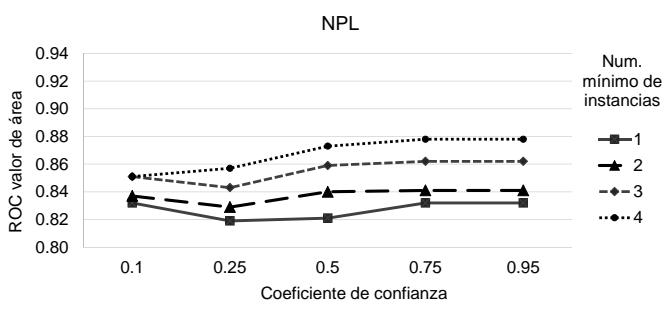

(d) Fiabilidad de la clase de nuevas plantaciones (NPL).

Figura 5.20: Valores de área ROC en función de los parámetros de poda de los árboles de decisión para las diferentes fiabilidades (global y por clase). 


\subsubsection{Resultados del ensayo II.A. Clasificación directa orien- tada a objetos y resultados de detección de cambios em- pleando las nuevas características geoestadísticas bitem- porales}

Las características que se seleccionaron para la detección de cambios mediante clasificación directa empleando árboles de decisión fueron: la media y la desviación estándar de las diferencias de NDVI (D_NDVI y D_STDNVI); la media de los valores de codispersión (CO_MEAN); y la media de los valores del semivariograma cruzado hasta el primer máximo (CS_MFM). Los resultados de la clasificación tienen una fiabilidad global del 93,76\%. La clase con mejores fiabilidades de productor y usuario es la clase de no cambio (NOC) con valores del 97,15\% y 96,26\% respectivamente (Figura 5.21). Los arranques (ARR) y las nuevas plantaciones (NPL) también obtienen valores de fiabilidad elevados. A pesar de ello, dentro de la clase de no cambios existe una clasificación por exceso de parcelas tanto de arranques como de nuevas plantaciones, lo que se traduce en valores de fiabilidad de productor y usuario menores, especialmente para el caso de las nuevas plantaciones con fiabilidades del 73,91\% para el productor, y 74,56\% para el usuario. Entre las dos clases de cambio existe poca confusión, lo que indica que las variables escogidas pueden diferenciar fácilmente entre los arranques y nuevas plantaciones. La matriz de confusión de los resultados de la clasificación directa se puede ver en la Figura 5.21.

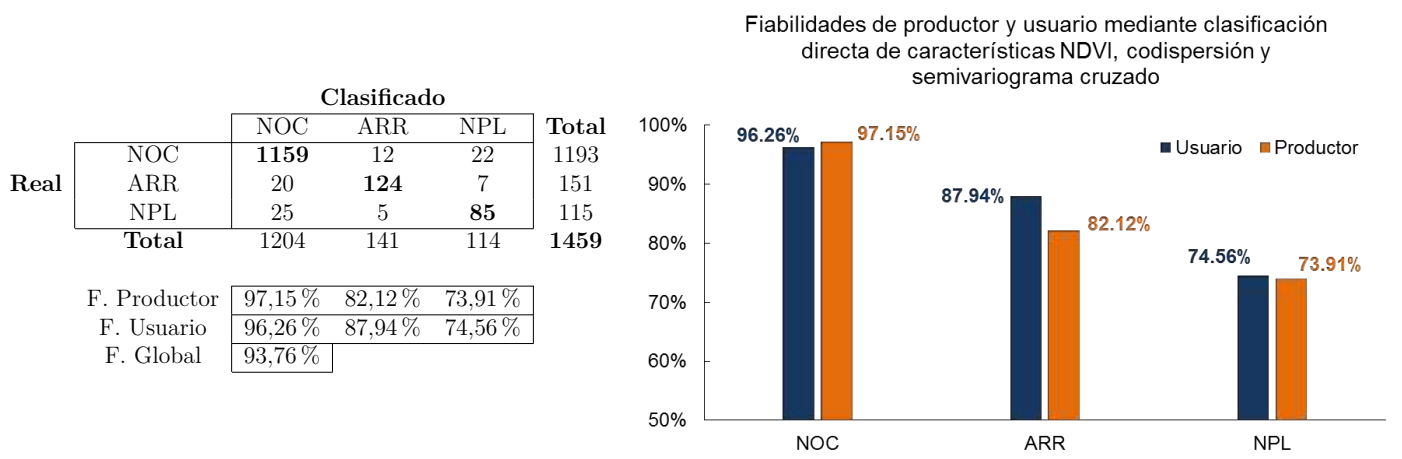

Figura 5.21: Resultados de clasificación directa mediante árboles de decisión empleando las características de NDVI (2 características), codispersión (CO_MEAN) y semivariograma cruzado (CS_MFM), y gráfica de fiabilidades de productor y usuario siendo NOC la clase de no cambio, ARR arranques y NPL nuevas plantaciones.

Los resultados de la detección de cambios considerando únicamente clases de cambio y no cambio también muestran elevadas fiabilidades en la detección con una fiabilidad 


\subsection{Resultados del ensayo II. Estudio de detección de cambios empleando nuevas características bitemporales derivadas de funciones geoestadísticas}

global del 94,59\% (Figura 5.22). Los errores detectables muestran una clasificación por exceso en las parcelas de no cambio al ser clasificadas como cambio con un error del $2,33 \%$. El porcentaje de errores indetectables es mayor al de errores detectables, con un valor de 3,08\%, indicando errores de parcelas de cambio clasificadas como no cambio. A la vista de los resultados, se puede concluir que la detección de cambios obtiene valores satisfactorios con altas fiabilidades globales, un alto porcentaje de detección (83,08\%), y un porcentaje de calidad en la detección superior al $73 \%$.

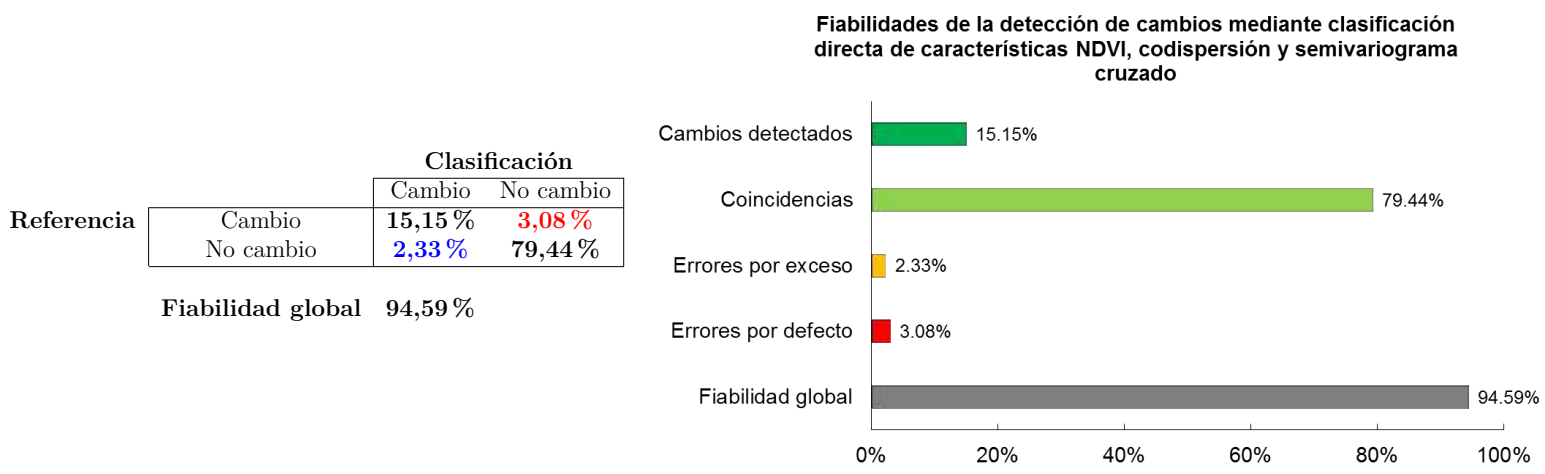

Figura 5.22: Resultados de detección de cambios empleando las características NDVI (2 características), codispersión ( $\mathrm{CO} \_$MEAN) y semivariograma cruzado (CS_MFM).

Con las características derivadas del semivariograma cruzado, la clase de arranques tiene la mayor fiabilidad al incluir la media de los valores hasta el primer máximo del semivariograma cruzado. Al incluir otras características del semivariograma cruzado, la confusión entre la clase de arranques y la clase de nuevas plantaciones aumenta. Empleando las características de codispersión, las parcelas de no cambio obtienen la mayor fiabilidad mediante análisis discriminante. Estos resultados muestran el poder discriminatorio de las características de codispersión a la hora de diferenciar cambios de no cambios a pesar de la confusión existente entre las propias clases de cambio.

Se puede concluir que este conjunto de características extraídas del semivariograma cruzado y codispersión son indicadores adecuados de cambio cuando los cambios afectan a la heterogeneidad, contraste o regularidad en los patrones de los elementos dentro de las parcelas u objetos de estudio, teniendo en estos casos grandes habilidades discriminantes entre clases de cambio y no cambio. Además, combinando estas características con información espectral, se consiguen altas fiabilidades de clasificación y la reducción de confusión entre clases. Esto indica una gran complementariedad entre los dos tipos de características (estructura y espectral), combinando la eficiencia de las características espectrales para identificar cambios sobre las reflectancias de los tipos de cobertura con el potencial de las características de estructura descritas para la detección de cambios 
en la estructura interna de las parcelas.

La configuración de la clasificación final para la detección de cambios, empleando la selección de los diferentes grupos de características, consigue un alto rendimiento para las tres clases de estudio. La clase que más se ve afectada por la confusión con la clase de parcelas de no cambio son las nuevas plantaciones, lo que se traduce en menores fiabilidades de clasificación, lo que también se debe a algunos errores de clasificación entre las dos clases de cambio.

\subsubsection{Resultados del ensayo II.B. Comparación de detección de cambios mediante diferencias entre variables espec- trales y geoestadísticas}

Los resultados obtenidos empleando las diferencias entre todas las variables espectrales y del semivariograma se pueden observar en la Figura 5.23. Los valores de las fiabilidades son ligeramente mayores que las fiabilidades obtenidas cuando se emplean las variables espectrales, de codispersión y semivariograma cruzado de la Figura 5.21 del apartado anterior 5.2.3. Lo mismo ocurre en los resultados de detección de cambios, en la que se obtiene una fiabilidad global del 94,79\% (Figura 5.24).

A la vista de estos resultados se puede confirmar la aptitud de las características derivadas del semivariograma cruzado y codispersión para la detección de cambios en cuanto a la estructura interna de las parcelas. Además, si se compara el número de características empleadas en las dos clasificaciones (49 características frente a 4), también se puede afirmar que estas 4 características contienen un nivel de información similar al proporcionado por la diferencia de características espectrales y de semivariograma. Por lo tanto, las características de semivariograma cruzado y codispersión sintetizan en muy pocas variables la información contenida en las variables de semivariograma de dos épocas de estudio, lo que resulta mucho más eficiente en estudios de detección de cambios obteniendo resultados similares. 


\subsection{Resultados del ensayo II. Estudio de detección de cambios empleando nuevas características bitemporales derivadas de funciones geoestadísticas}

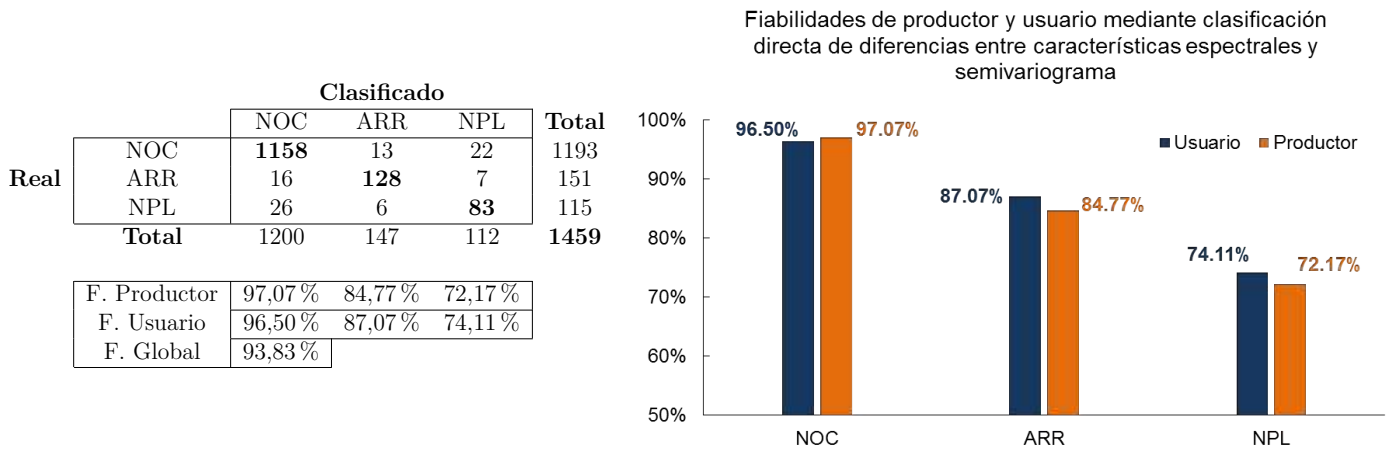

Figura 5.23: Resultados de clasificación directa mediante árboles de decisión empleando diferencias de características espectrales (35 características) y de semivariograma (14 características) y gráfica de fiabilidades de productor y usuario siendo NOC la clase de no cambio, ARR arranques y NPL nuevas plantaciones.

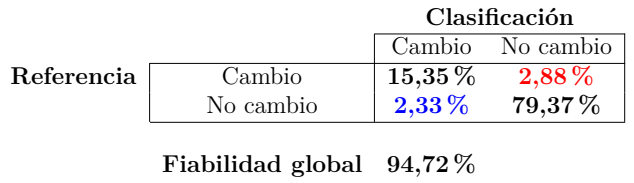

Fiabilidad global $\quad 94,72 \%$

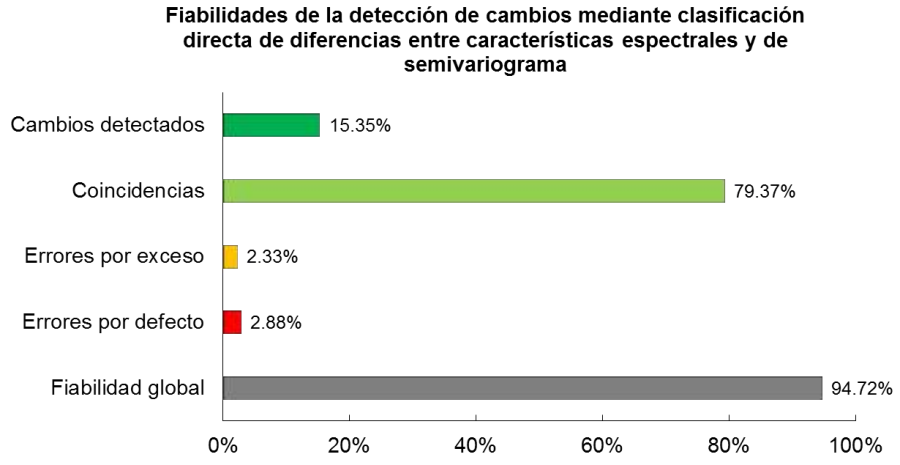

Figura 5.24: Resultados de detección de cambios empleando diferencias de características espectrales (35 características) y de semivariograma (14 características). 


\subsection{Resultados del ensayo III. Análisis de caracte- rísticas de fragmentación}

En esta sección se recogen los resultados del estudio de características de fragmentación en el que se analiza el comportamiento de dichas características sobre dos grupos de parcelas sintéticas, la clasificación y evaluación de los mapas de coberturas, y finalmente, la selección de características y clasificación directa orientada a objetos para la detección de cambios.

El análisis del comportamiento de características está dividido en función del tipo de información o propiedad extraída de los objetos y subobjetos. Al final del análisis del comportamiento de las características se muestra un resumen de los indicadores seleccionados tras el estudio de las parcelas sintéticas. Tras esto, se muestran los resultados de la clasificación no supervisada y de la asignación de coberturas para la generación de los mapas de coberturas y su evaluación.

En el último apartado de esta sección se muestran los resultados de la selección de características para la clasificación directa orientada a objeto mediante análisis discriminante y la detección de cambios a nivel de objeto. En la Figura 5.25 se muestra el del ensayo III.

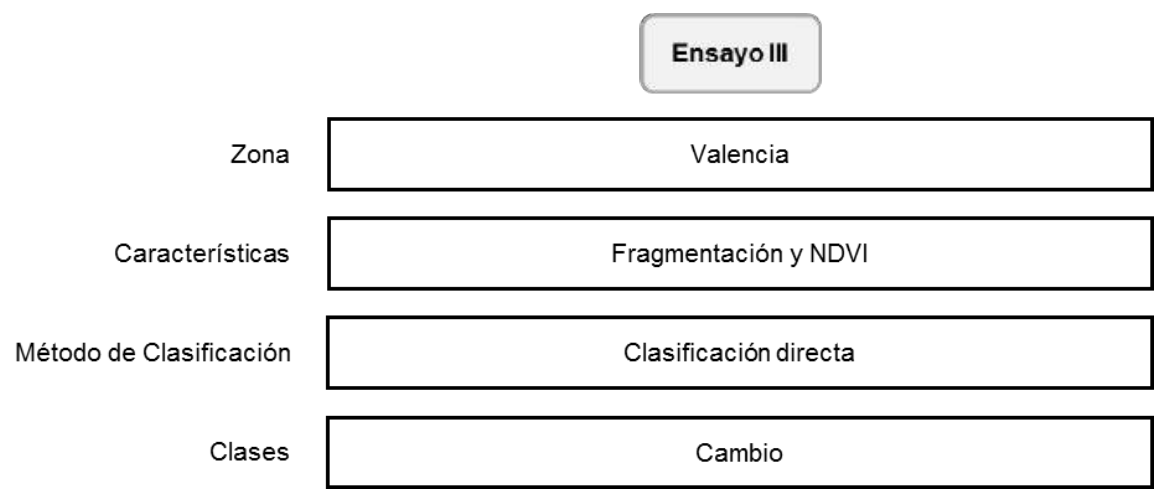

Figura 5.25: Esquema del Ensayo III. 


\subsubsection{Resultados del estudio de características de fragmenta- ción sobre parcelas sintéticas}

\subsubsection{Indicadores de área y perímetro}

Dentro de los indicadores de área están el área de clases (CA) y el porcentaje de área de cobertura (PLAND). Ambas características indican el área existente de la cobertura en la parcela, con la diferencia de que el porcentaje de área de cobertura (PLAND) se expresa mediante un porcentaje en función del área total de la parcela (Figura 5.26), lo que facilita la comparación con otras parcelas. Este indicador puede ayudar a diferenciar las clases de las parcelas de cultivos y de suelo arable o suelo desnudo, ya que al tratarse de clases muy homogéneas, la diferencia entre ellas es básicamente la extensión de una de las coberturas. De la misma forma para las parcelas que contienen edificios, un elevado porcentaje de área cubierto por un edificio puede significar que se trata de una parcela industrial o urbana, mientras que un porcentaje bajo, será indicativo de parcelas con casas de tipo rural.

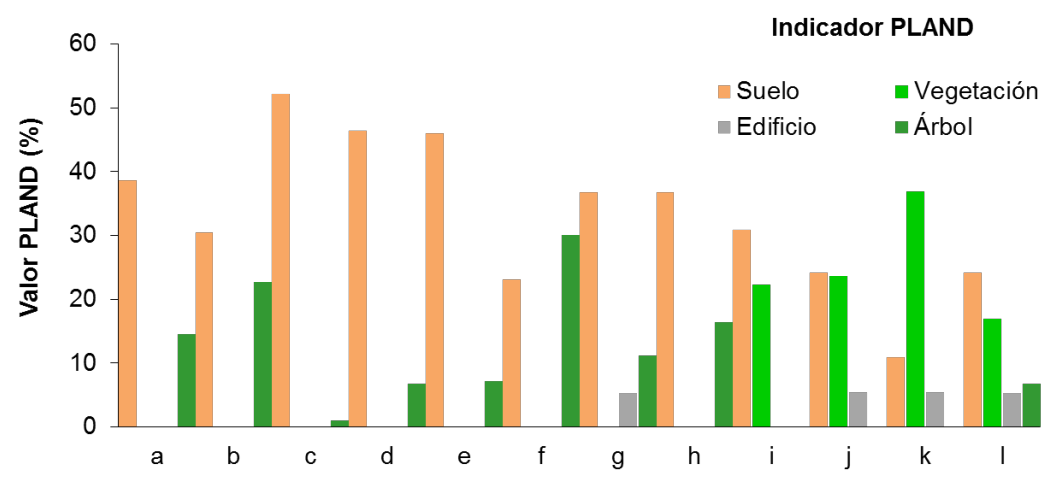

Figura 5.26: Porcentaje de área de cobertura (PLAND) de parcelas sintéticas del grupo A.

El índice de mayor objeto (LPI), que indica el tamaño del mayor subobjeto que se encuentra en la parcela, aporta información sobre el edificio, árbol o agrupación de árboles de mayor tamaño (Figura 5.27). Este índice no tiene sentido emplearlo para las coberturas de suelo y vegetación, ya que esta información no se considera relevante al estar empleando la variable del porcentaje de área de cobertura (PLAND) para la distinción entre los tipos de parcela con cultivos o suelo arable o suelo desnudo. 


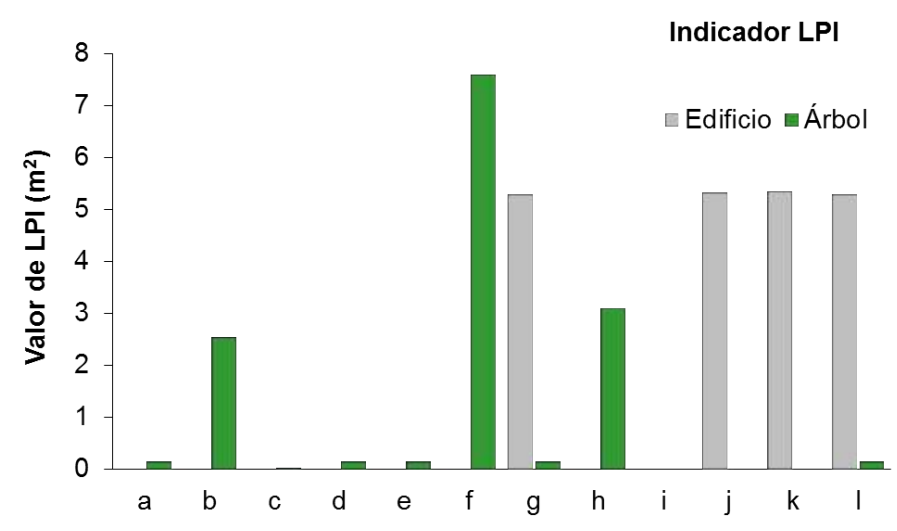

Figura 5.27: Índice de mayor objeto (LPI) de parcelas sintéticas del grupo A.

Así mismo, las variables de suma total de bordes (TE) y densidad de bordes (ED) tiene sentido emplearlas de nuevo en las clases de árboles y edificios. Un valor elevado de la suma de bordes o de su densidad puede ser indicativo de un número elevado de elementos de estas dos clases dentro de la parcela. En el caso de los árboles (Figura 5.29a) un elevado valor de TE o ED puede significar un gran número de árboles o una agrupación de árboles dentro de la parcela. Al combinar una de estas dos variables con las características de área, se podría llegar a distinguir entre los diferentes tipos de parcelas arbóreas. En el caso de los edificios (Figura 5.29b), un valor elevado del total de bordes puede estar indicando la existencia de más de un edificio en la parcela, como en la parcela de la Figura 4.18(e).

A pesar de que la variable TE parece que tiene mayor sentido emplearla en las características de clase o subobjetos, se considera que podría facilitar la distinción entre las diferentes clases de las parcelas al emplearla también a nivel de objeto. Su valor está relacionado con el número de subobjetos existentes en la parcela y el tamaño de estos. A mayor valor de TE, mayor número y mayor tamaño de subobjetos. Esto se puede observar en las parcelas con cítricos (Figura 4.17 (a, g)) con valores elevados de TE (Figura 5.28a). En cambio, una parcela de tipo cultivado con un edificio (Figura 4.17 (j)), presenta un TE menor al tener un perímetro menor que la suma de todos los bordes de los cítricos (Figura 5.28a). Entre las parcelas de edificios se puede observar lo mismo (Figura 5.28b), en la que el valor más elevado de TE corresponde a la parcela de la Figura 4.18 (e), con dos edificios de gran tamaño.

Por otra parte, si comparamos la parcela de la Figura 4.17 (b) de cítricos con la parcela de la Figura 4.17 (i) de cultivo, los valores de la suma total de bordes TE son 


\subsection{Resultados del ensayo III. Análisis de características de fragmentación}

similares (Figura 5.28a) a pesar de que se trate de clases diferentes, lo que puede también inducir a error.

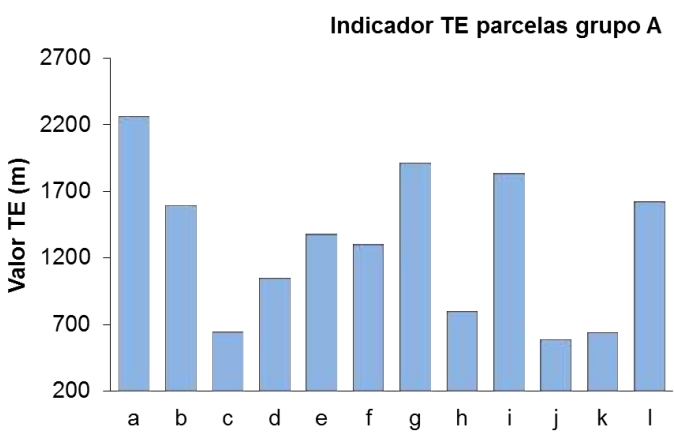

(a) Parcelas sintéticas grupo A.

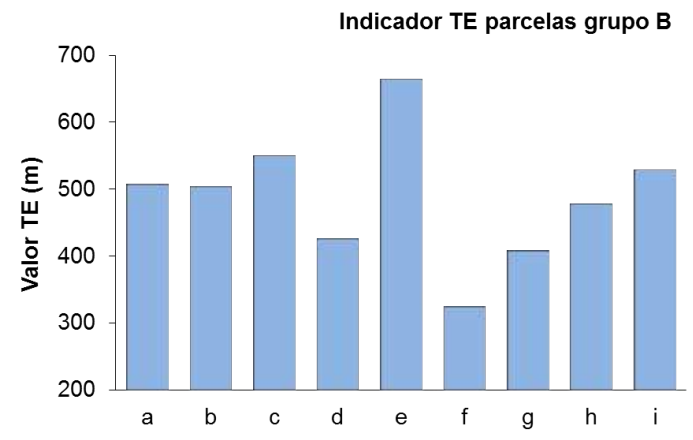

(b) Parcelas sintéticas grupo B.

Figura 5.28: Suma total de bordes (TE).

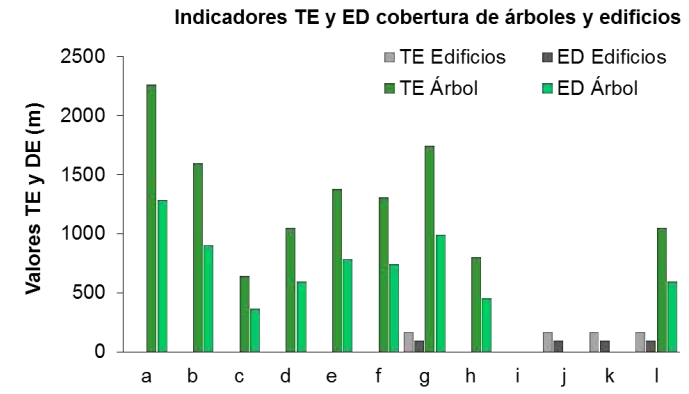

(a) Parcelas sintéticas grupo A

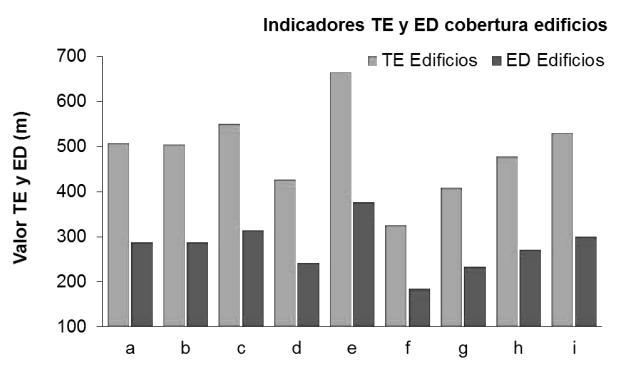

(b) Parcelas sintéticas grupo B

Figura 5.29: Suma total de bordes (TE) y densidad de bordes (ED) para las clases árboles y edificios.

Por último, las características de media y desviación de área (AREA_MN y DS) pueden aportar información del tamaño de los subobjetos de las diferentes clases dentro de la parcela. Si se emplea con las clases de árboles y edificios se puede conocer el tamaño medio de ambos (Figura 5.30). Mediante la desviación se puede saber si el tamaño de estos varía a lo largo de la parcela (Figura 5.30), como en el caso de las parcelas de la Figura 4.17 (b, h). En las parcelas con edificios del grupo A (Figura 4.17), la desviación estándar es 0 , ya que solo hay un elemento en cada una de ellas perteneciente a esa clase.

En las parcelas del grupo B (Figura 4.18) se puede ver cómo la desviación estándar varía de una parcela a otra al existir subobjetos de diferentes tamaños (Figura 5.31).

El último indicador de área estudiado es la densidad de árboles DA (Figura 5.32), indicando la relación que existe entre el área correspondiente a la cobertura de árboles con respecto al área total de la parcela. En las parcelas sintéticas, se puede observar 
que a mayor área cubierta por árboles, mayor indicador DA se obtiene, siendo la parcela 4.17 (f) la que mayor superficie de árboles representa. La DA, en este caso, está muy relacionada con las variables CA y PLAND debido a que las parcelas sintéticas son del mismo tamaño. En casos reales, se considera que esta variable es de gran utilidad, así como en otros trabajos realizados en los que se aplica este indicador a cobertura de edificios en zonas urbanas (Colaninno et al., 2011; Romano et al., 2010; Sapena y Ruiz, $2015 b)$.

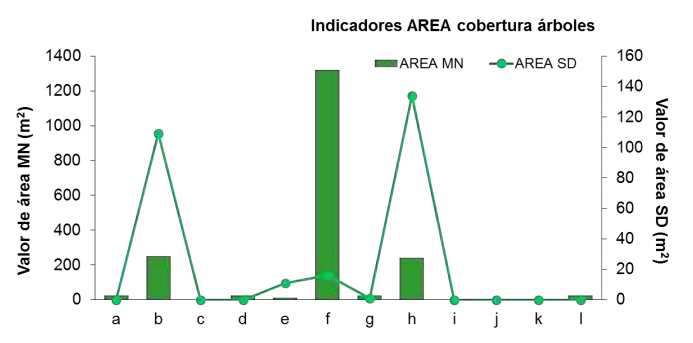

Figura 5.30: Indicadores AREA MN y SD de la cobertura árboles de parcelas del grupo A.

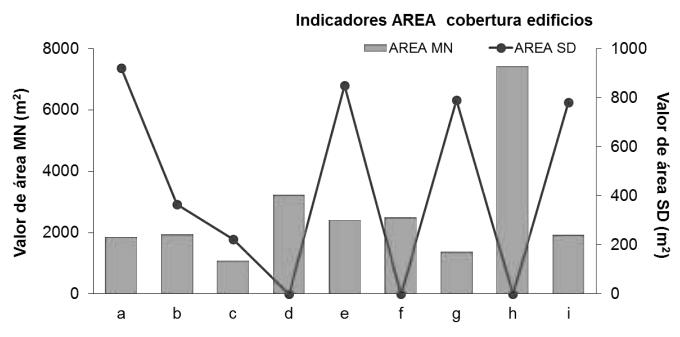

Figura 5.31: Indicadores AREA MN y SD de la cobertura edificios de parcelas del grupo B.

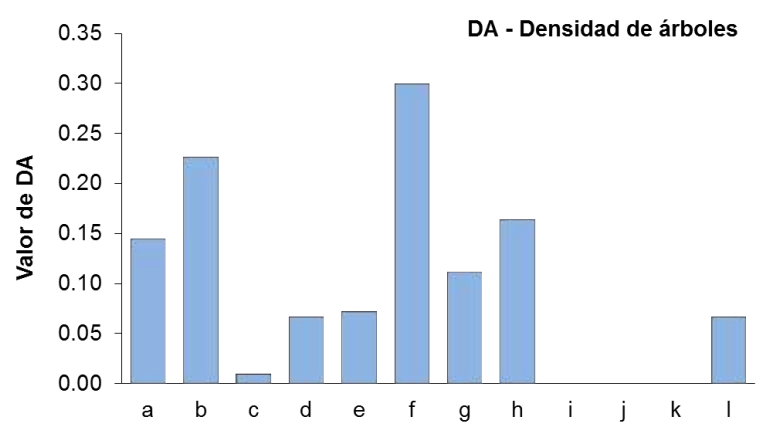

Figura 5.32: Indicador de densidad de árboles DA para las parcelas del Grupo A.

\subsubsection{Indicadores de forma}

Los estadísticos de los índices relacionados con la forma como la media y desviación son valores a tener en cuenta. El estudio de estas características a nivel de cobertura para las coberturas de árboles y edificios permite conocer la forma aproximada y la variación entre los subobjetos dentro de la parcela de estudio. Por ejemplo, los valores de media del índice de forma (SHAPE_MN) de los subobjetos contenidos en las parcelas arbóreas son similares (Figura 5.33) al tratarse de parcelas sintéticas con árboles exactamente circulares con excepción de las parcelas de la Figura 4.17 (b, f), en las que los árboles son 


\subsection{Resultados del ensayo III. Análisis de características de fragmentación}

irregulares, por lo que además presentan valores en la desviación estándar (SHAPE_SD) diferentes de cero. Para el caso de los edificios también se obtiene el mismo valor de índice de forma debido a que los edificios son iguales en todas las parcelas sintéticas, además, al existir únicamente un edificio, el valor de la desviación estándar es cero. A pesar de que no sean casos reales y la propia desviación no aporte demasiada información en estos casos, la variable de desviación se considera muy importante para el estudio.

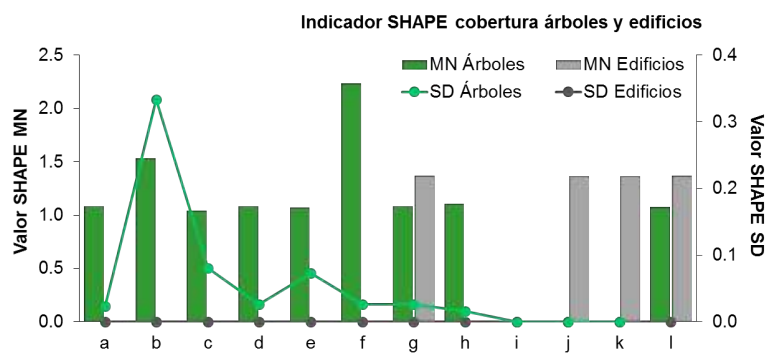

Figura 5.33: Indicadores SHAPE MN y SD de cobertura árboles y edificios de las parcelas del grupo A.

Tanto la dimensión fractal perímetro-área (PAFRAC) como el ratio perímetro-área (PARA) miden la complejidad de las formas de los subobjetos de cada cobertura. La diferencia entre ellos es que el ratio perímetro-área (PARA) varía según el tamaño de los subobjetos de la parcela. Además, la dimensión fractal perímetro-área (PAFRAC) solo se calcula si existen más de 10 subobjetos de la misma clase en la parcela.

Como se puede observar en la Figura 5.34a, los valores del perímetro-área PARA relacionados con la cobertura de árboles son elevados en aquellas parcelas con árboles de menor tamaño, como son las parcelas de la Figura 4.17 (c, e). Estos valores no están relacionados solo con el tamaño sino que también con la forma de los objetos, pero debido al pequeño tamaño de los plantones, se obtienen valores elevados de esta característica. Por esta misma razón, la desviación típica en estas dos parcelas es superior a las del resto. En teoría, los valores elevados del ratio PARA están relacionados con formas complicadas de perímetros elevados y/o áreas pequeñas. Al analizar los valores del ratio PARA en el grupo B de parcelas sintéticas con edificios (Figura 4.18), se puede ver que el menor valor destaca fácilmente debido al tamaño del subobjeto de la parcela, y los valores más elevados pertenecen a aquellas parcelas con objetos de menor tamaño (Figura 5.34b). Estos parámetros de forma se han estudiado con mayor detalle en las parcelas sintéticas de la Figura 5.35, las cuales contienen subobjetos de la cobertura de edificios de diferentes formas.

Según los valores que se pueden observar en la Figura 5.36, cuanto más simple es la forma del objeto, mayor valor del ratio PARA. A pesar de ello, los valores siguen 
estando muy influenciados por el área. Una forma simple pero alargada (como puede ser un rectángulo, Figura 5.35 (a)), al tener un mayor área tiene un menor valor de ratio PARA que un cuadrado (o en este caso un rectángulo de menor tamaño, Figura 5.35 (c)). De la misma manera, un perímetro simple como es el del círculo y un área pequeña, hace que su valor sea el más alto para todo el conjunto de parcelas (como en la parcela de la Figura 5.35 (f) con valor en la Figura 5.36).

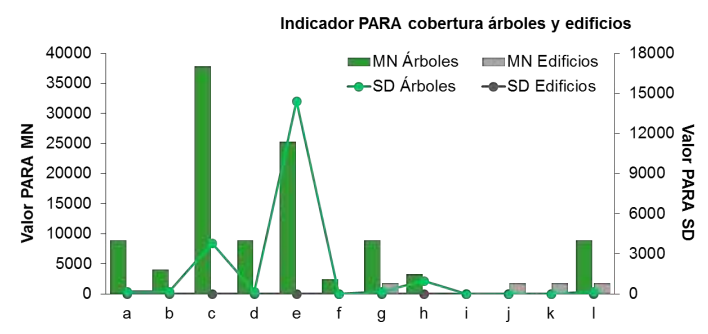

(a) Parcelas grupo A

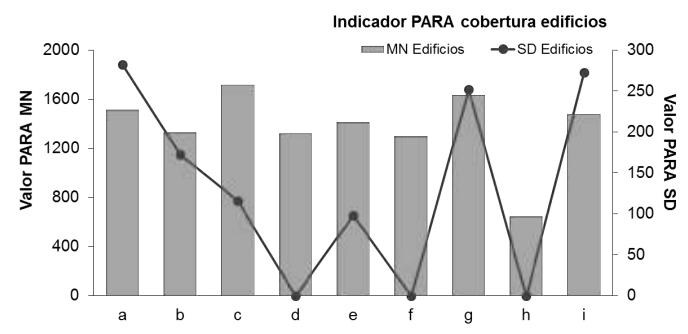

(b) Parcelas grupo B

Figura 5.34: Indicadores PARA MN y SD para las parcelas de los grupos A y B.

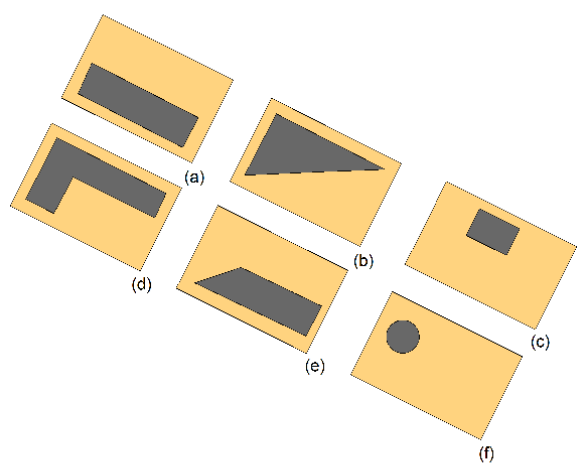

Figura 5.35: Parcelas edificios de formas simples.

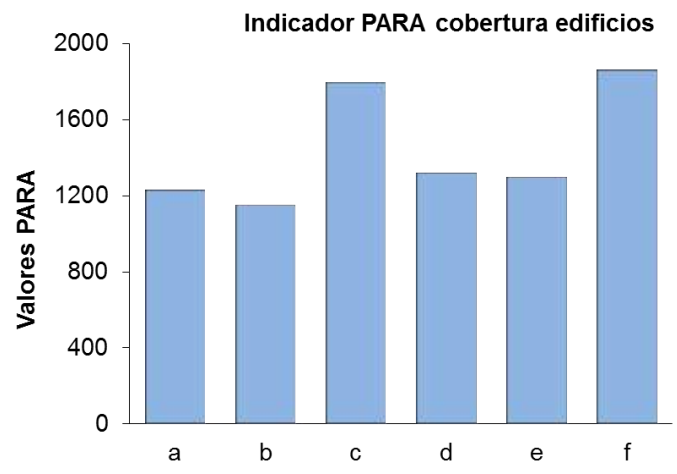

Figura 5.36: Valores PARA de edificios con formas simples.

Por otra lado, la dimensión fractal perímetro-área PAFRAC en la que interviene el área, el perímetro y el número de subobjetos de una misma clase, presenta valores elevados en aquellas parcelas que tiene mayor regularidad en sus objetos (Figura 5.37), como los árboles de las parcelas de la Figura 4.17 (a, d, g, l).

La dimensión fractal (FRAC) que indica lo que se repite de forma cíclica la forma de los subobjetos de la parcela, es otra característica que puede resultar útil en cuanto a formas de árboles y edificios se trata. El valor de esta característica es cercano a 1 cuando 


\subsection{Resultados del ensayo III. Análisis de características de fragmentación}

la forma de los elementos es simple como formas cuadradas, y aumentará de valor en cuanto aumente la complejidad de las forma. Por eso la mayoría de los valores en las parcelas tanto de árboles como de edificios son cercanos a la unidad (Figura 5.38), salvo en la parcela de plantones de la Figura 4.17 (c), en donde se genera confusión debido al pequeño tamaño de los elementos.

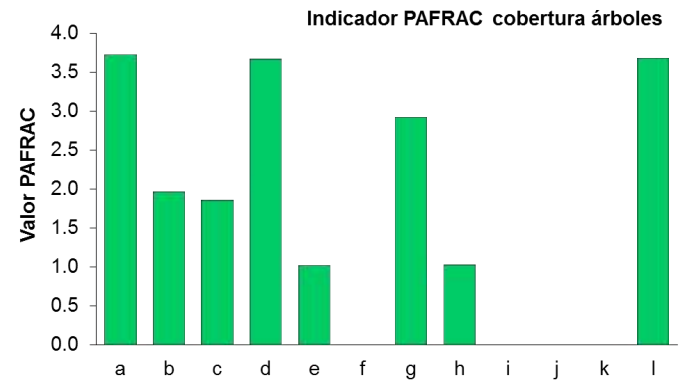

Figura 5.37: Valores PAFRAC para la clase de árboles.

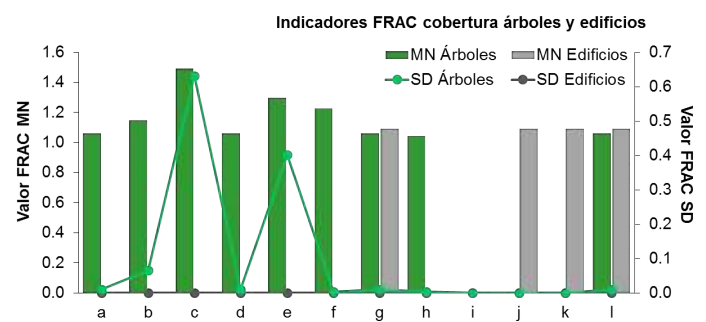

(a) Parcelas grupo A

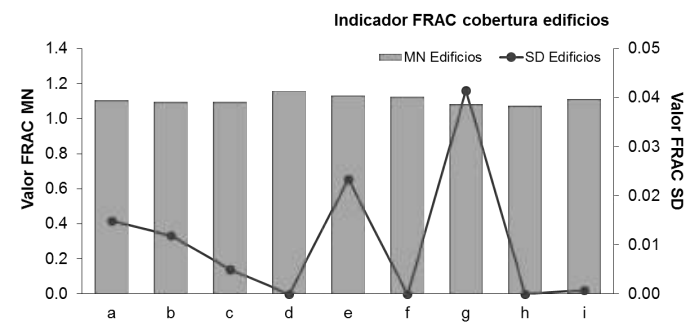

(b) Parcelas grupo B

Figura 5.38: Indicadores FRAC para las clases de árboles y edificios.

El valor de la variable de círculo circunscrito (CIRCLE) aporta información sobre cómo se ajusta la forma de los subobjetos de la parcela a un círculo. Es por esto que en las parcelas de la Figura 4.17 (b, f) se obtienen los valores más elevados para esta variable para la cobertura de árbol (Figura 5.39a) ya que sus elementos no se ajustan a un círculo. A pesar de que en la parcela de la Figura 4.17 (b) los árboles se puedan distinguir bien, a diferencia de la parcela de la Figura 4.17 (f), algunos de ellos se encuentran conectados entre sí. Por ello el ajuste de los elementos de parcela al círculo es variable y por lo tanto presenta un valor elevado en su desviación estándar (Figura 5.39a).

Esta característica también sería interesante introducirla para la distinción de diversos tipos de parcelas relacionadas con cultivos no arbóreos, como por ejemplo cultivos de superficie homogénea en los que toda la parcela está cubierta por una capa vegetal o cultivos de huerta, en la que la vegetación se distribuye en hileras. Un ejemplo de 


\section{Resultados}

esto se vería con la parcela (i) de la Figura 4.17, que al tener vegetación distribuida en hileras, presentaría valores de elongación mayores que las parcelas $4.17(\mathrm{j}, \mathrm{k}, \mathrm{l})$, donde las superficies con la clase de vegetación presentan una superficie compacta y de mayor tamaño.

A simple vista se puede observar que las parcelas que menor valor de índice de contigüidad (CONTIG) presentan son las parcelas que contienen plantones (Figura 4.17 (c, e)). El resto de parcelas tiene valores similares, lo que puede ser un buen indicador para las parcelas de plantones (Figura 5.40). Para el caso de los edificios se considera que esta variable no presenta demasiado interés.

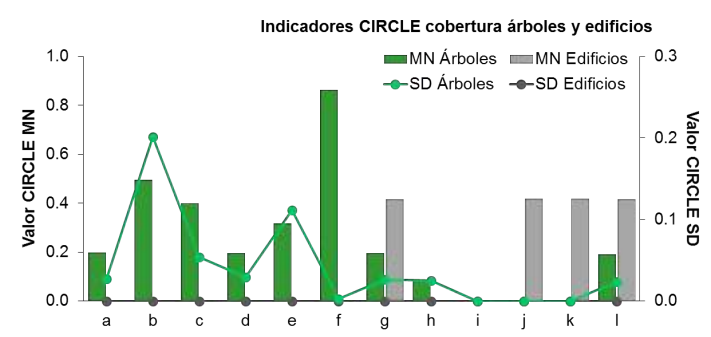

(a) Parcelas grupo A

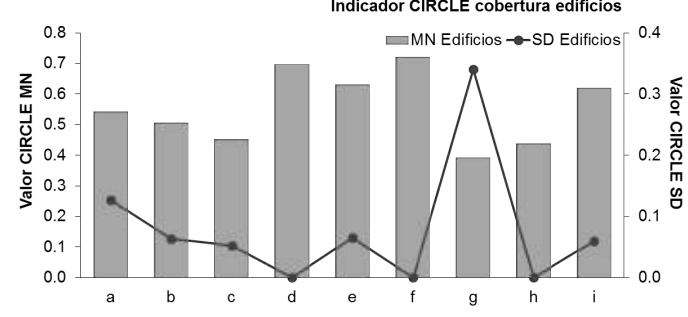

(b) Parcelas grupo B

Figura 5.39: Indicadores CIRCLE para las clases de árboles y edificios.

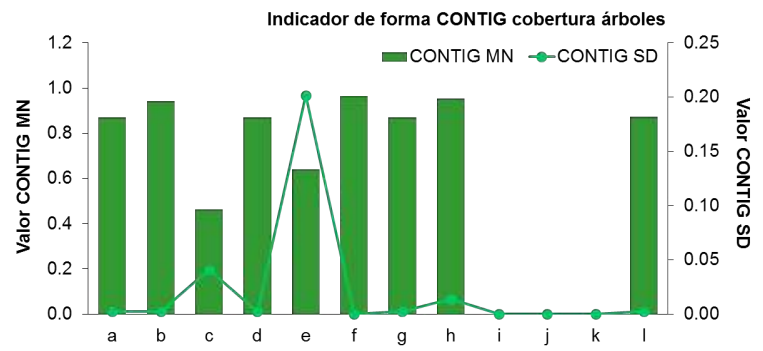

Figura 5.40: Valores CONTIG para la clase árboles del grupo de parcelas A.

\subsubsection{Indicadores de contraste}

Como se ha comentado antes, estos indicadores hacen referencia a la diferencia de magnitud entre los diferentes elementos adyacentes dentro de la parcela. La variable de media del índice de contraste de bordes ECON_MN cuantifica la media del contraste entre todos los elementos existentes dentro de la parcela, así como su desviación estándar ECON_SD. 


\subsection{Resultados del ensayo III. Análisis de características de fragmentación}

$\mathrm{Al}$ ser ECON una variable relativa, resulta útil para la detección de cambios de una misma parcela entre dos épocas diferentes. A pesar de esto puede dificultar la clasificación del contenido de la parcela ya que en casi todas ellas presenta valores similares, por lo que resulta interesante emplear también la característica del índice del contraste total de bordes TECI, que tiene el mismo significado que ECON en valor de porcentaje. El último indicador es el contraste ponderado de densidad de bordes CWED, que al estandarizar los bordes por unidad de área facilita la comparación entre parcelas de diferentes tamaños, por lo que puede ser otra característica interesante a la hora de detectar cambios.

Como se puede observar en las gráficas de la Figura 5.41, aquellas parcelas con mayor número de objetos en su interior tienen valores de contraste más elevados que en aquellas parcelas con menor número de objetos, independientemente de la clase a la que estos pertenezcan. De manera opuesta, aquellas parcelas que menor número de objetos contienen, tienen unos valores de desviación estándar superiores con respecto de aquellas parcelas que contienen más objetos.

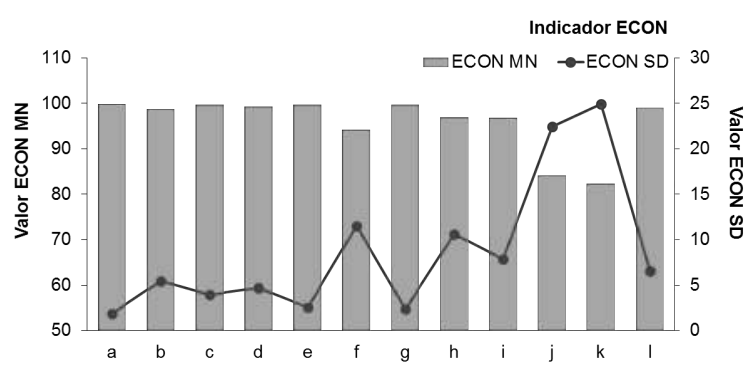

Figura 5.41: Valores ECON MN y SD grupo de parcelas A.

Los valores de TECI (Figura 5.43) y CWED (Figura 5.42) presentan valores semejantes. Siendo el contraste ponderado CWED una estandarización por área de parcela, se justifica que los valores sean similares a los del índice de contraste de bordes TECI ya que el tamaño de las parcelas sintéticas es siempre el mismo. En casos reales con parcelas de diferentes tamaños se considera que el índice TECI puede ser de mayor utilidad que CWED. 


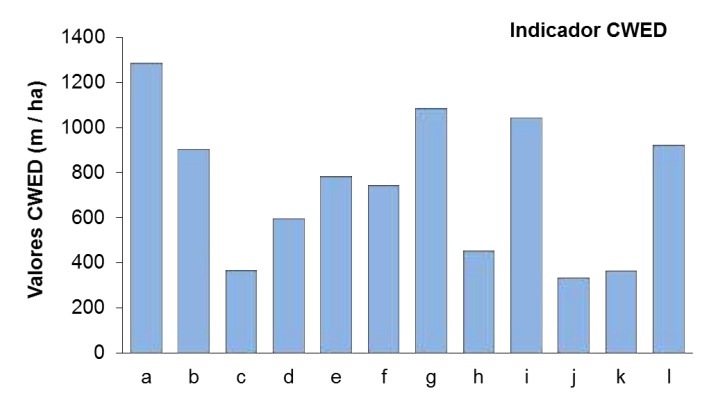

Figura 5.42: Valores CWED.

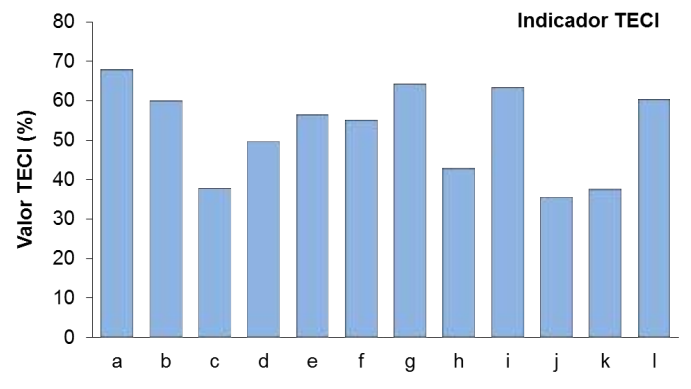

Figura 5.43: Valores TECI.

\subsubsection{Indicadores de agregación}

El primer índice es el índice de contagio CONTAG (Figura 5.44) calculado a nivel de parcela y que indica el agrupamiento de los elementos dentro de la parcela, obteniendo valores elevados en aquellas parcelas que presentan mayor agrupamiento. Un ejemplo se muestra en la figura 4.17 (c). Se trata de una parcela de plantones, en la que los plantones apenas se distinguen, por lo que la clase suelo se puede decir que está agrupada, así como las parcelas 4.17 (d, e). En estas parcelas los subobjetos están bastante agrupados, no dispersos, y se puede diferenciar y delimitar claramente en cada parcela las coberturas como son árboles, plantones y suelo desnudo. Lo mismo se puede decir de las parcelas $4.17(\mathrm{~g}, \mathrm{i}, \mathrm{j}, \mathrm{k}, \mathrm{l})$.

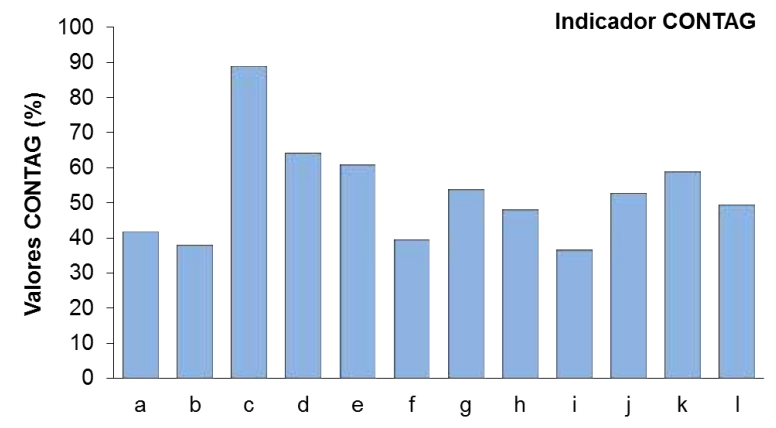

Figura 5.44: Valores de agregación CONTAG.

Los valores del índice de agregación AI (Figura 5.45) muestran sus valores más elevados en las parcelas 4.17 (c, h, j, k), en las que las superficies son más homogéneas y se encuentran agregadas. En el caso de la parcela de plantones 4.17 (c), sucede como en otros casos anteriores, en las que se considera que la clase de suelo es muy homogénea debido al pequeño tamaño de los plantones. Parcelas con coberturas más disgregadas, como la parcela 4.17 (a) y (g) muestran valores de AI menores. 


\subsection{Resultados del ensayo III. Análisis de características de fragmentación}

El índice tamaño efectivo de malla MESH, indica la probabilidad de que dos áreas de una misma región estén conectadas entre sí perteneciendo a un mismo objeto. Los valores de MESH de la Figura 5.46 para las parcelas de la Figura 4.17 (c, d, e) son elevados ya que en ellas existen subobjetos de gran tamaño o zonas homogéneas, como son las zonas de suelo, debido a que los plantones son muy pequeños y casi son despreciados. Esto también ocurre en la parcela de la Figura $4.17(\mathrm{k})$, que a pesar de contener tres tipos de coberturas diferentes, los objetos presentan grandes superficies homogéneas.

Cuando SPLIT tiene valor igual a 1, es indicador de que la parcela pertenece a una única cobertura. SPLIT aumenta su valor a medida que la parcela se pueda subdividir en elementos menores. De ahí los valores elevados en las parcelas 4.17 (b), (f) y (l) (Figura 5.47), ya que el tamaño de malla efectiva que se utiliza para dividir la parcela ha de ser menor que en los casos (c), (d) y (e). Esto muestra que el índice SPLIT puede ser de utilidad a la hora de identificar plantones o parcelas en las que existan grandes coberturas homogéneas. A pesar de ello, SPLIT presenta una relación inversa con MESH, por lo que empleando solo una de estas dos características, se evita introducir redundancias en el estudio.

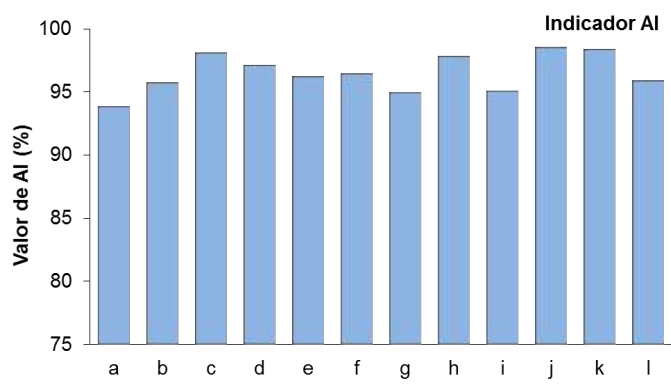

Figura 5.45: Valores de agregación AI.

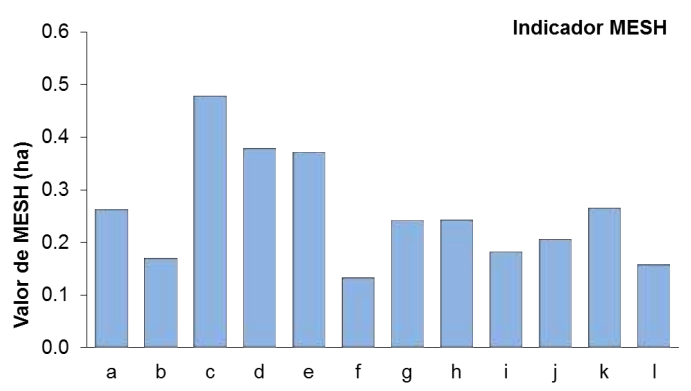

Figura 5.46: Valores de agregación MESH.

La variable de distancia euclídea entre elementos vecinos ENN indica la distancia que existe entre el borde de un objeto con el borde del objeto más cercano. Su media junto con la desviación estándar pueden ser buenos indicadores para la distinción entre tipos de parcelas. Este indicador se emplea con coberturas de árboles, edificios y cultivos, de esta forma se conoce la distancia que existe entre los subobjetos de estas coberturas concretas y no la media entre todos los subobjetos de todas las coberturas existentes de la parcela, que es lo que ocurriría si se calculara ENN a nivel de parcela.

Valores reducidos de ENN_SD para la cobertura de árboles, significa que los árboles 


\section{Resultados}

están distribuidos con cierta regularidad o que el tamaño de los árboles no es variable (Figura 5.48a (a, b, c, d, f, g, l)). Mientras que si la desviación estándar presenta valores elevados, puede existir una irregularidad en la distribución de los árboles en la parcela o existir árboles de diferentes tamaños (Figura 5.48a (e, h)). Con la clase de edificios generalmente se tienen parcelas con un único elemento de esa clase, por lo que no resulta tan interesante como con la clase de árbol. Aun así se ha realizado el estudio de ENN entre las parcelas de edificios del grupo B, en el que los valores de las gráficas en la Figura 5.48b indican la separación entre los edificios existentes dentro de cada parcela y su desviación estándar.

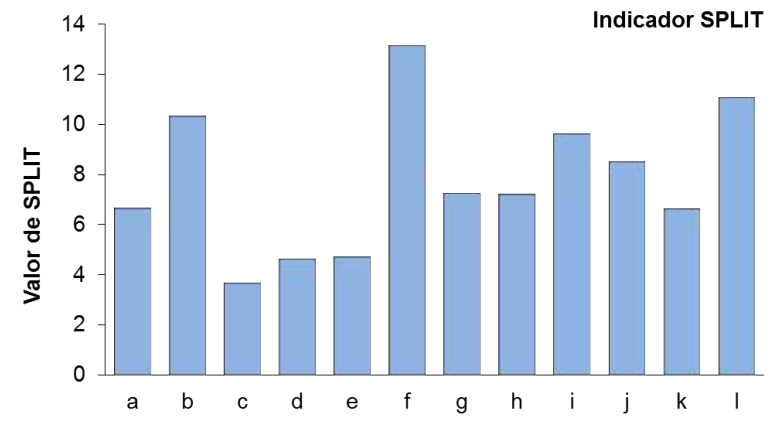

Figura 5.47: Valores de agregación SPLIT.

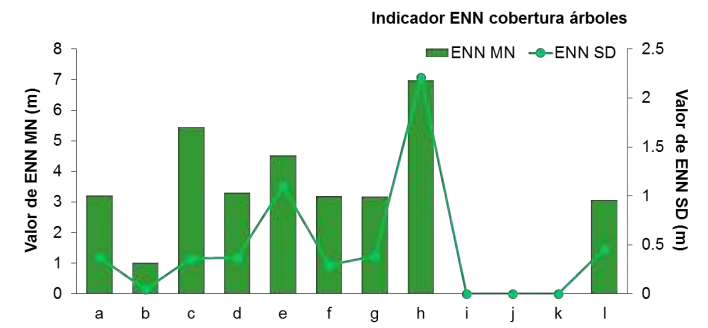

(a) Cobertura árboles parcelas grupo A

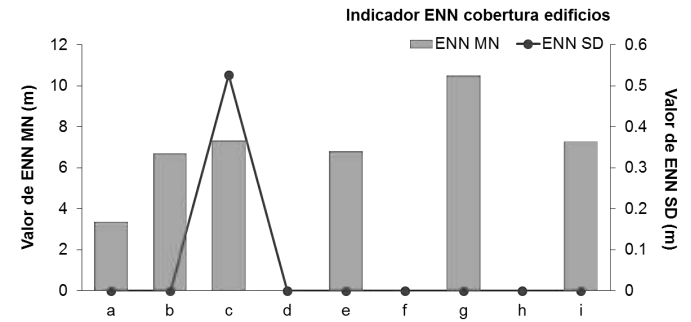

(b) Cobertura edificios parcelas grupo B

Figura 5.48: Valores de agregación ENN para las clases de árboles y edificios.

Los indicadores del número de elementos NP o número de subobjetos existentes dentro de la parcela son obtenidos a nivel de cobertura así como la densidad de elementos PD, y puede ser de gran interés para las parcelas con clases relacionadas con la cobertura de árboles. La Figura 5.49 muestra los valores de PD de árboles de las parcelas sintéticas. 


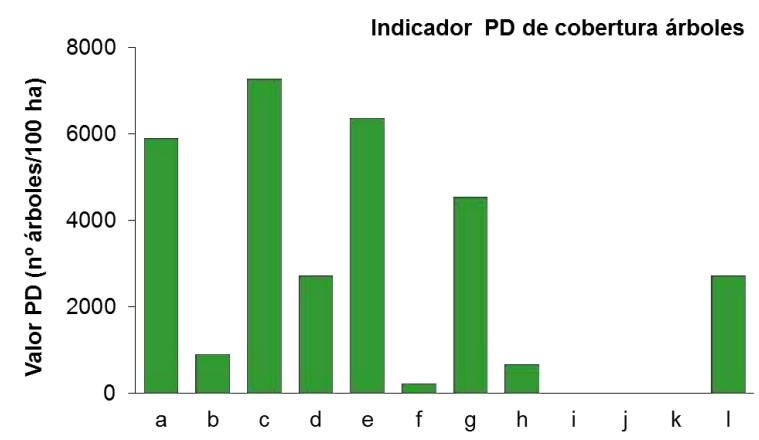

Figura 5.49: Valores de agregación PD de cobertura de árboles.

\subsubsection{Indicadores de diversidad}

Los índices de diversidad solo se encuentran presentes en las características descriptivas de parcela, ya que depende del número de coberturas que existe dentro del objeto de estudio. Si se empleasen a nivel de cobertura, el resultado sería siempre igual al considerar siempre una única cobertura de estudio.

Los valores de ciertos indicadores de diversidad están muy relacionados entre sí, como son los índices de Simpson y Shannon, por lo que escogiendo un único grupo de indicadores (o bien los de Simpson, o bien los de Shannon) se evita la introducción de redundancias, como bien se puede observar en las Figuras 5.50 y 5.51. En este estudio se decidió emplear los índices de Shannon.

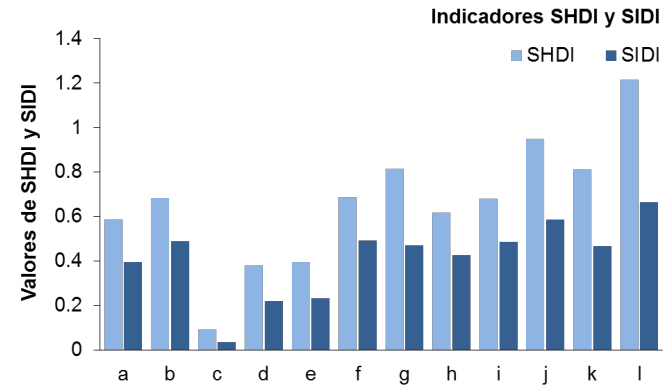

Figura 5.50: Valores de diversidad SHDI y SIDI.

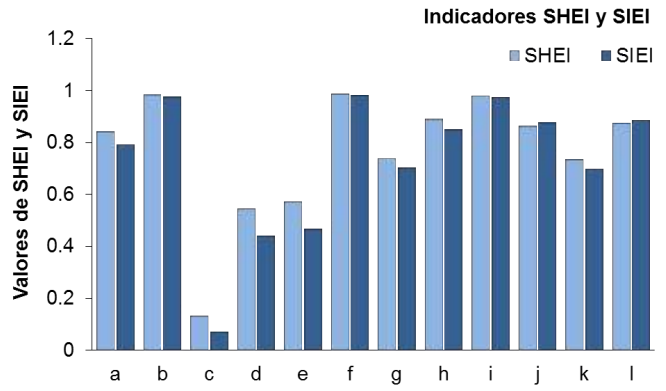

Figura 5.51: Valores de diversidad SHEI y SIEI.

Las características de diversidad de densidad de riqueza de elementos $\mathrm{PRD}$ o riqueza de elementos PR, resultan interesantes a la hora de comparar el contenido entre parcelas, indicando de forma relativa o absoluta el número de coberturas que hay dentro de cada parcela (Figuras 5.52 y 5.53). Para el estudio se escoge la variable de densidad de riqueza 


\section{Resultados}

de elementos PRD ya que los valores están normalizados según el área de la parcela. En este caso, la forma entre las gráficas PRD y PR son iguales debido al tamaño constante que presentan las parcelas sintéticas.

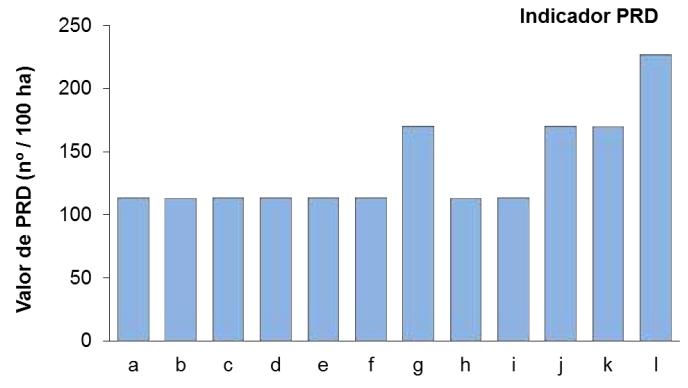

Figura 5.52: Valores de diversidad PRD.

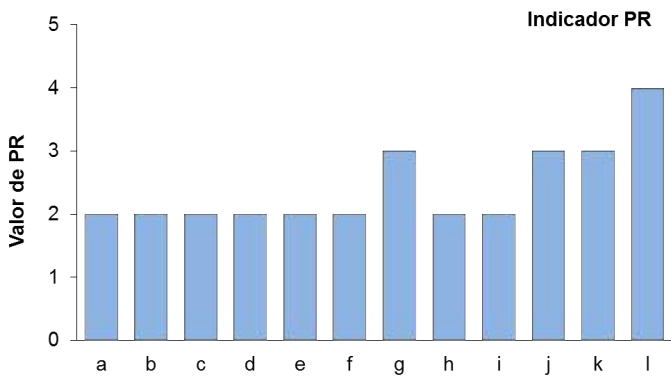

Figura 5.53: Valores de diversidad PR.

El indicador de diversidad DRA presenta la densidad de riqueza de árboles (Figura 5.54), obteniendo valores elevados en las parcelas de la Figura 4.17 (a, c, e, g), en las que los elementos pertenecientes a la cobertura de árboles son más elevados. El valor más elevado se presenta en la parcela de plantones (Figura 4.17 (c)), ya que el número de elementos de la cobertura, a pesar de su tamaño, es elevado. Este indicador puede resultar interesante ya que se podría detectar un incremento o un descenso de la densidad de árboles al comparar los indicadores de diferentes fechas.

El indicador IFFR relaciona el número total de coberturas estudiadas con el número de coberturas existentes en la parcela, presentando mayores valores cuando la parcela presenta un menor número de coberturas (Figura 5.55). Aquellas parcelas que presenten todas las coberturas de estudio, tendrán el valor 0, como es el caso de la parcela de la Figura 4.17 (l) (Figura 5.55). IFFR está muy relacionado con la riqueza de elementos PR.

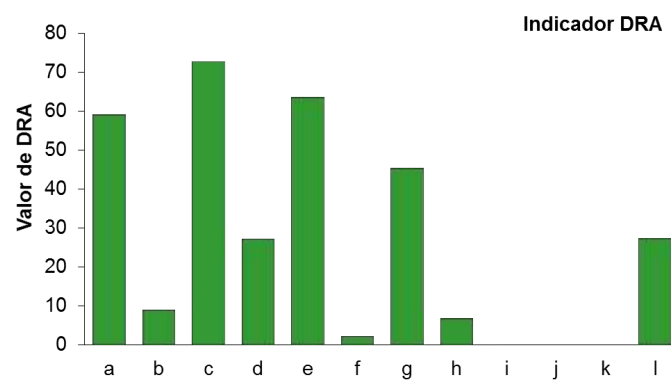

Figura 5.54: Valores de diversidad DRA.

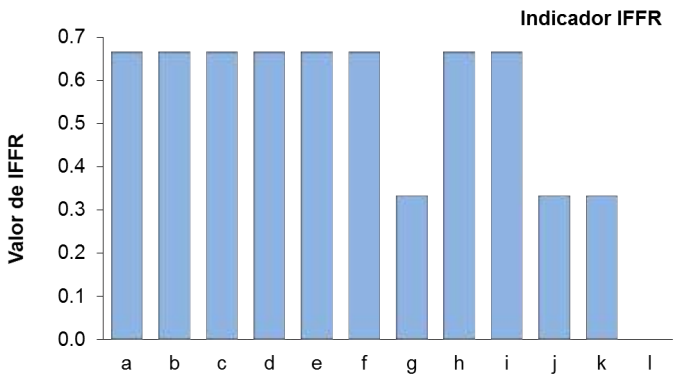

Figura 5.55: Valores de diversidad IFFR. 


\subsection{Resultados del ensayo III. Análisis de características de fragmentación}

El indicador IFFA obtiene sus valores más elevados en las parcelas 4.17 (c, h, j, k) ya que son éstas las que presentan objetos con el menor perímetro con respecto del área total de la parcela (Figura 5.56). Este indicador se encuentra más influenciado por el área y perímetro de los subobjetos que por el número de elementos, ya que por ejemplo la parcela de plantones (Figura 4.17 (c)), es una de las parcelas que mayor elementos presenta pero también la que menor tamaño de subobjetos tiene, presentando valores de IFFA muy elevados en comparación con el resto de parcelas que tienen un gran número de subobjetos. El indicador IFFA puede resultar más interesante que el IFFR, ya que aporta mayor información relacionada con el área y perímetro de los subobjetos que únicamente el número de coberturas existentes en la parcela.

Como último indicador de diversidad se tiene el indicador densidad-diversidad DD (Figura 5.57), que muestra valores elevados en aquellas parcelas con gran densidad de coberturas.

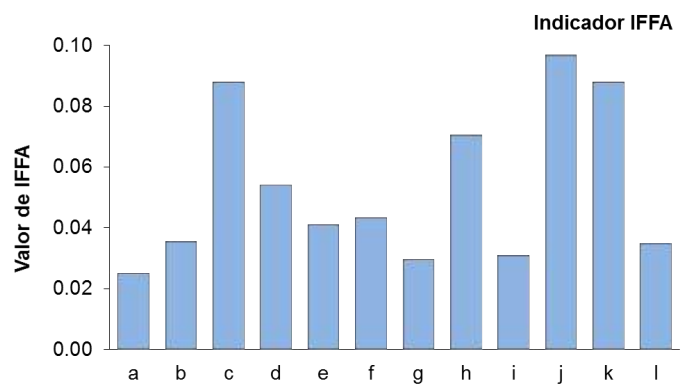

Figura 5.56: Valores de diversidad IFFA.

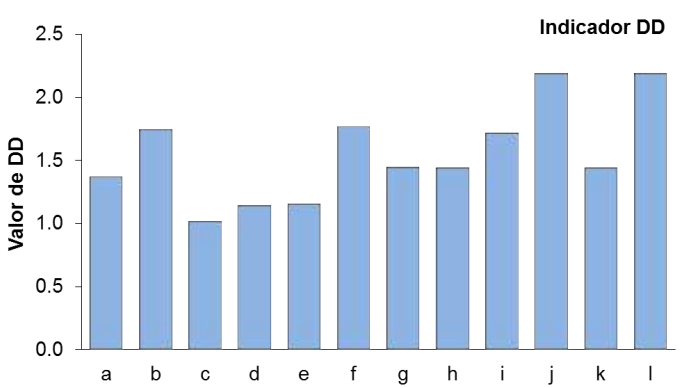

Figura 5.57: Valores de diversidad DD. 


\subsubsection{Resumen de indicadores seleccionados}

En la Tabla 5.1 se muestra el resumen de las características de fragmentación seleccionadas para introducir en el estudio de clasificaciones de tipos de parcelas.

\begin{tabular}{|c|c|c|c|}
\hline & & Tipo & \\
\hline & Objeto & Cla & \\
\hline & $\mathrm{TE}$ & PLAND & (Todas) \\
\hline & & LPI & $(\mathrm{A})(\mathrm{E})$ \\
\hline & & $\mathrm{TE}$ & $(\mathrm{A})(\mathrm{E})$ \\
\hline Area y perimetro & & $\mathrm{ED}$ & $(\mathrm{A})(\mathrm{E})$ \\
\hline & & AREA & $(\mathrm{A})(\mathrm{E})$ \\
\hline & & DA & (A) \\
\hline & & SHAPE & $(\mathrm{A})(\mathrm{E})$ \\
\hline & & PARA & $(\mathrm{A})(\mathrm{E})$ \\
\hline Eommo & & PAFRAC & $(\mathrm{A})$ \\
\hline Forma & & FRAC & $(\mathrm{A})$ \\
\hline & & CIRCLE & $(\mathrm{A})(\mathrm{V})$ \\
\hline & & CONTIG & (A) \\
\hline & ECON & & \\
\hline Contraste & TECI & & \\
\hline & CWED & & \\
\hline & CONTAG & ENN & $(\mathrm{A})(\mathrm{V})$ \\
\hline Agregación & $\mathrm{AI}$ & NP & $(\mathrm{A})(\mathrm{E})$ \\
\hline & MESH & $\mathrm{PD}$ & (A) \\
\hline & SHDI & DRA & (A) \\
\hline Diyoncidod & SHEI & & \\
\hline Diversidad & PRD & & \\
\hline & IFFA & & \\
\hline
\end{tabular}

Tabla 5.1: Tabla de indicadores de fragmentación seleccionados, siendo para los indicadores de coberturas las coberturas de (A) árboles, (V) vegetación, (E) edificios y (Todas) todas las clases de estudio. 


\subsubsection{Resultados de la generación de los mapas de coberturas para la extracción de características de fragmentación}

Para la obtención de los mapas de coberturas se empleó una combinación entre los mapas generados a partir de clasificaciones no supervisadas y los mapas de coberturas básicas generados mediante máscaras binarias. Las clasificaciones no supervisadas generadas se dividieron en función de dos tipos de elementos: elementos de mayor altura y elementos de menor altura. Las máscaras binarias se emplearon para dotar de un tipo de cobertura a cada uno de los objetos obtenidos en la clasificación no supervisada.

Las tablas de asignación de coberturas para la imagen QuickBird de 2004 se muestran en la Figura 5.58.

En la asignación de coberturas a la imagen de clases altas, la cobertura de sombras se puede diferenciar bastante bien (Figura 5.58a clases 1 y 2), así como los edificios (Figura 5.58a clases 8, 9, 10, 11, 12 y 13). La cobertura de árboles presenta bastante confusión con los edificios. Esto se debe al problema de registro entre los modelos digitales de elevaciones y la imagen QuickBird, lo que provoca confusiones en la clasificación no supervisada. A los objetos pertenecientes a estas clases (Figura 5.58a clases 3, 4, 5, 6 y 7) se les asigna una cobertura de manera individual con apoyo de los mapas de coberturas básicas.

En el caso de las clases bajas existe una menor confusión, y a cada una de las clases no supervisadas se le asigna el valor de cobertura que mayor porcentaje presenta en esa clase. A pesar de ello, las clases 3, 4 y 8 (Figura 5.58b) presentan cierta confusión. En las parcelas agrícolas de la zona de estudio existen en muchas ocasiones zonas en las que es difícil diferenciar si existe vegetación o no debido a la existencia de poca vegetación en las que el NDVI presenta valores alrededor del umbral seleccionado. A pesar de esto, en estas clases se aplica la regla general y se asigna la cobertura que mayor porcentaje presenta en dicha clase. 


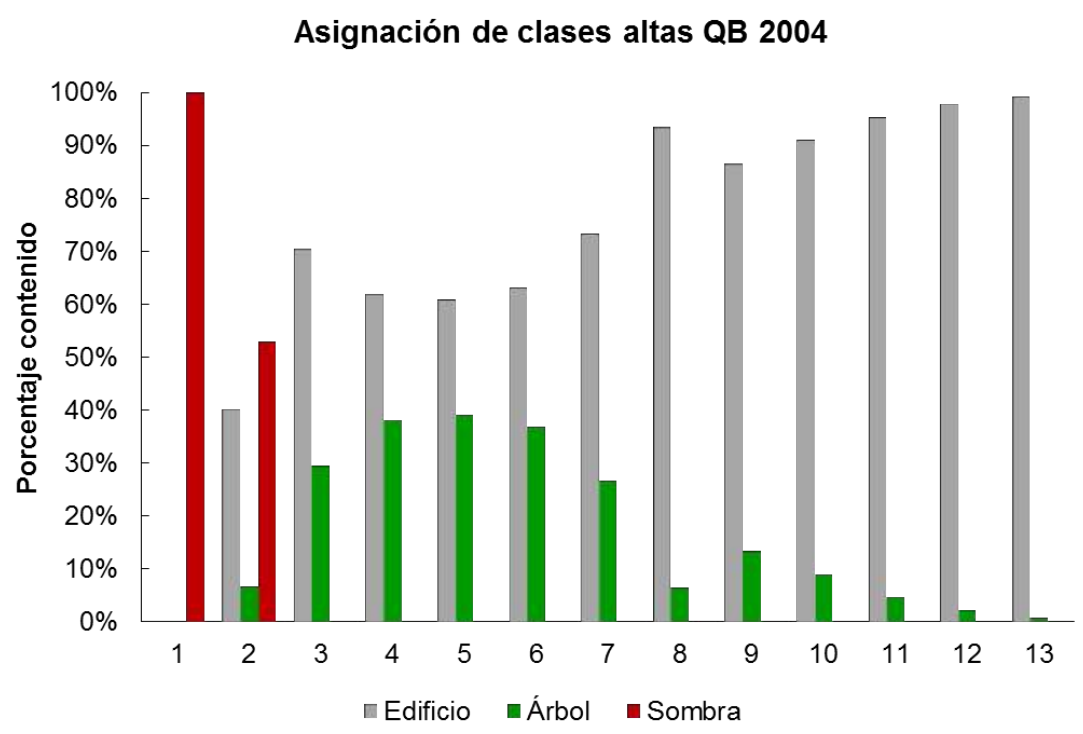

(a) Gráfica de clases altas

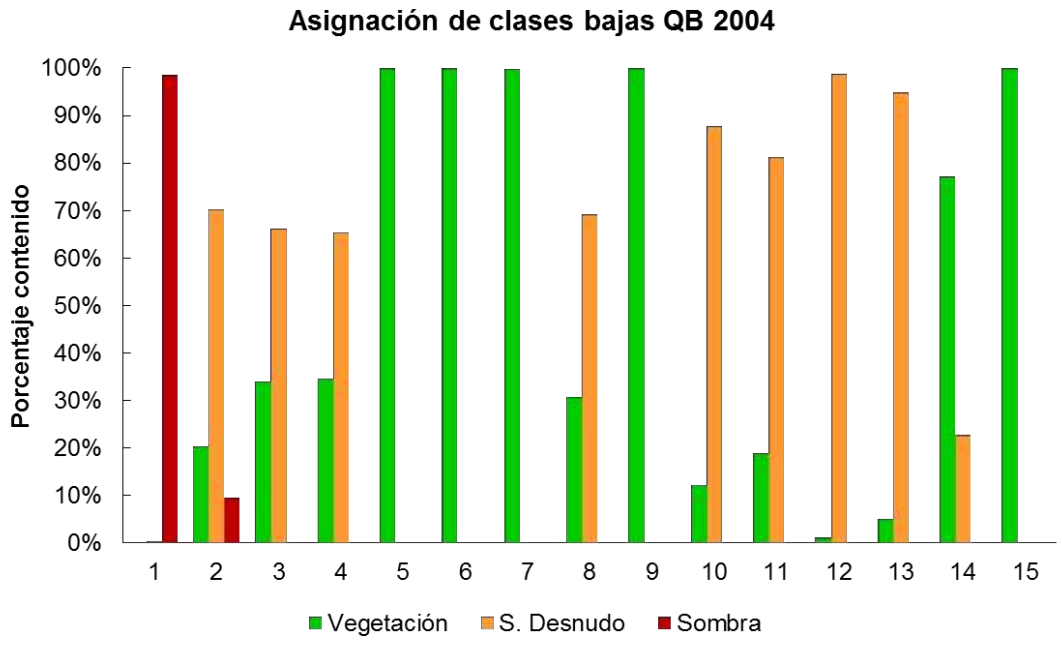

(b) Gráfica de clases bajas

Figura 5.58: Asignación de coberturas a la imagen QuickBird clasificada de 2004, en las que los ejes de abscisas contienen las clases numéricas resultantes de la clasificación no supervisada.

Las tablas de asignación de coberturas para la imagen PNOA de 2008 se muestran en la Figura 5.59.

Para el caso de la imagen PNOA de 2008 se obtiene una menor confusión en la asignación de coberturas en comparación con la imagen QuickBird de 2004. Debido a la mejor ortorectificación que tiene la imagen, el registro entre el modelo y la ortofotografía es mejor que en el caso anterior. A pesar de ello se puede diferenciar alguna clase en la que esta confusión está presente (Figura 5.59a clase 2). 


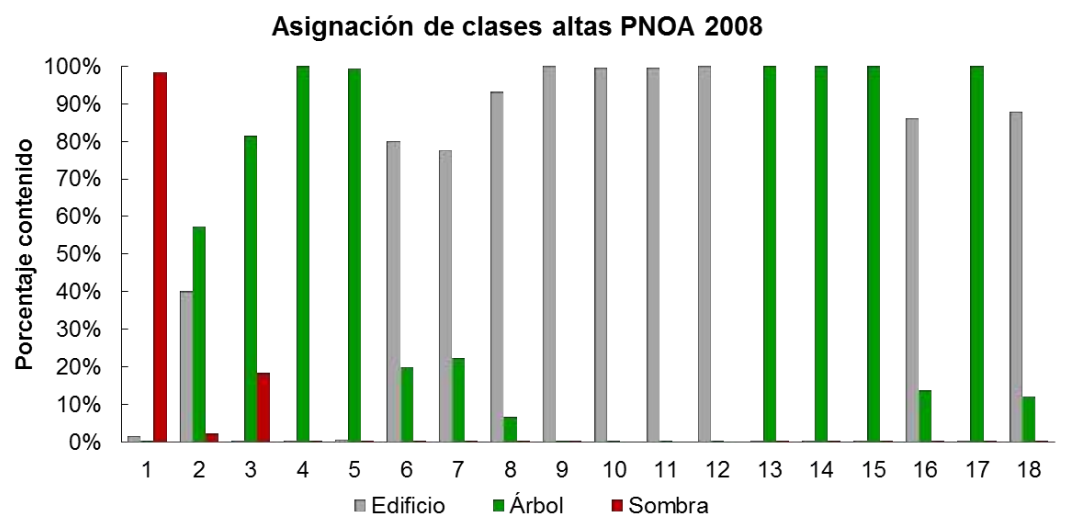

(a) Gráfica de clases altas

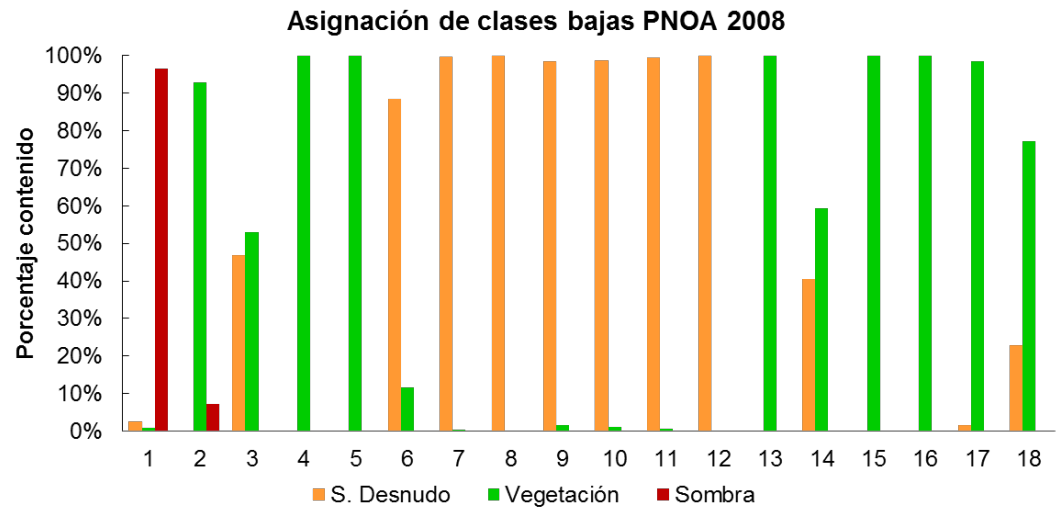

(b) Gráfica de clases bajas

Figura 5.59: Asignación coberturas a la imagen PNOA clasificada de 2008.

En la imagen clasificada de elementos bajos existe cierta confusión entre la clase de suelo desnudo y vegetación, como ocurrió en el caso de la clasificación de elementos bajos de la imagen de 2004. Como en el caso anterior se emplea la regla general para la asignación de coberturas a las clases.

Una vez generadas las imágenes de coberturas altas y bajas, se combinan las imágenes de cada fecha para conseguir el mapa de coberturas completo con las clases de suelo desnudo, vegetación, edificios, árboles y sombras. Para evaluar la clasificación se emplea una matriz de confusión a nivel de píxel en la que se comparan las regiones de interés tomadas como muestras sobre las imágenes con los mapas de coberturas obtenidos.

Los resultados de la evaluación para ambos mapas de coberturas muestran fiabilidades globales elevadas con porcentajes superiores al $90 \%$. Los resultados obtenidos para la imagen QuickBird (Tabla 5.2) muestran una fiabilidad global del 96,92\%. Las fiabilidades globales de usuario y productor son elevadas para todas las coberturas de estudio. 


\section{Resultados}

Existe una pequeña confusión para la cobertura de vegetación entre las coberturas de suelo y árboles pero se considera que son despreciables. Por otro lado, para el mapa de coberturas generado a partir de la imagen PNOA 2008 y a pesar de obtener un valor elevado de fiabilidad global, se obtienen valores de fiabilidad de usuario bajos para la cobertura árboles (Tabla 5.3). En esta cobertura existe una confusión con la cobertura de vegetación. Ambas coberturas presentan valores de NDVI similares, por lo que la diferencia entre ellas radica en la altura de los elementos. El desfase que existe entre la imagen PNOA y el modelo digital explica la confusión existente entre estas clases. Las fiabilidades de usuario se consideran elevadas con un valor del $82,52 \%$ en el peor de los casos para la clase de vegetación.

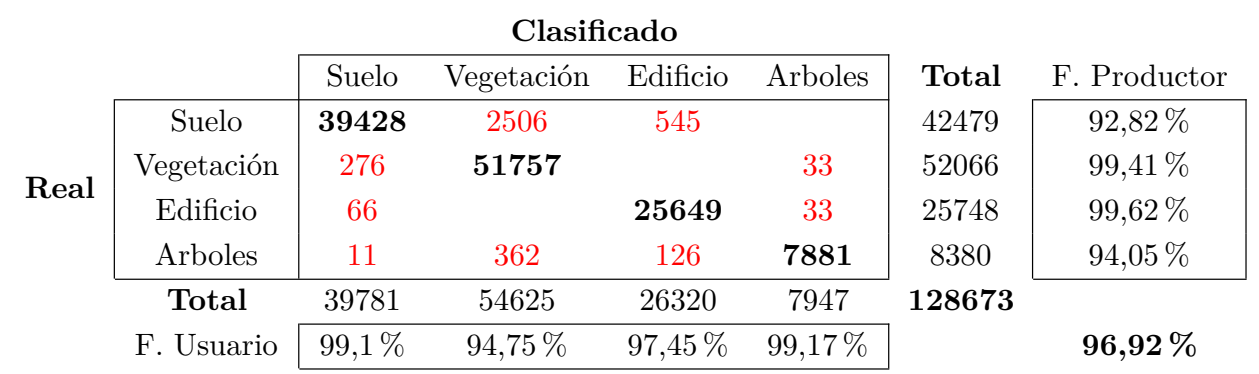

Tabla 5.2: Matriz de confusión de asignación de coberturas imagen QuickBird 2004.

\begin{tabular}{|c|c|c|c|c|c|c|c|}
\hline \multirow{8}{*}{ Real } & & \multicolumn{4}{|c|}{ Clasificado } & \multirow{3}{*}{$\begin{array}{l}\text { Total } \\
18810\end{array}$} & \\
\hline & & Suelo & Vegetación & Edificio & Arboles & & F. Productor \\
\hline & Suelo & 17997 & 813 & & & & $95,68 \%$ \\
\hline & Vegetación & & 20751 & & 4396 & 25147 & $82,52 \%$ \\
\hline & Edificio & 139 & & 11209 & 4 & 11352 & $98,74 \%$ \\
\hline & Arboles & & 453 & & 3698 & 4151 & $89,09 \%$ \\
\hline & Total & 18136 & 22017 & 11209 & 8098 & 59460 & \\
\hline & F. Usuario & $99,23 \%$ & $94,25 \%$ & $100,00 \%$ & $45,67 \%$ & & $90,24 \%$ \\
\hline
\end{tabular}

Tabla 5.3: Matriz de confusión de asignación de coberturas imagen PNOA 2008.

El siguiente paso tras la generación de los mapas de coberturas es la asignación de una cobertura a los píxeles pertenecientes a las sombras. La reclasificación de estos píxeles se realiza mediante los valores de los MDSn y de NDVI. Para poder realizar una evaluación aproximada de los mapas de coberturas, se emplea como referencia una imagen de 2006 que presenta un menor número de sombras que las imágenes de 2004 y 2008. A pesar de que se sabe que existen cambios en las zonas de sombra, es la opción que se considera como mejor aproximación para evaluar el método.

Los resultados de la clasificación de las zonas de sombra se pueden ver en las Tablas 5.4 y 5.5 . 


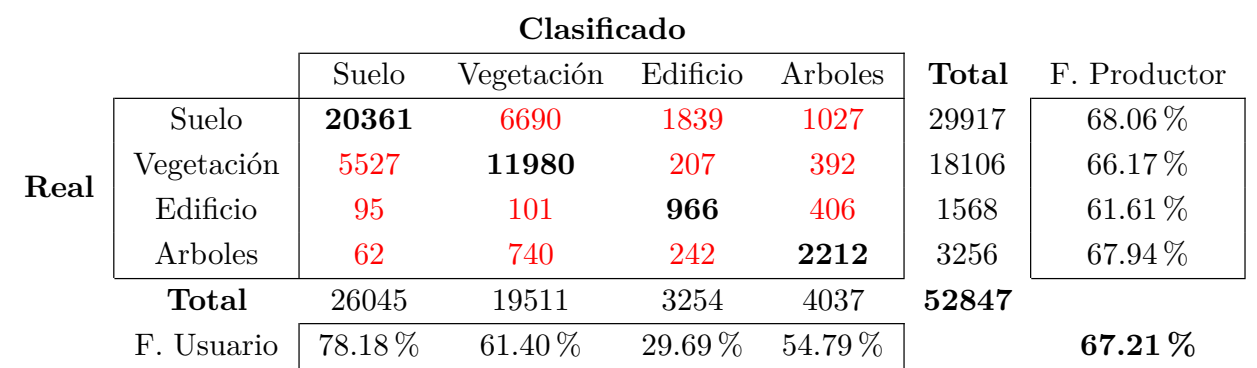

Tabla 5.4: Matriz de confusión de asignación de coberturas a las zonas de sombras imagen QuickBird 2004.

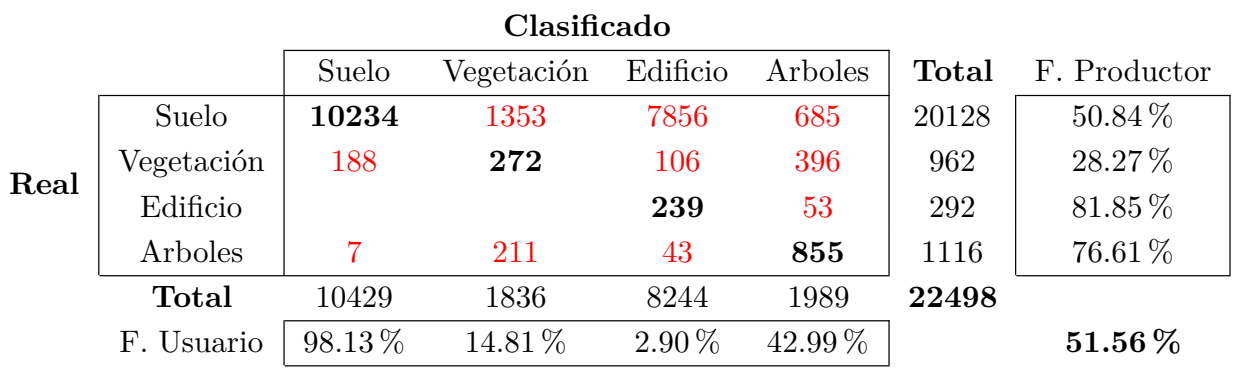

Tabla 5.5: Matriz de confusión de asignación de coberturas a las zonas de sombras imagen PNOA 2008.

Las zonas de sombras se sitúan junto a elementos con cierta altura como son edificios y árboles. Las sombras ocultan elementos que tienen menor altura que los elementos que provocan la sombra, lo que no significa que las coberturas ocultas por las sombras siempre sean suelo desnudo o vegetación. La toma de muestras de las zonas de sombra se realiza en regiones inmediatas a elementos con altura, por lo que los errores de registro entre imágenes multiespectrales y modelos digitales se perciban con una mayor intensidad. Además, parece ser que los valores de la banda infrarroja se ven afectados en las zonas de sombra y no se comportan de la misma manera que en las zonas de no sombra, lo que se traduce en valores elevados de NDVI en algunas de las regiones y dificulta la toma de umbrales entre las coberturas de suelo y vegetación.

Como en el caso anterior, se han obtenido mejores resultados con el mapa de coberturas de la imagen QuickBird. La fiabilidad global de la asignación de coberturas a las sombras para esta imagen es del 67,94\%. Las mejores fiabilidades de productor y usuario se obtienen para la cobertura de suelo y las peores en edificios, en la que la fiabilidad de la clasificación de edificios es menor del $30 \%$ (Tabla 5.4). En esta tabla también se reflejan las confusiones que existen entre suelo y vegetación, especialmente para la cobertura de vegetación, con un $61,40 \%$ de fiabilidad de productor y un elevado número de píxeles clasificados como suelo. Para la cobertura de árboles se obtiene una fiabilidad de productor del $54,79 \%$, en la que la mayoría de los errores existentes se debe 


\section{Resultados}

a la confusión con la clase de suelo. Esta confusión se puede justificar debido a que los valores anómalos de NDVI están situados en ciertas zonas de sombra.

Para la imagen de coberturas PNOA 2008 ambos efectos, tanto el registro del modelo digital como el comportamiento de la banda infrarroja, se ven aumentados, obteniendo una fiabilidad global de la clasificación del 51,56\%. Se obtienes altos porcentajes de confusión entre las clases de edificios, vegetación y árboles, en la que los valores de las fiabilidades del productor son extremadamente bajas (Tabla 5.5). Cabe destacar que la toma de muestras de las zonas de interés no es equitativa debido a que la zona de sombras es mucho más reducida en la imagen PNOA que en la QuickBird, por lo que se tiene una menor extensión para la evaluación.

A pesar de las bajas fiabilidades obtenidas en la evaluación de las sombras, el número de píxeles de sombra son escasos en comparación con la zona de estudio y los mayores errores se encuentran en zonas urbanas con edificios, que en la mayoría de los casos se encuentran fuera de las parcelas de estudio (polígonos pertenecientes a calles), por lo que se considera que no ejercen una gran influencia sobre los resultados de clasificación.

Los resultados finales del mapa de coberturas se pueden observar en las Figuras 5.60a y 5.60b, que muestran un ejemplo de la zona periurbana de estudio de Valencia Norte.

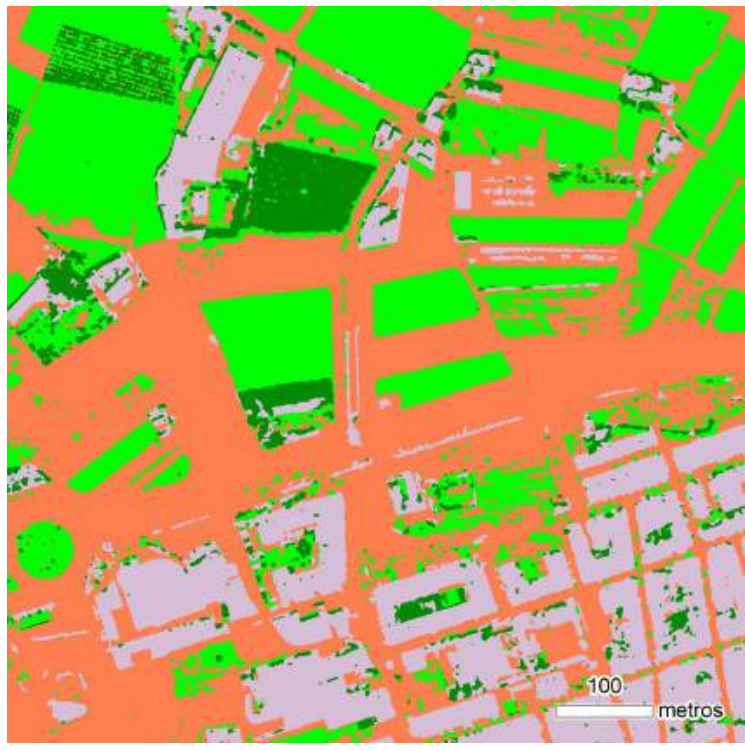

(a) Mapa de coberturas de 2004

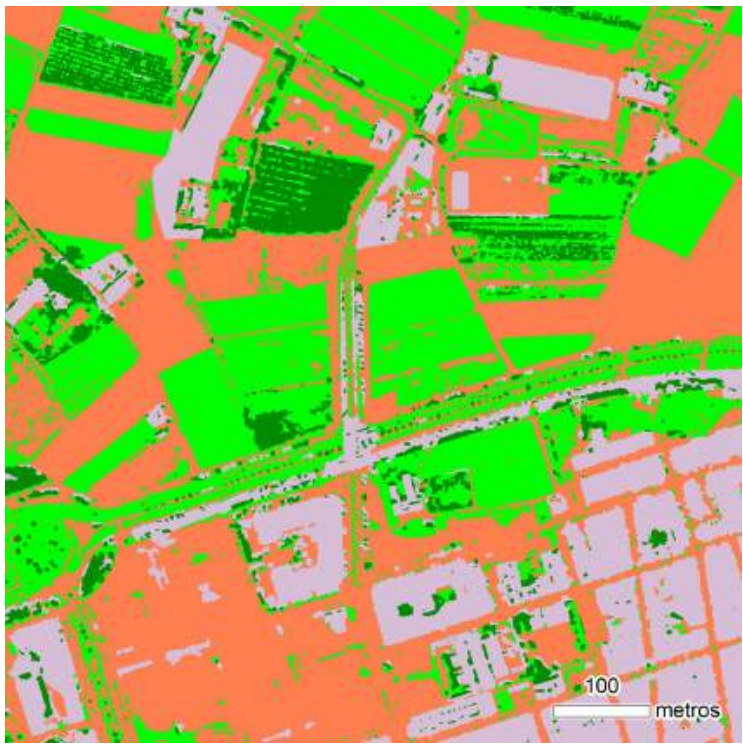

(b) Mapa de coberturas de 2008 Edificios $\square$ Árboles

Figura 5.60: Detalles de los mapas finales de coberturas. 


\subsubsection{Resultados de detección de cambios mediante clasifica- ción directa empleando características de fragmentación}

Tras la generación de los mapas de coberturas, se han extraído las características de fragmentación sobre las parcelas de estudio y se ha realizado la diferencia entre ellas. El número total de características empleadas es de 46, que coinciden con las seleccionadas en el estudio de parcelas sintéticas.

El resultado del análisis discriminante paso a paso se muestra en la gráfica de la Figura 5.61. Se puede observar que las primeras características introducidas en el sistema son las variables que se corresponden con los porcentajes de cobertura de edificio, suelo y vegetación contenidos en las parcelas (E_PLAND, S_PLAND y V_PLAND). Con estas características se obtienen altas fiabilidades para la mayoría de las clases salvo para las nuevas plantaciones (NPL) y arranques (ARR).

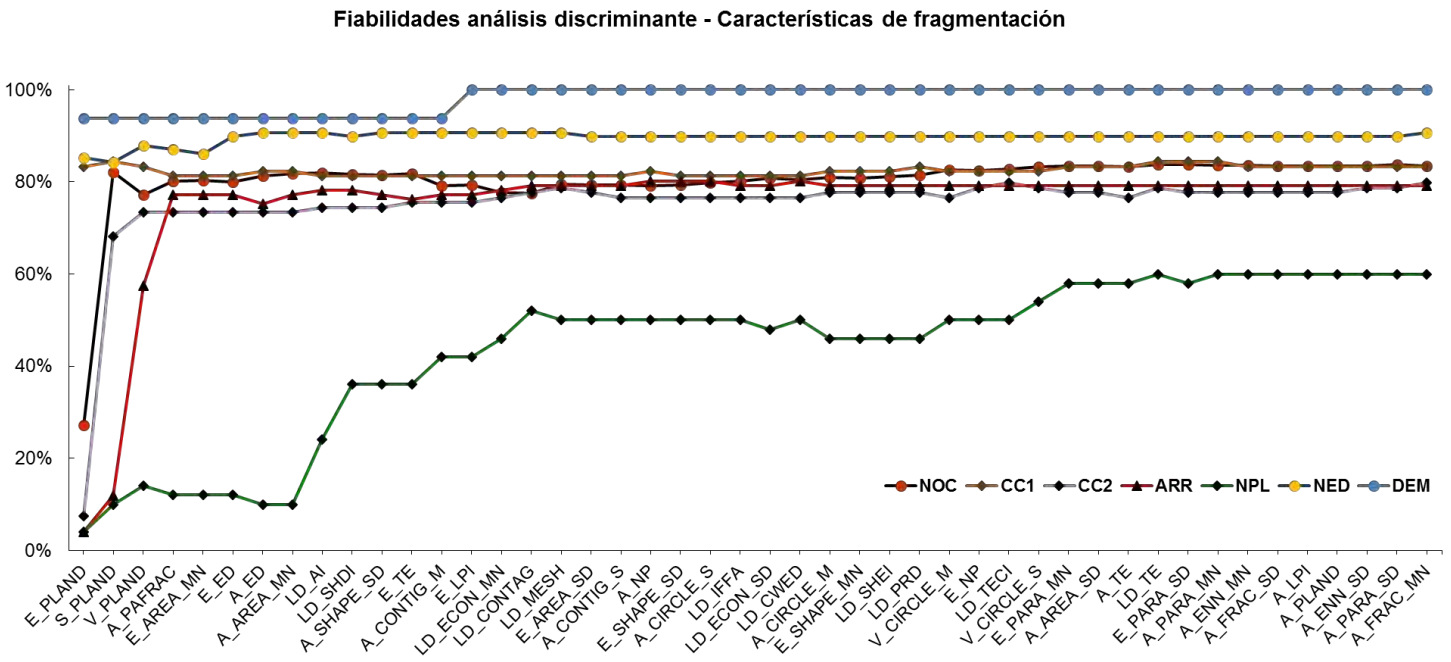

Figura 5.61: Fiabilidades de análisis discriminante paso a paso de características de fragmentación.

En la gráfica también se puede observar cómo la clase de demoliciones (DEM) es en la que se obtiene mayores fiabilidades desde la primera característica, al igual que los nuevos edificios (NED) y la primera clase de cambios en cultivos (CC1). La clase en la que peores fiabilidades se obtienen es la de nuevas plantaciones, cuyos valores de fiabilidad máximos se encuentran en torno al $60 \%$.

Tras la introducción de la característica del indicador de contagio (LD_CONTAG), se muestra una estabilización de las fiabilidades para todas las clases salvo para las nuevas plantaciones, por lo que se ha decidido emplear estas primeras 16 variables para las clasificaciones directas mediante árboles de decisión. Si se analiza la matriz de correla- 


\section{Resultados}

ciones (Figura 5.62) que existe entre estas primeras 16 características, se puede ver que existen características relacionadas entre sí. Al incluir estas características en el algoritmo clasificador, los propios árboles de decisión excluyen algunas de las características no determinantes en la clasificación, por lo que, a pesar de emplear dichas características en la clasificación, algunas de ellas serán excluidas. En la Figura 5.63 se muestran las correlaciones del subconjunto de las 16 características seleccionadas.

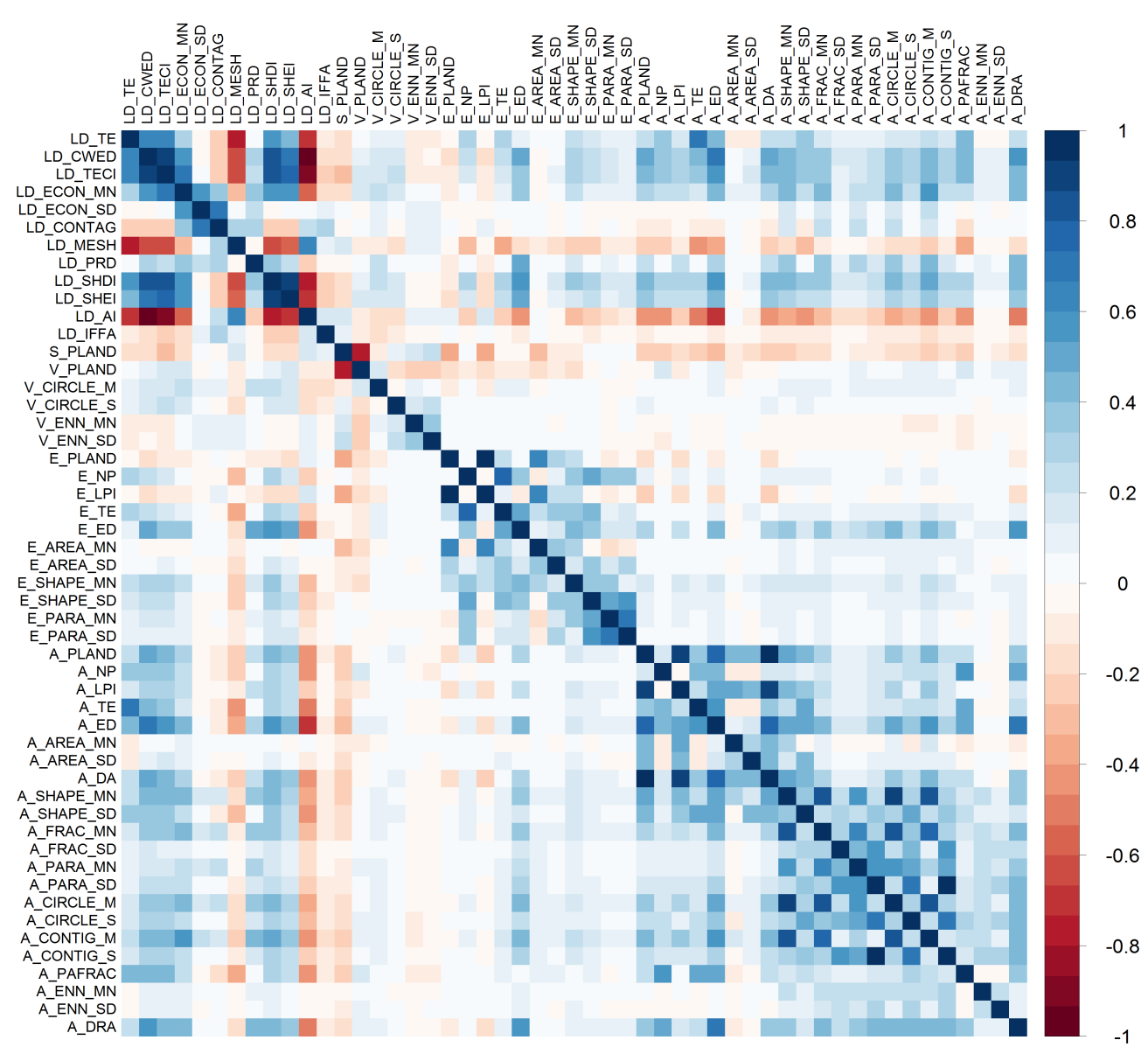

Figura 5.62: Matriz de valores de correlación entre variables de fragmentación. Los valores de mayor magnitud con colores más oscuros (azul oscuro y rojo oscuro) representan una mayor correlación.

Las 16 primeras variables seleccionadas mediante el análisis discriminante se introducen en el clasificador de árboles de decisión. Los resultados de la fiabilidad global y fiabilidades de productor y usuario por cada una de las clases se pueden ver en las Figuras 5.64, 5.65a y 5.65b respectivamente, en las que las 16 variables se corresponden con el Grupo I. 


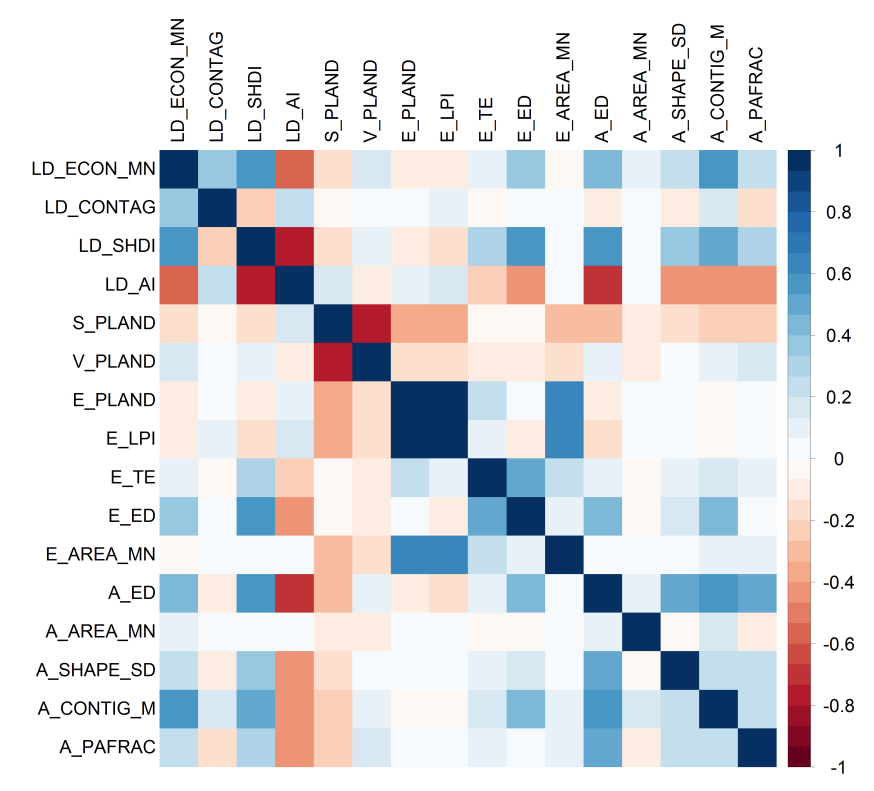

Figura 5.63: Matriz de valores de correlación entre variables de fragmentación seleccionadas en el análisis discriminante. Los valores de mayor magnitud con colores más oscuros (azul oscuro y rojo oscuro) representan una mayor correlación.

Los resultados obtenidos a partir de estas 16 variables o Grupo I, se han comparado con otras dos clasificaciones en las que se han eliminado del grupo original de 16 variables, el índice de diversidad de Shannon (LD_SHDI) y el indicador del mayor objeto para la cobertura de edificios (E_LPI). Se han eliminado estas dos características debido a su alta correlación con las características de índice de agregación (LD_AI) y porcentaje de cobertura de edificios (E_PLAND). Se ha decidido eliminar LD_SHDI y E_PLI en vez de LD_AI y E_PLAND ya que se obtenían peores fiabilidades al eliminar estas dos últimas características. El nuevo conjunto de características se corresponden con el Grupo II.

El Grupo II de características obtiene peores resultados en aquellas clases relacionadas con cultivos y en los arranques, pero mejora las fiabilidades para las clases de edificios (Figura 5.65a).

Con el fin de intentar mejorar las clases de cultivos y arranques, se han introducido las diferencias de NDVI (media y desviación) al conjunto de características del Grupo II (Grupo III). Estas dos características mejoran las clases de cultivos, y nuevas plantaciones, pero empeoran los resultados de los cambios relacionados con edificios (Figura 5.65a). En la Tabla 5.6 se muestra un resumen de las características contenidas en cada grupo estudiado. 


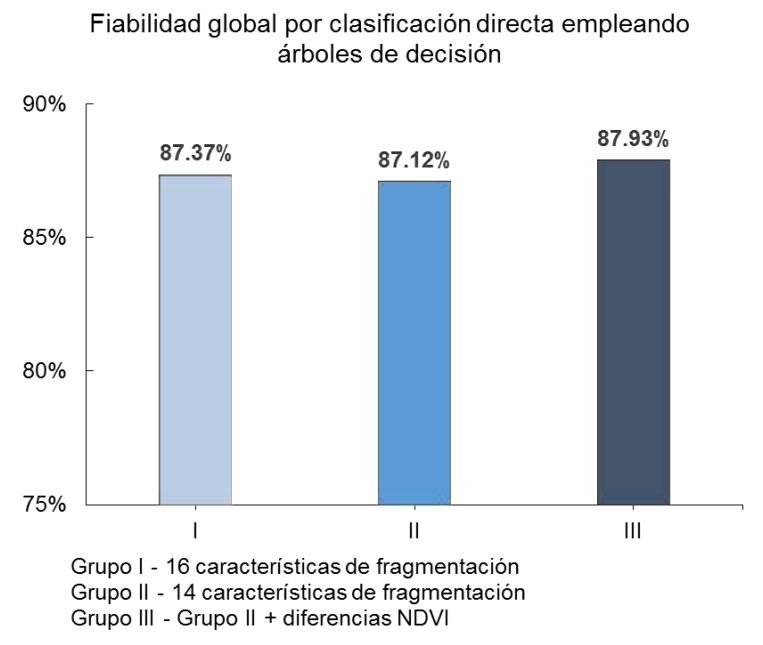

Figura 5.64: Fiabilidad global por clasificación directa de diferentes agrupaciones de características de fragmentación.

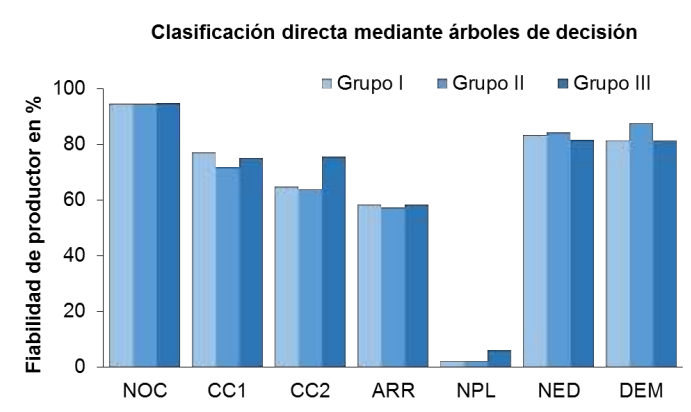

(a) Fiabilidades de productor.

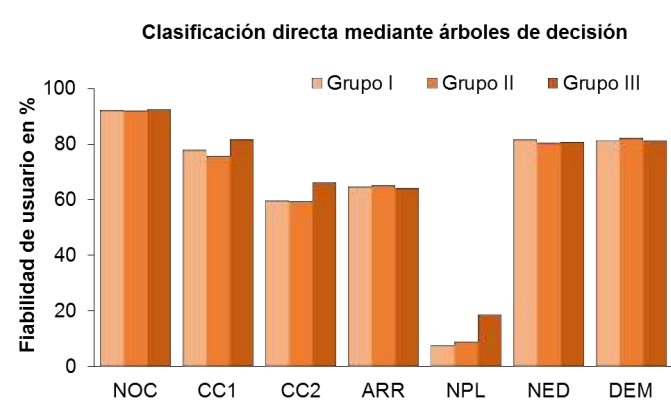

(b) Fiabilidades de usuario.

Figura 5.65: Fiabilidades de las clases de estudio mediante clasificación directa por árboles de decisión con características de fragmentación.

Éste último grupo consigue mejora hasta un $6 \%$ la clase de nuevas plantaciones (NPL) para la fiabilidad de productor, pero se reduce la en las clases de edificios además de introducir información que se considera redundante, ya que los mapas de coberturas se han generado empleando información de NDVI además de haber variables, como los porcentajes de contenido de coberturas en las parcelas, que indican directamente el contenido de vegetación en las parcelas. Las fiabilidades globales entre los tres grupos de variables estudiados, muestran una variación inferior a un 1\% entre sí (Figura 5.64).

Los resultados obtenidos en la detección de cambios empleando el Grupo II de características de fragmentación se puede observar en la Figura 5.66. Se ha seleccionado el Grupo II debido a su menor número de características y a su incremento en la detección de las demoliciones, considerando esta clase de mayor importancia que los cambios en 
terrenos cultivados debido a la variabilidad de los mismos.

\begin{tabular}{|c|c|c|c|}
\hline Características & Grupo I & Grupo II & Grupo III \\
\hline \hline LD_ECON_MN & $\mathrm{x}$ & $\mathrm{x}$ & $\mathrm{x}$ \\
\hline LD_CONTAG & $\mathrm{x}$ & $\mathrm{x}$ & $\mathrm{x}$ \\
\hline LD_SHDI & $\mathrm{x}$ & & \\
\hline LD_AI & $\mathrm{x}$ & $\mathrm{x}$ & $\mathrm{x}$ \\
\hline S_PLAND & $\mathrm{x}$ & $\mathrm{x}$ & $\mathrm{x}$ \\
\hline V_PLAND & $\mathrm{x}$ & $\mathrm{x}$ & $\mathrm{x}$ \\
\hline E_PLAND & $\mathrm{x}$ & $\mathrm{x}$ & $\mathrm{x}$ \\
\hline E_LPI & $\mathrm{x}$ & & \\
\hline E_TE & $\mathrm{x}$ & $\mathrm{x}$ & $\mathrm{x}$ \\
\hline E_ED & $\mathrm{x}$ & $\mathrm{x}$ & $\mathrm{x}$ \\
\hline E_AREA_MN & $\mathrm{x}$ & $\mathrm{x}$ & $\mathrm{x}$ \\
\hline A_ED & $\mathrm{x}$ & $\mathrm{x}$ & $\mathrm{x}$ \\
\hline A_AREA_MN & $\mathrm{x}$ & $\mathrm{x}$ & $\mathrm{x}$ \\
\hline A_SHAPE_SD & $\mathrm{x}$ & $\mathrm{x}$ & $\mathrm{x}$ \\
\hline A_CONTIG_M & $\mathrm{x}$ & $\mathrm{x}$ & $\mathrm{x}$ \\
\hline A_PAFRAC & $\mathrm{x}$ & $\mathrm{x}$ & $\mathrm{x}$ \\
\hline Dif. Media NDVI & & & $\mathrm{x}$ \\
\hline Dif. Desv. NDVI & & & $\mathrm{x}$ \\
\hline
\end{tabular}

Tabla 5.6: Grupos de características de fragmentación empleados en las clasificaciones.

Los resultados obtenidos son un porcentaje elevado de fiabilidad global próximo al $90 \%$, con un porcentaje de detección del $73,2 \%$ y un porcentaje de calidad del $62,16 \%$. A pesar de obtener porcentajes elevados de cambios detectados y de coincidencias, los errores por defecto y por exceso también se consideran elevados, con un valor de errores indetectables superiores al $6 \%$. La mayoría de estos errores se corresponden con la clase de nuevas plantaciones, en las que las características de fragmentación no han funcionado como se esperaba. Esto se considera que es debido a la propia naturaleza de la clase de estudio y a la resolución espacial y generación de los mapas de coberturas.

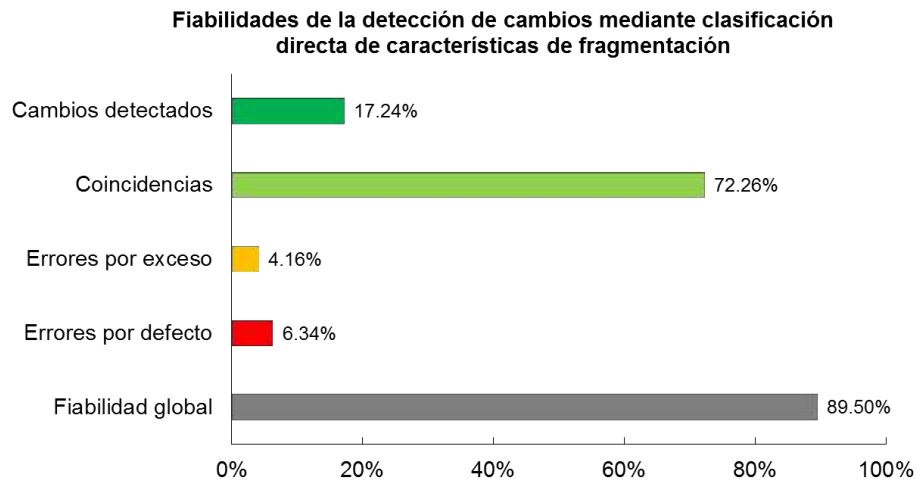

Figura 5.66: Fiabilidades de detección de cambios de características de fragmentación.

Las clases que mejor se comportan empleando las características de fragmentación para este estudio son las clases de edificios. Esto se debe en su mayor parte al tipo de parcelas de estudio, en las que en la mayoría de los casos, los edificios están presentes 
cubriendo un alto porcentaje de superficie dentro de la parcela. Empleando las características de fragmentación era de esperar que las clases relacionadas con árboles, al menos los arranques, obtuvieran mejores resultados empleando únicamente, características como los porcentajes de cobertura de parcelas, valor total de bordes, o densidad de árboles por parcela de estudio tal y como se deriva del ensayo.

\subsection{Resultados del ensayo IV. Análisis de caracte- rísticas temporales para la detección de cambios}

En este apartado se recogen los resultados de clasificación y detección de cambios aplicados sobre la zona de Valencia empleando todas las características estudiadas a lo largo del estudio. Los resultados de las clasificaciones se muestran en forma de fiabilidades tanto por cada una de las clases como de manera global, donde se puede ver cómo evolucionan los resultados al ir incluyendo en la clasificación directa los diferentes tipos de características estudiadas. En la Tabla 5.7 se muestran los grupos de los conjuntos de características estudiados en las clasificaciones de este ensayo. En la Figura 5.67 se puede ver un resumen del ensayo IV realizado.

\begin{tabular}{|c|c|}
\hline Grupo & Características \\
\hline \hline Grupo A & Espectrales, forma y textura \\
\hline Grupo B & Grupo A + tridimensionales \\
\hline Grupo C & Grupo B + codispersión y semivariograma cruzado \\
\hline Grupo D & Grupo C + fragmentación \\
\hline Grupo E & Grupo D + Clase previa $(2004)$ \\
\hline
\end{tabular}

Tabla 5.7: Grupos de los conjuntos de características empleados en el ensayo IV.

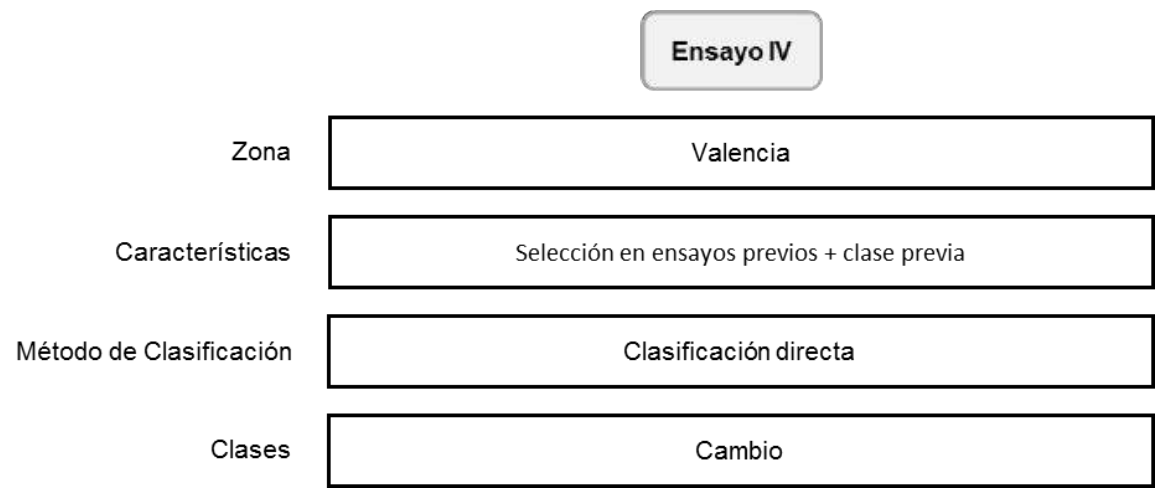

Figura 5.67: Esquema del Ensayo IV. 


\subsection{Resultados del ensayo IV. Análisis de características temporales para la detección de cambios}

En la Figura 5.68 se pueden ver las matrices de confusión de las clasificaciones de cada grupo de características estudiado.

En la Figura 5.69 y la Figura 5.70 se muestran los valores de fiabilidad de productor y usuario, respectivamente, por cada una de las clases de estudio, empezando con el primer grupo (Grupo A) que se corresponde con las características espectrales, textura y forma.
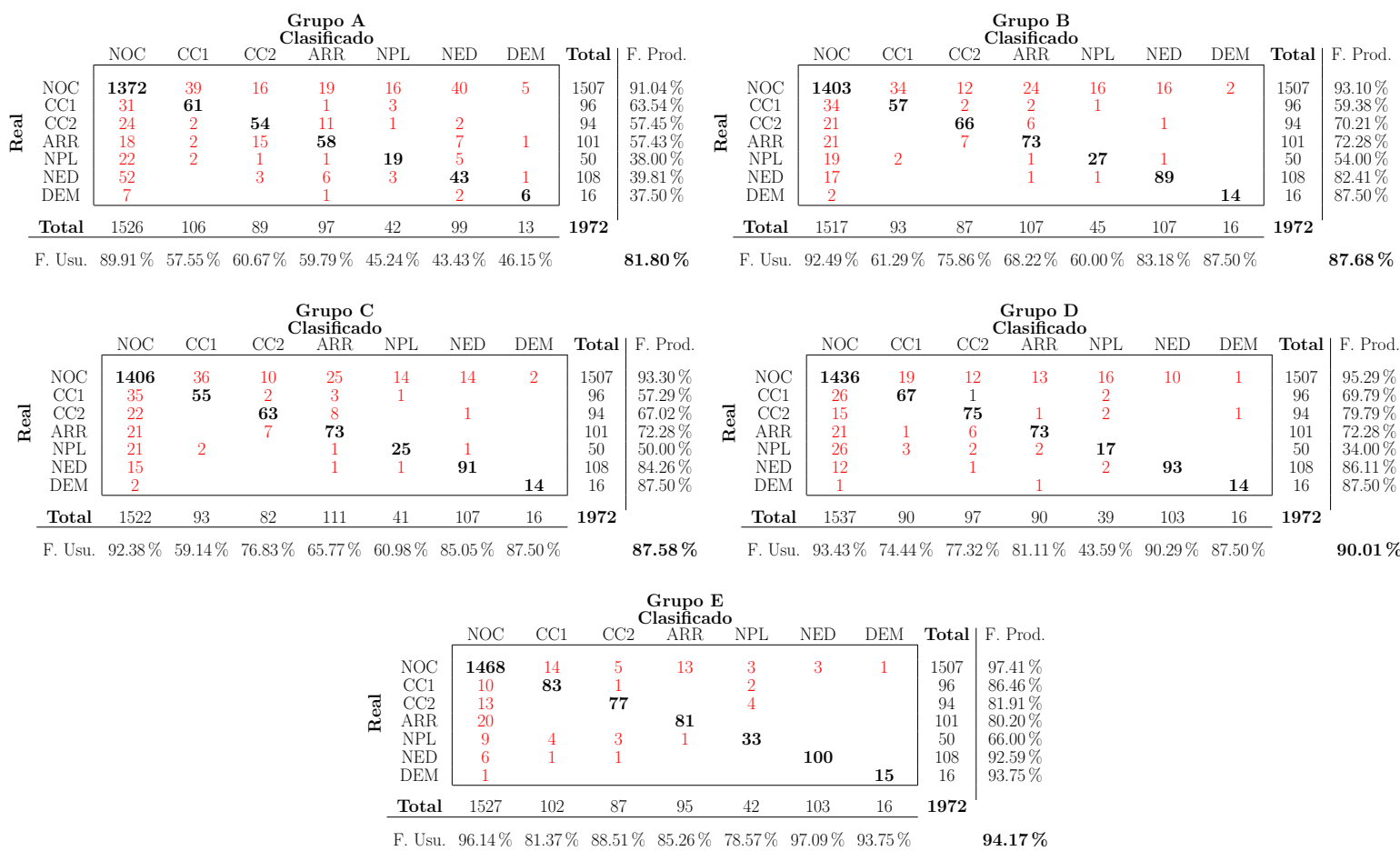

Figura 5.68: Matrices de confusión de clasificación directa de los grupos de características del Ensayo IV.

Al incluir en el Grupo A las características tridimensionales derivadas del LiDAR (Grupo B), se puede observar una mejora considerable de las clases de nuevos edificios (NED) y demoliciones (DEM). Del mismo modo, también se obtienen mayores valores de fiabilidad en las clases relacionadas con árboles (arranques - ARR, y nuevas plantaciones NPL). Las características tridimensionales aportan información muy útil para identificar cambios en los que intervienen las alturas de los objetos. Aquellas clases en las que mayor cambio de altura se haya producido, serán las clases en las que mayor mejora se produzca al emplear estas características, como las clases en las que intervienen edificios.

Las características del semivariograma cruzado y codispersión afectan principalmente a las clases en las que se producen cambios en la estructura interna de las parcelas, como puede ser un cambio en el patrón de plantación o en la disposición de los árboles. Es por 


\section{Resultados}

esto que estas características se centran en las clases de nuevas plantaciones y arranques. A pesar de esto, al introducir las clases derivadas de funciones estadísticas (Grupo C), la mayoría de las clases de estudio mantienen sus valores pero se produce un descenso en las clases de nuevas plantaciones y en las clases relacionadas con cambios en los cultivos. Los ensayos de selección de estas variables se realizaron en un principio sobre la zona de estudio de Murcia, cuyas parcelas tienen características diferentes a las de la zona de Valencia. Esto puede ser la causa de que en la zona de Valencia el grupo de variables seleccionado no se comporte de la misma manera que en la zona de Murcia.

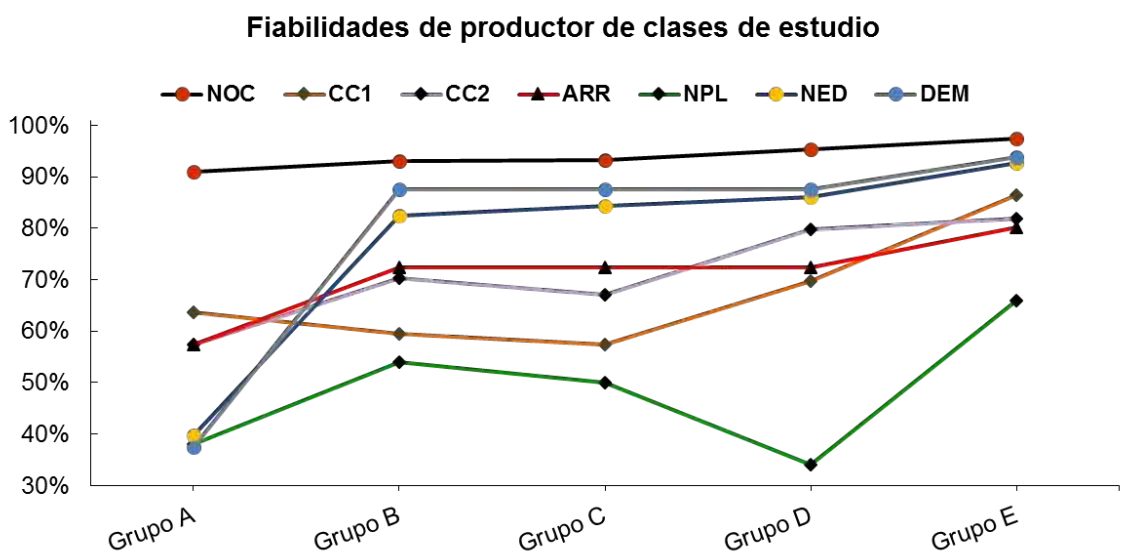

Figura 5.69: Fiabilidades de productor de clases de estudio por grupos de características. Grupo A: espectrales, textura y forma; Grupo B: Grupo A + tridimensionales; Grupo C: Grupo B + codispersión y semivariograma cruzado; Grupo D: Grupo C + fragmentación; Grupo E: grupo D + clase 2004.

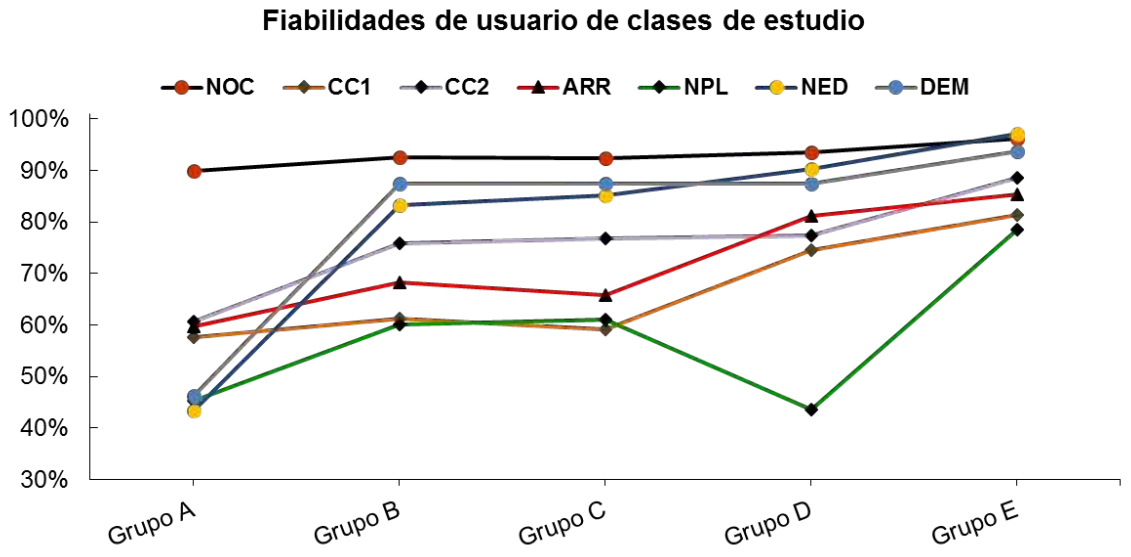

Figura 5.70: Fiabilidades de usuario de clases de estudio por grupos de características. Grupo A: espectrales, textura y forma; Grupo B: Grupo A + tridimensionales; Grupo C: Grupo B + codispersión y semivariograma cruzado; Grupo D: Grupo C + fragmentación; Grupo E: grupo D + clase 2004. 


\subsection{Resultados del ensayo IV. Análisis de características temporales para la detección de cambios}

Cuando se añaden al conjunto de características anterior las características de fragmentación (Grupo D), se puede percibir una mejora en todas las clases de estudio salvo en las nuevas plantaciones, con las que se obtienen valores bajos de fiabilidad. Este resultado es de esperar debido a que los mapas de coberturas no tienen la resolución espacial suficiente como para poder diferenciar los plantones existentes en la zona de huerta de Valencia debido al tamaño de estos, que es inferior al medio metro de resolución que tienen las imágenes y los modelos tridimensionales empleados en el estudio.

Como última clasificación, se añadió al grupo anterior de características la clase previa de cada una de las parcelas como si de una base de datos cartográfica se tratase (Grupo E). La introducción de esta característica vuelve a mejorar todas las clases de estudio, incluyendo la clase de nuevas plantaciones. A pesar de ser la clase de nuevas plantaciones la que peores resultados presenta en esta clasificación, sus valores de fiabilidad son mucho mayores que en todos los casos anteriores. La clase que mejores resultados presenta a lo largo de todo el estudio es la clase de no cambio, lo que también es de esperar debido al número de casos pertenecientes a esta clase.

La Figura 5.71 muestra las matrices de confusión de los resultados de detección de cambios de los grupos de características estudiados.

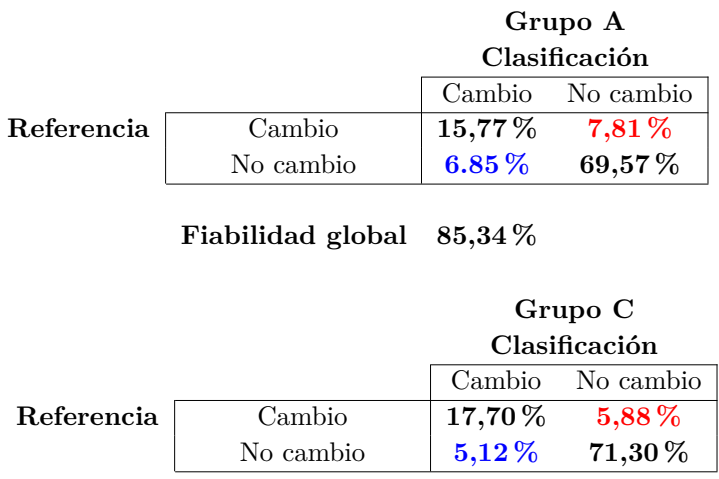

Fiabilidad global $\quad 89,00 \%$

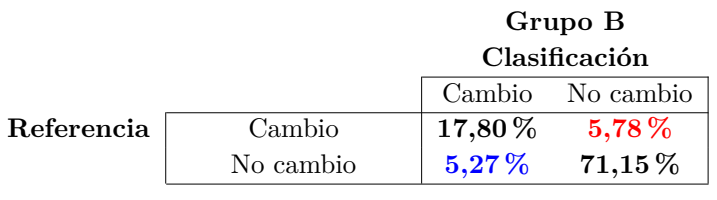

Fiabilidad global $\quad \mathbf{8 8 , 9 5 \%}$

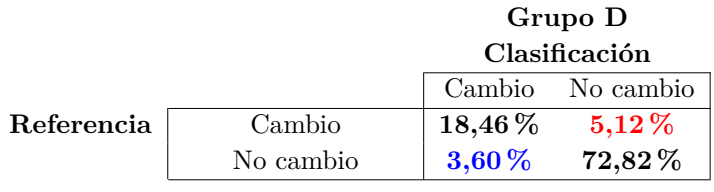

Fiabilidad global $\quad 91,28 \%$

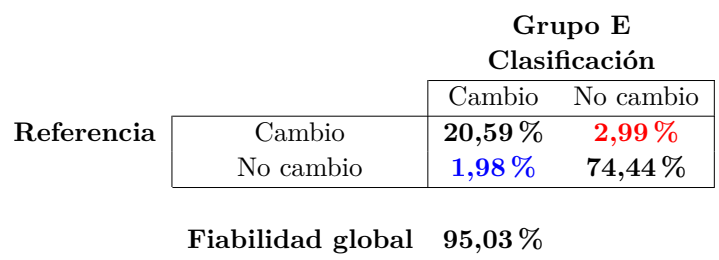

Figura 5.71: Matrices de confusión de los resultados de detección de cambios de los grupos de características del Ensayo IV.

En la Figura 5.72 se pueden observar los resultados de fiabilidad global en la cla- 


\section{Resultados}

sificación directa mediante árboles de decisión y la fiabilidad global en la detección de cambios. Se puede observar cómo mejoran los valores de ambas fiabilidades desde el grupo inicial de características hasta el último grupo, del mismo modo que se van reduciendo los errores, tanto detectables como indetectables (Figura 5.73). Se puede observar que las fiabilidades de detección de cambios son, para todos los grupos, más elevadas que las fiabilidades globales de clasificación. Esto es debido a que en la evaluación de la detección de cambios son considerados los cambios que han sido detectados, ya sean clasificados correctamente o no siempre y cuando hayan sido clasificados como cambios. En la fiabilidad global de las clasificaciones sólo están considerados los cambios clasificados con la clase correcta.

Fiabilidades globales de clasificación y detección

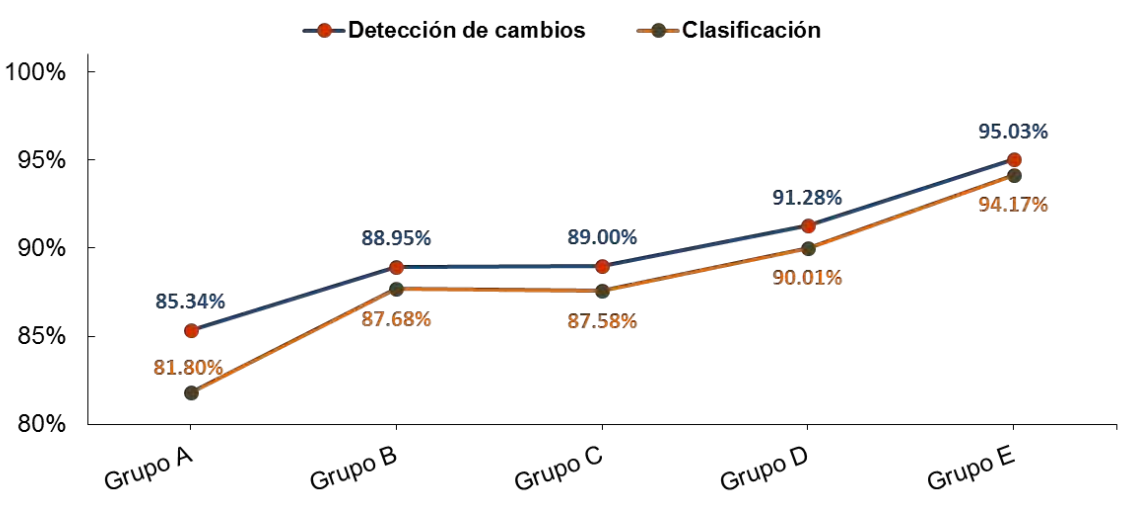

Figura 5.72: Fiabilidad global de clasificación y detección de cambios por grupos de características. Grupo A: espectrales, textura y forma; Grupo B: Grupo A + tridimensionales; Grupo C: Grupo B + codispersión y semivariograma cruzado; Grupo D: Grupo C + fragmentación; Grupo E: grupo D + clase 2004.

Los mayores cambios se dan al incluir las características derivadas de datos LiDAR (Grupo B) y al introducir la clase previa en el último grupo (Grupo E). Los valores finales de fiabilidad que se obtienen tanto para clasificación como para la detección de cambios se consideran valores elevados de fiabilidad. Lo mismo ocurre con los valores de calidad en la detección (Figura 5.74), con altas tasas de detección y altos porcentajes de calidad en la detección. Si se comparan los valores iniciales empleando las características del Grupo A, con los valores finales del Grupo E, se puede decir que se ha producido una mejora en la detección de cambios, y que el método y las características empleadas, mejoran el punto de partida previo a este trabajo. 


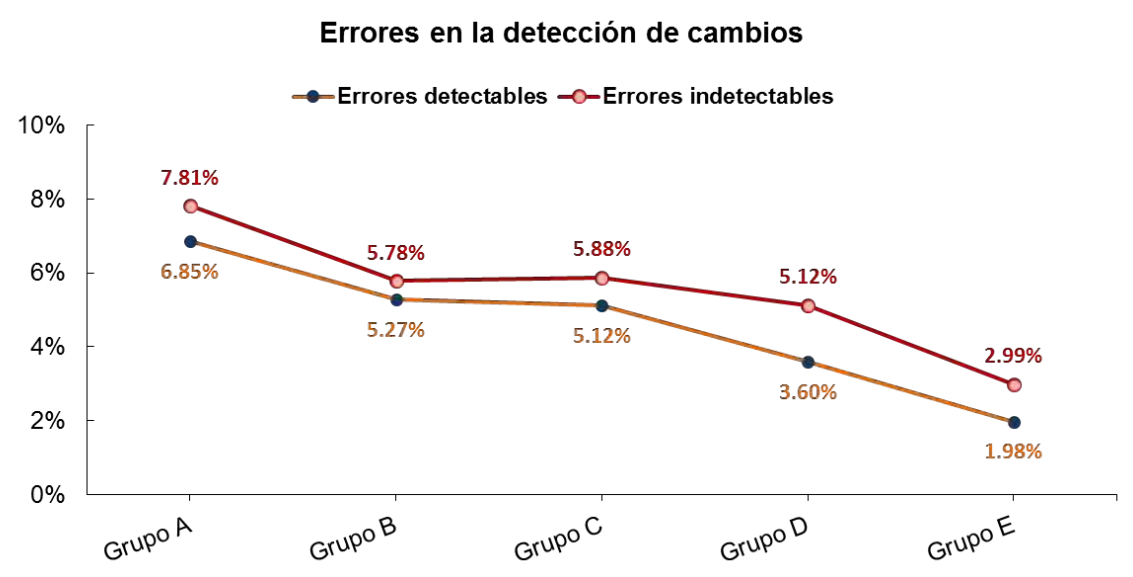

Figura 5.73: Resultados de los errores en la detección de cambios. Grupo A: espectrales, textura y forma; Grupo B: Grupo A + tridimensionales; Grupo C: Grupo B + codispersión y semivariograma cruzado; Grupo D: Grupo C + fragmentación; Grupo E: grupo D + clase 2004.

\section{Resultados de calidad y porcentajes de detección}

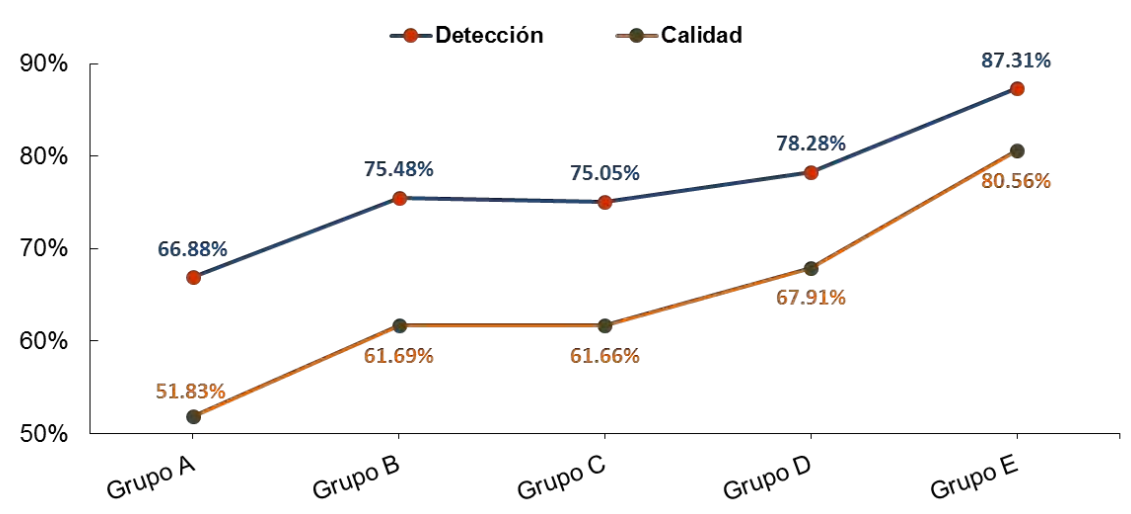

Figura 5.74: Resultados de calidad de detección con porcentajes de calidad y detección por grupos de características. Grupo A: espectrales, textura y forma; Grupo B: Grupo A + tridimensionales; Grupo C: Grupo B + codispersión y semivariograma cruzado; Grupo D: Grupo C + fragmentación; Grupo E: grupo D + clase 2004. 


\subsection{Discusión de resultados}

Los resultados de esta tesis han sido obtenidos en diferentes ensayos que fueron propuestos con el fin de evaluar el potencial de conjuntos diferentes de características sobre varias zonas de estudio para la detección de cambios de usos del suelo a nivel de parcela. Esta metodología de extracción de características y detección de cambios pretende asistir a la actualización de bases de datos de ocupación del suelo empleando información derivada de imágenes adquiridas por sensores remotos y datos LiDAR.

Los resultados de los distintos ensayos planteados fueron obtenidos sobre dos zonas de estudio diferentes, las cuales contienen estratos paisajísticos variados como áreas urbanas, agrícolas y mixtas. Estas zonas de estudio resultan de gran interés al tratarse de áreas muy dinámicas en las que los cambios se dan continuamente en periodos de tiempo relativamente pequeños. Los diferentes cambios propuestos y estudiados en este trabajo son considerados de gran importancia debido a su naturaleza y trascendencia para el correcto estudio y planificación urbana y territorial. Las clases de cambio relacionadas con edificios, como son los nuevos edificios o demoliciones, son especialmente importantes para el estudio de evolución en zonas urbanas y periurbanas, pudiendo aportar información sobre expansión o retraimiento de ciudades o zonas pobladas. Las clases de cambio relacionadas con zonas agrícolas, como cambio entre cultivos, nuevas plantaciones y arranques, son indicadoras del dinamismo y la evolución de cultivos en diferentes zonas, además de resultar imprescindibles para estudios de control e inventariado.

Se han propuesto tres conjuntos diferentes de características con significado temporal y se ha analizado su comportamiento en las diferentes zonas de estudio en función de la información que, a priori, pudiera describir los cambios de dichas zonas.

En el primer ensayo se estudiaron las características tridimensionales derivadas de los datos LiDAR. Estas características aportan información sobre la altura de los elementos, siendo de especial interés para aquellas clases relacionadas con árboles y edificios, por lo que resultan muy útiles para las clases de cambio relacionadas con estas dos coberturas de suelo, en las que se producen cambios de altura entre dos fechas. Los resultados obtenidos muestran que las características tridimensionales mejoran en mayor medida la clasificación de las clases relacionadas con edificios, por lo que los datos LiDAR resultan de gran utilidad en zonas urbanas, donde los cambios producidos en edificios tienen un contraste de alturas mucho más elevado que los cambios en plantaciones de árboles.

Los resultados obtenidos manifiestan que debido a la información tridimensional que aportan estas características, las características derivadas de datos LiDAR reducen la 
confusión entre coberturas como las de terreno yermo con edificios rurales e industriales. La confusión que existe entre estos usos puede ser debida a la propia variabilidad de la clase yermo y de la clase de edificio rural, y a la homogeneidad y/o respuesta espectral de los edificios industriales. Una de las diferencias más notables entre estos usos es la altura, por lo que los datos de altura que aportan las características tridimensionales mejoran la clasificación de estas clases.

Uno de los principales problemas que se presenta al emplear los datos LiDAR es el desfase temporal que puede existir entre la toma de este tipo de datos y la toma de imágenes, ya que resulta muy difícil y costosa la toma simultánea de estos dos tipos de datos. Este desfase puede provocar errores en la detección de cambios si en la zona de estudio se han producido variaciones entre las fechas de adquisición de los dos tipos de datos, como se ha observado en algún caso. Estos errores se eliminarían al adquirir datos LiDAR e imágenes de forma simultánea o en fechas próximas, que es la tendencia actual en los estudios sobre zonas dinámicas.

Además de las variaciones posiblemente ocurridas durante el lapso de tiempo entre las tomas, existían otros factores por los que los modelos LiDAR generados no se correspondían a la perfección con las imágenes de estudio. Esto ocasionó desfases entre imagen espectral y modelos tridimensionales en los bordes de aquellos objetos de cierta altura. Este efecto se notó especialmente a la hora de generar los mapas de coberturas, en los que se podían diferenciar zonas alrededor de objetos (especialmente edificios) en las que resultó complicado definir los límites entre coberturas de usos de suelo.

En este mismo ensayo, se estudiaron dos métodos de detección de cambios diferentes: el método de post-clasificación y el método de clasificación directa. A pesar de que los resultados al comparar métodos no presentasen grandes diferencias, los resultados obtenidos mediante clasificación directa fueron ligeramente más elevados. La principal ventaja que presenta el método de detección de cambios por clasificación directa utilizado en esta tesis, es la posibilidad de emplear características con significado temporal. La propia naturaleza del método de post-clasificación imposibilita el uso de características temporales en la detección de cambios, ya que las dos fechas de estudio diferentes han de ser clasificadas por separado. Este método presenta a su vez otros dos problemas: el empleo de un mayor número de características y no clasificar directamente los objetos en clases de cambio.

En el ensayo II se utilizaron las características derivadas de funciones geoestadísticas. Los resultados reflejaron que las características estructurales son importantes para los estudios de clasificación. En este sentido, las características temporales que se extrajeron 


\section{Resultados}

del semivariograma cruzado y de la codispersión son capaces de explicar las variaciones de estructura interna de las parcelas debido a los cambios de usos del suelo, combinando la información estructural de dos imágenes de fechas diferentes. Este nuevo conjunto de características propuesto es indicado para estudios de cambios ya que concentran gran información relativa a la estructura interna de la parcela en dos fechas diferentes y muestran una gran eficiencia, por lo que con un número reducido de características es suficiente para determinar si ha habido cambio o no. Además, el análisis de resultados confirmó la aptitud de este grupo de características y la capacidad de sintetizar la información contenida en las características derivadas del semivariograma en dos fechas.

Las características extraídas del semivariograma cruzado y codispersión propuestas se centraron en el estudio de dos cambios concretos en áreas agrícolas: arranques y nuevas plantaciones. Se escogieron estas clases de cambio debido a que los usos de suelo que intervienen en ellas presentan cambios opuestos de estructura, de un tipo de uso de suelo homogéneo a otro tipo con un patrón estructural regular. En los resultados se observaron altas tasas de fiabilidad en la detección de cambios en la zona de Murcia al combinar este conjunto de características con características espectrales. La información de estructura que aporta este nuevo conjunto de características complementa perfectamente con la información espectral en la detección de cambios, especialmente para las clases con estructura heterogénea, lo que demuestra su aptitud para detectar el tipo de cambios estudiados.

Los resultados sobre la zona de Valencia reflejaron que las características del semivariograma cruzado y codispersión actúan mejor en zonas totalmente agrícolas, como en la zona de Murcia. Esto puede ser debido principalmente a dos factores: el primero, la variabilidad y características de los objetos de la propia zona de Valencia; y segundo, la selección de características realizada, que se centró totalmente en la zona de Murcia. A pesar de ello, se ha visto que estas características presentan ventajas para la detección de cambios a nivel de objeto, obteniendo altos resultados en zonas agrícolas además de proveer de información temporal y de estructura de las parcelas a la vez que reducen el número de características y el tiempo de procesado.

En la evaluación de los parámetros de poda del clasificador empleando curvas ROC, se pudo observar que el clasificador de árboles de decisión empleado es un algoritmo adecuado para este estudio, ya que las gráficas presentaban altos valores bajo la curva ROC (AUC) en todos los parámetros estudiados.

En el ensayo III se utilizaron las características de fragmentación, que requieren generar los mapas de coberturas de suelo. La generación de los mapas de coberturas 
resultó complicada, a pesar de haber optado por un método que intentaba simplificar la segmentación de los objetos para la generación de dichos mapas. El principal problema que se observó fue el desfase tanto espacial como temporal existente entre los modelos digitales y la información espectral, ya que en términos generales, esto es una de las principales causas de generación de errores en los mapas de coberturas. Esto influyó directamente sobre la extracción de características posiblemente erróneas sobre algunos los objetos de estudio.

El método de generación de los mapas de coberturas que se utilizó combinaba la información tridimensional con la espectral para la generación de máscaras tanto espectrales como de alturas, que fueron empleadas junto con la clasificación no supervisada para la segmentación y asignación de coberturas.

A la vista de los resultados recabados se puede decir que las características de fragmentación permiten la obtención de información tanto a nivel de objeto como a nivel de subobjeto, lo que resulta de gran interés para los estudios de clasificación y detección de cambios. Las características de fragmentación presentan grandes ventajas a la hora de clasificar y detectar cambios en parcelas principalmente de edificios. Esto es debido a la homogeneidad de las coberturas en las parcelas de edificios, en las que la cobertura o subobjeto de esta clase se extiende casi en su totalidad sobre la superficie de la parcela estudiada.

Del mismo modo, los ensayos realizados sobre las parcelas sintéticas indican que las características de fragmentación aportan información para la descripción de los subobjetos de la cobertura de árboles en parcelas agrícolas, ya sea por la superficie que ocupan los subobjetos, o el número de estos. Por el contrario, los resultados de clasificación con estas características en parcelas reales son menores a los esperados al contrastarlos con las parcelas sintéticas.

En muchos casos se ha constatado que durante la generación de los mapas de coberturas los plantones no fueron detectados correctamente. Esto es debido a su pequeño tamaño, principalmente del tamaño de un único píxel detectado, o bien como árbol, o como vegetación. Si se combina el reducido tamaño de los plantones con el filtrado morfológico que se hizo en la generación de los mapas de coberturas, el resultado es que en la mayoría de los casos los plantones no aparecen en los mapas de coberturas, por lo que resulta difícil su descripción con las características de fragmentación. Esto fue debido principalmente a diversas causas. En primer lugar, a la poca densidad que presentan los datos LiDAR, que es insuficiente para capturar correctamente los plantones; en segundo lugar, a la baja altura de los plantones, que ronda alrededor del metro de altura y por lo 


\section{Resultados}

tanto, está en el límite del umbral que se empleó para detectar árboles; y en tercer lugar, a la resolución espacial empleada para la generación de los mapas de coberturas, que es la misma resolución que tienen las imágenes y modelos digitales. Esta resolución, a pesar de ser de gran utilidad para la mayoría de estudios relacionados con cambios, resulta en algunos casos insuficiente, como se ha visto en el estudio de la zona de Valencia. Aun así, tanto los resultados de clasificación como los de detección de cambios, consiguieron tasas de detección y de calidad elevados, por lo que dichos resultados abren la posibilidad a indagar más en el estudio de este tipo de características aplicadas a detección de cambios empleando posiblemente una mayor resolución espacial, inferior a los $0,5 \mathrm{~m}$ empleados en este trabajo.

En el último ensayo se estudiaron varios casos de clasificación y de detección de cambios aplicados en la zona de Valencia, en los que se compararon las características previamente estudiadas y seleccionadas a lo largo de toda la tesis. En estos estudios, se pudo ver la variación de los resultados al ir incluyendo en una clasificación directa los diferentes grupos de características. Estos estudios expusieron de forma global y por clase, la variación de las diferentes fiabilidades en las clasificaciones y en la detección de cambios según las características descriptivas utilizadas. El uso de la clase previa existente en una base de datos de usos del suelo complementaba de forma correcta al resto de características al emplear el método de clasificación directa para la detección de cambios, obteniendo los mejores resultados de fiabilidad y detección y los menores errores tanto en clasificación como en detección. Estos resultados animan a proponer una metodología de detección de cambios en la que se cuente con la clase previa como información adicional a las imágenes de sensores remotos y datos LiDAR para estudios de actualización de las bases de datos.

Los resultados de detección de cambios obtenidos en este último ensayo, empleando los diferentes conjuntos de características temporales mediante clasificación directa, tienen valores de fiabilidad similares a los de otros autores en diferentes trabajos. Zhou et al. (2008) obtuvieron una fiabilidad global del $90 \%$ en la detección de cambios basado en objetos mediante el método de post-clasificación sobre áreas metropolitanas. En otro estudio, Hazeu et al. (2011) obtuvieron fiabilidades del $97 \%$ en la detección de cambios al comparar muestras de cambio y no cambio durante el proceso de actualización de una base de datos de usos del suelo a nivel nacional.

Además, en este último ensayo, los resultados de detección de cambios presentaban mayores fiabilidades globales que en las clasificaciones. Esto es debido a que en la evaluación de la detección de cambios, se consideran como aciertos todos los cambios que 
han sido detectados como clase de cambio, a pesar de que no se correspondan con la clase correcta de cambio, lo que es un error en la identificación. Por el contrario, en la evaluación de las clasificaciones directas, solo se consideran como aciertos aquellos cambios detectados e identificados correctamente. En la metodología general de detección de cambios para actualización de bases de datos, todos los cambios detectados son revisados por un operador previo a la asignación de la nueva clase al objeto en la base de datos. Este método de evaluación es aceptable de acuerdo a esta metodología, ya que a pesar de no haber identificado el tipo de cambio correcto, el operador determinaría la clase final a asignar en la base de datos. En el caso de una metodología de actualización de bases de datos de usos del suelo totalmente automática, los resultados de fiabilidades proporcionados por este sistema de evaluación no son los más adecuados, ya que a pesar de detectar el cambio, se cometería un error en la identificación asignando al objeto o parcela de la base de datos una clase incorrecta.

En general, los resultados generados en esta tesis remarcan que el conjunto de características propuesto generan altas fiabilidades en las clasificaciones y métodos de detección de cambios, siendo la principal ventaja de los estudios realizados el empleo de diferentes grupos de características en función del cambio que se desee estudiar.

Tras el análisis global de los resultados obtenidos, se propone la incorporación de métodos de detección de cambios para la actualización de bases de datos de ocupación del suelo siguiendo un procedimiento que conste de las siguientes fases:

- (i) identificación de la zona sobre la que se desea realizar el estudio de cambios e identificación de los tipos de cambios que existen sobre dicha zona de estudio.

- (ii) definición de los objetos de estudio, siendo los objetos de estudio las parcelas de la base de datos a actualizar

- (iii) extracción de características de diferentes tipologías con significado temporal a nivel de parcela.

- (iv) clasificación de objetos entre clases de cambio y no cambio mediante el proceso de clasificación directa empleando el conjunto de características extraídas a nivel de objeto además de la información de la clase previa contenida en la base de datos a actualizar.

- (v) revisión mediante fotointerpretación de las parcelas de cambio.

- (vi) y finalmente, la actualización de la base de datos tras el proceso de revisión.

En este proceso, en función del tipo de la zona de estudio, los datos disponibles y de los tipos de cambio estudiados, se podrían emplear diferentes conjuntos de características 
temporales propuestos en esta tesis además de la clase previa. La disponibilidad de datos LiDAR en zonas urbanas con las que poder extraer las características tridimensionales de fechas diferentes o la extracción de características de fragmentación, resulta en una mejora apreciable de la clasificación. En el caso de zonas puramente agrícolas, resultaría más interesante la extracción de características geoestadísticas, y poder diferenciar la estructura interna de las parcelas en función de los cultivos presentes en ellas. 


\section{Capítulo 6}

\section{Conclusiones y líneas futuras de investigación}

\subsection{Conclusiones}

En esta tesis se han estudiado metodologías de procesado de imágenes de alta resolución y datos LiDAR para la extracción de características a nivel de objeto y subobjeto, que permiten la caracterización de parcelas para su clasificación y detección de cambios para la actualización de bases de datos de ocupación del suelo.

Las metodologías de procesado de imágenes, detección de cambios y evaluación de resultados se han aplicado sobre casos reales en diferentes zonas de estudio para el completo análisis de las características propuestas en el trabajo.

Se han extraído diversos conjuntos de características a partir de imágenes de satélite, imágenes aéreas y datos LiDAR capaces de proporcionar información sobre objetos y subobjetos con el propósito de detectar cambios, y se han diseñado nuevos conjuntos de características con carácter temporal que permiten caracterizar cambios en el contenido de los objetos entre dos fechas de estudio. Estas características han sido testeadas y probadas en diferentes estratos paisajísticos en diversos ensayos de clasificación y detección de cambios. Las características y los métodos de detección empleados han sido evaluados a lo largo de los ensayos realizados.

Teniendo en cuenta los objetivos propuestos en esta tesis, se pueden formular las siguientes conclusiones:

Se han comparado los métodos de detección de cambios de post-clasificación y clasi- 


\section{Conclusiones y líneas futuras de investigación}

ficación directa en los que se han empleado imágenes y datos LiDAR para la extracción de características a nivel de objeto. El método de clasificación directa permite emplear características con significado temporal y al mismo tiempo incluye como clases de estudio las clases de cambio. De esta forma, se obtienen los resultados de detección de cambios en una única clasificación. Los resultados obtenidos muestran que este método es el más adecuado en las condiciones en las que se ha llevado a cabo el estudio.

Se han generado diferentes conjuntos de características extraídas de imágenes y datos LiDAR con carácter temporal que resultan eficientes para caracterizar los diferentes tipos de cambios estudiados. La asignación de carácter temporal depende del tipo de características estudiadas, generando dichas características de dos formas diferentes: la primera, mediante el cálculo de diferencias simples, bien entre características de dos fechas diferentes, o bien píxel a píxel y posterior extracción de características; y la segunda, mediante el cálculo de funciones geoestadísticas generadas a partir de imágenes de dos fechas diferentes, como en el caso de las nuevas características de codispersión y semivariograma cruzado presentadas en esta tesis. Las características extraídas por ambos métodos contienen en sí mismas información relativa a los tipos de cambio estudiados.

El cálculo de diferencias simples permite, además de combinar información de dos fechas de una manera sencilla, reducir el número de características a introducir en los estudios de clasificaciones.

El conjunto de características tridimensionales fue estudiado y evaluado con respecto a su aplicabilidad en entornos periurbanos para la detección de cambios, donde se encontraban zonas tanto de tipo urbano como de tipo agrícola. Este conjunto de características resultan de especial interés en las clases de cambio que presentan relación con cambios en alturas, como son las clases relacionadas con árboles y edificios. Las características tridimensionales mejoran los resultados de clasificación de clases relacionadas especialmente con edificios, por lo que se pueden considerar datos de gran importancia en estudios realizados en zonas urbanas, en donde los cambios mostrarán un alto contraste de alturas.

Así mismo, las características tridimensionales reducen la confusión entre clases que presentan gran variabilidad espectral en las que la altura de los elementos contenidos en la parcela son imprescindibles para la correcta identificación de los usos del suelo, como en parcelas improductivas y abandonadas como terreno yermo con parcelas de edificios rurales o huertos familiares.

Tras los problemas que se han experimentado en este estudio al emplear datos LiDAR, se propone que los datos LiDAR e imágenes de las zonas de estudio se tomen de manera 
simultánea o que la distancia temporal entre tomas sea la menor posible. De esta forma se evitarían errores de desfase temporal entre toma y toma de datos. Esta tendencia es la actual en estudios de zonas dinámicas.

Los modelos digitales de elevaciones resultan una forma cómoda de trabajar con datos LiDAR ya que permiten su uso e integración con imágenes espectrales. Así mismo, son capaces de combinar información temporal de dos fechas diferentes sobre una única banda ráster.

Con los nuevos conjuntos de características derivadas del semivariograma cruzado y codispersión también se realizaron estudios de aplicabilidad en zonas completamente agrícolas, cuyos resultados fueron evaluados en ensayos de detección de cambios. Los nuevos conjuntos de características derivadas de funciones geoestadísticas son buenos indicadores de cambios cuando los cambios afectan a la heterogeneidad, contraste o patrones de regularidad de los elementos contenidos en los objetos o parcelas de estudio, teniendo en estos casos gran poder discriminatorio entre cambios y no cambios.

Las características de codispersión y semivariograma cruzado son de carácter bitemporal ya que explican la variación de la estructura interna de un objeto debida a cambios en las coberturas y usos del suelo al poder combinar información estructural proporcionada por imágenes de dos fechas distintas. Estas características son capaces de sintetizar información temporal con respecto a la estructura interna de la parcela, pudiendo contener en unas pocas variables información contenida en los semivariogramas de dos fechas distintas.

Las nuevas características de codispersión y semivariograma cruzado se complementan a la perfección con las características espectrales de diferencias entre NDVI para la detección de cambios, ya que se combina información espectral que describe la reflectancia general de las coberturas en las parcelas, con el potencial de las características geoestadísticas para detectar cambios en la estructura interna de las parcelas.

Las clases sobre las que las características de codispersión y semivariograma cruzado obtienen mejores resultados son las clases de arranques y nuevas plantaciones. Esto se debe a que estas clases de cambio presentan cambios notables en la distribución espacial de los objetos. En dichas clases, se produce un cambio de suelo homogéneo a otro tipo de suelo con un patrón de estructura regular y viceversa, por lo que son características a tener en cuenta en regiones agrícolas, centradas en cambios relacionados con plantaciones de árboles.

La mayoría de parcelas de cambio empleadas como referencia en los ensayos anteriores contienen cambios que afectan a la mayor parte de su superficie. Independientemente de 


\section{Conclusiones y líneas futuras de investigación}

las características empleadas, las fiabilidades y capacidades de los métodos de detección de los cambios se pueden ver afectadas con respecto a la superficie de cambio que afecta a la parcela. Por norma general, los cambios que afectan a toda la superficie de la parcela son más fáciles de detectar que aquellos cambios que afectan a las parcelas de forma parcial. Este inconveniente en las técnicas de detección también se menciona en Walter (2004). Es por esto que el conjunto de características de fragmentación resulta de especial interés en estudios de detección de cambios, ya que aportan información sobre los subobjetos contenidos dentro una misma parcela.

Las características de fragmentación permiten la extracción de información tanto a nivel de objeto o parcela como de los subobjetos contenidos en ellas. Estas características muestran una gran aplicabilidad en la detección de cambios en parcelas de edificios en entornos urbanos, ya que la superficie de estas parcelas está ocupada casi en su totalidad por la cobertura de edificios.

De la misma forma, en el caso de parcelas de cultivos arbóreos, estas características aportan información relacionada con el número de objetos, superficie y forma. La utilidad de esta información se manifiesta de forma clara en el análisis de parcelas sintéticas, por lo que se pretende continuar con el estudio de este tipo de características a pesar de que los estudios de clasificación empleando estas características mostraran bajas fiabilidades en los cambios relacionados con cultivos arbóreos.

Las características de fragmentación dependen en gran medida de la escala con la que se han generado los mapas de coberturas. La resolución espacial empleada en este estudio ha sido insuficiente para algunas de las clases de cambios estudiadas, debido a la imposibilidad de la correcta generación de los mapas de coberturas de algunos elementos, como son los plantones de árboles. No obstante, los resultados de clasificación fueron elevados y junto con el estudio realizado sobre parcelas sintéticas de este conjunto de características, se considera que las características de fragmentación tienen gran potencial para la detección de cambios.

En el último ensayo se estudiaron varios casos de clasificación y de detección de cambios aplicados en la zona de Valencia, en los que se compararon las características previamente estudiadas y seleccionadas a lo largo de toda la tesis. En este ensayo, se pudo ver la variación de los resultados al ir incluyendo en una clasificación directa los diferentes grupos de características. Estos estudios expusieron de forma global y por clase, la variación de las diferentes fiabilidades en las clasificaciones y en la detección de cambios. El uso de la clase previa existente en una base de datos de usos del suelo complementaba de forma correcta al resto de características al emplear el método de clasificación directa 
para la detección de cambios, obteniendo los mejores resultados de fiabilidad y detección y los menores errores tanto en clasificación como en detección. Estos resultados confirman la conveniencia de incluir la clase previa como información adicional a las imágenes de sensores remotos y datos LiDAR para estudios de actualización de las bases de datos.

La metodología de detección de cambios para la actualización de bases datos de ocupación del suelo propuesta en este estudio sigue unas directrices generales para su aplicación en diferentes entornos paisajísticos: desde la selección de la zona de estudio, la identificación de los tipos de cambios, la extracción de características con significado temporal a nivel de objeto o parcela de estudio, el empleo de la clase previa contenida en la base de datos, la clasificación de las parcelas mediante el método de clasificación directa, la revisión de los cambios y finalmente la asignación de las nuevas clases a las parcelas de estudio. No obstante, dependiendo del entorno de estudio y de los datos disponibles, se deben extraer y utilizar los diferentes conjuntos de características adecuados que mejor se adapten tanto a la zona de estudio como a los cambios que se deseen detectar. De esta forma, es recomendable emplear las características tridimensionales y de fragmentación en entornos urbanos cuando se disponga de datos LiDAR, mientras que el nuevo conjunto de características derivadas de funciones geoestadísticas poseen un gran potencial en entornos agrícolas, donde las diferencias texturales de los cambios en los tipos de cultivo se caracterizan de forma más eficiente mediante el uso de estas características que describen esta transición entre dos fechas.

Los resultados conseguidos por los conjuntos de características estudiados en esta tesis muestran un gran potencial para posibles investigaciones futuras que exploren la aplicación de estas características en diferentes y más complejos estudios de detección de cambios.

\subsection{Líneas futuras de investigación}

Los estudios realizados en esta tesis han obtenido resultados que han planteado cuestiones para futuras líneas de desarrollo en la mejora de la extracción de características bitemporales y su aplicabilidad en estudios de detección de cambios para actualización de bases de datos de ocupación del suelo.

En primer lugar se plantea la necesidad de nuevos tipos de datos y sensores con resoluciones espaciales mayores a las empleadas en este trabajo lo que permitiría una mayor y mejor definición de los elementos internos o subobjetos de las parcelas de estudio. En este sentido, se podría extraer mayor información y conseguir una mejor caracterización 


\section{Conclusiones y líneas futuras de investigación}

de parcelas en entornos agrícolas. Las nuevas tendencias en vehículos aéreos no tripulados, o UAVs (drones) podrían proporcionar los datos necesarios para tal propósito. El mismo caso se podría aplicar a los datos LiDAR cuya adquisición podría realizarse con una densidad mayor, lo que derivaría en modelos de elevaciones de mayor detalle.

En cuanto a la caracterización de objetos, se pueden proponer y analizar nuevas características descriptivas basadas en la codispersión y semivariograma y características de fragmentación. La codispersión y semivariograma cruzado han demostrado su gran utilidad para la detección de cambios en la estructura interna de las parcelas en dos fechas de estudio, por lo que resultaría de gran interés profundizar y probar este tipo de características aplicadas a otros tipos de cambios en otros entornos: forestales, urbanos, etc. Las características de fragmentación proporcionan información de los subobjetos de las parcelas. El empleo de una mayor resolución en los datos de estudio otorgaría mayor y mejor definición de los subobjetos, lo que a su vez permitiría la detección de cambios a una escala mayor, y se podrían identificar cambios no solo a nivel de parcela sino a nivel de subobjeto.

Por otra parte, también podría combinarse esta metodología no sólo con datos de gran resolución espacial, sino también con datos de mayor resolución espectral o temporal. En este sentido, se podrían emplear datos adquiridos por los sensores de la misión Sentinel-2 de Copernicus para aplicar y desarrollar nuevos métodos de caracterización de objetos para la detección de cambios con una resolución temporal mucho mayor y así permitir una monitorización de forma continuada sobre zonas de gran interés.

Los métodos de detección de cambios y la automatización de estos es una de las líneas de investigación a seguir en cuanto a la actualización de bases de datos se refiere, tendiendo a que la intervención del operador sea mínima y se eviten los procedimientos de revisión de los cambios. Para esto, habría primero que profundizar tanto en los algoritmos y métodos de detección, como en los métodos de evaluación.

La toma continua de datos y la disponibilidad de series de datos para una misma zona en diferentes épocas de estudio es previsible en un futuro no muy lejano, lo que posibilitaría estudios y análisis temporal continuo de las principales zonas de interés. Estos estudios de monitorización requerirían un procesado y actualización continua de datos, por lo que el desarrollo de métodos de detección de cambios automáticos es de gran importancia.

Cabe destacar que ciertas ideas ya han sido puestas en marcha en proyectos de investigación y han sido financiados para continuar con el estudio de detección de cambios mediante imágenes espectrales de muy alta resolución adquiridas de forma aérea por 
6.2 Líneas futuras de investigación

drones. 



\section{Bibliografía}

Addink, E. A., de Jong, S. M., Pebesma, E. J., 2007. The importance of scale in objectbased mapping of vegetation parameters with hyperspectral imagery. Photogrammetric Engineering \& Remote Sensing 73 (8), 905-912.

Al-Khudhairy, D. H. A., Caravaggi, I., Glada, S., 2005. Structural damage assessments from Ikonos data using change detection, object-oriented segmentation, and classification techniques. Photogrammetric Engineering and Remote Sensing 71 (7), 825-837.

Antonarakis, A., Richards, K., Brasington, J., 2008. Object-based land cover classification using airborne LiDAR. Remote Sensing of Environment 112 (6), 2988-2998.

Arbel, E., Hel-Or, H., 2011. Shadow removal using intensity surfaces and texture anchor points. IEEE transactions on pattern analysis and machine intelligence 33 (6), 1202 1216 .

Arozarena, A., García, L., Villa, G., Hermosilla, J., Papí, F., Valcárcel, N., Peces, J., Doménech, E., García, C., Tejeiro, J., 2008. Spanish national plan for territory observation (PNOT). International Archives of Photogrammetry and Remote Sensing and Spatial Information Sciences 37 (B4), 1729-1733.

Arroyo, L. A., Johansen, K., Armston, J., Phinn, S., 2010. Integration of LiDAR and QuickBird imagery for mapping riparian biophysical parameters and land cover types in Australian tropical savannas. Forest Ecology and Management 259 (3), 598-606.

Atkinson, P. M., Lewis, P., 2000. Geostatistical classification for remote sensing: an introduction. Computers and Geosciences 26 (4), 361-371.

Awrangjeb, M., Zhang, C., Fraser, C. S., 2013. Automatic extraction of building roofs using LIDAR data and multispectral imagery. ISPRS Journal of Photogrammetry and Remote Sensing 83, 1-18. 


\section{Bibliografía}

Baker, W. L., Cai, Y., 1992. The r.le programs for multiscale analysis of landscape structure using the GRASS geographical information system. Landscape Ecology 7, 291-302.

Balaguer, A., Ruiz, L., Hermosilla, T., Recio, J., 2010. Definition of a comprehensive set of texture semivariogram features and their evaluation for object-oriented image classificatio. Computers \& Geosciences 36, 231-240.

Balaguer-Beser, A., Ruiz, L., Hermosilla, T., Recio, J., 2013. Using semivariogram indices to analyse heterogeneity in spatial patterns in remotely sensed images. Computers and Geosciences 50, 115-127.

Ballabio, C., Panagos, P., Monatanarella, L., 2016. Mapping topsoil physical properties at European scale using the LUCAS database. Geoderma 261, 110-123.

Benz, U. C., Hofmann, P., Willhauck, G., Lingenfelder, I., Heynen, M., 2004. Multiresolution, object-oriented fuzzy analysis of remote sensing data for GIS-ready information. ISPRS Journal of Photogrammetry and Remote Sensing 58 (3-4), 239-258.

Berberoglu, S., Akin, A., 2009. Assessing different remote sensing techniques to detect land use/cover changes in the eastern Mediterranean. International Journal of Applied Earth Observation and Geoinformation 11 (1), 46-53.

Berberoglu, S., Curran, P., 2004. Merging spectral and textural information for classifying remotely sensed images. Remote Sensing Image Analysis: Including the Spatial Domain. Kluwer Academic Publishers, Netherlands, pp. 113-136.

Berberoglu, S., Lloyd, C., Atkinson, P., Curran, P., 2000. The integration of spectral and textual information using neural networks for land cover mapping in the Mediterranean. Computers \& Geosciences 26, 385-396.

Blanco, P. D., Colditz, R. R., López Saldaña, G., Hardtke, L. A., Llamas, R. M., Mari, N. A., Fischer, A., Caride, C., Aceñolaza, P. G., del Valle, H. F., Lillo-Saavedra, M., Coronato, F., Opazo, S. A., Morelli, F., Anaya, J. A., Sione, W. F., Zamboni, P., Arroyo, V. B., 2013. A land cover map of Latin America and the Caribbean in the framework of the SERENA project. Remote Sensing of Environment 132, 13-31.

Blaschke, T., 2010. Object based image analysis for remote sensing. ISPRS Journal of Photogrammetry and Remote Sensing 65 (1), 2-16. 
Blaschke, T., Strobl, J., 2001. What is wrong with pixels? Some recent developments interfacing remote rensing and GIS. En: GIS-Zeitschrift fur Geoinformationsysteme, Heidelberg. pp. 12-17.

Bogaert, J., Rousseau, R., Van Hecke, P., Impens, I., 2000. Alternative area-perimeter ratios for measurement of $2 \mathrm{D}$ shape compactness of habitats. Applied Mathematics and Computation 111 (1), 71-85.

Bontemps, S., Bogaert, P., Titeux, N., Defourny, P., 2008. An object-based change detection method accounting for temporal dependences in time series with medium to coarse spatial resolution. Remote Sensing of Environment 112 (6), 3181-3191.

Bradley, A. P., 1997. The use of the area under the ROC curve in the evaluation of machine learning algorithms. Pattern Recognition 30 (7), 1145-1159.

Brennan, R., Webster, T. L., 2006. Object-oriented land cover classification of lidarderived surfaces. Canadian Journal of Remote Sensing 32 (2), 162-172.

Broadbent, E., Almeyda Zambrano, A., Dirzo, R., Durham, W., Driscoll, L., Gallagher, P., Salters, R., Schultz, J., Colmenares, A., Randolph, S., 2012. The effect of land use change and ecotourism on biodiversity: a case study of Manuel Antonio, Costa Rica, from 1985 to 2008. Landscape Ecology 27 (5), 731-744.

Büttner, G., Kosztra, B., 2014. CLC2012 addendum to CLC2006 technical guidelines, $1-33$.

Cabrera-Barona, P., Wei, C., Hagenlocher, M., 2016. Multiscale evaluation of an urban deprivation index: Implications for quality of life and healthcare accessibility planning. Applied Geography 70, 1-10.

Carpintero, I. R., Granado, L., Méndez, E., Montoya, G., Pino, I., Prieto, R., Vales, J. J., 2010. Detección de cambios en zonas forestales para la actualización de SIOSEAndalucía 2005 a 2009 con imágenes SPOT-5 ( REDIAM ). En: Teledetección: bosques y cambio climático. M. Vol. 5. Mieres del Camino (Asturias), España, pp. 293-296.

Carvalho, L. M. T., Fonseca, L. M. G., Murtagh, F., Clevers, J. G. P. W., 2001. Digital change detection with the aid of multiresolution wavelet analysis. International Journal of Remote Sensing 22 (18), 3871-3876.

Castaño, S., Ruiz-Gallardo, J., Gómez-Alday, J., Hoyos, J., Sánchez, J., 2005. Metodología para la elaboración de la cartografía europea de usos del suelo (Corine Land 


\section{Bibliografía}

Cover 2000). Aplicación a la región de Castilla-La Mancha (España). En: 6 ${ }^{\text {a }}$ Setmana Geomática.

CE, 2011. Urban Atlas. Delivery of land use/cover maps of major european urban agglomerations. Reporte técnico, Comisión Europea.

Champion, N., Boldo, D., Pierrot-Deseilligny, M., Stamon, G., 2010. 2D building change detection from high resolution satellite imagery: a two-step hierarchical method based on 3D invariant primitives. Pattern Recognition Letters 31 (10), 1138-1147.

Chatfield, C., 1991. Avoiding statistical pitfalls. Statistical Science 6 (3), 240-268.

Chavez, P., Suart, C., Anderson, J., 1991. Comparison of three different methods to merge multiresolution and multispectral data: Landsat TM and SPOT panchromatic. Photogrammetric Engineering and Remote Sensing 57 (3), 295-303.

Chen, G., Hay, G. J., Carvalho, L. M. T., Wulder, M. A., 2012. Object-based change detection. International Journal of Remote Sensing 33 (14), 4434-4457.

Chen, X., Vierling, L., Deering, D., 2005. A simple and effective radiometric correction method to improve landscape change detection across sensors and across time. Remote Sensing of Environment 98 (1), 63-79.

Chen, Z., Gao, B., 2014. An object-based method for urban land cover classification using airborne Lidar data. IEEE Journal of Selected Topics in Applied Earth Observations and Remote Sensing 7 (10), 4243-4254.

Chuvieco, E., 1996. Fundamentos de teledeteccion espacial, 3a Edición. Ediciones Rialp S.A., Madrid.

Cihlar, J., Latifovic, R., Beaubien, J., 2000. A comparison of clustering strategies for unsupervised classification. Canadian Journal of Remote Sensing 26 (5), 446-454.

Colaninno, N., Alhaddad, B., Roca, J., 2011. Urban models definition through Image processing and morphological features, the case study of Catalonia, Spain. En: 7th Virtual Cities and Territories. Lisbon, Portugal 11-13 Octubre.

Colditz, R. R., 2015. An evaluation of different training sample allocation schemes for discrete and continuous land cover classification using decision tree-based algorithms. Remote Sensing 7 (8), 9655-9681. 
Collier, K., Clapcott, J., Hamer, M., Young, R., 2013. Extent estimates and land cover relationships for functional indicators in non-wadeable rivers. Ecological Indicators 34, $53-59$.

Colmenárez, G., Pardo-Pascual, J. E., Ruiz, L. A., Segura Beltrán, F., 2010. Estudio de la rela- ción de la rugosidad topográfica obtenida a partir de datos LIDAR y GPS con el coeficiente de rugosidad N de Manning. Revista Cuaternario y Geomorfología 24, $135-151$.

Congalton, R. G., 1991. A review of assessing the accuracy of classifications of remotely sensed data. Remote Sensing of Environment 37 (1), 35-46.

Coppin, P., Jonckheere, I., Nackaerts, K., Muys, B., Lambin, E., 2004. Digital change detection methods in ecosystem monitoring: a review. International Journal of Remote Sensing 25 (9), 1565-1596.

Curran, P. J., 1988. The semivariogram in remote sensing: an introduction. Remote Sensing of Environment 24 (3), 493-507.

Dare, P. M., 2005. Shadow analysis in high-resolution satellite imagery of urban areas. Photogrammetric Engineering \& Remote Sensing 71 (2), 169-177.

De Brogniez, D., Ballabio, C., van Wesemael, B., Jones, R. J. A., Stevens, A., Montanarella, L., 2014. Topsoil organic carbon map of Europe. Springer International Publishing, pp. 393-405.

Desclée, B., Bogaert, P., Defourny, P., 2006. Forest change detection by statistical objectbased method. Remote Sensing of Environment 102 (1-2), 1-11.

Di Georgio, A., Jansen, L. J. M., 1996. Part I: technical documentation on the Africover land cover classification scheme. En: FAO (1997). Africover Land Cover Classification. pp. 4-33, 63-76.

Du, S., Zhang, F., Zhang, X., 2015. Semantic classification of urban buildings combining VHR image and GIS data: An improved random forest approach. ISPRS Journal of Photogrammetry and Remote Sensing 105, 107-119.

Duda, R. O., Hart, P. E., Stork, D. G., 2001. Pattern classification, 2a Edición. New York. 


\section{Bibliografía}

Dunwoody, E., Apan, A., Liu, X., 2013. Effects of spatial resolution on measurement of landscape function using the landscape leakiness calculator. En: Actas de Surveying \& Spatial Science Conference. Canberra, Australia.

Durieux, L., Lagabrielle, E., Nelson, A., 2008. A method for monitoring building construction in urban sprawl areas using object-based analysis of Spot 5 images and existing GIS data. ISPRS Journal of Photogrammetry and Remote Sensing 63 (4), 399-408.

Ebert, D., Wade, T., 2004. Analytical tools interface for landscape assessments I (ATtILA). Reporte técnico, U.S. Environmental Protection Agency.

EEA, 1985. CORINE land cover. Reporte técnico, European Environment Agency.

ESA, 2014. CCI-LC product user guide v2.4. Reporte técnico, Agencia Espacial Europea.

Escolano, S., 2009. Tendencias recientes de la organización espacial de los usos del suelo en las grandes ciudades latinoamericanas: el caso del Gran Santiago (Chile). Estudios Geográficos 70 (266), 97-124.

Estornell, J., Ruiz, L., Velázquez-Martí, B., Hermosilla, T., 2011. Analysis of the factors affecting LiDAR DTM accuracy in a steep shrub area. International Journal of Digital Earth 4 (6), 521-538.

EUROSTAT, 2015. LUCAS. Technical reference document C3. Classification. (Land cover \& Land use). Reporte técnico, Comisión Europea.

Fawcett, T., 2006. An introduction to ROC analysis. Pattern Recognition Letters 27 (8), 861-874.

Feranec, J., Hazeu, G., Christensen, S., Jaffrain, G., 2007. Corine land cover change detection in Europe (case studies of the Netherlands and Slovakia). Land Use Policy 24 (1), 234-247.

Feranec, J., Súri, M., Ot'ahel', J., Cebecauer, T., Kolár, J., Soukup, T., Zdenková, D., Waszmuth, J., Vâjdea, V., Vîjdea, A.-M., Nitica, C., 2000. Inventory of major landscape changes in the Czech Republic, Hungary, Romania and Slovak Republic 1970s - 1990s. International Journal of Applied Earth Observation and Geoinformation $2(2), 129-139$.

Ferro, C. J., Warner, T. A., 2002. Scale and texture in digital image classification. Photogrammetric Engineering \& Remote Sensing 68 (1), 51-63. 
Forman, R., Godron, M., 1986. Landscape ecology.

Frohn, R., 1998. Remote sensing for landscape ecology: new metric indicators for monitoring, modeling, and assessment of ecosystems. CRC Press LLC.

Fuller, R., Groom, G., Jones, A. R., 1994. The land cover map of Great Britain: an automated classification of Landsat Thematic Mapper data. Photogrammetric Engineering and Remote Sensing 60 (5), 553-562.

Fuller, R. M., Cox, R., Clarke, R. T., Rothery, P., Hill, R. A., Smith, G. M., Thomson, A. G., Brown, N. J., Howard, D. C., Stott, A. P., 2005. The UK land cover map 2000: planning, construction and calibration of a remotely sensed, user-oriented map of broad habitats. International Journal of Applied Earth Observation and Geoinformation 7 (3), 202-216.

Gallego, J., Bamps, C., 2008. Using CORINE land cover and the point survey LUCAS for area estimation. International Journal of Applied Earth Observation and Geoinformation 100 (4), 467-475.

Galletti, C., Myint, S., 2014. Land-use mapping in a mixed urban-agricultural arid landscape using object-based image analysis: a case study from Maricopa, Arizona. Remote Sensing 6 (7), 6089-6110.

Gamanya, R., Demaeyer, P., Dedapper, M., 2009. Object-oriented change detection for the city of Harare, Zimbabwe. Expert Systems with Applications 36 (1), 571-588.

Gamanya, R., Maeyer, P., Dapper, M., 2007. An automated satellite image classification design using object-oriented segmentation algorithms: a move towards standardization. Expert Systems with Applications 32 (2), 616-624.

Garcia-Pedrero, A., Gonzalo-Martin, C., Fonseca-Luengo, D., Lillo-Saavedra, M., 2015. A GEOBIA methodology for fragmented agricultural landscapes. Remote Sensing 7, $767-787$.

Gascon, L. H., Eva, H. D., Gobron, N., Simonetti, D., Fritz, S., 2012. The application of medium-resolution MERIS satellite data for continental land-cover mapping over South America: results and caveats. En: Giri, C. P. (Ed.), Remote sensing of land use and land cover: principles and applications. Vol. 8. CRC Press, Boca Raton, Florida, pp. 325-337. 


\section{Bibliografía}

Ghulam, A., Qin, Q., Teyip, T., Li, Z.-L., 2007. Modified perpendicular drought index (MPDI): a real-time drought monitoring method. ISPRS Journal of Photogrammetry and Remote Sensing 62, 150-164.

Gil-Yepes, J., Hermosilla, T., Ruiz, L. A., 2013. Estudio de técnicas de detección de cambios basadas en la clasificación directa de objetos para la actualización de bases de datos agrícolas. En: XV Congreso de la Asociación Española de Teledetección. INTA. Torrejón de Ardoz (Madrid).22-24 octubre, 2013, pp. 22-25.

Gil-Yepes, J., Ruiz, L. A., Recio, J., Balaguer-Beser, A., Hermosilla, T., 2016. Description and validation of a new set of object-based temporal geostatistical features for land-use/land-cover change detection. ISPRS Journal of Photogrammetry and Remote Sensing 121, 77-91.

Gilichinsky, M., Peled, A., 2014. Detection of discrepancies in existing land-use classification using IKONOS satellite data. Remote Sensing Letters 5 (1), 93-102.

Gladstone, C., Gardiner, A., Holland, D., 2012. A semi-authomatic method for detecting changes to ordnance survey topographic data in rural environments. En: Actas de the 4th GEOBIA. pp. 396-401.

Gong, J., Sui, H., Sun, K., Ma, G., Liu, J., 2008. Object-level change detection based on full-scale image segmentation and its application to Wenchuan Earthquake. Science in China, Series E: Technological Sciences 51, 110-122.

Guillemain, M., Mondain-Monval, J., Weissenbacher, E., Brochet, A., Olivier, A., 2008. Hunting bag and distance from nearest day-roost in Camargue ducks. Wildlife Biology $14(3), 379-385$.

Gustafson, E. J., 1998. Quantifying landscape spatial pattern: what is the state of the art? Ecosystems 1 (2), 143-156.

Guyon, I., Elisseeff, A., 2003. An introduction to variable and feature selection. Journal of Machine Learning Research 3, 1157-1182.

Hall, O., Hay, G., 2003. A multiscale object-specific approach to digital change. International Journal of Applied Earth Observation and Geoinformation 4 (4), 311-327.

Haralick, R. M., Shanmugam, K., Dinstein, I., 1973. Textural features for image classification. IEE Transactions on Systems, Man, and Cybernetics 3 (6), 610-621. 
Harley, J., 1987. The history of cartography. The University of Chicago Press.

Hartfield, K. A., Landau, K. I., van Leeuwen, W. J. D., 2011. Fusion of high resolution aerial multispectral and lidar data: land cover in the context of urban mosquito habitat. Remote Sensing 3 (11), 2364-2383.

Hay, G. J., Castilla, G., 2006. Object-based image analysis: strengths, weaknesses, opportunities and threats (SWOT). OBIA, 2006: The International Archives of the Photogrammetry, Remote Sensing and Spatial Information Sciences, 3.

Hazeu, G. W., Bregt, A. K., de Wit, A. J., Clevers, J. G., 2011. A Dutch multi-date land use database: Identification of real and methodological changes. International Journal of Applied Earth Observation and Geoinformation 13 (4), 682-689.

He, C., Wei, A., Shi, P., Zhang, Q., Zhao, Y., 2011. Detecting land-use/land-cover change in rural-urban fringe areas using extended change-vector analysis. International Journal of Applied Earth Observation and Geoinformation 13 (4), 572-585.

He, H., DeZonia, B., Mladenoff, D., 2000. An aggregation index (AI) to quantify spatial patterns of landscapes. Landscape Ecology (15), 591-601.

Hebel, M., Arens, M., Stilla, U., 2013. Change detection in urban areas by object-based analysis and on-the-fly comparison of multi-view ALS data. ISPRS Journal of Photogrammetry and Remote Sensing 86, 52-64.

Hermosilla, T., 2011. Detección automática de edificios y clasificación de usos del suelo en entornos urbanos con imágenes de alta resolución y datos LiDAR. Tesis doctoral, Universidad Politécnica de Valencia.

Hermosilla, T., Gil-Yepes, J. L., Recio, J. A., Ruiz, L. A., 2012. Change detection in peri-urban areas based on contextual classification. Photogrammetrie Fernerkundung Geoinformation 4 (August), 355-366.

Hermosilla, T., Ruiz, L. A., Recio, J., 2010. Detección automática de edificios mediante imágenes de alta resolución y datos Lidar para la actualización de bases de datos cartográficas en entornos urbanos. Revista de Teledetección 34, 89-93.

Hermosilla, T., Wulder, M. A., White, J. C., Coops, N. C., Hobart, G. W., 2015. Regional detection, characterization, and attribution of annual forest change from 1984 to 2012 using Landsat-derived time-series metrics. Remote Sensing of Environment 170, 121132. 


\section{Bibliografía}

Herold, M., Menz, G., 2000. Landscape metric signatures ( LMS ) to improve urban land use information derived from remotely sensed data. En: Actas of the 20th EARSeL Symposium. Vol. 24. Dresden, pp. 251-256.

Herold, M., Scepan, J., Clarke, K. C., 2002a. The use of remote sensing and landscape metrics to describe structures and changes in urban land uses. Environment and Planning A 34 (8), 1443-1458.

Herold, M., Scepan, J., Müller, A., Günther, S., 2002b. Object-oriented mapping and analysis of urban land use/cover using IKONOS data. En: Actas of 22nd EARSEL Symposium - Geoinformation for European-wide integration. Prague, pp. 531-538.

Hoffer, R., 1975. Natural resource mapping in mountainous terrain by computer analysis of ERTS-1 Satellite Data. Reporte técnico, LARS Technical Note 061575, Purdue University, Indiana.

Holmgren, J., Persson, Å., Söderman, U., 2008. Species identification of individual trees by combining high resolution LiDAR data with multi-spectral images. International Journal of Remote Sensing 29 (5), 1537-1552.

Hu, L. Y., Chen, Y. L., Xu, Y., Zhao, Y. Y., Yu, L., Wang, J., Gong, P., 2014. A 30 meter land cover mapping of China with an efficient clustering algorithm CBEST. Science China: Earth Sciences 57 (10), 2293-2304.

Huang, L., Zhang, G., Li, Y., 2010. An object-based change detection approach by integrating intensity and texture differences. En: 2nd International Asia Conference on Informatics in Control, Automation and Robotics (CAR 2010). No. 2. IEEE, pp. $258-261$.

Huang, Y., Yu, B., Zhou, J., Hu, C., Tan, W., Hu, Z., Wu, J., 2013. Toward automatic estimation of urban green volume using airborne LiDAR data and high resolution remote sensing images. Frontiers of Earth Science 7 (1), 43-54.

Huang, Y., Yue, A., Wei, S., Li, D., Luo, M., Jiang, Y., Zhang, C., 2008. Texture feature extraction for land-cover classification of remote sensing data in land consolidation district using semi-variogram analysis. WSEAS Transactions on Computers 7 (7), $857-866$.

Hudak, A. T., Evans, J. S., Stuart Smith, A. M., 2009. LiDAR utility for natural resource managers. Remote Sensing 1 (4), 934-951. 
Hussain, M., Chen, D., Cheng, A., Wei, H., Stanley, D., 2013. Change detection from remotely sensed images: from pixel-based to object-based approaches. ISPRS Journal of Photogrammetry and Remote Sensing 80, 91-106.

IGN, 2015. Metodología de actualización SIOSE. Reporte técnico, Instituto Geográfico Nacional.

Im, J., Jensen, J. R., Hodgson, M. E., 2008. Object-based land cover classification using high-posting-density LiDAR data. GIScience \& Remote Sensing 45 (2), 209-228.

Inglada, J., Arias, M., Tardy, B., Hagolle, O., Valero, S., Morin, D., Dedieu, G., Sepulcre, G., Bontemps, S., Defourny, P., Koetz, B., 2015. Assessment of an operational system for crop type map production using high temporal and spatial resolution satellite optical imagery. Remote Sensing 7 (9), 12356-12379.

Inglada, J., Vincent, A., Arias, M., Tardy, B., Morin, D., Rodes, I., 2017. Operational high resolution land cover map production at the country scale using satellite image time series. Remote Sensing 9 (1), 95.

Jacquin, A., Misakova, L., Gay, M., 2008. A hybrid object-based classification approach for mapping urban sprawl in periurban environment. Landscape and Urban Planning 84 (2), 152-165.

Jain, A. K., Farrokhnia, F., 1991. Unsupervised texture segmentation using Gabor filters. Pattern Recognition 24 (12), 1167-1186.

Jenson, J., 1983. Urbanl/suburban land use analysis. Manual of Remote Sensing, Vol. 2, 2a Edición. (Falls Church, Virginia: American Society of Photogrammetry) pp: 1571-1666.

Jin, H., Stehman, S. V., Mountrakis, G., 2014. Assessing the impact of training sample selection on accuracy of an urban classification: a case study in Denver, Colorado. International Journal of Remote Sensing 35 (6), 2067-2081.

Jin, S., Yang, L., Danielson, P., Homer, C., Fry, J., Xian, G., 2013. A comprehensive change detection method for updating the National Land Cover Database to circa 2011. Remote Sensing of Environment 132, 159-175.

Jin, X., Davis, C., 2005. Automated building extraction from high-resolution satellite imagery in urban areas using structural, contextual, and spectral information. EURASIP Journal on Applied Signal Processing 14, 2198-2206. 


\section{Bibliografía}

Johnson, R. D., Kasischke, E. S., 1998. Change vector analysis: a technique for the multispectral monitoring of land cover and condition. International Journal of Remote Sensing 19 (3), 411-426.

Kane, K., Connors, J. P., Galletti, C. S., 2014. Assessing patch shape in landscape mosaics. Applied Geography 52, 123-134.

Kibret, K. S., Marohn, C., Cadisch, G., 2016. Assessing patch shape in landscape mosaics. Remote Sensing Applications: Society and Environment 3, 1-19.

Kouchi, K., Yamazaki, F., 2007. Characteristics of tsunami-affected areas in moderateresolution satellite images. IEEE Transactions on Geoscience and Remote Sensing 45 (6), 1650-1657.

Krummel, J. R., Gardner, R. H., Sugihara, G., O’Neill, R. V., Coleman, P. R., 1987. Landscape patterns in a disturbed environment. Oikos 48 (3), 321-324.

LaGro, J. J., 1991. Assessing patch shape in landscape mosaics. Photogrammetric Engineering and Remote Sensing (57), 285-93.

Laliberte, A. S., Rango, A., Havstad, K. M., Paris, J. F., Beck, R. F., McNeely, R., Gonzalez, A. L., 2004. Object-oriented image analysis for mapping shrub encroachment from 1937 to 2003 in southern New Mexico. Remote Sensing of Environment 93 (1-2), $198-210$.

Lambin, E., Baulies, X., Bockstael, X., Fischer, N., Krug, G., Leemans, T., Moran, R., Rindfuss, E., Sato, R., Skole, Y., Turner, D., Vogel, B., 1999. Land-use and landcover change: implementation strategy. Reporte técnico, IGBP Secretariat, Stockholm, Sweden.

Lang, S., Tiede, D., 2003. Vlate extension für ArcGIS - vektorbasiertes tool zur quantitativen landschaftsstrukturanalyse. En: ESRI Anwenderkonferenz 2003. Innsbruck, Alemania.

Latham, J., Cumani, R., Rosati, I., Bloise, M., 2014. Global land cover SHARE (GLCSHARE) database beta-release version 1.0. Reporte técnico, Organización de las Naciones Unidas para la alimentación y la agricultura - FAO.

Latifovic, R., Homer, C., Ressel, R., Pouliot, D., Hossain, N., Colditz, R., Olthof, I., Giri, C., Victoria, A., 2012. North American land change monitoring system. En: Giri, C. P. 
(Ed.), Remote sensing of land use and land cover: principles and applications. Vol. 8. CRC Press, Boca Raton, Florida, pp. 303-324.

Latifovic, R., Pouliot, D., 2005. Multitemporal land cover mapping for Canada. Canadian Journal of Remote Sensing 31 (5), 347-363.

Laws, K. I., 1985. Goal-directed textured-image segmentation. Proc. SPIE 0548, Applications of Artificial Intelligence II, 19-26.

Lesschen, J. P., Cammeraat, L. H., Kooijman, A. M., van Wesemael, B., 2008. Development of spatial heterogeneity in vegetation and soil properties after land abandonment in a semi-arid ecosystem. Journal of Arid Environments 72 (11), 2082-2092.

Lin, Y., Hong, N., Wu, P., Wu, C., Verburg, P., 2007. Impacts of land use change scenarios on hydrology and land use patterns in the $\mathrm{Wu}-\mathrm{Tu}$ watershed in Northern Taiwan. Landscape and Urban Planning 80 (1-2), 111-126.

Lindsay, F., Townshend, J., Jaja, J., Humphries, J., Plaisant, C., Shneiderman, B., 1999. Developing the next generation of Earth science data systems: the global land cover facility. En: Actas IEEE Geoscience and Remote Sensing Symposium IGARSS. Vol. 1. pp. 616-618.

Liu, W., Yamazaki, F., 2012. Object-based shadow extraction and correction of highresolution optical satellite images. IEEE Journal of Selected Topics in Applied Earth Observations and Remote Sensing 5 (4), 1296-1302.

Löw, F., Knöfel, P., Conrad, C., 2015. Analysis of uncertainty in multi-temporal objectbased classification. ISPRS Journal of Photogrammetry and Remote Sensing 105, 91-106.

Löw, F., Michel, U., Dech, S., Conrad, C., 2013. Impact of feature selection on the accuracy and spatial uncertainty of per-field crop classification using Support Vector Machines. ISPRS Journal of Photogrammetry and Remote Sensing 85, 102-119.

Lu, D., Mausel, P., Brondizio, E., Moran, E., 2004. Change detection techniques. International Journal of Remote Sensing 25 (12), 2365-2401.

Lu, D., Weng, Q., 2007. A survey of image classification methods and techniques for improving classification performance. International Journal of Remote Sensing 5 (28), $823-870$. 


\section{Bibliografía}

Lunetta, R., Elvidge, C., 1999. Remote sensing change detection: environmental monitoring methods and applications. Taylor \& Francis.

Luus, F. P. S., van den Bergh, F., Maharaj, B. T. J., 2013. The effects of segmentationbased shadow removal on across-date settlement type classification of panchromatic QuickBird images. IEEE Journal of Selected Topics in Applied Earth Observations and Remote Sensing 6 (3), 1274-1285.

Lymburner, L., Tan, P., Mcintyre, A., Lewis, A., Thankappan, M., 2013. Dynamic land cover dataset version $2: 2001$ - Now ... a land cover odyssey. 2013 IEEE International Geoscience and Remote Sensing Symposium - IGARSS, 3297-3300.

Malinverni, E. S., 2011. Change detection applying landscape metrics on high remote sensing images. Photogrammetric Engineering \& Remote Sensing 77 (10), 1045-1056.

Mallat, S. G., 1989. A theory of multirresolution signal decomposition: the wavelet representation. IEEE Transactions on Pattern Analysis Machine Intelligence 11 (7), 674-693.

Marceau, D., Gratton, D., Fournier, R., Fortin, J., 1994. Remote sensing and the measurement of geographical entities. Part 2: the optimal spatial resolution. Remote Sensing of Environment 49, 105-117.

Marinescu, I., Avram, S., 2012. Evaluation of urban fragmentation in Craiova City, Romania. Procedia Environmental Sciences 14, 207-215.

Marrocco, C., Duin, R. P. W., Tortorella, F., 2008. Maximizing the area under the ROC curve by pairwise feature combination. Pattern Recognition 41 (6), 1961-1974.

Martino, L., Fritz, M., 2008. New insights into land cover and land use in Europe. Statistics in Focus 33.

McDermid, G. J., Linke, J., Pape, A. D., Laskin, D. N., McLane, A. J., Franklin, S. E., 2008. Object-based approaches to change analysis and thematic map update: challenges and limitations. Canadian Journal of Remote Sensing 34 (5), 462-466.

McGarigal, K., Cushman, S., Ene, E., 2014. FRAGSTATS v4: spatial pattern analysis program for categorical and continuous maps.

McGarigal, K., Marks, B. J., 1995. FRAGSTAT: spatial pattern analysis program for quantifying landscape structure. Reporte técnico. 
Metz, C. E., 1979. Applications of ROC analysis in diagnostic image evaluation. The American Institute of Physics, 1-27.

Mialhe, F., Gunnell, Y., Ignacio, J. A. F., Delbart, N., Ogania, J. L., Henry, S., 2015. Monitoring land-use change by combining participatory land-use maps with standard remote sensing techniques: showcase from a remote forest catchment on Mindanao, Philippines. International Journal of Applied Earth Observation and Geoinformation $36,69-82$.

Miller, O., Pikaz, A., Averbuch, A., 2005. Objects based change detection in a pair of gray-level images. Pattern Recognition 38 (11), 1976-1992.

Ming, D., Li, J., Wang, J., Zhang, M., 2015. Scale parameter selection by spatial statistics for GEOBIA: using mean-shift based multi-scale segmentation as an example. ISPRS Journal of Photogrammetry and Remote Sensing 106, 28-41.

Moeller, M., Blaschke, T., 2005. Monitoring LULC dynamics in the urban - rural fringe. Goiania, Brasil: INPE, 2005. Artigos, S. 3821-3828, en CD, ISBN 85-17-00018-8.

Mui, A., He, Y., Weng, Q., 2015. An object-based approach to delineate wetlands across landscapes of varied disturbance with high spatial resolution satellite imagery. ISPRS Journal of Photogrammetry and Remote Sensing 109, 30-46.

Musacchio, L. R., Coulson, R. N., 2001. Landscape ecological planning process for wetland, waterfowl, and farmland conservation. Landscape and Urban Planning 56 (34), 125-147.

O’Neill, R., Krummel, J., Gardner, R., Sugihara, G., Jackson, B., DeAngelis, D., Milne, B., Turner, M., Zygmunt, B., Christensen, S., Dale, V., Graham, R., 1988. Indices of landscape pattern. Landscape Ecology (1), 153-162.

Panagos, P., Ballabio, C., Yigini, Y., Dunbar, M. B., 2013. Estimating the soil organic carbon content for European NUTS2 regions based on LUCAS data collection. Science of the Total Environment 442, 235-246.

Parent, J. R., Volin, J. C., Civco, D. L., 2015. A fully-automated approach to land cover mapping with airborne LiDAR and high resolution multispectral imagery in a forested suburban landscape. ISPRS Journal of Photogrammetry and Remote Sensing 104, 18-29. 


\section{Bibliografía}

Patel, N., Upadhyay, S., 2012. Study of various decision tree pruning methods with their empirical comparison in WEKA. International Journal of Computer Applications 60 (12), 20-25.

Peled, A., 1994. Revision of digital maps and GIS databases. En: Actas de ISPRS Symposium Mapping and Geographic Information Systems, Athens, Georgia, USA. ISPRS International Archives of Photogrammetry. Vol. 30, part 4. pp. 268-272.

Petropoulos, G. P., Kalaitzidis, C., Prasad Vadrevu, K., 2011. Support vector machines and object-based classification for obtaining land-use/cover cartography from Hyperion hyperspectral imagery. Computers \& Geosciences, 1-9.

Pippuri, I., Suvanto, A., Maltamo, M., Korhonen, K. T., Pitkänen, J., Packalen, P., 2016. Classification of forest land attributes using multi-source remotely sensed data. International Journal of Applied Earth Observation and Geoinformation 44, 11-22.

Piqueras Haba, J., 1999. El espacio valenciano. Una síntesis geográfica. Ed. Gules.

Platt, R., Rapoza, L., 2008. An evaluation of an object-oriented paradigm for land use/land cover classification. The Professional Geographer 60 (1), 87-100.

Powers, R. P., Hermosilla, T., Coops, N. C., Chen, G., 2015. Remote sensing and objectbased techniques for mapping fine-scale industrial disturbances. International Journal of Applied Earth Observations and Geoinformation 34, 51-57.

Priestnall, G., Jaafar, J., Duncan, A., 2000. Extracting urban features from LiDAR digital surface models. Computers, Environment and Urban Systems 24 (2), 65-78.

Provost, F., Fawcett, T., 2001. Robust classification for imprecise environments. Machine Learning 42 (3), 203-231.

Pyrcz, M. J., Deutsch, C. V., 2003. The whole story on the hole effect. Geostatisitical Association of Australasia, Newsletters, 18.

Quinlan, J., 1993. C4.5: programs for machine learning. Morgan Kaufmann, San Mateo, CA, USA.

Raza, A., Kainz, W., 2002. An object-oriented approach for modeling urban land-use changes. URISA Journal 14 (1), 37-55. 
Recio, J., 2009. Técnicas de extracción de características y clasificación de imágenes orientada a objetos aplicadas a la actualización de bases de datos de ocupación del suelo. Tesis doctoral, Universidad Politécnica de Valencia.

Recio, J., Hermosilla, T., Ruiz, L., Fernández-Sarría, A., 2011. Historical land use as a feature for image classification. Photogrammetric Engineering and Remote Sensing 77 (4), 377-387.

Recio, J., Ruiz, L., Fernández-Sarría, A., Hermosilla, T., 2006. Integration of multiple feature extraction and object-oriented classification of aerial images for map updating. En: Second Recent Advances in Quantitative Remote Sensing.

Romano, Y., Colaninno, N., Cerda, J., Roca, J., Burns, M., 2010. The relation between land occupation, density and spatial fragmentation (Spain 1956-2006). En: European Regional Science Association (ERSA) 50th Congress. Jönköping, Suecia. 19-23 Agosto, pp. $1-18$.

Romero, D., Gil, Y., Ortega, E., Domínguez, M. C., Navas, P., Patiño, M., Vicent, C., Santos, M., Quijada, J., Giménez de Azcárate, F., Cáceres, F., Moreira, J. M., 2010. Actualización SIOSE en Andalucía 2009.

Rottensteiner, F., Trinder, J., Clode, S., Kubik, K., 2007. Building detection by fusion of airborne laser scanner data and multi-spectral images: performance evaluation and sensitivity analysis. ISPRS Journal of Photogrammetry and Remote Sensing 62 (2), $135-149$.

Rozenstein, O., Karnieli, A., 2011. Comparison of methods for land-use classification incorporating remote sensing and GIS inputs. Applied Geography 31 (2), 533-544.

Ruiz, L., Recio, J., Fernández-Sarría, A., Hermosilla, T., 2011. A feature extraction software tool for agricultural object-based image analysis. Computers and Electronics in Agriculture 76 (2), 284-296.

Ruiz, L. A., Fernández Sarría, A., Recio, J. A., 2002. Evaluation of texture analysis techniques to characterize vegetation. Actas de Recent Advances in Quantitative Remote Sensing, 16-20 Septiembre, Torrent, España, pp. 514-521.

Ruiz, L. A., Recio, J. A., Crespo-Peremarch, P., Sapena, M., 2016. An object-based approach for mapping forest structural types based on low density LiDAR and multispectral imagery. Geocarto International 6049 ((in press)), 0-1. 


\section{Bibliografía}

Ruiz, L. A., Recio, J. A., Hermosilla, T., 2007. Methods for automatic extraction of regularity patterns and its appliction to object-oriented image classification. International Archives of Photogrammetry and Remote Sensing and Spatial Information Sciences $36,117-121$.

Salinas, E., 2010. Fragmentación urbana y su relevancia en la planificación urbana y territorial actual. Ignire - Centro de Estudio de Política Pública, 49-58.

Sapena, M., Ruiz, L. A., 2015a. Analysis of urban development by means of multitemporal fragmentation metrics from LULC data. En: ISPRS Archives: 36th International Symposium on Remote Sensing of Environment (Volume XL-7/W3). Berlin, Germany, pp. 1411-1418.

Sapena, M., Ruiz, L. A., 2015b. Descripción y cálculo de índices de fragmentación urbana: Herramienta IndiFrag. Revista de Teledección 43 (1), 77-89.

Sarabandi, P., Yamazaki, F., Matsuoka, M., Kiremidjian, A., 2004. Shadow detection and radiometric restoration in satellite high resolution images. En: Actas 2004 IEEE International Geoscience and Remote Sensing Symposium, 2004. IGARSS '04. No. 2. Anchorage, AK, pp. 3744-3747.

Saraf, A. K., Cracknell, A. P., 1989. Linear discriminant and profile analysis - an aid in remote-sensing for geobotanical investigation. International Journal of Remote Sensing 10 (11), 1735-1748.

Saura, S., Torné, J., 2009. Conefor Sensinode 2.2: a software package for quantifying the importance of habitat patches for landscape connectivity. Environmental Modelling and Software 24 (1), 135-139.

Schott, J., Salvaggio, C., Volchok, W., 1988. Radiometric scene normalization using pseudoinvariant features. Remote Sensing of Environment (26), 1-6.

See, L., Schepaschenko, D., Lesiv, M., McCallum, I., Fritz, S., Comber, A., Perger, C., Schill, C., Zhao, Y., Maus, V., Siraj, M. A., Albrecht, F., Cipriani, A., Vakolyuk, M., Garcia, A., Rabia, A. H., Singha, K., Marcarini, A., Kattenborn, T., Hazarika, R., Schepaschenko, M., Van Der Velde, M., Kraxner, F., Obersteiner, M., 2015. Building a hybrid land cover map with crowdsourcing and geographically weighted regression. ISPRS Journal of Photogrammetry and Remote Sensing 103, 48-56.

Shu, J. S., Freeman, H., 1990. Cloud shadow removal from aerial photographs. Pattern Recognition 23 (6), 647-656. 
Silva, M., Câmara, G., Escada, M. I., de Souza, R., 2008. Remote-sensing image mining: detecting agents of land-use change in tropical forest areas. International Journal of Remote Sensing 29 (16), 4803-4822.

Singh, A., 1989. Digital change detection techniques using remotely-sensed data. International Journal of Remote Sensing 10 (6), 989-1003.

Smits, P. C., Annoni, A., 1999. Updating land-cover maps by using texture information from very high-resolution space-borne imagery. IEEE Transactions on Geoscience and Remote Sensing 37 (3), 1244-1254.

Sohn, G., Dowman, I., 2007. Data fusion of high-resolution satellite imagery and LiDAR data for automatic building extraction. ISPRS Journal of Photogrammetry and Remote Sensing 62 (1), 43-63.

Song, H., Huang, B., Zhang, K., 2014. Shadow detection and reconstruction in highresolution satellite images via morphological filtering and example-based learning. IEEE Transactions on Geoscience and Remote Sensing 52 (5), 2545-2554.

Sutton, R., Hall, E., 1972. Texture measures for automatic classification of pulmonary disease. IEEE Transactions on Computers 21 (7), 667-676.

Tabachnick, B., Fidell, L., 1989. Using multivariate statistics, 2a Edición. HarperCollins Publisher, Inc., New York.

Tateishi, R., Uriyangqai, B., Al-Bilbisi, H., Ghar, M. A., Tsend-Ayush, J., Kobayashi, T., Kasimu, A., Hoan, N. T., Shalaby, A., Alsaaideh, B., Enkhzaya, T., Gegentana, Sato, H. P., 2011. Production of global land cover data-GLCNMO. International Journal of Digital Earth 4 (1), 22-49.

Taubenböck, H., Kraff, N. J., 2014. The physical face of slums: a structural comparison of slums in Mumbai, India, based on remotely sensed data. Journal of Housing and the Built Environment 29 (1), 15-38.

Tewkesbury, A. P., Comber, A. J., Tate, N. J., Lamb, A., Fisher, P. F., 2015. A critical synthesis of remotely sensed optical image change detection techniques. Remote Sensing of Environment 160, 1-14.

Tortini, R., Mayer, A., Maianti, P., 2015. Using an OBCD approach and Landsat TM data to detect harvesting on nonindustrial private property in upper Michigan. Remote Sensing 7 (6), 7809-7825. 


\section{Bibliografía}

Tou, J. T., Gonzalez, R. C., 1974. Pattern recognition principles. Addison-Wesley Publishing Company, Reading, Massachusetts.

Tsachalidis, E. P., Hadjisterkotis, E., 2008. Wild boar hunting and socioeconomic trends in Northern Greece, 1993-2002. European Journal of Wildlife Research 54 (4), 643649.

Tsai, V., 2006. A comparative study on shadow compensation of color aerial images in invariant color models. IEEE Transactions on Geoscience and Remote Sensing 44 (6), $1661-1671$.

Tso, B., Mather, P. M., 2009. Classification methods for remotely sensed data, 2a Edición. CRC Press.

Uuemaa, E., Mander, Ü., Marja, R., 2013. Trends in the use of landscape spatial metrics as landscape indicators: A review. Ecological Indicators 28, 100-106.

Valcárcel Sanz, N., Castaño Fernández, S., 2012. Cartografía de Ocupación del Suelo en España. Proyecto SIOSE. Instituto Geográfico Nacional.

Van de Voorde, T., Genst, W. D., Canters, F., 2007. Improving pixel-based VHR landcover classifications of urban areas with post-classification techniques. Photogrammetric Engineering and Remote Sensing 73 (9), 1017-1027.

Van der Kwast, J., Van de Voorde, T., Canters, F., Uljee, I., Van Looy, S., Engelen, G., 2011. Inferring urban land use using the optimised spatial reclassification kernel. Environmental Modelling and Software 26 (11), 1279-1288.

Van der Meer, F., 2012. Remote-sensing image analysis and geostatistics. International Journal of Remote Sensing 33 (18), 5644-5676.

Velázquez-Martí, B., Fernández-González, E., Estornell, J., Ruiz, L. A., 2010. Dendrometric and dasometric analysis of the bushy biomass in Mediterranean forests. Forest Ecology and Management 259 (5), 875-882.

Vila-García, D., Gil-Docampo, M., Iniesto-Alba, M., 2015. Change detection in land use from unsupervised classifications for updating SIOSE. Implementation in Galicia. Revista de Teledetección (43), 63-76.

Vogt, P., Riitters, K. H., Estreguil, C., Kozak, J., Wade, T. G., Wickham, J. D., 2007. Mapping spatial patterns with morphological image processing. Landscape Ecology $22(2), 171-177$. 
Vosselman, G., Gorte, B., Sithole, G., 2004. Change detection for updating medium scale maps using laser altimetry. En: The International Archives of the Photogrammetry, Remote Sensing and Spatial Information Sciences. Vol. 34 of Commission III, WG $\mathrm{III} / 3$.

Vu, T., Matsuoka, M., Yamazaki, F., 2004a. LIDAR-based change detection of buildings in dense urban areas. En: IEEE International Geoscience and Remote Sensing Symposium 2004 IGARSS 04 Proceedings. pp. 3413-3416.

Vu, T., Matsuoka, M., Yamazaki, F., 2004b. Shadow analysis in assisting damage detection due to earthquakes from QuickBird imagery. Actas de the 10th international society for photogrammetry and remote sensing congress, 607-611.

Wackernagel, H., 2003. Multivariate geostatistics, 3a Edición. Springer, New York.

Walter, V., 2004. Object-based classification of remote sensing data for change detection. ISPRS Journal of Photogrammetry and Remote Sensing 58 (3-4), 225-238.

Wan, L., Zhang, Y., Zhang, X., Qi, S., Na, X., 2015. Comparison of land use/land cover change and landscape patterns in Honghe National Nature Reserve and the surrounding Jiansanjiang Region, China. Ecological Indicators 51, 205-214.

Weih, R. C., Riggan, N. D., 2008. Object-based classification vs. pixel-based classification: comparitive importance of multi-resolution imagery. The International Archives of the Photogrammetry, Remote Sensing and Spatial Information Sciences XXXVIII4 .

Witten, I., Eibe, F., Hall, M., 2011. Data mining: practical machine learning tools and techniques, 3a Edición. Morgan Kaufmann Publishers Inc., San Francisco.

Wu, J., Jenerette, G. D., Buyantuyev, A., Redman, C. L., 2011. Quantifying spatiotemporal patterns of urbanization: the case of the two fastest growing metropolitan regions in the United States. Ecological Complexity 8 (1), 1-8.

Wu, X., Peng, J., Shan, J., Cui, W., 2015. Evaluation of semivariogram features for object-based image classification. Geo-spatial Information Science 18 (4), 159-170.

Xian, G., Homer, C., 2010. Updating the 2001 national land cover database impervious surface products to 2006 using Landsat imagery change detection methods. Remote Sensing of Environment 114 (8), 1676-1686. 


\section{Bibliografía}

Xian, G., Homer, C., Fry, J., 2009. Updating the 2001 National Land Cover Database land cover classification to 2006 by using Landsat imagery change detection methods. Remote Sensing of Environment 113 (6), 1133-1147.

Xie, Z., Roberts, C., Johnson, B., 2008. Object-based target search using remotely sensed data: a case study in detecting invasive exotic Australian Pine in south Florida. ISPRS Journal of Photogrammetry and Remote Sensing 63 (6), 647-660.

Yamazaki, F., Liu, W., Takasaki, M., 2009. Characteristics of shadow and removal of its effects for remote sensing imagery. En: IEEE International Geoscience and Remote Sensing Symposium, IGARSS 2009. Cape Town, pp. 426-429.

Yan, W. Y., Shaker, A., El-Ashmawy, N., 2015. Urban land cover classification using airborne LiDAR data: a review. Remote Sensing of Environment 158, 295-310.

Yu, B., Liu, H., Gao, Y., Wu, J., 2008. Object-based algorithms and methods for quantifying urban growth pattern using sequential satellite images. Proceedings of SPIE 7083, 1-11.

Yu, X., Hyyppä, J., Kaartinen, H., Maltamo, M., 2004. Automatic detection of harvested trees and determination of forest growth using airborne laser scanning. Remote Sensing of Environment 90 (4), 451-462.

Yuan, D., Elvidge, C. D., 1996. Comparison of relative radiometric normalization techniques. ISPRS Journal of Photogrammetry and Remote Sensing 51 (3), 117-126.

Yue, A., Zhang, C., Yang, J., Su, W., Yun, W., Zhu, D., 2013. Texture extraction for object-oriented classification of high spatial resolution remotely sensed images using a semivariogram. International Journal of Remote Sensing 34 (11), 3736-3759.

Zaragozí, B., Belda, A., Linares, J., Martínez-Pérez, J. E., Navarro, J. T., Esparza, J., 2012. A free and open source programming library for landscape metrics calculations. Environmental Modelling and Software 31, 131-140.

Zhang, S., York, A. M., Boone, C. G., Shrestha, M., 2012. Methodological advances in the spatial analysis of land fragmentation. The Professional Geographer.

Zhang, Y., Mishra, R., 2012. A review and comparison of commercially available pansharpening techniques for high resolution satellite image fusion. En: IEEE International Geoscience and Remote Sensing Symposium. pp. 182-185. 
Zhou, G., Song, C., Simmers, J., Cheng, P., 2004. Urban 3D GIS from LiDAR and digital aerial images. Computers and Geosciences 30 (4), 345-353.

Zhou, W., Huang, G., Troy, A., Cadenasso, M., 2009. Object-based land cover classification of shaded areas in high spatial resolution imagery of urban areas: a comparison study. Remote Sensing of Environment 113 (8), 1769-1777.

Zhou, W., Troy, A., Grove, M., 2008. Object-based land cover classification and change analysis in the Baltimore metropolitan area using multitemporal high resolution remote sensing data. Sensors 8 (3), 1613-1636. 



\section{Apéndice A}

\section{Publicaciones relacionadas con esta tesis}

A continuación se referencian las publicaciones científicas derivadas total o parcialmente de los trabajos realizados por el autor durante el desarrollo de esta tesis.

Artículos en revistas indexadas:

- Gil-Yepes, J.L., Ruiz L., Recio, J., Balaguer-Beser, A. y Hermosilla, T. 2016. Description and validation of a new set of object-based temporal geostatistical features for land-use/land-cover change detection, ISPRS Journal of Photogrammetry and Remote Sensing 121, 77-91.

- Hermosilla, T., Gil-Yepes, J. L., Recio, J. A. y Ruiz, L. A. 2012. Change detection in peri-urban areas based on contextual classification, Photogrammetrie Fernerkundung Geoinformation, 4, 355-366

Publicaciones en congresos:

- Gil-Yepes, J.L. Hermosilla, T. y Ruiz, L.A. 2013 Estudio de técnicas de detección de cambios basadas en la clasificación directa de objetos para la actualización de bases de datos agrícolas. XV Congreso de la Asociación Española de Teledetección. INTA. Torrejón de Ardoz (Madrid), 22-25 Octubre.

- Hermosilla, T., Ruiz, L.A., Gil-Yepes, J.L., Recio, J.A., Pardo-Pascual, J.E., 2013. Multi-level object-based urban mapping from remote sensing and GIS data. Symposium GIS Ostrava 2013 - Geoinformatics for City Transformation. 21-23 Enero, Ostrava, República Checa. 



\section{Apéndice B}

\section{Listado de acrónimos}

A_AREA_MN - Fragmentación. Área media de los subobjetos de la cobertura de árboles en una parcela.

A_AREA_SD - Fragmentación. Desviación típica del área de los subobjetos de la cobertura de árboles en una parcela.

A_CIRCLE_MN - Fragmentación. Media del valor del círculo circunscrito de los subobjetos de la cobertura de árboles en la parcela.

A_CIRCLE_SD - Fragmentación. Desviación estándar del valor del círculo circunscrito de los subobjetos de la cobertura de árboles en la parcela.

A_CONITG_MN - Fragmentación. Media del índice de contigüidad de los subobjetos de la cobertura de árboles en la parcela.

A_CONITG_SD - Fragmentación. Desviación estándar del índice de contigüidad de los subobjetos de la cobertura de árboles en la parcela.

A_ED - Fragmentación. Densidad de bordes de la cobertura de árboles en una parcela.

A_ENN_MN - Fragmentación. Valor medio de la distancia euclídea entre elementos vecinos de la cobertura de árboles en una parcela.

A_ENN_SD - Fragmentación. Desviación estándar de la distancia euclídea entre elementos vecinos de la cobertura de árboles en una parcela.

A_FRAC_MN - Fragmentación. Media de la dimensión fractal de los subobjetos de la cobertura de árboles en la parcela.

A_FRAC_SD - Fragmentación. Desviación típica de la dimensión fractal de los subobjetos de la cobertura de árboles en la parcela.

A_LPI - Fragmentación. Índice de mayor objeto de la cobertura de árboles en una parcela. 
A_NP - Fragmentación. Número de elementos de la cobertura de árboles en una parcela.

A_PAFRAC_MN - Fragmentación. Media de la dimensión fractal perímetro-área de los subobjetos de la cobertura de árboles en la parcela.

A_PAFRAC_SD - Fragmentación. Desviación típica de la dimensión fractal perímetro-área de los subobjetos de la cobertura de árboles en la parcela.

A_PARA_MN- Fragmentación. Media del ratio perímetro-área de los subobjetos de la cobertura de árboles en la parcela.

A_PARA_SD- Fragmentación. Desviación estándar del ratio perímetro-área de los subobjetos de la cobertura de árboles en la parcela.

A_PD - Fragmentación. Densidad de elementos pertenecientes a la cobertura de árboles en una parcela.

A_PLAND - Fragmentación. Porcentaje de cobertura de árboles en una parcela.

A_SHAPE_MN - Fragmentación. Media de índice de forma de los subobjetos de la cobertura de árboles en la parcela.

A_SHAPE_SD - Fragmentación. Desviación estándar de índice de forma de los subobjetos de la cobertura de árboles en la parcela.

A_TE - Fragmentación. Suma total de bordes de la cobertura de árboles en una parcela.

AFM - Semivariograma. Área entre el valor del semivariograma en el primer lag y el primer máximo.

AI - Fragmentación. Índice de agregación.

AREA_MN - Fragmentación. Área media de los objetos/subobjetos.

AREA_SD - Fragmentación. Desviación típica del área de los objetos/subobjetos.

CA - Fragmentación. Área de cobertura.

CIRCLE_MN - Fragmentación. Media del valor del círculo circunscrito de los subobjetos de las parcelas.

CIRCLE_SD - Fragmentación. Desviación estándar del valor del círculo circunscrito de los subobjetos de las parcelas.

CO_MEAN - Codispersión. Media absoluta de los valores de codispersión.

CO_SMAX1 - Codispersión. Posición del primer máximo local.

CO_SMIN1 - Codispersión. Posición del primer mínimo local.

CO_STD - Codispersión. Desviación estándar de los valores de codispersión.

CO_VMIN1 - Codispersión. Valor del primer mínimo local. 
CONITG_MN - Fragmentación. Media del índice de contigüidad de los subobjetos de las parcelas.

CONITG_SD - Fragmentación. Desviación estándar del índice de contigüidad de los subobjetos de las parcelas.

CONTAG - Fragmentación. Índice de contagio.

CS_DMM - Semivariograma cruzado. Distancia entre el primer y segundo máximo.

CS_FDO - Semivariograma cruzado. Primera derivada cerca al origen.

CS_MFM - Semivariograma cruzado. Media de los valores de semivariograma hasta el primer máximo.

CS_SMAX1 - Semivariograma cruzado. Posición del primer máximo local.

CS_SMIN1 - Semivariograma cruzado. Posición del primer mínimo local.

CS_VFM - Semivariograma cruzado. Varianza de los valores del semivariograma cruzado hasta el primer máximo.

CWED - Fragmentación. Contraste ponderado de densidad de bordes.

D_NDVI - Diferencia de valores de media NDVI entre dos fechas.

D_STDNDVI - Diferencia de valores de desviación estándar NDVI entre dos fechas.

DA - Fragmentación. Densidad de árboles.

DD - Fragmentación. Densidad-diversidad.

DMF - Semivariograma. Diferencia entre la media de los valores del semivariograma hasta el primer máximo y la semivarianza en el primer lag.

DMM - Semivariograma. Distancia entre el primer máximo y el primer mínimo.

DMS - Semivariograma. Distancia entre la posición del primer máximo local y el segundo máximo.

DRA - Fragmentación. Densidad de riqueza de árboles.

E_AREA_MN - Fragmentación. Área media de los subobjetos de la cobertura de edificios en una parcela.

E_AREA_SD - Fragmentación. Desviación típica del área de los subobjetos de la cobertura de edificios en una parcela.

E_ED - Fragmentación. Densidad de bordes de la cobertura de edificios en una parcela.

E_LPI - Fragmentación. Índice de mayor objeto de la cobertura de edificios en una parcela.

E_NP - Fragmentación. Número de elementos de la cobertura de edificios en una parcela.

E_PARA_MN- Fragmentación. Media del ratio perímetro-área de los subobjetos de la cober- 
tura de edificios en la parcela.

E_PARA_SD- Fragmentación. Desviación estándar del ratio perímetro-área de los subobjetos de la cobertura de edificios en la parcela.

E_PLAND - Fragmentación. Porcentaje de cobertura de edificios en una parcela.

E_SHAPE_MN - Fragmentación. Media de índice de forma de los subobjetos de la cobertura de edificios en la parcela.

E_SHAPE_SD - Fragmentación. Desviación estándar de índice de forma de los subobjetos de la cobertura de edificios en la parcela.

E_TE - Fragmentación. Suma total de bordes de la cobertura de edificios en una parcela.

ECON_MN - Fragmentación. Media del índice de contraste de bordes de los subobjetos de la parcela.

ECON_SD - Fragmentación. Desviación estándar del índice de contraste de bordes de los subobjetos de la parcela.

ED - Fragmentación. Densidad de bordes.

ENN_MN - Fragmentación. Valor medio de la distancia euclídea entre elementos vecinos en una parcela.

ENN_SD - Fragmentación. Desviación estándar de la distancia euclídea entre elementos vecinos en una parcela.

FDO - Semivariograma. Primera derivada cercana al origen.

FML - Semivariograma. Valor del lag donde se encuentra el primer máximo.

FRAC_MN - Fragmentación. Media de la dimensión fractal de los subobjetos de las parcelas.

FRAC_SD - Fragmentación. Desviación típica de la dimensión fractal de los subobjetos de las parcelas.

HA - Semivariograma. Área del efecto agujero.

IFFA - Fragmentación. Índice de fragmentación total absoluta.

IFFR - Fragmentación. Índice de fragmentación.

LPI - Fragmentación. Índice de mayor objeto.

MESH - Fragmentación. Tamaño efectivo de malla.

MFM - Semivariograma. Media de los valores del semivariograma hasta el primer máximo.

NP - Fragmentación. Número de elementos en una parcela.

PAFRAC_MN - Fragmentación. Media de la dimensión fractal perímetro-área de los subobjetos de las parcelas. 
PAFRAC_SD - Fragmentación. Desviación típica de la dimensión fractal perímetro-área de los subobjetos de las parcelas.

PARA_MN- Fragmentación. Media del ratio perímetro-área de los subobjetos de las parcelas.

PARA_SD- Fragmentación. Desviación estándar del ratio perímetro-área de los subobjetos de las parcelas.

PD - Fragmentación. Densidad de elementos en una parcela.

PLAND - Fragmentación. Porcentaje de cobertura.

PR - Fragmentación. Riqueza del tipo de elementos.

PRD - Fragmentación. Densidad de riqueza de elementos.

RMM - Semivariograma. Ratio entre la semivarianza en el primer máximo local y la media de los valores del semivariograma hasta el primer máximo.

RSF - Semivariograma. Ratio entre los valores de semivarianza entre el segundo y el primer lag.

RVF - Semivariograma. Ratio entre el valor total de la varianza y el semivariograma en el primer lag.

S_PLAND - Fragmentación. Porcentaje de cobertura de suelo en una parcela.

SDF - Semivariograma. Diferencia de segundo orden entre el primer lag y el primer máximo.

SDT- Semivariograma. Segunda derivada en el tercer lag.

SHAPE_MN - Fragmentación. Media de índice de forma de los subobjetos de las parcelas.

SHAPE_SD - Fragmentación. Desviación estándar de índice de forma de los subobjetos de las parcelas.

SHDI - Fragmentación. Índice de diversidad de Shannon.

SHEI - Fragmentación. Índice de uniformidad de Shannon.

SIDI - Fragmentación. Índice de diversidad de Simpson.

SIEI - Fragmentación. Índice de uniformidad de Simpson.

SPLIT - Fragmentación. Índice de división.

TE - Fragmentación. Suma total de bordes.

TECI - Fragmentación. Índice de contraste total de bordes.

V_CIRCLE_MN - Fragmentación. Media del valor del círculo circunscrito de los subobjetos de la cobertura de vegetación en la parcela.

V_CIRCLE_SD - Fragmentación. Desviación estándar del valor del círculo circunscrito de los subobjetos de la cobertura de vegetación en la parcela. 
V_ENN_MN - Fragmentación. Valor medio de la distancia euclídea entre elementos vecinos de la cobertura de vegetación en una parcela.

V_ENN_SD - Fragmentación. Desviación estándar de la distancia euclídea entre elementos vecinos de la cobertura de vegetación en una parcela.

V_PLAND - Fragmentación. Porcentaje de cobertura de vegetación en una parcela.

VFM - Semivariograma. Varianza de los valores del semivariograma hasta el primer máximo. 